\title{
Simulation of Venturi Tube Design for Column Flotation Using Computational Fluid Dynamics
}

Wan Wang

Follow this and additional works at: https://researchrepository.wvu.edu/etd

\section{Recommended Citation}

Wang, Wan, "Simulation of Venturi Tube Design for Column Flotation Using Computational Fluid Dynamics" (2017). Graduate Theses, Dissertations, and Problem Reports. 6909.

https://researchrepository.wvu.edu/etd/6909

This Dissertation is protected by copyright and/or related rights. It has been brought to you by the The Research Repository @ WVU with permission from the rights-holder(s). You are free to use this Dissertation in any way that is permitted by the copyright and related rights legislation that applies to your use. For other uses you must obtain permission from the rights-holder(s) directly, unless additional rights are indicated by a Creative Commons license in the record and/ or on the work itself. This Dissertation has been accepted for inclusion in WVU Graduate Theses, Dissertations, and Problem Reports collection by an authorized administrator of The Research Repository @ WVU.

For more information, please contact researchrepository@mail.wvu.edu. 


\title{
Simulation of Venturi Tube Design for Column Flotation Using Computational Fluid Dynamics
}

\author{
Wan Wang \\ Dissertation submitted \\ to the Benjamin M. Statler College of Engineering and Mineral Resources \\ at West Virginia University \\ in partial fulfillment of the requirements for the degree of \\ Doctor of Philosophy in \\ Mining Engineering
}

\author{
Felicia F. Peng, Ph.D., Chair \\ John A. Herbst, Ph.D. \\ Yi Luo, Ph.D. \\ Lian-Shin Lin, Ph.D. \\ William M. Hart, Ph.D.
}

Department of Mining Engineering

West Virginia University

Morgantown, West Virginia

2017

Keywords: cavitation, PBM, venturi, pico-nano bubbles, column flotation

Copyright 2017 Wan Wang 


\title{
Abstract \\ Simulation of Venturi Tube Design for Column Flotation Using Computational Fluid Dynamics
}

\begin{abstract}
Wan Wang
Froth flotation is the process of using physicochemical methods to separate valuable minerals from gangue. It is one of the most important methods in mineral processing. Previous studies have found that using cavitation bubbles can widen flotation particle size-range, increase the probability of bubble particle attachment, and reduce the probability of bubble particle detachment; all of which improve flotation recovery. Collector and frother dosages can also be reduced with cavitation-generated bubbles. Therefore, this technology reduces both energy consumption and operating costs.

Hydrodynamic cavitation is the most economical method used for creating tiny bubbles for flotation. It is the development and growth of a gas and/or vapor filled void in a liquid. Cavitation bubbles are generated at the throat of devices, when liquid passes through a constricted area, such as a valve, orifice, venturi, or nozzle. Liquid velocity increases at the throat or vena-contracta. As the velocity increases, the kinetic energy associated with the liquid increases, and the pressure decreases. Once the local pressure falls below the vapor pressure of the liquid, hydrodynamic cavitation happens.
\end{abstract}

The efficiency of cavitation bubble generating devices and their geometry design is analyzed using computational fluid dynamics (CFD) in this study. CFD is used to analyze multiple interacting phases, understand complex physical changes, and test all possible parameters without consuming a large amount of resources. Different geometries, venturi tubes, nozzles, and orifices from literature were used. Mathematical models were validated through comparison with experimental results. Critical cavitation velocities and volume fractions of venturi and orifices with different geometries, circular, square, and slot, were compared. Circular venturi tubes were found to be the best design for cavitation bubble generation.

To optimize the geometric design of the venturi tube, six parameters were modified. These include the inlet diameter, throat and inlet diameter ratio, convergent angle, divergent angle, throat length, and entrance length. A response surface method central composite design was conducted for evaluating the effect of these six parameters affecting the efficiency of the Venturi tube. The response of the model is called critical velocity for cavitation, which means the minimum required velocity for cavitation is generated by each geometry. Because flotation column eliminates rotor and stator, the only energy supply is mixing and pumping prepared feed. The smaller critical cavitation velocity means the easier for cavitation to happen. Therefore the lower energy required, the better the design for hydrodynamic cavitation design is. 48 venturi tubes with designed geometry were created using ANSYS ICEM. Vapor volume fractions of each 
geometry were calculated using ANSYS FLUENT. Critical velocities of cavitation of different designs were compared.

Simulation shows that the diameter ratio is the most significant factor, which has the biggest impact on the critical velocity for cavitation and venturi design. Several interactions of key parameters were found to be significant $(\mathrm{P}<0.0001)$. These include diameter ratio and inlet diameter interaction, diameter ratio and convergent angle interaction, diameter ratio and divergent angle interaction, diameter ratio and entrance length interaction, and convergent angle and divergent angle interaction. The results also show that the minimum critical velocity is $12.39 \mathrm{~m} / \mathrm{s}$ when the inlet diameter is 215.92 $\mathrm{mm}$. Additionally, the diameter ratio is 0.42 , the convergent angle is 30 , the divergent angle is 14.14, and the throat length and entrance length are 0.5 and 0 times the throat diameter, respectively. These results are in agreeance with previous experimental work.

Besides the volume fraction, bubble size distribution is another important factor for cavitation devices to simulate and design. Geometry of venturi tube was created with computational fluid dynamics (CFD). Population Balance Module (PBM) was developed to analyze the bubble size distribution for the secondary phase. This module includes the rates of nucleation, growth, dispersion, aggregation, and breakage. A mathematical model was created and written as User Defined Functions (UDF) code and complied with ANSYS-FLUENT, in order to calculate nucleation rate for PBM model. In order to understand the interactions of bubble size distribution with particle size distribution, a $200 \mu \mathrm{m}$ and a $400 \mu \mathrm{m}$ diameter ball were added to the venturi grid. These were used to simulate the flow field affected by particles within. Using room temperature liquid water as medium, with the same inlet velocity, the cavitation generated more vapor volume. This indicated that particles could enhance cavitation and reduce the bubble size. This is consistent with experimental measurement results.

Column flotation with cavitation bubbles technology has been successfully developed in the lab, and thus it is important to apply it in industry. Venturi design from a previous CFD study with a minimum critical velocity was used as the standard tube. One 15 times of the diameter $(\mathrm{D}=3.24 \mathrm{~m})$ and one lab scale $(\mathrm{D}=0.012 \mathrm{~m})$ venturi tube were compared with the standard diameter tube. Besides inlet diameter, the throat lengths used the same ratio $(0.12: 0.22: 3.24)$. The diameter ratio, convergent angle, divergent angle were set as the same values of the standard venturi tube design. The results show that, with the same throat velocity, the vapor volume ratio (vapor volume/venturi tube volume) of the standard venturi tube has the highest value. This indicates that the standard venturi tube can generate the most amount of vapor at a certain volume, which is favorable for flotation process. That matched the result from response surface method, the required energy increases as the diameter increases, after $215.96 \mathrm{~mm}$. For an industry flotation column, multiple standard venturi tubes function better than one scale-up tube. Additionally, smaller tubes are easier to fabricate and replace. Multiple tubes may also prevent process shutdown during maintenance. Thus, multiple standard venturi tubes design is recommended. 
One packed column and venturi tube, either in series or in parallel for cavitation bubble generation, were used in previous experiments. It was found that placing the column and venturi tube in series is better than placing them in parallel. Additionally, micro size bubbles are generated most from the packed column, and pico and nano bubbles are generated by the venturi tube. The various orders of having the packed column and venturi tube in parallel and series were tested. For the different designs of the packed column and venturi tube in series: the first design placed the packed column first, then the venturi tube second. The second design placed the venturi tube first, then the packed column second. The results show that with the same flow rate, the amount of cavitation bubbles generated in series is higher than in parallel. The first design created more vapor than the second one. Also, the bubble sizes generated using series designs are smaller than the parallel design. Therefore, placing the packed column and venturi tube in series with the packed column first and venturi tube second is recommended. 


\section{Acknowledgments}

There are a number of people I would like to thank for help and guidance throughout graduate school. Completion would not have been possible, without the individuals who contributed generously to this work.

My deepest gratitude goes first to my advisor and mentor, Dr. Felicia F. Peng, for her support, advice, encouragement, and kindness. Her wisdom, guidance, and patience are truly inspiring. Her advice has been invaluable for my research, as well as with my career and life. I also greatly appreciate the insightful comments, advice and enthusiasm from my other committee members, Dr. John A. Herbst, Dr. Yi Luo, Dr. Lian-Shin Lin, and Dr. Mark Hart. I could not have accomplished nearly as much, without their help.

I would like to extend my appreciation to the Mining Engineering department, which provides a friendly and enjoyable study and working environment. My sincere appreciation goes towards many former and current faculty members and students whom I have been fortunate to collaborate with. All of their contributions have made graduate school a great experience.

Finally, a special thanks to my family and my friends for their understanding, support, and love. In particular, I would like express appreciation to my beloved parents and husband for their unconditional love and always believing in me. 


\section{Table of Contents}

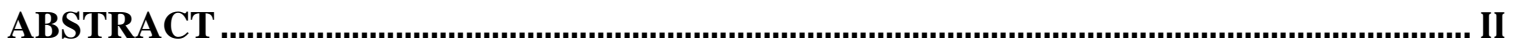

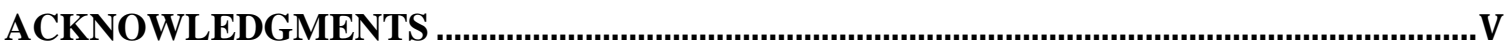

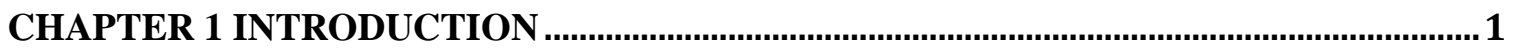

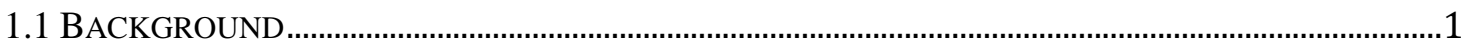

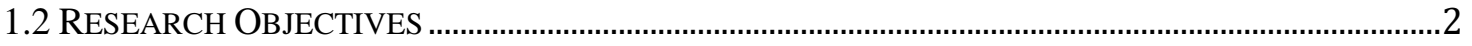

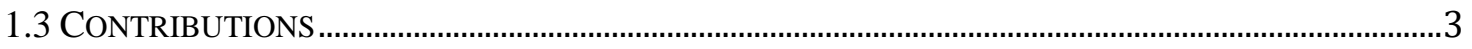

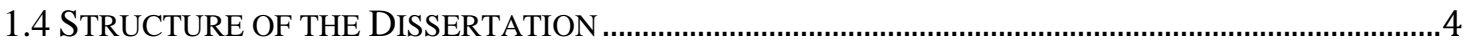

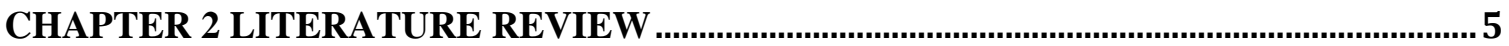

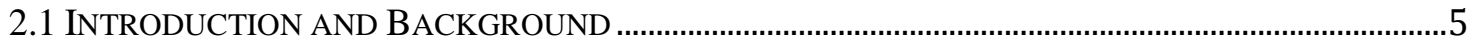

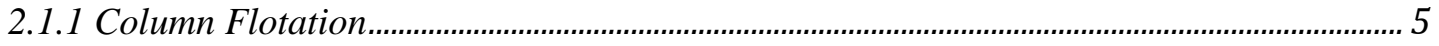

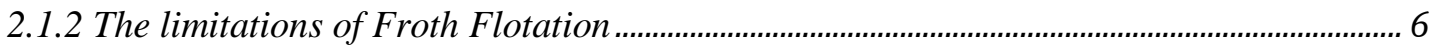

2.1.3 Bubble Generation and Size Distribution …............................................................................. 7

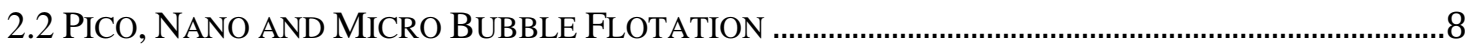

2.2.1 Mechanism

2.2.2 Pico, Nano Bubble Formation................................................................................................10

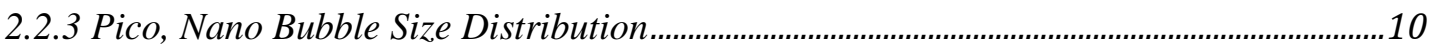

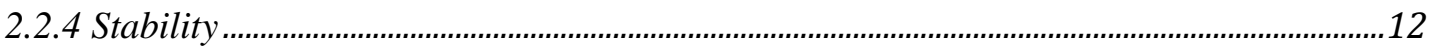

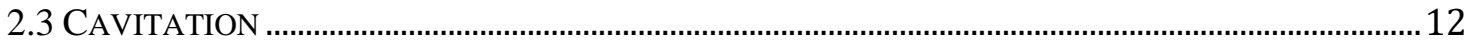

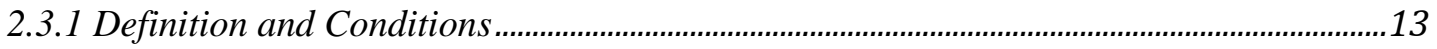

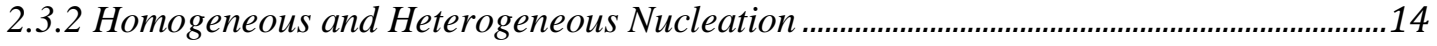

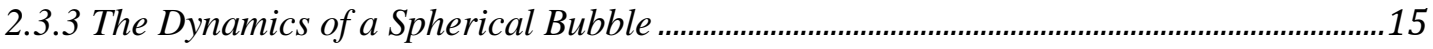

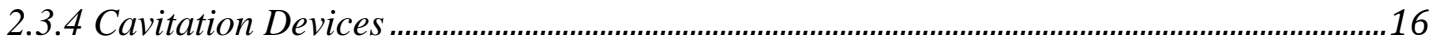

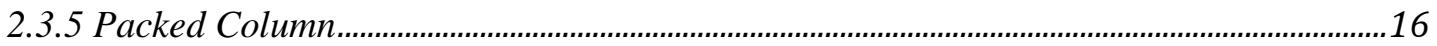

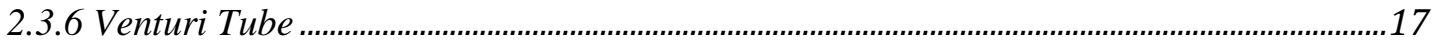

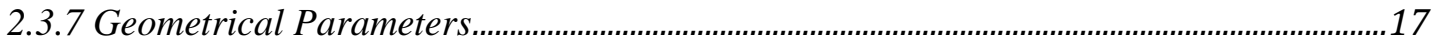

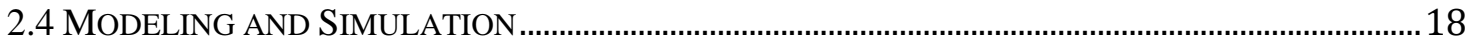

2.4.1 Computation Fluid Dynamics (CFD)..................................................................................

2.4.2 Geometry

2.4.3 Empirical vs. Numerical Analysis........................................................................................39

2.4.4 Experimental Design \& Statistical Data Analysis ...............................................................39

CHAPTER 3 NUMERICAL SIMULATION METHODS................................................... 40

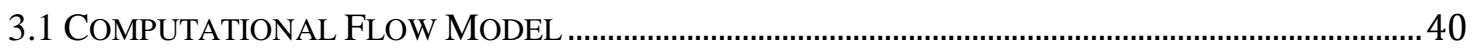

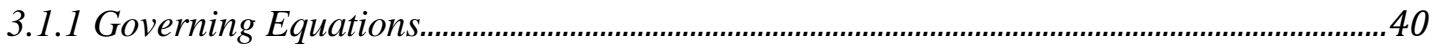

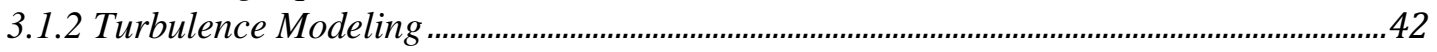

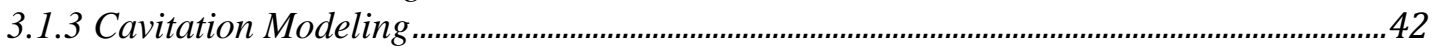

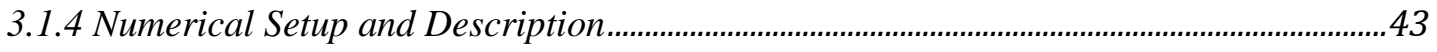

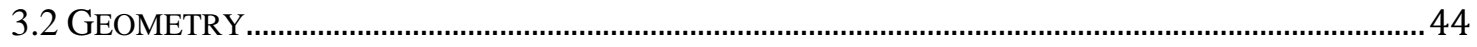

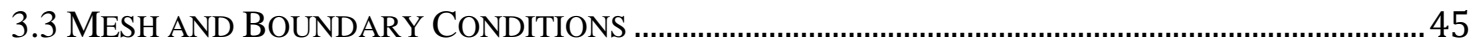

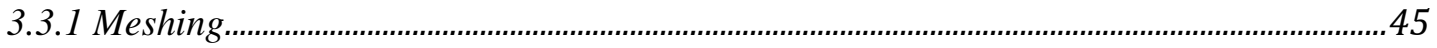

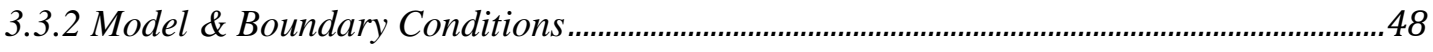

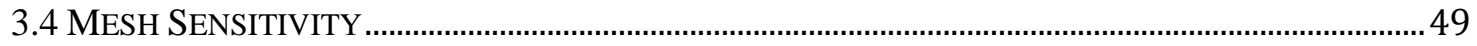

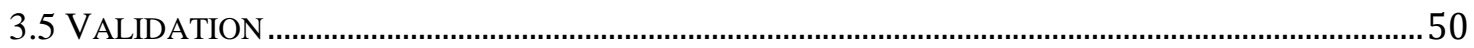

3.6 CONTOURS OF PRESSURE, VELOCITY AND VOLUME FRACTION OF VAPOR .............................55

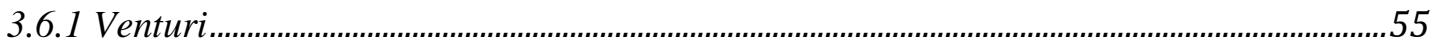

3.6.2 Rectangular Venturi..................................................................................................................5

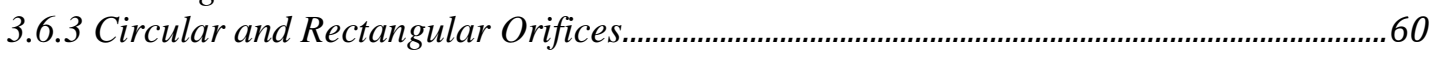


3.6.4 Nozzle...

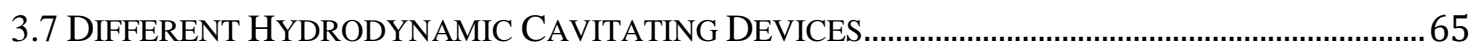

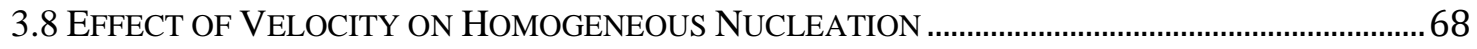

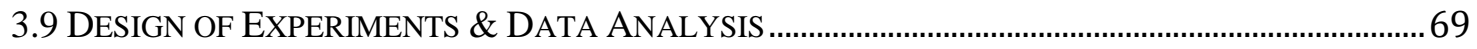

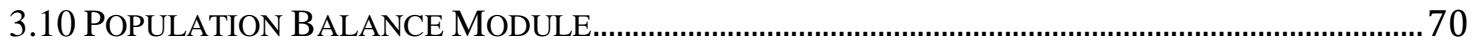

CHAPTER 4 SIMULATION OF CAVITATION VENTURI DESIGN.................................. 71

4.1 IMPORTANCE OF FACTORS ON CRITICAL CAVITATION VELOCITY ……................................... 71

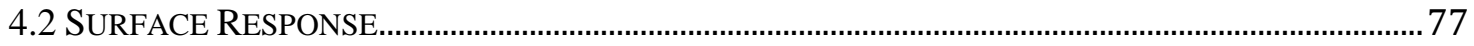

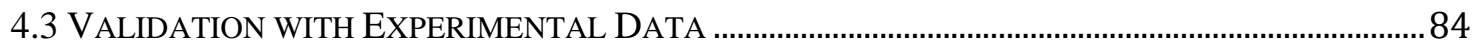

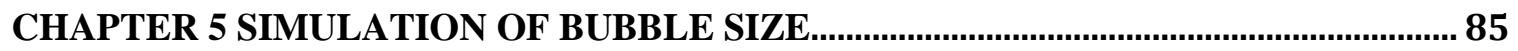

5.1.1 Equation

5.1.2 Bubble Number Density ........................................................................................................8

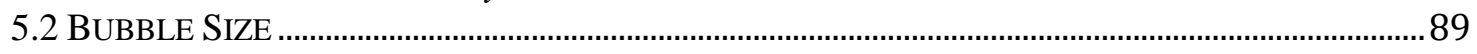

5.3 SOLID PARTICLE EFFECTS ................................................................................................ 90

5.4 EFFECTS OF BUBBLE SIZE WITH DIFFERENT PARTICLE SIZE/DIFFERENT THROAT

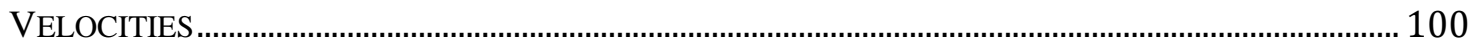

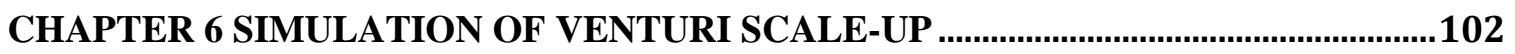

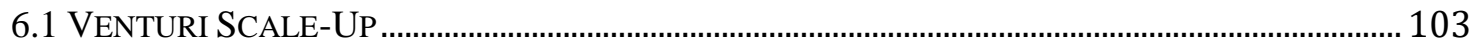

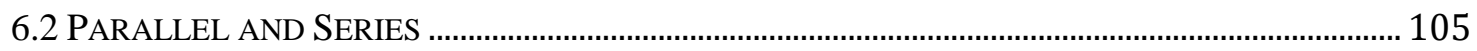

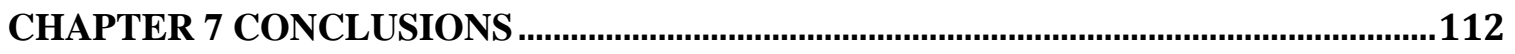

RECOMMENDATIONS FOR FUTURE WORK .............................................................115

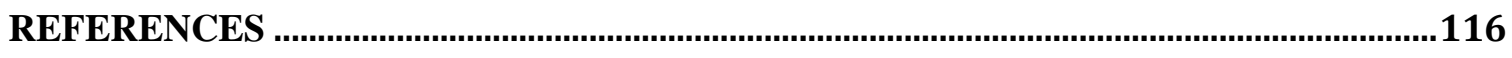

APPENDIX A

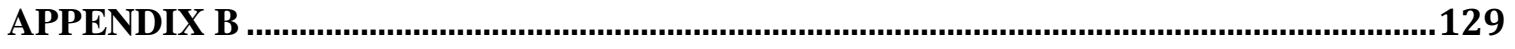

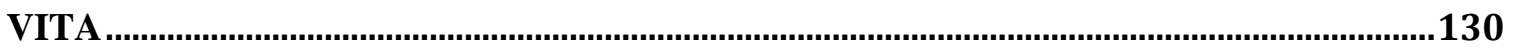




\section{List of Tables}

Table 2-1 Summary of Applications of CFD in Flotation Modeling ........................................... 33

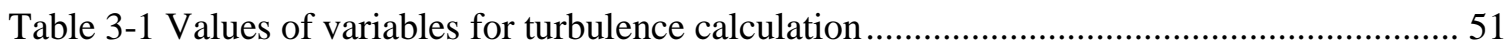

Table 3-2 Critical Cavitation Velocity and Vapor Volume of Different Geometries ................... 67

Table 3-3 Values of variables for response surface design of venturi tube design ...................... 69

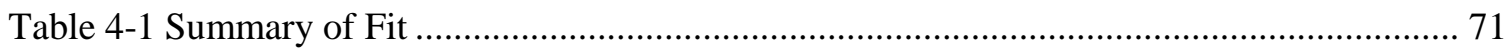

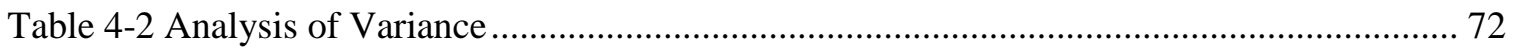

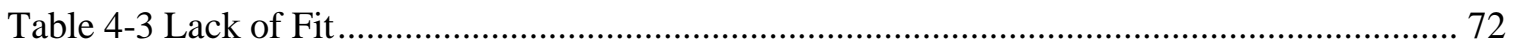

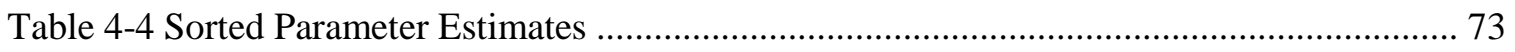

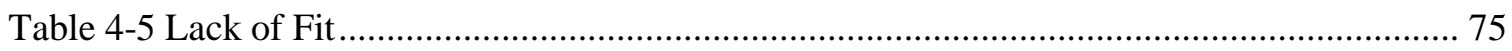

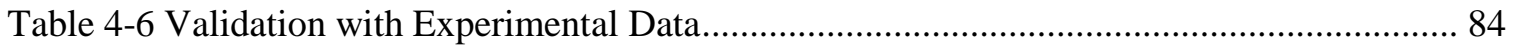

Table 6-1 Geometries of Different Flotation Columns ............................................................ 102

Table 6-2 Vaper Generated Rates of Different Venturi Tubes with 20 m/s Throat Velcocity.... 103

Table A-1 Response surface design for venturi tube design tests .......................................... 127 


\section{List of Figures}

Figure 2-1 Particle size ranges of coal and mineral in effective froth flotation (Jowett, 1980) ...... 6 Figure 2-2 Kinetic limiting and carry capacity limiting flotation conditions (Honaker and

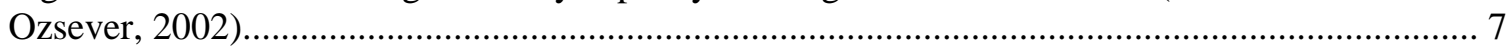

Figure 2-3 Bridging two hydrophobic surfaces with cavitation generated bubbles ..................... 10 Figure 2-4 Tiny bubbles generated by the cavitation tube only with $20 \times 10^{-6}$ MIBC (Xiong \&

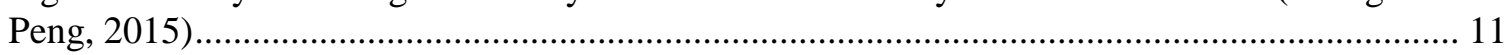
Figure 2-5 Nano bubble size distribution at varying concentrations of surfactant (MIBC) (Xiong

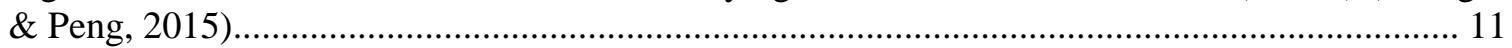

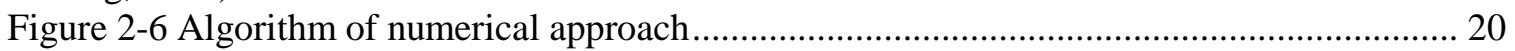
Figure 2-7 Fundamental Hydrodynamic models (Zhang, 2007) .............................................. 31

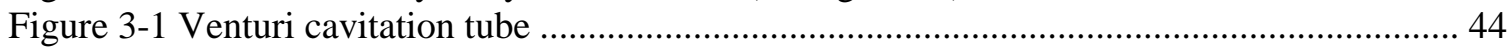

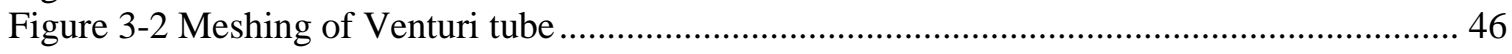

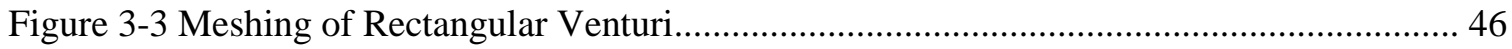

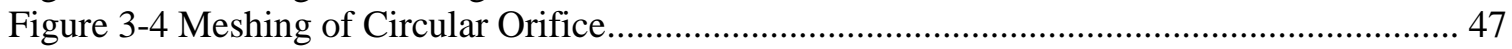

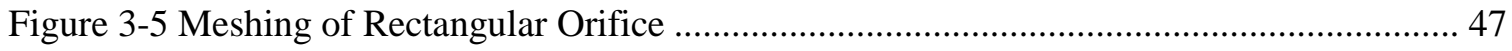

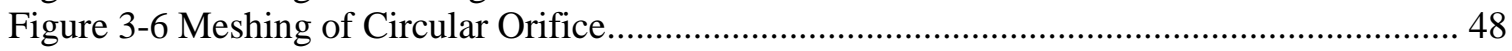

Figure 3-7 Net Integral Pressure versus the cell number........................................................ 50

Figure 3-8 Pressure distributions along the venturi tube: experimentally measured pressures at corresponding water flow rates $(\mathrm{H} . \mathrm{Hu}$, et al., 1998) ............................................................... 51

Figure 3-9 Pressure distributions along the venturi tube: ANSYS fluent model at different flow

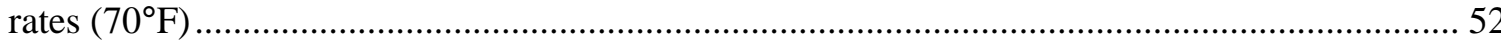

Figure 3-10 Static pressure distributions along the nozzle: ANSYS fluent vs. Abuaf et al., (1981)

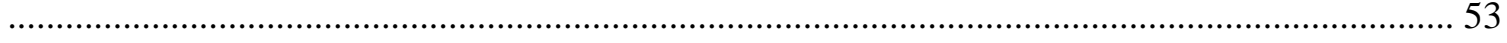

Figure 3-11 Vapor fraction along the nozzle: ANSYS fluent vs. Abuaf et al., (1981) ................ 53

Figure 3-12 Pressure profile through an orifice (Yan and Thorpe, 1981) ................................... 54

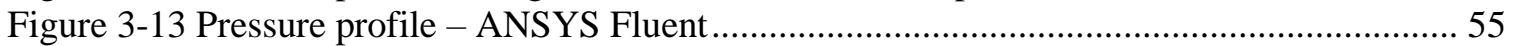

Figure 3-14 Contours of static pressure at flow rates $6.7 \mathrm{~m} / \mathrm{s}, 8.5 \mathrm{~m} / \mathrm{s}, 10.6 \mathrm{~m} / \mathrm{s}, 12.7 \mathrm{~m} / \mathrm{s}$ and 15.9

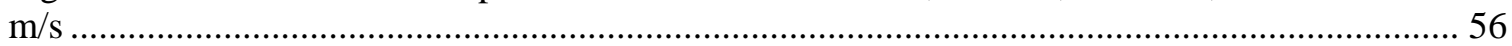

Figure $3-15$ Contours of velocity at flow rates $6.7 \mathrm{~m} / \mathrm{s}, 8.5 \mathrm{~m} / \mathrm{s}, 10.6 \mathrm{~m} / \mathrm{s}, 12.7 \mathrm{~m} / \mathrm{s}$ and $15.9 \mathrm{~m} / \mathrm{s}$

Figure 3-16 Contours of volume fraction (vapor) at flow rates $6.7 \mathrm{~m} / \mathrm{s}, 8.5 \mathrm{~m} / \mathrm{s}, 10.6 \mathrm{~m} / \mathrm{s}, 12.7 \mathrm{~m} / \mathrm{s}$

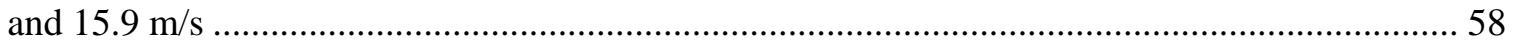

Figure 3-17 Contours of static pressure, velocity and volume fraction (vapor) at $12.5 \mathrm{~m} / \mathrm{s} \ldots \ldots \ldots . .59$ Figure 3-18 Contours of static pressure for circular and rectangular orifices at throat flow rates

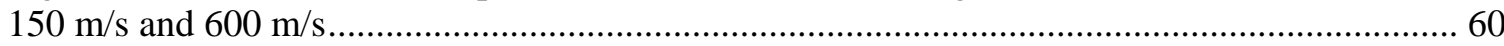
Figure 3-19 Contours of velocity for circular and rectangular orifices at throat flow rates $150 \mathrm{~m} / \mathrm{s}$

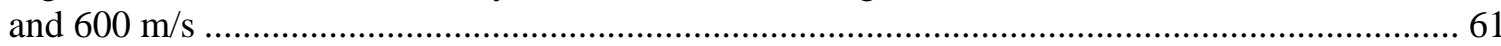
Figure 3-20 Contours of velocity for circular and rectangular orifices at throat flow rates $150 \mathrm{~m} / \mathrm{s}$

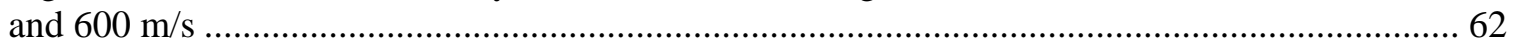
Figure 3-21 Contours of static pressure at mass rates $8.8 \mathrm{~kg} / \mathrm{s}$ at $294.26 \mathrm{~K}$ and $420 \mathrm{~K}$............... 63 Figure 3-22 Contours of velocity at mass rates $8.8 \mathrm{~kg} / \mathrm{s}$ at $294.26 \mathrm{~K}$ and $420 \mathrm{~K}$......................... 63 Figure 3-23 Contours of volume fraction (vapor) at mass rates $8.8 \mathrm{~kg} / \mathrm{s}$ at $294.26 \mathrm{~K}$ and $420 \mathrm{~K} \ldots 64$ Figure 3-24 (a) circular venturi, (b) circular orifice, (c) square venturi, (d) square orifice, (e) slot

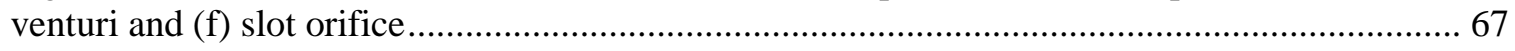

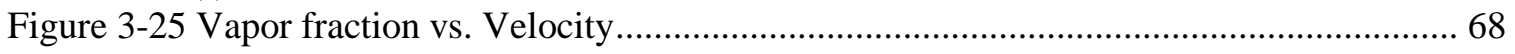

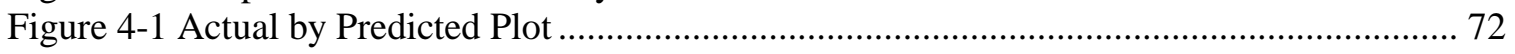

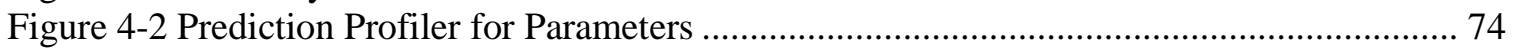




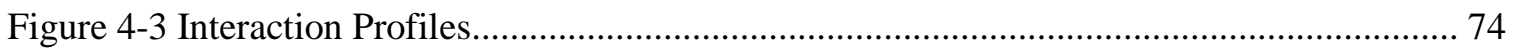

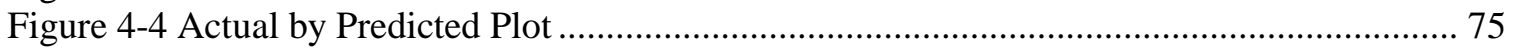

Figure 4-5 Leverage Plots of (1) Critical Velocity vs. Inlet Diameter; (2) Critical Velocity vs.

Diameter Ratio; (3) Critical Velocity vs. Convergent Angle; (4) Critical Velocity vs. Throat

Length; (5) Critical Velocity vs. Entrance Length; (6) Critical Velocity vs. Inlet

Diameter*Diameter Ratio; (7) Critical Velocity vs. Diameter Ratio*Convergent Angle; (8)

Critical Velocity vs. Diameter Ratio*Entrance Length; (9) Critical Velocity vs. Diameter

Ratio*Diameter Ratio;

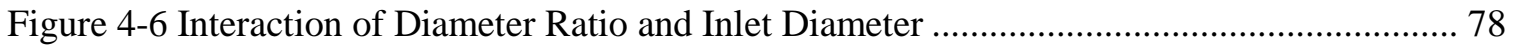

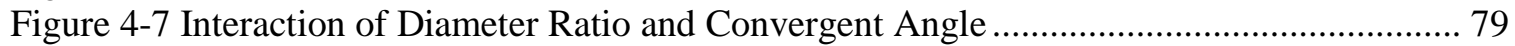

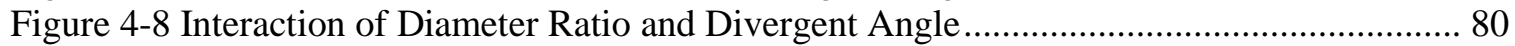

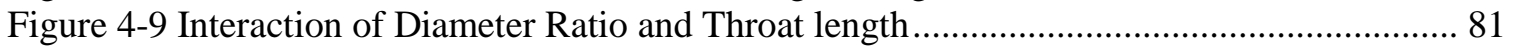

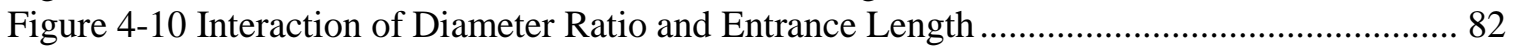

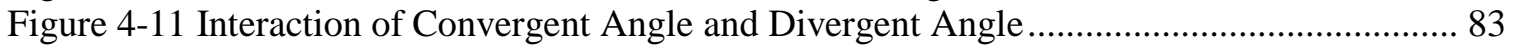

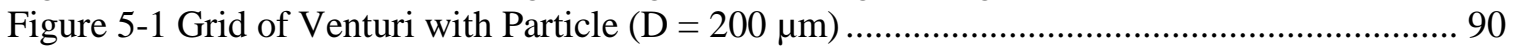

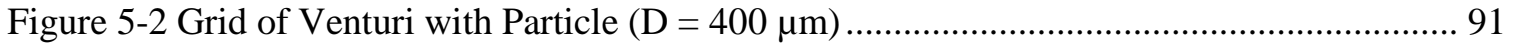

Figure 5-3 Histogram of Bubble Size with Three Geometries ................................................... 92

Figure 5-4 Pressure Distribution Along the Venturi Tube - Without Particle ............................. 93

Figure 5-5 Pressure Distribution Along the Venturi Tube - With Particle D = 200 $\mu$ m............... 93

Figure 5-6 Pressure Distribution Along the Venturi Tube - With Particle D $=400 \mu$ m.............. 94

Figure 5-7 Maximum/Minimum Pressure of Venturi and Venturi with Particles at Different

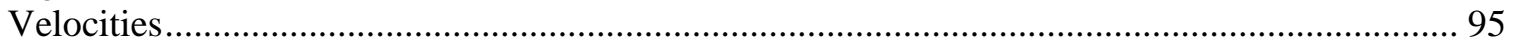

Figure 5-8 Contour Images of Vapor Volume Fractions (Throat Velocity is $15 \mathrm{~m} / \mathrm{s}$ ) ................ 96

Figure 5-9 Contour Images of Vapor Volume Fractions (Throat Velocity is $20 \mathrm{~m} / \mathrm{s}$ ) ................ 97

Figure 5-10 Contour Images of Pressure (Throat Velocity is $20 \mathrm{~m} / \mathrm{s}$ ) ........................................ 98

Figure 5-11 Contour Images of Velocity (Throat Velocity is $20 \mathrm{~m} / \mathrm{s}$ ) .................................... 99

Figure 5-12 Bubbles Generated at Different Throat Velocities................................................. 100

Figure 6-1 Vapor volume ratio of three venturi tubes at different velocities ............................... 104

Figure 6-2 Schematics of (a) Packed Column and Venturi Tube in Parallel Order (b) Packed

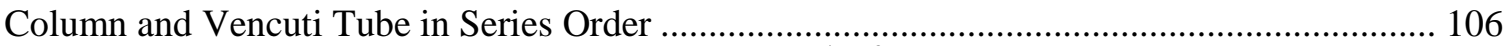

Figure 6-3 Contour Images of Pressure with $2.41 \times 10^{-4} \mathrm{~m}^{3} / \mathrm{s}$ inlet flow rate of (a) Parallel Design;

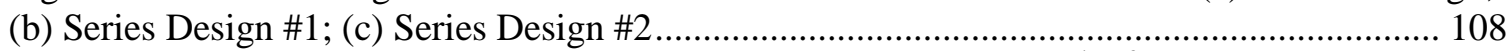

Figure 6-4 Contour Images of Vapor Volume Fractions with $2.41 \times 10^{-4} \mathrm{~m}^{3} / \mathrm{s}$ inlet flow rate of (a)

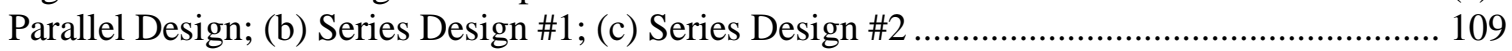

Figure 6-5 Vapor volume integral of three design with different inlet flow rates....................... 110

Figure 6-6 Vapor bubble size of three design with different inlet flow rates .............................. 111 


\section{List of Nomenclature}

$\begin{array}{lll}a & \text { aggregation kernel } & \text { dimensionless } \\ C & \text { sound velocity } & \mathrm{m} / \mathrm{s} \\ d & \text { throat diameter } & \mathrm{mm} \\ D & \text { inlet diameter } & \mathrm{mm} \\ \vec{F} & \text { body force } & \mathrm{N} \\ f & \text { phase mass fraction } & \text { dimensionless } \\ g & \text { gravitational acceleration } & \mathrm{m} / \mathrm{s}^{2} \\ G & \text { turbulent kinetic energy } & \mathrm{m}^{2} / \mathrm{s}^{2} \\ k & \text { turbulent kinetic energy } & \mathrm{m}^{2} / \mathrm{s}^{2} \\ N & \text { bubble number density } & \# / \mathrm{m}^{3} \\ P & \text { pressure } & \mathrm{Pa} \\ R & \text { change rate; bubble radius } & \mathrm{kg} / \mathrm{s} ; \mathrm{m} \\ S & \text { source term } & \\ R e & \text { Reynolds number } & \mathrm{dimensionless} \\ T & \text { Temperature } & { }^{\circ} \mathrm{C} ;{ }^{\circ} \mathrm{F} ; \mathrm{K} \\ t & \text { time } & \mathrm{s} \\ v & \text { velocity } & \mathrm{m} / \mathrm{s}\end{array}$

\section{Greek Letters}

$\alpha \quad$ phase volume fraction

$\beta \quad$ probability; diameter ratio $d / D$

$\gamma \quad$ surface tension

$\varepsilon \quad$ energy dissipation rate

$\mu \quad$ viscosity

$v \quad$ kinematic viscosity

$\rho$ density

$\sigma \quad$ cavitation number

$\omega \quad$ specific rate of dissipation of kinetic energy

$\Gamma \quad$ diffusion coefficient dimensionless

dimensionless

$\mathrm{N} / \mathrm{m}$

$\mathrm{m}^{2} / \mathrm{s}^{3}$

$\mathrm{Pa} \cdot \mathrm{S}$

$\mathrm{m}^{2} / \mathrm{s}$

$\mathrm{kg} / \mathrm{m}^{3}$

dimensionless

$\mathrm{m}^{2} / \mathrm{s}$

\section{Subscripts}

$\begin{array}{cl}b & \text { bubble; buoyancy } \\ k & \text { phase } \\ m & \text { mixture } \\ l & \text { liquid } \\ v & \text { vapor }\end{array}$




\section{CHAPTER 1 Introduction}

\subsection{Background}

Froth flotation is the process of using physicochemical methods to separate valuable minerals from gangue, and it is one of the most important methods in mineral processing engineering. The performance of the flotation machine depends on the solid-liquid-gas three-phase interaction. Particles are separated by attaching to air bubbles and floating, or by falling to the bottom of the cell or column, based on their hydrophobicity.

Flotation recovery is dependent on the particle size. The limited particle size range for minerals has been a problem both economically and environmentally. However, introducing tiny bubbles in the flotation process has proven to be effective in improving particle recovery (Tao et al., 2006; Fan et al., 2010; Sobhy and Tao, 2013; Peng and Xiong, 2015). Previous studies have found that small bubbles generated by hydrodynamic cavitation in the feed could enhance fine and coarse particle flotation, by increasing the contact angle of particles and the contact area between the bubble and particles and by increasing the attachment force. Thus, the probability of bubble particle attachment could be increased, and the probability of detachment could be reduced. Therefore, the recovery would be improved (Zhou et al., 1997; Xu et al., 2001). Additionally, with cavitation generated bubbles, the collector and frother dosages can both be reduced (Tao et al., 2006; Zhou et al., 2009; Fan et al., 2010). This technology reduces both energy consumption and capital costs.

Cavitation is the most economical and efficient method for creating tiny bubbles for froth separation. It is the development and growth of a gas and/or vapor filled void in an originally liquid medium. The tiny bubbles are formed when the gas is super-saturated, where the local pressure is lower than the vapor pressure of the liquid (Ryan and Hemmingsen, 1993, Saracoglu, 2013). 
To design the cavitation bubble generating devices for flotation, mathematical analysis is a good way to model the multiple interacting phases, understand complex physical changes, and test all the possible parameters without consuming a large amount of time. Computational fluid dynamics (CFD) is a division of fluid mechanics that uses computer programmed systems to simulate the flow of fluids. For flotation process, liquid velocities, turbulent dissipation rates, gas hold-up, particle-bubble attachment rates, and detachment rates can be simulated. The performance of flotation equipment can be obtained by CFD simulations. Different modules can also calculate vapor volume fractions and bubble size distributions from cavitation. Thus, CFD is suitable, in order to prove the experiment results and provide more practical designs.

Population Balance Model (PBM) in FLUENT is an add-on module. It can be used for simulating nucleation, growth, dispersion, dissolution, aggregation, and breakage processes involving a secondary phase with a size distribution. PBM can describe the population of different secondary phase sizes and their behavior. To analyze the bubble size distribution generated by a cavitation device, PBM is applicable for this study.

User-defined functions (UDFs) are a customized action of ANSYS Fluent. They enhance the abilities of ANSYS by allowing the user to calculate very specific aspects of research, beyond the scope of the default software. Theoretical equations from a previous used were as a baseline to generate UDF for calculating bubble number density in this study.

\subsection{Research Objectives}

The objective of this study is to simulate a venturi tube design for the column flotation system. The main goals of this dissertation were to:

- Review characteristics of pico, nano bubbles, and the improvement of flotation with pico, nano bubbles.

- Analyze the pico, nano bubbles creation by cavitation. 
- Compare different shapes of tubes for cavitation using CFD.

- Understand the mechanism of cavitation of venturi tube, and optimize the design with CFD.

- Validate the models through simulation and comparison with experimental results.

- Investigate the cavitation bubble size distribution, and the relationship with particle size.

- Scale-up venturi tube design for industry flotation column.

\subsection{Contributions}

In this research effort, ventutri tube design was simulated using cavitation model for vapor volume fraction calculation, and a PBM model was used for bubble size analysis. The main achievements are:

- This study analyzed the efficiency of different cavitation bubble-generating devices and compared the critical cavitation velocities and volume fractions of venturi and orifice with different geometries: circular, square, and slot. Circular venturi tubes were identified to be the best design for cavitation bubble generation for flotation process.

- It optimized the geometric design of venturi tube, by evaluating six parameters. A term "critical velocity", which means the minimum required velocity for cavitation for different geometries was proposed and used as the response for the response surface method. The geometry requires the minimum critical velocity, which is also the optimum design for flotation column cavitation. This was achieved.

- It calculated the bubble size for the secondary phase with PBM, including the rates of nucleation, growth, dispersion, aggregation and breakage. A mathematical model for bubble number density calculation was written as UDF and complied with ANSYS-Fluent, in order to calculate the nucleation rate. It confirmed that solid particles enhance cavitation and reduce the cavitation bubble size. 
- It compared the performances of packed column and venturi tube in parallel and in series in two orders. The packed column and venturi tube in series and with packed column first and the venturi tube second in order was found to be better.

- It applied to industry via scaled-up design. The lab scale, standard scale, and industry scaled-up sized venturi tubes were compared. The model predicted that multiple standard scale venturi tubes was the most efficient design.

\subsection{Structure of the Dissertation}

This study is presented in seven chapters. Chapter 1 gives an overview and introduction of column flotation with cavitation bubbles. Chapter 2 reviewed background and previous work from literature. Chapter 3 presents the equations and methods that are used. The model used was validated with literature results. The minimum velocities required for cavitation for the system of different geometries were compared. Chapter 4 contains the simulation of cavitation venturi analysis using CFD and RSM. The design requires that the minimum critical velocity was achieved. Chapter 5 is the simulation of the cavitation bubble size distribution calculation with PBM. User-defined functions (UDFs) were written and compiled, and the cavitation bubble sizes were calculated. The effects with solid particles were considered. Chapter 6 investigates the performances of packed column and venturi tube in parallel and in two different series. The scale-up venturi tube

application for industry is also discussed. Chapter 7 is the conclusions of this study and recommendations for future work. 


\section{CHAPTER 2 Literature Review}

\subsection{Introduction and Background}

\subsubsection{Column Flotation}

Froth flotation is a process which separates minerals based on the physical properties and surface chemistry of particles. It is widely used in different industries, and it is one of the most important methods in mineral process engineering. Separation occurs when hydrophobic particles attach to air bubbles and float to the froth, leaving the hydrophilic particles suspended in the slurry. The hydrophilic particles eventually settle to the bottom, and they are discharged as tailings.

Flotation equipment, cells, and columns have increased in popularity since froth flotation has been found to be successful in mineral processing plants. It has been recognized as the most effective method for separating fine particles (Luttrell and Yoon, 1988).

The column flotation method was introduced in 1962, installed in 1980, used in industry in 1983, and widely accepted throughout in 1990 (Finch and Dobby, 1991). It has been applied to several industrial minerals. $\mathrm{Cu}, \mathrm{Mo}$, and Au roughing and cleaning as well as coal and kaolinite are amongst the most common (Lee et al., 1991). There are several advantages to using flotation columns, as opposed to the conventional flotation cell. Construction of the columns is simple; the rotor and stator are no longer needed. Hydrophilic minerals are separated by countercurrent flow, which reduces energy consumption, operating costs, and maintenance costs. Flotation columns also have higher degrees of selectivity. The larger height-to-diameter ratio provides more opportunities for particle collision and a longer retention time for recollection. Thus, the flotation column method has a higher recovery (Finch and Dobby, 1991). 


\subsubsection{The limitations of Froth Flotation}

\subsubsection{The Particle Size}

The particle size range for flotation is narrow, which limits the flotation recovery. As shown in Figure 2-1, the particle size for coal is approximately 45 to $250 \mu \mathrm{m}$ and minerals are 10 to $150 \mu \mathrm{m}$ in diameter (Jowett, 1980). Recovery drops significantly, for particle sizes outside of this range.

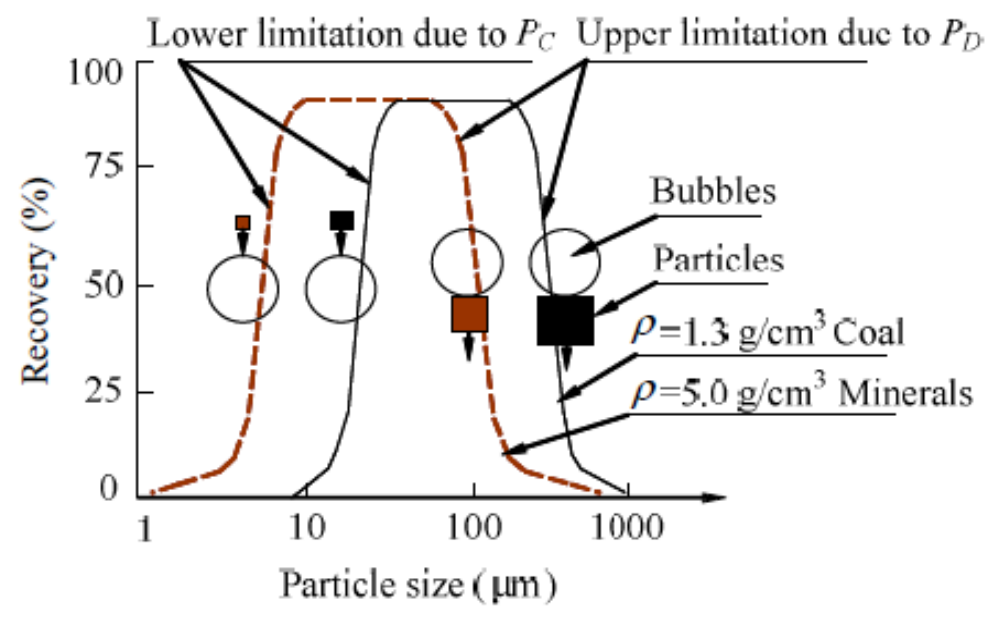

Figure 2-1 Particle size ranges of coal and mineral in effective froth flotation (Jowett, 1980)

Koh and Schwarz (2006) also found that particles size outside of 120-240 $\mu \mathrm{m}$ do not float well. The effective range is limited by low bubble-particle collision and detachment at the lower and upper ends, respectively.

\subsubsection{Mass Flux Rate}

The carrying capacity is the amount of flotation mass carried over time, per column cross-section area; it limits the throughput capacity of a flotation system. Koh and Schwarz (2008) found that the bubble surface area flux for the attachment of all valuable particles present in the pulp is the limiting factor in the recovery rate, rather than the collision or attachment rate. The maximum capacity can be estimated from the bubble 
surface area flux. The limitation is when there is not enough bubble surface area to carry additional hydrophobic particles. This limitation is shown in Figure 2-2, where there is insufficient bubble surface area. When the bubble surface is full of particles, the product mass rate gets limited.

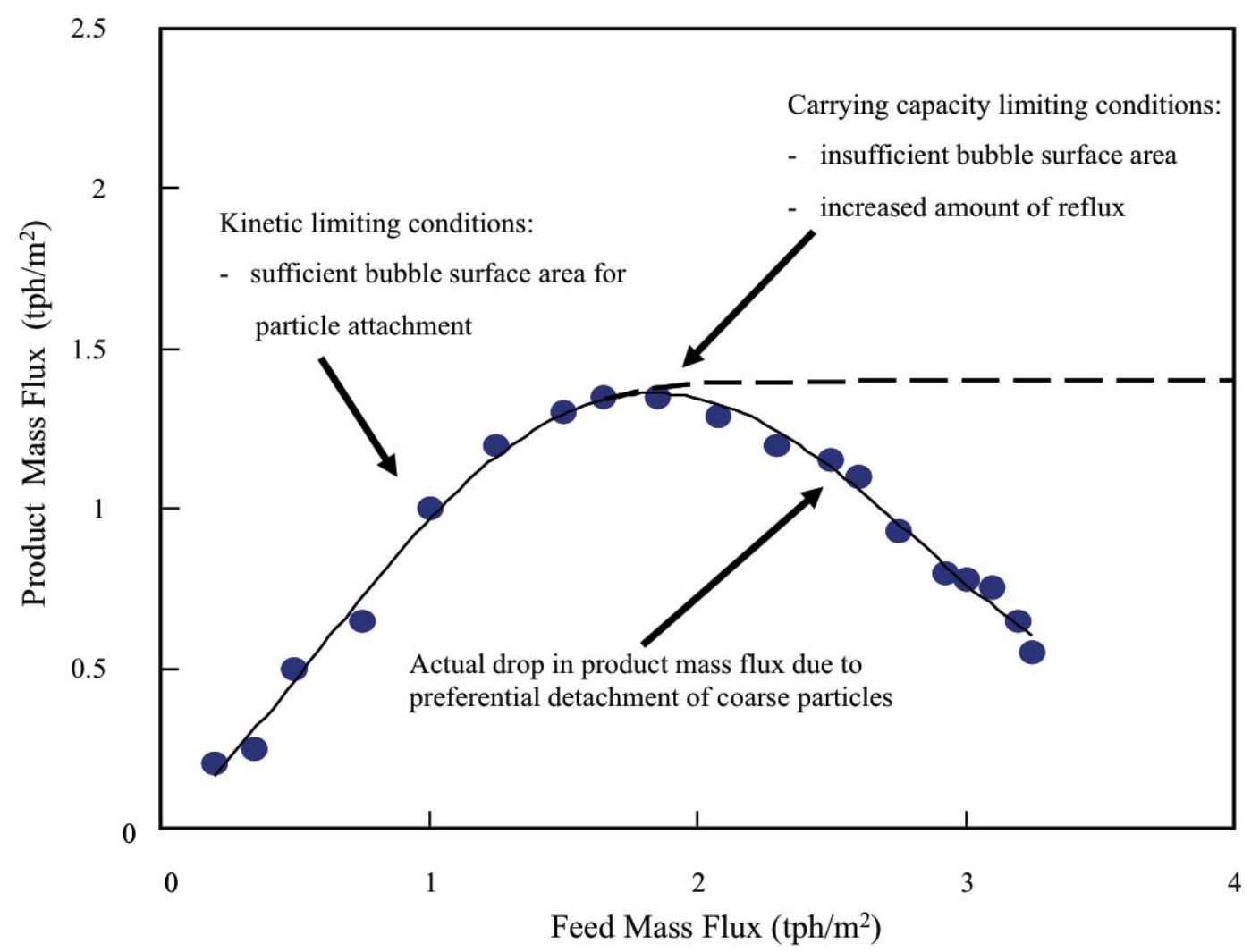

Figure 2-2 Kinetic limiting and carry capacity limiting flotation conditions (Honaker and Ozsever, 2002)

However, both limitations can be reduced by increasing air flow, decreasing the solid concentration, and modifying the hydrophilicity of the particles by introducing reagents and/or cavitation bubbles.

\subsubsection{Bubble Generation and Size Distribution}

Bubbles are necessary for flotation. Several devices have been developed to generate air bubbles. In early froth flotation development, electrolysis was used or electro-flotation, while pressure reduction was used for vacuum flotation. Agitation was developed for 
mechanical cells, and pressure release was designed for dissolved air flotation. Air dispersing spargers were used for pneumatic cells (Xu et al., 2013). More recently, micro-bubble generation has increased in popularity; it can slow flotation kinetics of fine particles.

Bubble size distribution is an important factor to determine how well the air and liquid phases are mixed. Kho and Sohn (1989) performed laboratory column flotation experiments and mathematical modeling. They concluded that air bubble size is the most important parameter in enhancing the flotation recovery.

To measure the bubble size distribution, the primary analysis methods in mining engineering are image, electroresistivity, optical, porous plate, and drift-flux analysis. The average bubble sizes obtained from Rodrigues and Rubio's (2003) flotation techniques are as follows: Electroflotation $(20-40 \mu \mathrm{m})$, gas aphrons $(10-100 \mu \mathrm{m})$, cavitation air flotation $(40 \mu \mathrm{m})$, dissolved air flotation $(10-100 \mu \mathrm{m})$, air sparged hydrocyclone, bubble accelerated flotation $(200 \mu \mathrm{m})$, jet flotation $(100-600 \mu \mathrm{m})$, microcel flotation $(400 \mu \mathrm{m})$, nozzle flotation $(400-800 \mu \mathrm{m})$, column flotation $(1000 \mu \mathrm{m})$, and induced air flotation $(700-1500 \mu \mathrm{m})$.

Sam et al. (1996) found that the type of froth used affects the bubble size distribution. Rodrigues and Rubio (2003) investigated the frother effect on bubble size, and found that when the frother concentration increases, the bubble size decreases. This is because the additional surfactants decrease the surface tension. However, Finch and Dobby (1990) found that after a certain concentration, the bubble size becomes constant and additional froth has no effect.

\subsection{Pico, Nano and Micro Bubble Flotation}

Previous research has found that pico, nano bubbles may increase particle collision and attachment and reduce particle detachment. Additionally, pico, nano bubbles may increase the size range and overall improve the flotation recovery. This is especially true 
for fine particles (Li et al., 2003; Tao et al., 2006; Fan et al., 2012; Sobhy and Tao, 2013; Peng and Xiong, 2015). Ultrafine particles may attach to the pico, nano bubbles without the need of collision. Using pico, nano bubbles for flotation may also lower frother dosage and air consumption. This would improve the carrying capacity and reduce operating costs.

\subsubsection{Mechanism}

Zhou et al. (1996) found that nano bubbles, in combination with standard-sized bubbles, increased recovery yield. Nano bubbles generate a clustering effect, which increases the probability of collision. Particles covered with nano bubbles increases its hydrophobicity, making it easier for them to attach to standard bubbles. Pico, nano bubbles may also reduce the rising velocities of standard bubbles. This may increase the bubble-particle sliding time, decrease tangential velocities of particles sliding on the bubble surfaces, and increase the probability of particle attachment (Yoon, 2000). Fan et. al. (2010; 2012) found that they are acting as a secondary collector and that they reduce the collector dosage by 33-50 percent. Additionally, since cavitation bubbles are produced from air that is naturally dissolved in water, the air consumption may be reduced (Sobhy and Tao, 2013).

However, pico, nano bubbles are not large enough on their own to float mineral particles to the surface. This is especially true with coarse particles. Thus, standard-size bubbles are still needed. Zhou (1994) found that there is a two-stage frothing process with pico, nano bubbles. This is shown in Figure 2-3. Pico, nano bubbles attach themselves to the particles. Then, the combination of those two attach to conventional bubbles to be carried to the froth layer. Hampton and Nguyen (2010) used atomic force microscopy (AFM) to study the function of coalescence-tiny-bubbles for two hydrophobic surfaces. They found that the tiny bubbles act as a bridge between particles and bubbles. It has also been found that the bridging effect makes the cluster more stable (Schubert, 2005; Hampton and Nguyen, 2010). 
Ghorbani and Ghorbani (2014) found that 1 cubic mm volume of nano- bubbles is 10,000 times greater in surface area than 1 cubic mm of conventional air bubbles. This means the bubble surface area flux and carry capacity can be increased for flotation.
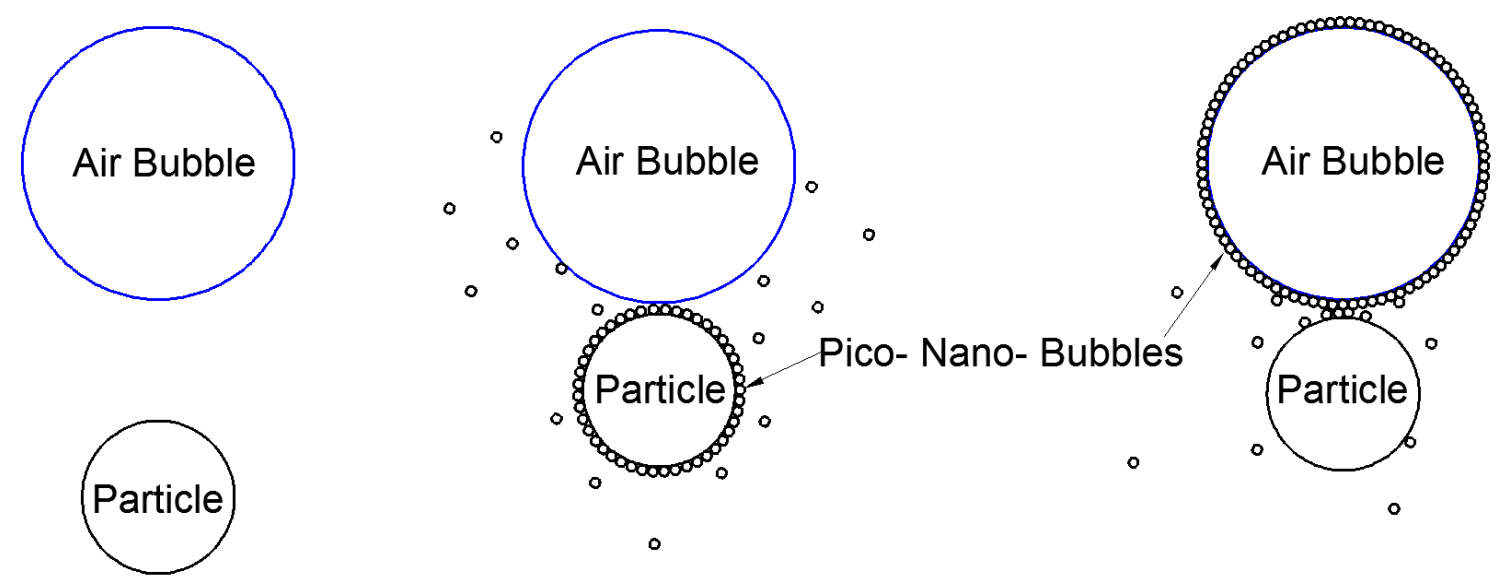

Figure 2-3 Bridging two hydrophobic surfaces with cavitation generated bubbles

\subsubsection{Pico, Nano Bubble Formation}

Ahmed (2013) found that Pico $\left(10^{-12} \mathrm{~m}\right)$, nano $\left(10^{-9} \mathrm{~m}\right)$ and micro $\left(10^{-6} \mathrm{~m}\right)$ bubbles can be generated by ultrasonic cavitation, solvent exchange, changed in temperature or pressure, turbulent flow, microporous diffusion, electrolysis, and chemical reactions. The most economical way of generating these bubbles is hydrodynamic cavitation in a liquid, caused by the rupture of a liquid-liquid or liquid-solid (Tao et al., 2006). The formation of bubbles occurs as a result of various interactions between the liquid solution, solid particles, and dissolved gas, when the gas in the system is super saturated.

\subsubsection{Pico, Nano Bubble Size Distribution}

Xiong \& Peng (2015) analyzed the size distribution of pico, nano bubbles created by cavitation. They measured the distribution using a laser. This is shown in Figure 2-4. There are two distinct modes observed on the population frequency curve, which are 0.08 $\mu \mathrm{m}$ and $0.7 \mu \mathrm{m}$. 


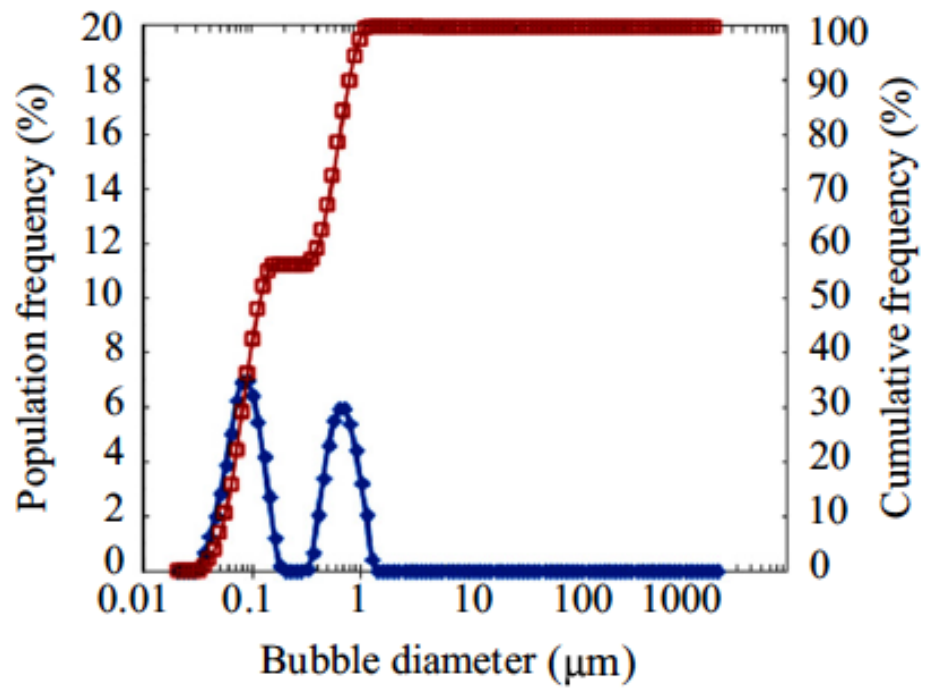

Figure 2-4 Tiny bubbles generated by the cavitation tube only with $20 \times 10^{-6} \mathrm{MIBC}$ (Xiong \& Peng, 2015)

Bubble sizes are affected by liquid surface tension. Figure 2-5 shows nano bubbles generated by a cavitation tube with different surfactant concentrations. The bubble size decreases as the surfactant concentration increases, ranging from 0.3 to $0.8 \mu \mathrm{m}$ in diameter.

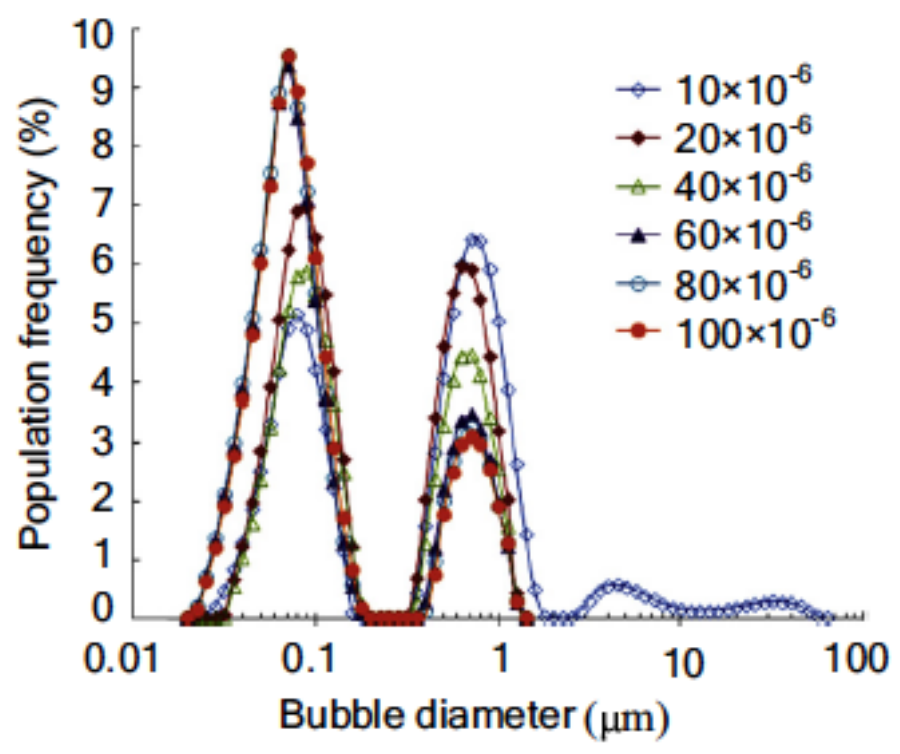

Figure 2-5 Nano bubble size distribution at varying concentrations of surfactant (MIBC) (Xiong \& Peng, 2015) 


\subsubsection{Stability}

Stability is a common problem associated with pico, nano bubbles. High internal pressures cause premature ruptures. However, a couple studies (Zhang et al., 2008; Kohno et al, 2013) have found that the pico, nano bubbles can last at least nine orders of magnitude longer than theoretical lifetimes. Sobhy and Tao (2013) also found that cavitation bubbles with an average diameter of $700 \mathrm{~nm}$ is stable in water solution for more than 20 minutes. Zhang (2008) calculated that the lifetime of pico, nano bubbles could be increased up to four orders of magnitude, when the inner density of the gas bubbles is high. Johnson et al. (2012) measured the hydrophobicity of nano bubles, and he found that they are very stable in the order of hours. Furthermore, Ushikubo et al. (2010) found repulsion between the surfaces of the nano bubbles, due to a double positive electron layer. Yang et al. (2007) found that increasing the water temperature also increases the density of the nano bubbles; they also discovered that the bubbles do not dissipate when the fluid is cooled back down. Therefore, the stability of pico, nano bubbles in solution is quite high, and the bubbles maintain their size without significant change.

\subsection{Cavitation}

Cavitation is the generation of gas or vapor-filled voids in a liquid medium. It happens at constant temperature with lower pressure. Tiny cavitation bubbles may be generated in liquids containing trace amounts of gas. Cavitation bubbles have also been observed with super-saturated gases trapped in the cracks of hydrophobic solid particles (Ryan and Hemmingsen, 1993, Saracoglu, 2013).

Zhou et. al. (1997) discovered when incorporating hydrodynamic cavitation to flotation, there was a significant increase in overall movement. He also found that increasing the liquid flowrate, gas content, and temperature generated more bubbles. 


\subsubsection{Definition and Conditions}

As previously defined, cavitation is the formation of vapor or gas-filled cavities in liquid medium. Young (1989) found that the liquid-to-air phase change takes place inside the cavity, or on the solid surface. Low pressure and rapid movement are required for cavitation to occur. Cavitation is not desirable for all industrial equipment. It limits operation speeds, generates noise and vibrations, and may be factor in the development of erosion. However, for mineral processing, cavitation aids particle bubble attachment and flotation acceleration.

Nurick (1976) proposed a condition for cavitation based on the mass flowrate. The condition for cavitation is that pressure decreases whenever you increase velocity. Once the pressure is lower than the vapor pressure $\left(\mathrm{P}_{\mathrm{v}}\right)$, this is the critical cavitation condition. Young (1989) refers to this as cavitation nuclei. These gas nuclei cause weak spots in the liquid and reduce the surface tension of the liquid medium. The basis for this lies within the calculation of Bernoulli's principle:

$$
\frac{P_{s}-P_{v}}{\frac{1}{2} \rho V^{2}}<\left[\left(\frac{v}{V}\right)^{2}-1\right]
$$

Where $P_{S}$ is the static pressure, $P_{v}$ is the vapor pressure, $V$ is velocity of the fluid without cavitation, $v$ is cavitation velocity, and $\rho$ is the density of the liquid medium. The lefthand side of Equation 2.1 is the cavitation number $(\sigma)$; it is a dimensionless number. As illustrated in the formula, low net pressure forces and high velocities yield a small cavitation number. Thus, decreasing net pressure forces and increasing the fluid flowrate are ways to generate cavitation (D'Agostino amd Maria, 2007). The Bernoulli's equation can be rearranged as:

$$
V^{2}+\frac{2 P}{\rho}=\frac{2 C}{\rho}
$$


Where $C$ is a constant. The rearranged formula allows us to visually isolate the effects of velocity, relative to pressure. Specifically, when the fluid flowrate is greater than $\sqrt{2 C / \rho}$, the pressure side of the equation is negative. Negative pressure indicates that the water is forming cavities to expand (Young, 1999).

Zhou (1996) found that dissolving gas and introducing solids with rough surfaces is more effective at generating cavitation. Wu (1969) discovered that surfactants, such as the frother, produce smaller and denser cavities. This is because the decreased surface tension delays the collapse of the cavity. Zhou (1997) found that this encourages the formation of more bubbles. Reagents may also be introduced to further enhance bubble generation and sustainability.

\subsubsection{Homogeneous and Heterogeneous Nucleation}

There are two types of nucleation to be considered: homogeneous and heterogeneous. Homogenous nucleation occurs simply when increasing or decreasing the pressure. This causes the liquid to become gas, when initiated by microscopic voids in the medium. In this study, it specifically refers to the gas nucleation in the fluid system.

Heterogenous nucleation happens at the surface of solids, in the cracks of rough surfaces within the particles suspended in the liquid and the container itself holding the fluid (Brennen, 1995). Multiple studies (Qian and Ma, 2009; Li, 2014) have found that the energy barrier for heterogeneous nucleation is much lower than that of homogeneous nucleation. This means nucleation on the particle surface is easier than within the fluid. 


\subsubsection{The Dynamics of a Spherical Bubble}

The Rayleigh-Plesset equation is the basis for cavitation models:

$$
\frac{P_{b}(t)-P_{\infty}(t)}{\rho_{l}}=R \frac{d^{2} R}{d t^{2}}+\frac{3}{2}\left(\frac{d R}{d t}\right)^{2}+\frac{4 v_{L}}{R} \frac{d R}{d t}+\frac{2 S}{\rho_{L} R}
$$

Where $P_{b}(t)$ is the pressure inside the bubble, $P_{\infty}(t)$ is the external pressure theoretically an infinite distance away from the particle, $\rho_{l}$ is the density of the fluid, $R(t)$ is the radius of the bubble, $v_{L}$ is the kinematic viscosity of the fluid, and $S$ is the surface tension of the bubble. Known $P_{b}(t)$ and $P_{\infty}(t)$ values easily provide a model to calculate bubble size changes with respect to time. Surface tension and viscosity are negligible for noncondensable gases. If $P_{\infty}$ is constant, equation 2.3 can be simplified as:

$$
\frac{d^{2} R}{d t^{2}}=\frac{2}{3} \frac{P_{v}-P_{\infty}}{\rho}\left[1-\left(\frac{R_{0}}{R}\right)^{3}\right]
$$

The system is in equilibrium when $P_{\infty}$ equals the vapor pressure $P_{v}$. The bubble size increases when $P_{\infty}$ is lower than $P_{v}$, and the bubbles collapse when $P_{\infty}$ is higher than $P_{v}$. The corresponding rates are as follows (D'Agostino et al. 2007):

If $P_{\infty}<P_{v}$

$$
\frac{d R}{d t} \cong \sqrt{\frac{2}{3} \frac{P_{v}-P_{\infty}}{\rho}}
$$

If $P_{\infty}>P_{v}$

$$
\frac{d R}{d t} \cong \sqrt{\frac{2}{3} \frac{P_{\infty}-P_{v}}{\rho}\left[\left(\frac{R_{0}}{R}\right)^{3}-1\right]}
$$

The bubble lifetime is also called Rayleigh time: 


$$
t_{p} \cong 0.915 R_{0} \sqrt{\frac{\rho}{P_{\infty}-P_{v}}}
$$

\subsubsection{Cavitation Devices}

Hydrodynamic cavitation is generated at the throat of devices, when the liquid passes through constriction, such as a valve, orifice, venturi, or nozzle. Velocity increases at the throat or vena-contracta, because the diameter decreases and the velocity increases. The velocity is also increased even further, because of the slip condition boundary. Bubbles at the throat also decrease the effective diameter (Salvador et al., 2011). As the velocity increases, the pressure at the throat decreases, which causes hydrodynamic cavitation to occur.

Increasing the inlet velocity retains a high-level velocity at the throat, which decreases the pressure and reduces the size of the bubbles. The decrease in pressure increases the likelihood of cavitation generation at the throat. The findings of Bertoldi et al., (2015) support this. By experimentally evaluating the effect of the mass flow rate, they found that higher flowrates increased cavitation, due to larger pressure drops, friction, and flow acceleration in the throat. Thang and Davis $(1979 ; 1981)$ found that bubble aggregation in the converging section and bubble breakage in the diverging section significantly altered the bubble density

\subsubsection{Packed Column}

The packed column is used for generating conventional sized bubbles for flotation. Zhou et.al. (1994) discovered that bubbles can be produced by active stirring or turbulent circulation of the liquid. Turbulent circulation was also found to be the primary method for breaking up the bubbles. The rate of which the bubbles break depends on how often collisions between bubbles occur. Kerdouss et al. (2006) found when the hydrodynamic 
forces in the liquid are larger than the surface tension force, the bubbles separate into smaller bubbles (Kerdouss et al., 2006).

\subsubsection{Venturi Tube}

The velocity of the fluid increases as the venturi tube diameter decreases. Therefore, the pressure at the throat decreases, generating cavitation. The venturi tube is widely regarded as the best flotation column design for inducing cavitation. Studies (Hart et al., 2002; Saracoglu, 2013) have shown that the throat is largely unobstructed, due to the gradual diameter reduction and increase before and after the throat, respectively.

\subsubsection{Geometrical Parameters}

Hydrodynamic cavitation is also affected by the geometry of the fluid container and the physical properties of the fluid within. The geometry of the containment system determines the residence time of the voids in the low-pressure zones and the intensity of their respective cavitational collapses. Geometry also affects the pressure recovery downstream of the throat (Saharan et al., 2013). Thus, geometrical parameters, such as inlet area, throat length to diameter, and divergent angle can be used to manipulate cavitation generation.

K. and Virendra, (2016) studied the following geometric parameters: divergence angle, throat height/diameter-to-length ratio, inlet pressure, and number of holds. They found that the divergence angle controls the pressure recovery rate, and therefore the intensity of cavity collapse. They also found that the throat height/diameter-to-length affects the residence time of the cavity in low pressure regions and the intensity of cavity collapse. Additionally, increasing the inlet flow area may also increase the volume and intensity of cavitation. Zhong et al., (2014) performed an experimental study on different nozzle structures and found that the nozzles with small length-to-diameter ratios generated more cavitation. They also had a higher discharge coefficient. Ohrn et al., (1991) found that the 
geometric shape and physical conditions of nozzle inlets affects the discharge coefficient. Bashir et al., (2011) found that the length-to-height ratio of the throat determined the maximum size of the cavity. They also found that the divergent angle has the biggest effect on the cavity collapse rate. Salvador et al., (2016) also found that varying convergent and divergent levels affects cavitation. They also numerically found that mass flow, momentum flux, and effective velocity are affected by convergent-divergent levels.

\subsection{Modeling and Simulation}

Quantitative modeling techniques and methods have become extremely helpful tools in process engineering. Complex problems may now be solved without while minimizing resources (King, 2001). Modeling and simulation is excellent for equipment comparison, selection, installation, scale-up, and optimization. In this study, Computation Fluid Dynamics (CFD) was used for analyzing cavitation characteristics and simulating tiny bubble generation within different geometries.

\subsubsection{Computation Fluid Dynamics (CFD)}

FLUENT is one of leading computational fluid dynamics (CFD) software packages. It was developed by FLUENT Inc. The company merged with ANSYS Inc. in 2006, and became the premiere computer-aided engineering (CAE) software company. CFD is established on the fundamental conservation equations, uses numerical methods, and algorithms to analyze and solve fluid flow problems (Yu et al., 2008). CFD calculates values for pressure, fluid velocity, temperature, species, and various phase compositions on a computation grid throughout the solution domain. It is used to quickly develop a wide array of designs, which can save time and money. These simulations can then be compared and validated with laboratory and/or field experiments. It provides

comprehensive information where measurements and tests are difficult or impossible to operate. Additionally, it is based on the root of the problems; trouble-shooting would not be difficult. 


\subsubsection{Discretization Methods}

CFD has several methods used to transfer continuous measures into discrete quantities. The most common methods are the three finite methods: finite difference method (FDM), finite volume method (FVM), and finite element method (FEM). FDM uses approximate difference formulas to solve more complicated differential equations. FVM is based on an integral form of the partial differential equation (PDE). The domain is separated into finite volumes, and the PDE is solved for a given finite volume. FEM divides larger, more complicated elements into finite elements. The finite elements are then combined to represent a much larger representation of the system. FEM differs from FDM and FVM, in that it provides a continuous solution, while the other two methods provide discrete solutions.

\subsubsection{CFD Packages}

CFD packages consist of three primary phases: pre-processing, solver, and postprocessing. Pre-processing is used to convert data so solver is able to define the geometries and fluid properties of the system. It is also used to divide domains of interest and to establish boundaries and conditions. Solver is then used to calculate and generate results. Finally, post-processing generates visuals of the results, including plots, images, and animations. Figure 2-6 illustrates the entire process tree of CFD packages. 


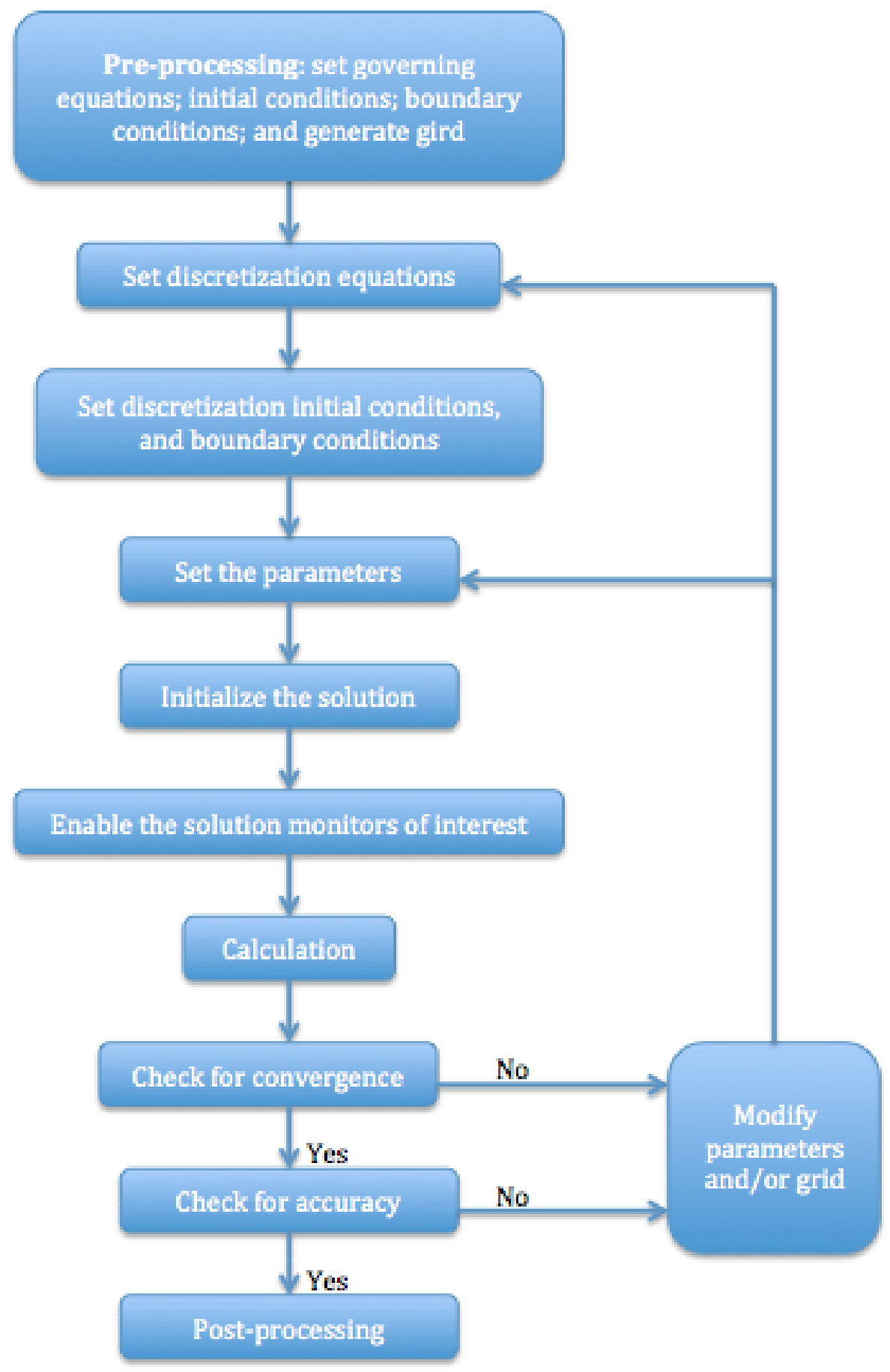

Figure 2-6 Algorithm of numerical approach 


\subsubsection{Fluid Properties}

The properties of the fluid are integral throughout the CFD process tree. They are necessary in determining which models and methods to use, which parameters need to be set, and even the results. Amongst the most common properties to consider include the laminarity, the viscosity, Newtonian state, steadiness, and compressibility of the fluid flow.

The fluid flow is considered laminar whenever the Reynolds number $(\mathrm{Re})$ is less than 2300. Visually and experimentally, laminar fluids will flow in parallel with no lines of interaction. Whenever the fluid exceeds a Re of 8000 , the flow is considered turbulent. Turbulent flows involve lots of interaction lines and mixing. Turbulent flows are more common (Wang, 2004).

The viscosity of the fluid flow is measured by its resistance to deformation due to shear or tensile stress. This is commonly associated with a fluid's thickness. Viscosity increases with temperature, and its stress increases with the relative velocity. Ideals fluid does not resist to shear stress, but is a concept only used in theory.

A fluid is considered to be Newtonian if the dynamic viscosity is constant, maintains a linear relationship between shear stress and shear rates, and it passes through the origin. All other liquids are considered to be a non-Newtonian.

A flow is considered to be steady if its fluid properties do not depend on time. Fluid flows dependent on time are considered to be unsteady. Similarly, incompressible fluids maintain a constant density, while compressible fluids do not. 


\subsubsection{Multiphase Flow}

Various conditions can alter the physical state of fluids. Multiphase flows of two or more phases may be present. Thus, multiphase flow must be considered within the design phase, within CFD.

(1) Two-Phase Flow: Includes gas-liquid, gas-solid, and liquid-solid flows. CFD analysis of two-phase flows treats the fluid phase as continuous and the second phase a continuous or dispersed, depending on the volume fraction.

(2) Multi-Phase Flow: Multi-phase flow contains two or more phases that are not chemically related in one system. Each phase has its own volume fraction, velocity profile, and conservation equation.

\subsubsection{The Approaches for Multiphase Flows}

Flotation processes contain gas-liquid-solid flow. There are two primary methods of calculating these multi-phase flows. The first is the Euler-Lagrange approach, and the second is the Euler-Euler approach. The Euler-Lagrange approach tracks an individual flow point as it moves about the system, while the Euler-Euler approach monitors movement across specific zones in the system.

(1) The Euler-Lagrange approach solves the time-averaged Navier-Stokes equations for the continuous fluid phase. It also solves the dispersed phase by tracking particles, bubbles, or droplets as they move about the system. The primary weakness of this approach is that the dispersed phase takes a low volume fraction in the system.

(2) The Euler-Euler approach treats all the phases as continuous. Each phase derives a set of conservation equations. The total volume fraction of all of the phases is equal to one. Volume of fluid (VOF) model, mixture model, and Eulerian model are all Euler-Euler multi-phase models used with CFD. 
- The VOF model is a surface-tracking method used under a fixed Eulerian mesh. VOF is designed for non-homogeneously mixed multi-fluids. All phases use one set of momentum equations, and the volume fraction of each phase is recorded. In addition to surface tracking, the VOF model also tracks the volume fraction of each fluid based on the function of volume fraction (Yu, 2008). VOF is a simple and effective model that uses very little computer memory.

- The mixture model is used to describe the mixture characteristics of a multi-phase fluid field. It considers properties of interface transferring, diffusion, coupling, and slip velocity between phases. This is done to establish different velocities in the system.

- The Eulerian model is the most complicated multi-phase model. It treats particles and gas as two different fluids. Each has its own unique velocities, temperatures, and densities at every location throughout the computational domain. Different phases affect one another, but they have different volume fractions and have a slip boundary between each other. Each phase has a set of momentum and continuity equations.

\subsubsection{Turbulence Models}

Turbulence modeling greatly improves the quality of numerical simulations. CFD incorporates several common turbulence models, all of which reference the full spectrum of Navier-Stokes equations. As summarized by Wang (2004), CFD uses the following turbulence models: (1) Reynolds Averaged Navier-Stokes (RANS) based turbulence models: (a) Zero equation model: mixing length model; (b) One equation model: SpalartAlmaras; (c) Two equation models: $k-\varepsilon$ (standard/RNG/realizable), $k-\omega$ (standard/shear stress transport (SST)), and Algebraic stress model (ASM); (d) Seven equation model: Reynolds stress model (RSM). (2) Nonlinear eddy viscosity models. (3) Large eddy simulation (LES). (4) Detached eddy simulation (DES). (5) Direct numerical simulation (DNS). 
The three following turbulence models were used in this study: standard $k-\varepsilon$, realizable $k-\varepsilon$, and standard $k-\omega$.

Standard $k-\varepsilon$ is the most common model, because it has a very high convergence rate and it consumes very few computer resources. The $k$ value symbolizes turbulent kinetic energy, and the $\varepsilon$ symbolizes is the turbulent dissipation rate. They reflect the characteristic velocity and time scale. By solving $k$ and $\varepsilon$ equations, the characteristics of the mean flow can be simulated. With this information, turbulence can be described (Launder et al., 1974). The transport equations used within the ANSYS Fluent software (2013) are as follows:

$$
\begin{gathered}
\frac{\partial}{\partial t}(\rho k)+\frac{\partial}{\partial x_{i}}\left(\rho k u_{i}\right) \\
=\frac{\partial}{\partial x_{j}}\left[\left(\mu+\frac{\mu_{t}}{\sigma_{k}}\right) \frac{\partial k}{\partial x_{j}}\right]+G_{k}+G_{b}-\rho \varepsilon-Y_{M} \\
+S_{k} \\
\frac{\partial}{\partial t}(\rho \varepsilon)+\frac{\partial}{\partial x_{i}}\left(\rho \varepsilon u_{i}\right) \\
=\frac{\partial}{\partial x_{j}}\left[\left(\mu+\frac{\mu_{t}}{\sigma_{\varepsilon}}\right) \frac{\partial \varepsilon}{\partial x_{j}}\right]+C_{1 \varepsilon} \frac{\varepsilon}{k}\left(G_{k}+C_{3 \varepsilon} G_{b}\right)-C_{2 \varepsilon} \rho \frac{\varepsilon^{2}}{k} \\
+S_{\varepsilon}
\end{gathered}
$$

The turbulent viscosity $\mu=\rho C_{\mu} k^{2} / \varepsilon, \sigma_{k}$ and $\sigma_{\varepsilon}$ are Prandtl numbers corresponding to $k$ and $\varepsilon . S_{k}$ and $S_{\varepsilon}$ add source terms. $C_{1 \varepsilon}=1.44$ and $C_{2 \varepsilon}=1.92$. $C_{3 \varepsilon}=1$ when the flow is parallel to with respect to gravity; $C_{3 \varepsilon}=0$ when the flow is perpendicular with respect to gravity. $C_{\mu}=0.09, \sigma_{k}=1.0, \sigma_{\varepsilon}=1.3 . Y_{M}=0, P_{b}=0$ when the fluid is impressible (ANSYS Theory, 2013). $S_{k}=0, S_{\varepsilon}=0$ are used in this study

Realizable $k-\varepsilon$ is a $k-\varepsilon$ model with vortex modification. It has a new formulation for the turbulent viscosity, and improved transport equation for $\varepsilon$. It uses variable $C_{\mu}$ instead 
of a constant. The transport equations used within the ANSYS Fluent software (2013) are as follows:

$$
\begin{aligned}
& \frac{\partial}{\partial t}(\rho k)+\frac{\partial}{\partial x_{j}}\left(\rho k u_{j}\right) \\
& =\frac{\partial}{\partial x_{j}}\left[\left(\mu+\frac{\mu_{t}}{\sigma_{k}}\right) \frac{\partial k}{\partial x_{j}}\right]+G_{k}+G_{b}-\rho \varepsilon-Y_{M}+S_{k} \\
& \frac{\partial}{\partial t}(\rho \varepsilon)+\frac{\partial}{\partial x_{j}}\left(\rho \varepsilon u_{j}\right) \\
& =\frac{\partial}{\partial x_{j}}\left[\left(\mu+\frac{\mu_{t}}{\sigma_{\varepsilon}}\right) \frac{\partial \varepsilon}{\partial x_{j}}\right]+\rho C_{1} S_{\varepsilon}-\rho C_{2} \frac{\varepsilon^{2}}{k+\sqrt{v \varepsilon}} \\
& +C_{1 \varepsilon} \frac{\varepsilon}{k} C_{3 \varepsilon} G_{b}+S_{\varepsilon}
\end{aligned}
$$

Where $C_{1}=\max \left[0.43, \frac{\eta}{\eta+5}\right], \eta=S \frac{k}{\varepsilon}, S=\sqrt{2 S_{i j} S_{i j}}, \mu_{t}=\rho C_{\mu} \frac{k^{2}}{\varepsilon}, C_{\mu}=\frac{1}{A_{0}+A_{s} \frac{k U^{*}}{\varepsilon}}$, $U^{*} \equiv \sqrt{S_{i j} S_{i j}+\widetilde{\Omega}_{i j} \widetilde{\Omega}_{i j}}, \widetilde{\Omega}_{i j}=\Omega_{i j}-2 \varepsilon_{i j k} \omega_{k}, \Omega_{i j}=\overline{\Omega_{\imath \jmath}}-\varepsilon_{i j k} \omega_{k}$, where $\overline{\Omega_{\imath j}}$ is the mean rate of rotation tensor viewed in a rotating reference frame with the angular velocity $\omega_{k}$. $A_{0}=4.04, A_{S}=\sqrt{6} \cos \phi, C_{1 \varepsilon}=1.44, C_{2 \varepsilon}=1.9, \sigma_{k}=1.0, \sigma_{\varepsilon}=1.2$ (ANSYS Theory, 2013).

RNG (renormalization group) $k-\varepsilon$ is used to account for the effects of smaller scales of motion. It includes turbulent swirling effects by modifying the turbulent viscosity. It is effective for a wide range of turbulent intensities. This provides a more accurate and reliable model than the standard model. The transport equations where buoyancy is neglected, as used within the ANSYS Fluent software (2013), are as follows:

$$
\frac{\partial}{\partial t}(\rho k)+\frac{\partial}{\partial x_{i}}\left(\rho k u_{i}\right)=\frac{\partial}{\partial x_{j}}\left[\left(\mu+\frac{\mu_{t}}{\sigma_{k}}\right) \frac{\partial k}{\partial x_{j}}\right]+G_{k}-\rho \varepsilon
$$




$$
\frac{\partial}{\partial t}(\rho \varepsilon)+\frac{\partial}{\partial x_{i}}\left(\rho \varepsilon u_{i}\right)=\frac{\partial}{\partial x_{j}}\left[\left(\mu+\frac{\mu_{t}}{\sigma_{\varepsilon}}\right) \frac{\partial \varepsilon}{\partial x_{j}}\right]+C_{1 \varepsilon} \frac{\varepsilon}{k} G_{k}-C_{2 \varepsilon}^{*} \rho \frac{\varepsilon}{k}
$$

Where $C_{2 \varepsilon}^{*}=C_{2 \varepsilon}+\frac{C_{\mu} \eta^{3}\left(1-\eta / \eta_{0}\right)}{1+\beta \eta^{3}}, C_{1 \varepsilon}=1.42, C_{2 \varepsilon}=1.68, \eta_{0}=4.38, C_{\mu}=0.0845, \sigma_{k}=$ $0.7194, \sigma_{\varepsilon}=0.7194, \beta=0.012$ (ANSYS Theory, 2013).

Standard $k-\omega$ is similar to $k-\varepsilon$, where $\omega=\varepsilon / k$ is the dissipation rate of the kinetic energy. This model includes a modified version of the $k$ equation used in the $k-\varepsilon$ model. There is also one additional transport equation for $\omega$. The transport equations used within the ANSYS Fluent software (2013) are as follows:

$$
\begin{aligned}
\frac{\partial}{\partial t}(\rho k)+\frac{\partial}{\partial x_{i}} & \left(\rho k u_{i}\right) \\
& =\frac{\partial}{\partial x_{j}}\left(\Gamma_{k} \frac{\partial k}{\partial x_{j}}\right)+G_{k}-Y_{M}+S_{k} \\
\frac{\partial}{\partial t}(\rho \omega)+\frac{\partial}{\partial x_{i}} & \left(\rho \omega u_{i}\right) \\
& =\frac{\partial}{\partial x_{j}}\left(\Gamma_{\omega} \frac{\partial \omega}{\partial x_{j}}\right)+G_{\omega}-Y_{\omega}+S_{\omega}
\end{aligned}
$$

Where $G_{k}$ and $G_{\omega}$ are the generation of $k$ and $\omega . \Gamma_{k}$ and $\Gamma_{\omega}$ are the effective diffusivity of $k$ and $\omega$ (ANSYS Theory, 2013).

The SST modeling method combines $k-\varepsilon$ in the free stream and $k-\omega$ near the walls. The transport equations used within the ANSYS Fluent software (2013) are as follows:

$$
\begin{aligned}
\frac{\partial}{\partial t}(\rho k)+\frac{\partial}{\partial x_{i}} & \left(\rho k u_{i}\right) \\
& =\frac{\partial}{\partial x_{j}}\left(\Gamma_{k} \frac{\partial k}{\partial x_{j}}\right)+G_{k}-Y_{M}+S_{k}
\end{aligned}
$$




$$
\begin{aligned}
\frac{\partial}{\partial t}(\rho \omega)+\frac{\partial}{\partial x_{j}} & \left(\rho \omega u_{j}\right) \\
& =\frac{\partial}{\partial x_{j}}\left(\Gamma_{\omega} \frac{\partial \omega}{\partial x_{j}}\right)+G_{\omega}-Y_{\omega}+D_{\omega}+S_{\omega}
\end{aligned}
$$

$D_{\omega}$ is the cross-diffusion term (ANSYS Theory, 2013).

\subsubsection{Scheme}

Discretization (approximation) schemes of convective terms may potentially affect the accuracy and numerical stability of finite volume equations. Two numerical methods used by Fluent are pressure- and density-based solvers. The basic discretization schemes the software uses are the central differencing scheme, upwind differencing scheme, hybrid scheme, exponential scheme, power-law scheme, second-order upwind scheme, and QUICK scheme. There are also segregated SIMPLE, SIMPLEC, PISO, Fractional Step, and Coupled pressure-based solvers.

\subsubsection{Cavitation Models}

Two-phase cavitation models are based on mixture transport equations or the Eulerian and $k-\varepsilon$ models. The Lee model vapor transport equation used by ANSYS (2013) is as follows:

$$
\frac{\partial}{\partial t}\left(\alpha \rho_{v}\right)+\nabla\left(\alpha \rho_{v} \vec{V}_{v}\right)=R_{e}-R_{c}
$$

Where $v$ is vapor phase, $\alpha$ is vapor volume fraction, $\rho_{v}$ is the vapor density, $\vec{V}_{v}$ is vapor phase velocity, $R_{e}$ is the rate of mass transfer due to evaporation, and $R_{c}$ is the rate of mass transfer due to condensation (ANSYS Theory, 2013). 
Neglecting the force of surface tension and the second-order terms, Equation 2.3 can be simplified as:

$$
\frac{D R_{b}}{D t}=\sqrt{\frac{2}{3} \frac{P_{b}-P_{\infty}}{\rho_{l}}}
$$

Where $R_{b}$ is the radius of the bubble, $\rho_{l}$ is density of the liquid, $P_{b}$ is the pressure of the bubble surface, and $P_{\infty}$ is the pressure theoretically infinitely far away from the bubble surface.

The ANSYS Fluent software contains three cavitation models: (1) Singhal et al. (2002) model, (2) Zwart-Gerber-Belamri (2004) model, and (3) Schnerr and Sauer model (2001)

1) Singhal et al. model (2002)

According to the ANSYS (2013) manual, this model requires the primary and secondary phases to be liquid and vapor, respectively. The manual also states that, by default, it is the only model that takes the effect of noncondensable gases into account. However, it cannot be used the multi-phase mixture model. The rate of the phase change is as follows:

$$
R=\frac{3 \alpha}{R_{b}} \frac{\rho_{v} \rho_{l}}{\rho} \sqrt{\frac{2}{3} \frac{\left(P_{b}-P_{\infty}\right)}{\rho_{l}}}
$$

The rates of mass exchange for this model are:

$$
\begin{aligned}
& \text { If } P_{\infty} \leq P_{v} \quad R_{e}=F_{v a p} \frac{\max (1.0, \sqrt{k})\left(1-f_{v}-f_{g}\right)}{\sigma} \rho_{v} \rho_{l} \sqrt{\frac{2\left(P_{v}-P_{\infty}\right)}{3}} \\
& \text { If } P_{\infty}>P_{v} \\
& \qquad R_{c}=F_{\text {cond }} \frac{\max (1.0, \sqrt{k}) f_{v}}{\sigma} \rho_{l} \rho_{l} \sqrt{\frac{2}{3} \frac{\left(P_{\infty}-P_{v}\right)}{\rho_{l}}}
\end{aligned}
$$


Where $f_{v}$ is the vapor mass fraction, $f_{g}$ is the non-condensable gases fraction, $P_{v}$ is saturation vapor pressure, $F_{v a p}=0.02$ and $F_{c o n d}=0.01$ are constants (ANSYS Theory, 2013).

2) Zwart-Gerber-Belamri model (2004)

According to the ANSYS (2013) manual, this model assumes that the bubbles in the system are all the same size. From this assumption, the total net interphase mass transfer rate per unit volume can be calculated as follows:

$$
R=\frac{3 \alpha \rho_{v}}{R_{b}} \sqrt{\frac{2}{3} \frac{\left(P_{b}-P_{\infty}\right)}{\rho_{l}}}
$$

The rates of mass exchange for this model are:

If $P_{\infty} \leq P_{v}$

$$
R_{e}=F_{v a p} \frac{3 \alpha_{n u c}\left(1-\alpha_{v}\right) \rho_{v}}{R_{b}} \sqrt{\frac{2}{3} \frac{\left(P_{v}-P_{\infty}\right)}{\rho_{l}}}
$$

If $P_{\infty}>P_{v}$

$$
R_{c}=F_{\text {cond }} \frac{3 \alpha_{v} \rho_{v}}{R_{b}} \sqrt{\frac{2}{3} \frac{\left(P_{\infty}-P_{v}\right)}{\rho_{l}}}
$$

Where $R_{b}=10^{-6} \mathrm{~m}$ is the radius of the bubble, $\alpha_{n u c}=5 \times 10^{-4}$ is the volume fraction of the nucleation site, $F_{\text {vap }}=50$ is the constant evaporation coefficient, $F_{\text {cond }}=0.01$ is the constant condensation coefficient (ANSYS Theory, 2013).

3) Schnerr and Sauer model (2001)

According to the ANSYS (2013) manual, the Schnerr and Sauer model (2001) followed a similar derivation approach as the Singhal et al. model (2002). They found that the mass transfer rates can be expressed as follows: 


$$
\begin{gathered}
R=\frac{\rho_{v} \rho_{l}}{\rho} \alpha(1-\alpha) \frac{3}{R_{b}} \sqrt{\frac{2}{3} \frac{\left(P_{b}-P_{\infty}\right)}{\rho_{l}}} \\
R_{b}=\left(\frac{\alpha}{1-\alpha} \frac{3}{4 \pi} \frac{1}{n}\right)^{\frac{1}{3}}
\end{gathered}
$$

Equation 2.26 was further used to model the condensation process, as expressed finally as follows:

If $P_{\infty} \leq P_{v}$

$$
R_{e}=\frac{\rho_{v} \rho_{l}}{\rho} \alpha(1-\alpha) \frac{3}{R_{b}} \sqrt{\frac{2}{3} \frac{\left(P_{v}-P_{\infty}\right)}{\rho_{l}}}
$$

If $P_{\infty}>P_{v}$

$$
R_{c}=\frac{\rho_{v} \rho_{l}}{\rho} \alpha(1-\alpha) \frac{3}{R_{b}} \sqrt{\frac{2}{3} \frac{\left(P_{\infty}-P_{v}\right)}{\rho_{l}}}
$$

All ANSYS cavitation equations broken down in this section were provided by the ANSYS manual (2013) via their subsidiary, SAS IP Inc.

For this particular study, the Singhal et al., model (2002) was not considered. This is because the model is not as reliable. And the coupled solver was chosen, because it is more robust and converges more faster.

\subsubsection{Model Selection}

Model selection is the most important step in multi-phase simulation. Not all models work interchangeably. Following guidelines is necessary for selecting the appropriate model needed. Zhang, (2007) established a hierarchy of models to assist with selecting the correct model. This is illustrated in Figure 2-7. 


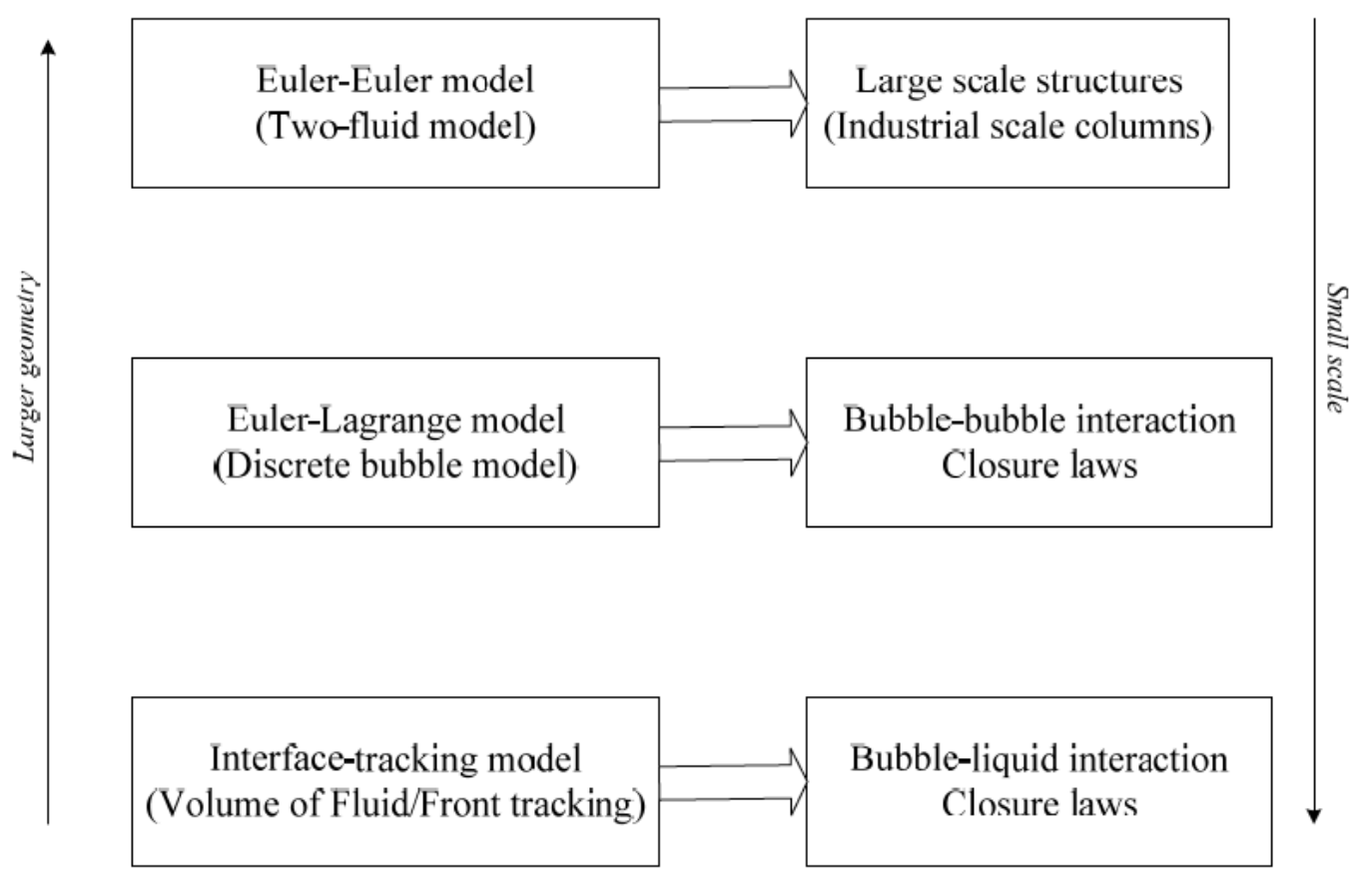

Figure 2-7 Fundamental Hydrodynamic models (Zhang, 2007)

Mixture models are necessary when there is a wide array of dispersed phases. Eulerian models are more accurate when the drag force is known. However, Eulerian model calculations are more difficult, and provide more room for error, since there are more equations.

The venturi tube is discretized into individual finite volumes where local values of flow properties are calculated. The fluids in flotation columns are complex, viscous, nonNewtonian, incompressible, turbulent, and steady multi-phase flows. The process is subsonic. Since this study sought to numerically analyze the gas-liquid-solid flows, the Euler approach Euler-Euler model was chosen.

\subsubsection{CFD Models for Flotation Process}

CFD has become a valuable tool with developing flotation processing models. The process is very complex, since it considers turbulent hydrodynamic forces and surface forces by adding the surfactants (Liu et al., 2006). Schwarz (1991) presented the 
possibility of modeling mineral processing with mathematical modeling software. He compared different packages with user-written code. Koh and Schwarz (2000; 2003a, b; 2005; 2008; 2009) developed CFD models for flotation columns, baffled tanks, and various flotation cells. They used these to understand complex flows and flotation hydrodynamics, including collisions, attachments and detachments, and the overall effects of different design parameters and operating conditions on their performances. Tiitinen et al., (2003) analyzed the hydrodynamics of Outokumpu flotation cells and built a model for flow field and solid distribution based on the layout of the design. Sarrot et al., (2005) analyzed the collision efficiency of a rising bubble in a small non-inertial particles fluid, by direct numerical simulation (DNS). Liu and Schewarz (2009) developed a 3D numerical model based on the scales of the cells and bubbles, to analyze bubble and particle collision rates and predict flotation kinetics. Xia et al., (2009) compared three turbulence models to predict the flow performance and pressure distribution of an Outotec flotation cell. Li et al., (2009) investigated an air-charging froth flotation machine with gas-liquid-solid flow simulation. They analyzed the effects to the inner flow, velocity distribution, volume fraction, and turbulent intensity. Yuan et al., (2010) used FLUENT CFD to study the velocity and pressure flow patterns of cyclone flotation cells. Sahbaz et al., (2012) found that the dissipation rate of energy a highly significant parameter in determining the recovery rate grade of flotation. Using CFD, they were able to determine the turbulent regions and upper size limitation in a Jameson flotation cell. Shen and Chen (2012) used CFD to analyze the flow field of flotation cells. Comparing different turbulence models, they determined that the standard $k-\varepsilon$ turbulence model is the best model to use for liquid phase flow field characterization. Yang and Wang $(2012,2013)$ used FLUENT to design a wide flotation machine, based on its analysis of the velocity, turbulent intensity, flow field, and the fluid dynamics environments required for coarse and fine particle flotation. Table 2-1 provides detailed summary of these CFD studies. 
Table 2-1 Summary of Applications of CFD in Flotation Modeling

\begin{tabular}{|c|c|c|c|c|c|c|c|}
\hline References & Type & $\begin{array}{c}\text { Multiphase } \\
\text { Approach }\end{array}$ & Parameter Studied & Models Used & Algorithm & Grid & Scheme \\
\hline $\begin{array}{l}\text { Koh and } \\
\text { Schwarz } \\
(2000)\end{array}$ & $\begin{array}{l}\text { Designed laboratory } \\
\text { flotation cell } \\
\text { (Denver), a } \\
\text { cylindrical tank } \\
\text { fitted with a } \\
\text { Rushton turbine }\end{array}$ & $\begin{array}{l}\text { Eulerian-Eularian, } \\
\text { two-phase/three-phase }\end{array}$ & $\begin{array}{l}\text { Collision rates: the number of } \\
\text { bubble-particle collisions per unit } \\
\text { time and unit volume }\end{array}$ & Standard k- $\varepsilon$ & & & \\
\hline $\begin{array}{l}\text { Koh and } \\
\text { Schwarz } \\
\text { (2003 a) }\end{array}$ & $\begin{array}{l}\text { Metso and } \\
\text { Outokumpu } \\
\text { flotation cells }\end{array}$ & $\begin{array}{l}\text { Eulerian-Eularian, } \\
\text { single-phase extended } \\
\text { to multiple phases, } \\
\text { Multiple Reference } \\
\text { Frame } \\
\text { (MRF)/Sliding-mesh }\end{array}$ & Hydrodynamics of flotation cells & $\begin{array}{l}\mathrm{k}-\varepsilon \\
\text { differential } \\
\text { stress model; } \\
\text { RSM }\end{array}$ & & $\begin{array}{l}156,820 \\
146,912 \\
\text { grid points }\end{array}$ & $\begin{array}{l}\text { Hybrid, } \\
\text { upwind; } \\
\text { second- } \\
\text { order } \\
\text { central }\end{array}$ \\
\hline $\begin{array}{l}\text { Koh and } \\
\text { Schwarz } \\
(2003 \text { b) }\end{array}$ & $\begin{array}{l}\text { Denver flotation } \\
\text { cell }\end{array}$ & $\begin{array}{l}\text { Eulerian-Eularian, } \\
\text { three-phase }\end{array}$ & $\begin{array}{l}\text { Turbulent velocities, turbulent } \\
\text { energy dissipation rates size and } \\
\text { number concentrations of bubbles } \\
\text { and particles in different parts of } \\
\text { the cell; collision rates; recovery }\end{array}$ & $\mathrm{k}-\varepsilon$ & & & \\
\hline $\begin{array}{l}\text { Tiitinen et } \\
\text { al., (2003) }\end{array}$ & $\begin{array}{l}\text { Outokumpu } \\
\text { flotation cell }\end{array}$ & $\begin{array}{l}\text { Multiple Reference } \\
\text { Frame (MRF) }\end{array}$ & $\begin{array}{l}\text { Velocity, mixing time, and power } \\
\text { consumption }\end{array}$ & $\mathrm{k}-\varepsilon$ & & Hexahedral & Hybrid \\
\hline $\begin{array}{l}\text { Koh and } \\
\text { Schwarz } \\
(2005)\end{array}$ & $\begin{array}{l}\text { Laboratory } \\
\text { mechanically stirred } \\
\text { floration cell } \\
\text { (Denver); a } \\
\text { cylindrical tank } \\
\text { fitted with a } \\
\text { Rushton turbine } \\
\text { impeller }\end{array}$ & $\begin{array}{l}\text { Eulerian-Eularian, } \\
\text { three-phase }\end{array}$ & $\begin{array}{l}\text { Flotation kinetic; bubble-particle } \\
\text { collision rate; turbulent energy } \\
\text { dissipation rates; volumetric } \\
\text { fraction of air phase }\end{array}$ & $\mathrm{k}-\varepsilon$ & & & \\
\hline $\begin{array}{l}\text { Liu and } \\
\text { Schewarz } \\
(2006) \\
\end{array}$ & $\begin{array}{l}\text { Denver flotation } \\
\text { cell }\end{array}$ & Lagrangian & $\begin{array}{l}\text { Turbulent bubble-particle collision } \\
\text { efficiency with mobile surfaces, } \\
\text { particle trajectories }\end{array}$ & $\mathrm{k}-\varepsilon$ & & $\begin{array}{l}3.84 \text { million } \\
\text { cells }(6 \times 8 \\
\mathrm{mm})\end{array}$ & \\
\hline $\begin{array}{l}\text { Koh and } \\
\text { Schwarz }\end{array}$ & $\begin{array}{l}\text { Denver flotation } \\
\text { cell }\end{array}$ & $\begin{array}{l}\text { Eulerian-Eularian, } \\
\text { two-phase }\end{array}$ & $\begin{array}{l}\text { Bubble size distribution and } \\
\text { particle size distribution; flotation }\end{array}$ & $\begin{array}{l}\text { Multiple- } \\
\text { size-group }\end{array}$ & & $\begin{array}{l}103,000 \\
\text { gird points }\end{array}$ & \\
\hline
\end{tabular}




\begin{tabular}{|c|c|c|c|c|c|c|c|}
\hline (2008) & & & rate & (MUSIG) & & & \\
\hline $\begin{array}{l}\text { Beneventi et } \\
\text { al., (2009) }\end{array}$ & $\begin{array}{l}\text { Venturi aerated } \\
\text { laboratory ozone } \\
\text { flotation column }\end{array}$ & Eulerian multiphase & Flow patterns and gas distribution & Standard k- $\varepsilon$ & & $\begin{array}{l}1,380,307 \\
\text { nodes }\end{array}$ & \\
\hline $\begin{array}{l}\text { Koh and } \\
\text { Schwarz } \\
(2009)\end{array}$ & $\begin{array}{l}\text { Microcel flotation } \\
\text { column; Jameson } \\
\text { flotation cell }\end{array}$ & $\begin{array}{l}\text { Eulerian-Eularian, } \\
\text { three-phase }\end{array}$ & $\begin{array}{l}\text { Hydrodynamics, liquid velocities, } \\
\text { turbulent dissipation rates, gas } \\
\text { hold-up, particle-bubble } \\
\text { attachment rates and detachment } \\
\text { rates }\end{array}$ & Standard k- $\varepsilon$ & & & \\
\hline $\begin{array}{l}\text { Liu and } \\
\text { Schwarz } \\
(2009)\end{array}$ & $\begin{array}{l}\text { Mechanically } \\
\text { stirred flotation cell }\end{array}$ & $\begin{array}{l}\text { Volume of fluid } \\
\text { (VOF) }\end{array}$ & $\begin{array}{l}\text { Flow fields, bubble size } \\
\text { distribution (population balance } \\
\text { model), Collision frequencies and } \\
\text { efficiencies, detachment rates, drag } \\
\text { coefficients and coalescence rates } \\
\text { (turbulent model) }\end{array}$ & & & & \\
\hline $\begin{array}{l}\text { Li et al., } \\
\text { (2009) }\end{array}$ & $\begin{array}{l}\text { Mechanically } \\
\text { stirring air-charging } \\
\text { flotation machine }\end{array}$ & $\begin{array}{l}\text { Mixture Multi-fluid, } \\
\text { three-phase }\end{array}$ & $\begin{array}{l}\text { Velocity, volume fraction, } \\
\text { turbulent intensity }\end{array}$ & $\mathrm{k}-\varepsilon$ & $\begin{array}{l}\text { Pressure- } \\
\text { Velocity: } \\
\text { Coupled } \\
\text { SIMPLE }\end{array}$ & $1,392,119$ & $\begin{array}{l}\text { Central } \\
\text { difference; } \\
\text { Solid-gas: } \\
\text { Second } \\
\text { Order } \\
\text { Upwind }\end{array}$ \\
\hline $\begin{array}{l}\text { Xia et al., } \\
(2009)\end{array}$ & $\begin{array}{l}\text { Outotec flotation } \\
\text { cell }\end{array}$ & MRF & $\begin{array}{l}\text { Flow mechanism, turbulence } \\
\text { models and stress model } \\
\text { comparison }\end{array}$ & $\begin{array}{l}\text { Standard k- } \varepsilon ; \\
\text { Realizable k- } \\
\varepsilon ; \text { RSM }\end{array}$ & $\begin{array}{l}\text { Pressure- } \\
\text { Velocity: } \\
\text { Coupled } \\
\text { SIMPLE }\end{array}$ & & $\begin{array}{l}\text { Second } \\
\text { Order }\end{array}$ \\
\hline $\begin{array}{l}\text { Lin et al., } \\
(2010)\end{array}$ & $\begin{array}{l}\text { self-absorbing } \\
\text { microbubble } \\
\text { generator for } \\
\text { cyclonic-static } \\
\text { microbubble } \\
\text { flotation column }\end{array}$ & Euler, two-phase & $\begin{array}{l}\text { Area ratio, velocity, turbulent } \\
\text { kinetic energy, minimum static } \\
\text { pressure and gas holdup }\end{array}$ & $\begin{array}{l}\mathrm{k}-\varepsilon \text { double } \\
\text { function }\end{array}$ & & & \\
\hline $\begin{array}{l}\text { Yuan et al., } \\
(2010)\end{array}$ & $\begin{array}{l}\text { Cyclone flotation } \\
\text { cell }\end{array}$ & Mixture Multi-fluid & Velocity, pressure patterns & $\mathrm{k}-\varepsilon$ & $\begin{array}{l}\text { Pressure- } \\
\text { Velocity: } \\
\text { coupled } \\
\text { PISO; } \\
\text { Pressure: }\end{array}$ & & $\begin{array}{l}\text { Discrete } \\
\text { convection } \\
\text { phase: } \\
\text { First order } \\
\text { upwind; }\end{array}$ \\
\hline
\end{tabular}




\begin{tabular}{|c|c|c|c|c|c|c|c|}
\hline & & & & & PRESTO! & & $\begin{array}{l}\text { Diffusion } \\
\text { phase: } \\
\text { Central } \\
\text { difference }\end{array}$ \\
\hline $\begin{array}{l}\text { Emmanouil } \\
\text { et al., (2011) }\end{array}$ & $\begin{array}{l}\text { Dissolved-air } \\
\text { flotation tank }\end{array}$ & $\begin{array}{l}\text { 2-D, Eularian- } \\
\text { Eularian; Mixture, } \\
\text { three-phase }\end{array}$ & $\begin{array}{l}\text { Spatial distributions of water } \\
\text { velocity, volume fraction of air } \\
\text { bubbles, solid particles, and } \\
\text { bubble/particle aggregates; solid } \\
\text { recovery }\end{array}$ & $\begin{array}{l}\text { Standard k- } \varepsilon \\
\text { k- } \omega\end{array}$ & $\begin{array}{l}\text { Pressure- } \\
\text { Velocity: } \\
\text { Coupled } \\
\text { SIMPLE }\end{array}$ & 29,071 & \\
\hline $\begin{array}{l}\text { Sahbaz et } \\
\text { al., (2012) }\end{array}$ & $\begin{array}{l}\text { Jameson flotation } \\
\text { cell }\end{array}$ & $\begin{array}{l}\text { Eulerian Multi-fluid, } \\
\text { two-phase }\end{array}$ & $\begin{array}{l}\text { Turbulence, upper floatable size } \\
\text { limit, flow characteristics and } \\
\text { hydrodynamic behavior }\end{array}$ & Standard k- $\varepsilon$ & $\begin{array}{l}\text { Pressure- } \\
\text { Velocity: } \\
\text { Coupled } \\
\text { SIMPLE }\end{array}$ & $\begin{array}{l}\text { triangular } \\
\text { and } \\
\text { quadrilateral }\end{array}$ & $\begin{array}{l}\text { Second } \\
\text { Order } \\
\text { Upwind }\end{array}$ \\
\hline $\begin{array}{l}\text { Shen and } \\
\text { Chen (2012) }\end{array}$ & $\begin{array}{l}\text { Air-blowing } \\
\text { mechanical } \\
\text { flotation cell }\end{array}$ & $\begin{array}{l}\text { Eulerian Multi-fluid, } \\
\text { two-phase }\end{array}$ & Flow field, turbulence models & $\begin{array}{l}\text { Standard k- } \varepsilon ; \\
\text { k- } \omega ; \\
\text { Realizable k- } \\
\varepsilon\end{array}$ & $\begin{array}{l}\text { Pressure- } \\
\text { Velocity: } \\
\text { Coupled } \\
\text { SIMPLE }\end{array}$ & 492,218 & \\
\hline $\begin{array}{l}\text { Yang and } \\
\text { Wang } \\
(2012) \\
\end{array}$ & $\begin{array}{l}\text { Wide-size-fraction } \\
\text { flotation machine }\end{array}$ & $\begin{array}{l}\text { Eulerian Multi-fluid, } \\
\text { two-phase }\end{array}$ & $\begin{array}{l}\text { Fluid velocity, turbulence intensity } \\
\text { and gas phase concentration }\end{array}$ & $\begin{array}{l}\text { Realizable k- } \\
\varepsilon\end{array}$ & $\begin{array}{l}\text { Phase } \\
\text { Coupled } \\
\text { SIMPLE } \\
\end{array}$ & 650,000 & \\
\hline $\begin{array}{l}\text { Yang and } \\
\text { Wang } \\
(2013)\end{array}$ & $\begin{array}{l}\text { Wide-size-fraction } \\
\text { flotation machine }\end{array}$ & $\begin{array}{l}\text { Eulerian Multi-fluid, } \\
\text { two-phase }\end{array}$ & $\begin{array}{l}\text { Fluid velocity, turbulent intensity } \\
\text { and flow field }\end{array}$ & $\begin{array}{l}\text { Realizable k- } \\
\varepsilon\end{array}$ & $\begin{array}{l}\text { Pressure- } \\
\text { Velocity: } \\
\text { coupled } \\
\text { PISO; } \\
\text { Pressure: } \\
\text { PRESTO! }\end{array}$ & 650,000 & $\begin{array}{l}\text { Second } \\
\text { Order } \\
\text { Upwind }\end{array}$ \\
\hline
\end{tabular}


2.4.1.11 CFD Models for hydrodynamic cavitation devices

In addition to flotation processing, CFD is also widely used in designing and simulating hydrodynamic cavitation devices. A detailed summary of CFD models for hydrodynamic cavitation devices is listed in Table 2-2. 
Table 2-2 Summary of Applications of CFD in Hydrodynamic Cavitation Devices

\begin{tabular}{|c|c|c|c|c|}
\hline References & Geometry & Purposes & Parameter Studied & Models Used \\
\hline $\begin{array}{l}\text { Ashrafizadeh and } \\
\text { Ghassemi (2015) }\end{array}$ & $\begin{array}{l}\text { cavitating } \\
\text { venturi }\end{array}$ & & $\begin{array}{l}\text { effects of upstream and downstream pressures, geometrical } \\
\text { parameters: throat diameter, throat length, diffuser angle on } \\
\text { the mass flow rate and critical pressure ratio }\end{array}$ & $\begin{array}{l}\text { 2D, mixture } \\
\text { multiphase, realizable } \\
\mathrm{k}-\varepsilon, \text { SIMPLE }\end{array}$ \\
\hline Bashir et al., (2011) & venturi & & $\begin{array}{l}\text { geometrical parameters based on cavity inception, growth, } \\
\text { and collapse }\end{array}$ & $\begin{array}{l}\mathrm{k}-\varepsilon, \text { multiphase } \\
\text { cavitation }\end{array}$ \\
\hline Brinkhorst et al., (2015) & Herschel venturi & meter & hydrodynamic cavitating measuring & RANS, CCM+ \\
\hline Charriere et al., (2015) & venturi & & $\begin{array}{l}\text { an aperiodic cavitation pocket, re-entrant jet, void ratio } \\
\text { profiles and pressure fluctuations }\end{array}$ & $\begin{array}{l}\text { RANS, k- } \omega \text { SST, } \\
\text { OpenFOAM }\end{array}$ \\
\hline Chen et al., (2015) & $\begin{array}{l}\text { convergent- } \\
\text { divergent } \\
\text { channel } \\
\end{array}$ & & $\begin{array}{l}\text { quasi-periodic pressure fluctuations, three stages of quasi- } \\
\text { periodic sheet/cloud cavitation }\end{array}$ & unsteady, RANS \\
\hline Chen et al., (2006) & venturi & $\begin{array}{l}\text { NACA0012 } \\
\text { hydofoil }\end{array}$ & cavitation around NACA0012 & unsteady, RNG k- $\varepsilon$ \\
\hline $\begin{array}{l}\text { Decaix and Goncalves } \\
\text { (2013) }\end{array}$ & venturi & & cavitation pocket, dynamic of sheet cavities & hybrid RANS/LES \\
\hline Goncalves et al., (2010) & venturi & & turbulence models, geometry and comparisons & $\begin{array}{l}\text { RANS, KWSST, KE, } \\
\text { and SA turbulence } \\
\text { models }\end{array}$ \\
\hline He et al., (2015) & $\begin{array}{l}\text { rectangular } \\
\text { nozzle }\end{array}$ & $\begin{array}{l}\text { water- } \\
\text { submerged gas } \\
\text { jets }\end{array}$ & $\begin{array}{l}\text { shock wave structures, submerged jet gas/water interface } \\
\text { characteristics }\end{array}$ & unsteady, RANS \\
\hline He et al., (2016) & nozzle & diesel injector & $\begin{array}{l}\text { hole shape effects on internal flow and near-nozzle spray } \\
\text { behavior }\end{array}$ & $\begin{array}{l}\text { SIMPLEC, k- } \varepsilon \text {, } \\
\text { single bubble collapse } \\
\text { model }\end{array}$ \\
\hline He et al., (2016) & $\begin{array}{l}\text { rectangular } \\
\text { nozzle orifice }\end{array}$ & diesel fuel & periodic cloud cavitation shedding and re-entrant jet & LES \\
\hline K. \& Saharan (2016) & $\begin{array}{l}\text { venturi and } \\
\text { orifice }\end{array}$ & $\begin{array}{l}\text { hydrodynamic } \\
\text { cavitating } \\
\text { devices }\end{array}$ & geometrical parameters & $\begin{array}{l}\text { 2D axis, } \\
\text { steady,SIMPLEC, } \\
\text { standard k- } \varepsilon\end{array}$ \\
\hline Kabeel and Abdelgaied & sharp-edge & alumina & turbulent kinetic energy, turbulent intensity, turbulent & mixture cavitation, \\
\hline
\end{tabular}




\begin{tabular}{|c|c|c|c|c|}
\hline (2016) & orifice & & $\begin{array}{l}\text { viscosity, and volume fraction of vapor at different alumina } \\
\text { concentrations }\end{array}$ & standard k- $\varepsilon$ \\
\hline $\begin{array}{l}\text { Rodio and Congedo } \\
\text { (2014) }\end{array}$ & venturi & & various sources of uncertainty & RANS, k- $\varepsilon$ \\
\hline Salvador et al., (2011) & nozzle & diesel injector & $\begin{array}{l}\text { geometries and conditions; mass flow, momentum flux at } \\
\text { exit, effective injection velocity }\end{array}$ & $\begin{array}{l}\text { OpenFOAM, HEM } \\
\text { with a barotropic } \\
\text { equation }\end{array}$ \\
\hline Salvador et al., (2013) & $\begin{array}{l}\text { multi-hole } \\
\text { microsac nozzle }\end{array}$ & diesel engine & $\begin{array}{l}\text { turbulence developed in the discharge orifices and its } \\
\text { interaction with cativation }\end{array}$ & LES \\
\hline Salvador et al., (2016) & $\begin{array}{l}\text { convergent- } \\
\text { divergent nozzle }\end{array}$ & $\begin{array}{l}\text { diesel injector: } \\
\text { air-fuel mixing } \\
\text { process }\end{array}$ & $\begin{array}{l}\text { mass flow, momentum flux, effective velocity, cavitation, } \\
\text { and mixing processing with different convergent-divergent } \\
\text { levels }\end{array}$ & $\begin{array}{l}\text { Open FOAM, RANS, } \\
\text { RNGk- } \varepsilon\end{array}$ \\
\hline Shah et al., (2012) & orifice & orifice meter & track vena-contracta, new scheme, better accuracy & $\begin{array}{l}\text { OpenFOAM, } \\
\text { SIMPLE, RNG k- } \varepsilon\end{array}$ \\
\hline $\begin{array}{l}\text { Singh and Tharakan } \\
(2015)\end{array}$ & $\begin{array}{l}\text { multi-hole } \\
\text { orifice }\end{array}$ & flow meter & $\begin{array}{l}\text { reyonds number, beta ratio, pipe surface roughness and } \\
\text { upsetam and downstream flow boundary conditions }\end{array}$ & hexahedral grids, $\mathrm{k}-\varepsilon$ \\
\hline Sun et al., (2015) & nozzle & diesel engine & $\begin{array}{l}\text { geometric parameters: inlet, orifice coefficient, length to } \\
\text { diameter ratio, roughness of inner wall }\end{array}$ & $\begin{array}{l}\text { interface tracking, } \\
\text { multi-phase, and } \\
\text { homogeneous } \\
\text { equilibrium models }\end{array}$ \\
\hline Taghavifar et al., (2015) & nozzle & $\begin{array}{l}\text { spary diesel } \\
\text { injection }\end{array}$ & $\begin{array}{l}\text { nozzle structure: inclination angle, length to width ratio, } \\
\text { needle position }\end{array}$ & $\begin{array}{l}\text { Euler-Euler/Euler- } \\
\text { Lagrange }\end{array}$ \\
\hline Wang et al., (2012) & diesel nozzle & fuel injection & $\begin{array}{l}\text { upstream pressure fluctuations, cavitation content, and } \\
\text { dynamic behavior of local bubbles }\end{array}$ & $\begin{array}{l}\text { RANS, k- } \varepsilon \text {, bubble } \\
\text { number density }\end{array}$ \\
\hline Zhu et al., (2016) & ogive & $\begin{array}{l}\text { fuel (liquid } \\
\text { hydrogen) }\end{array}$ & $\begin{array}{l}\text { vapor content, temperature and pressure field, partially } \\
\text { shedding mode }\end{array}$ & $\begin{array}{l}\text { mixture, Schnerr- } \\
\text { Sauer cavitation, LES }\end{array}$ \\
\hline
\end{tabular}




\subsubsection{Geometry}

There are three types of convergent sections in classical ventrui tubes: machined, roughcast and rough-welded (BS 1042, 1992). 50mm $\leq D \leq 250 \mathrm{~mm}$ is the inlet diameter range; $\beta=d / D$ is the diameter ratio with the following parameters $0.4 \leq \beta \leq$ $0.75 ; 2 \times 10^{5} \leq \beta \leq 1 \times 10^{6}$.

Saracoglu (2013) found that the ideal conditions for venturi exist when the conical convergent section is $21^{\circ}$, the entrance cylinder length is $\geq$ the internal diameter, and the conical divergent section is $7-15^{\circ}$.

\subsubsection{Empirical vs. Numerical Analysis}

Empirical analysis is a design process which references real observations, measurements, and experiences; thus, it is limited to these observations. Conversely, numerical modeling is structured and based on theory and mathematical approximation. While numerical modeling is capable of solving complex systems, it is limited in that it requires validation by means of comparison with experimental results.

\subsubsection{Experimental Design \& Statistical Data Analysis}

The design of an experiment is crucial in effectively testing a hypothesis. Statistical analysis is important in determining the importance of variables and their respective relationship with the response. Statistical analysis is also useful in developing models relating the response to the variables introduced to a system, and to use these models for to improve systems and/or processes (Montgomery and Montgomery, 2012).

Response surface methodology (RSM) is a statistical method which is used to optimize response variables by manipulating several independent variables. 


\section{CHAPTER 3 Numerical Simulation Methods}

This study analyzed the geometric parameters of cavitation within a venturi tube influenced by the generation of pico, nano bubbles, using the ANSYS FLUENT 15.0 finite volume computational fluid dynamics code. The computational results were then compared with the experimental results of Peng and Xiong (2015). The objectives of this study were to analyze the flow behavior and cavity dynamics inside the cavitating devices at different operating and geometrical parameters; investigate the conditions of homogeneous nucleation and the generation of tiny bubbles; optimize the design of the bubble generator and feed velocity; determine the property cavitation generator geometry based on vapor volume fraction and bubble size distribution.

\subsection{Computational Flow Model}

Eulerian and Mixture multiphase models were applied to derive the Navier-Stokes equation. This was carried out by solving the continuity, momentum and energy equations for the mixture and the volume fraction equation for the secondary phase. Liquid and vapor are incompressible, viscous fluids, and are treated as continua, interpenetrating and interacting with each other in the computational domain. The motion of each phase is governed by the mass and momentum conservation equations, respectively.

\subsubsection{Governing Equations}

The motions of any fluid follow the conservation of mass, conservation of momentum (also called Newton's second law), and conservation of energy. The model solves the continuity equation, the momentum equation, and the energy equation for the mixture. It also computes the volume fraction equation for the secondary phases, as well as algebraic expressions for the relative velocities. 


\subsubsection{Continuity Equation}

The continuity equation for the mixture is as follows:

$$
\frac{\partial}{\partial t}\left(\rho_{m}\right)+\nabla \cdot\left(\rho_{m} \vec{v}_{m}\right)=0
$$

Where the mass-averaged velocity, $\vec{v}_{m}=\frac{\sum_{k=1}^{n} \alpha_{k} \rho_{k} \vec{v}_{m}}{\rho_{m}}$, and the mixture density, $\rho_{m}=$ $\sum_{k=1}^{n} \alpha_{k} \rho_{k}$, and $\alpha_{k}$ is the volume fraction of phase $k$.

\subsubsection{Momentum Equation}

To sum the individual momentum equations for all the phases in the system, we can get the momentum equation for the mixture:

$$
\begin{aligned}
\frac{\partial}{\partial t}\left(\rho_{m} \vec{v}_{m}\right)+\nabla & \cdot\left(\rho_{m} \vec{v}_{m} \vec{v}_{m}\right) \\
& =-\nabla_{P}+\nabla \cdot\left[\mu_{m}\left(\nabla \vec{v}_{m}+\nabla v_{m}^{T}\right)\right]+\rho_{m} \vec{g}+\vec{F} \\
& +\nabla \cdot\left(\sum_{k=1}^{n} \alpha_{k} \rho_{k} \vec{v}_{d r, k} \vec{v}_{d r, k}\right)
\end{aligned}
$$

Where $n$ is the number of phases, $\vec{F}$ is a body force, and the viscosity of the mixture, $\mu_{m}=\sum_{k=1}^{n} \alpha_{k} \mu_{k}$, the drift velocity for second phase $k: \vec{v}_{d r, k}=\vec{v}_{k}-\vec{v}_{m}$.

\subsubsection{Energy Equation}

The energy equation for the mixture is as follows:

$$
\frac{\partial}{\partial t} \sum_{k=1}^{n}\left(\alpha_{k} \rho_{k} E_{k}\right)+\nabla \cdot \sum_{k=1}^{n}\left(\alpha_{k} \vec{v}_{k}\left(\rho_{k} E_{k}+p\right)\right)=\nabla \cdot\left(k_{e f f} \nabla T\right)+S_{E}
$$


Where the effective conductivity, $k_{e f f}=\sum \alpha_{k}\left(k_{k}+k_{t}\right), k_{t}$ is the turbulent thermal

conductivity, for a compressible phase, $E_{k}=h_{k}-\frac{p}{\rho_{k}}+\frac{v_{k}^{2}}{2}$; for an incompressible phase, $E_{k}=h_{k}, h_{k}$ is the sensible enthalpy for phase $k$, and $S_{E}$ is volumetric heat sources.

\subsubsection{Volume Fraction for the Secondary Phases}

For secondary phase, $p$, the volume fraction equation takes the following form:

$$
\frac{\partial}{\partial t}\left(\alpha_{p} \rho_{p}\right)+\nabla \cdot\left(\alpha_{p} \rho_{p} \vec{v}_{m}\right)=-\nabla \cdot\left(\alpha_{p} \rho_{p} \vec{v}_{d r, p}\right)+\sum_{k=1}^{n}\left(\dot{m}_{q p}-\dot{m}_{q p}\right)
$$

Where $q$ presents the primary phase.

\subsubsection{Turbulence Modeling}

The different turbulence models and their transport equations were discussed in 2.4.1.6. The implosion of bubbles is considered as the source of the production of turbulence for the momentum exchange. Realizable $k-\varepsilon$ viscous developed by Shih et al. (1995), is a very suitable model for high-speed multiphase flows incorporating separation and circulation. It is used as turbulence model in this study, in order to solve turbulence kinetic energy and turbulence dissipation energy for each phase.

\subsubsection{Cavitation Modeling}

Cavitation is the liquid vapor mass transfer, such as, evaporation and condensation. The Schnerr and Sauer cavitation model was used in this study. It involves cavity dynamics, standard governing equations, and the mixture turbulence model, which describes the flow and turbulence effects. Temperature is not a primary factor in this study. 


\subsubsection{Numerical Setup and Description}

The calculations in this study are based on the venturi tube. The Reynolds number and cavitation number are the same as measured within the experiment.

Turbulent intensity is calculated as:

$$
I=\frac{u^{\prime}}{U}=0.16(R e)^{-1 / 8}, \quad R e=\frac{\rho_{l} u_{\text {avg }} D}{\mu_{l}}
$$

Where $u^{\prime}$ is the root-mean-square of the turbulent velocity fluctuations and $U$ is the average flow velocity. Turbulent energy is determined as:

$$
k=\frac{3}{2}(U I)^{2}
$$

The discretization method of the equations was based on the finite volume approach. The coupling of velocity and pressure was achieved using SIMPLE algorithm. Second-order upwind scheme was used for discretizing the convective terms. A no-slip boundary condition was imposed on all of the domain sides. Standard wall functions were used along the solid boundaries.

The computational flow conditions matched the experimental conditions. The initial and boundary conditions were the velocity inlet and pressure outlet. The cavitation runs were initialized with steady-state, fully-wetted calculations, to avoid any vapor fraction at the initial time step.

Local continuity and the residuals of all the flow variables were used as the convergence criteria. All the solutions were considered to be fully converged, when the sum of residuals was below $10^{-5}$. 


\subsection{Geometry}

The geometry of the venturi tube and the operating conditions were chosen to match those of the experimental study.

Figure 3-1 illustrates a Venturi tube was specially designed for the pico, nano bubbleenhanced flotation column. The particles that settle to the bottom of the column were pumped through the packed column and the Venturi tube, so they have a greater chance of recovery.
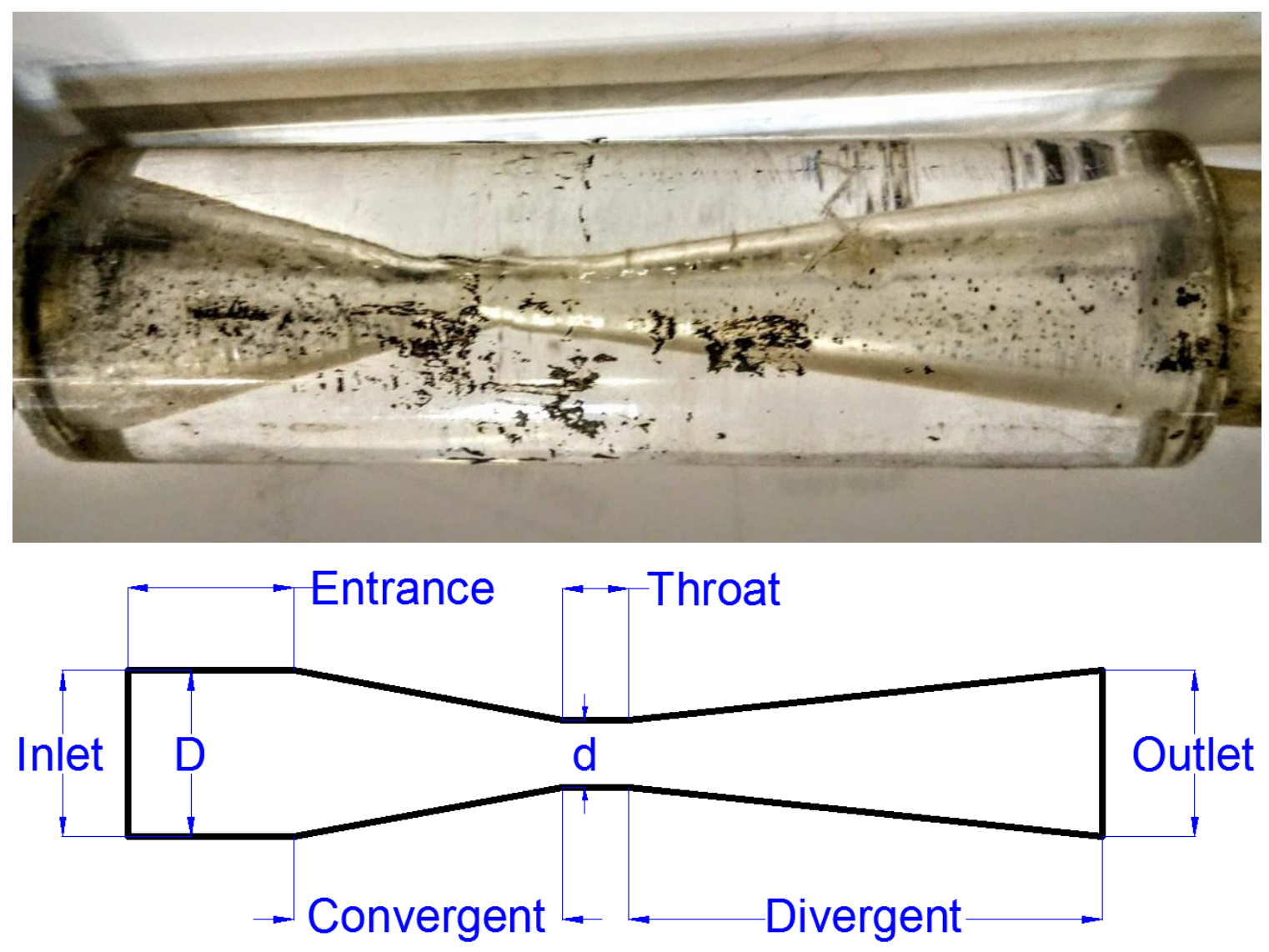

Figure 3-1 Venturi cavitation tube

Some specifications for the geometry were given by Peng and Xiong (2015). Other specifications had to be made based on assumptions related to the capabilities of ANSYS. The experimentally designed venturi tube is made of Plexiglass with a $12 \mathrm{~mm}$ diameter 
and the neck diameter of $3.2 \mathrm{~mm}$. Finite volume grids were constructed using ANSYS ICEM 15.0, in order to perform 3D simulations of cavitation devices flow field. For PBM calculation, a quadrilateral structured mesh of the whole geometry was used, because the tubes are symmetry.

\subsection{Mesh and Boundary Conditions}

\subsubsection{Meshing}

The meshing module ICEM, within the ANSYS software, was used to grid different geometries. Figure 3-2 was used as the geometry basis for creating a mesh and later calculating a solution in ANSYS.

Good quality mesh can ensure minimum numerical diffusion as well as skewness and an aspect ratio at an optimum value. The O-grid method was used for building all of the circular geometries. In order to have a grid-independent solution, finer mesh was used for the first cell near the wall, when the higher velocities are calculated. This is based on the "standard wall function $\left(y^{+} \approx 30-300\right)$ " in law of the wall.

\subsubsection{Venturi Tube}

A three-dimensional Venturi tube system was created using ANSYS ICEM 15.0, with one inlet and one outlet. The geometry of the Venturi tube is not complicated; hexahedral or tetrahedron meshing could be used. It has been found that hexahedral meshing yields better results for three-dimensional incompressible flows analysis. Hexahedral has a wider aspect ratio, which would not have the skewness and affect the accuracy and convergence of calculation. As shown in Fig 3-2, there are 24,886 quads, 383,755 hexas, and 396,480 total nodes. The qualities of blocking are all above 0.696 (the quality scale is between 0 and 1; 1 is the highest). A good grid quality can shorten computing time and improve the calculation accuracy. Unstructured grids were used because they have more 
flexibility. Mesh at the convergent, throat, and divergent (where cavitation happens) are encrypted.

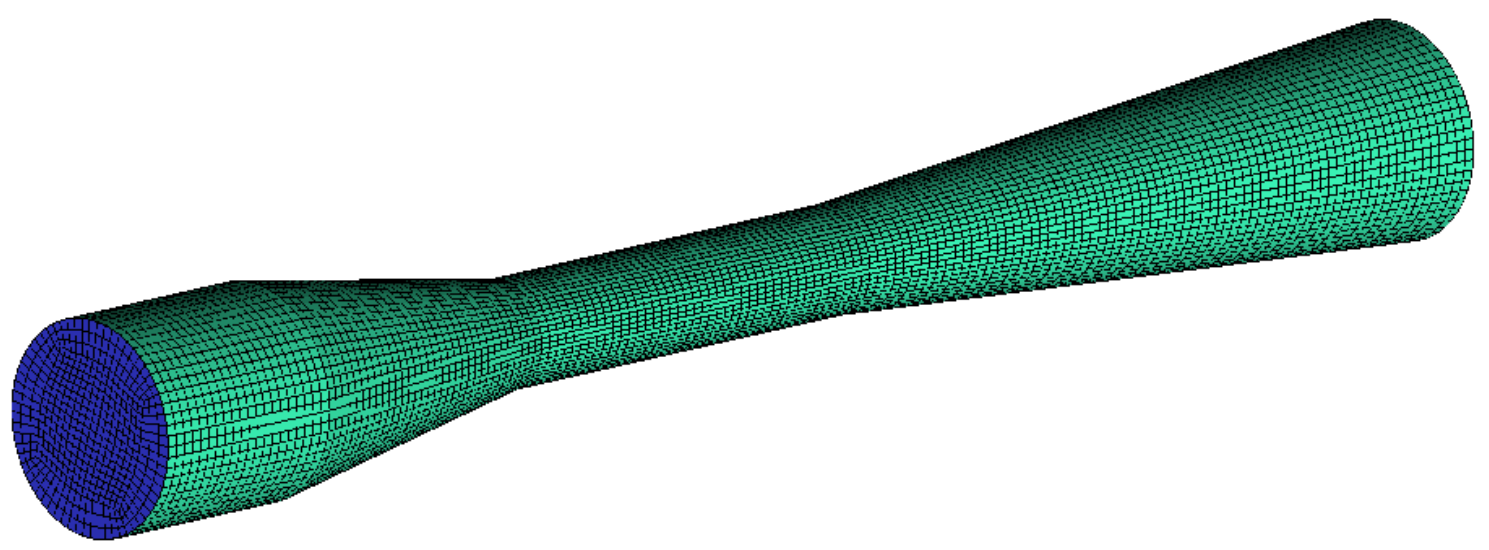

Figure 3-2 Meshing of Venturi tube

\subsubsection{Rectangular Venturi}

The meshing of the rectangular venturi tube is shown in Figure 3-3. It has 7,942 quads, 26,620 hexas, and 30,744 total nodes.

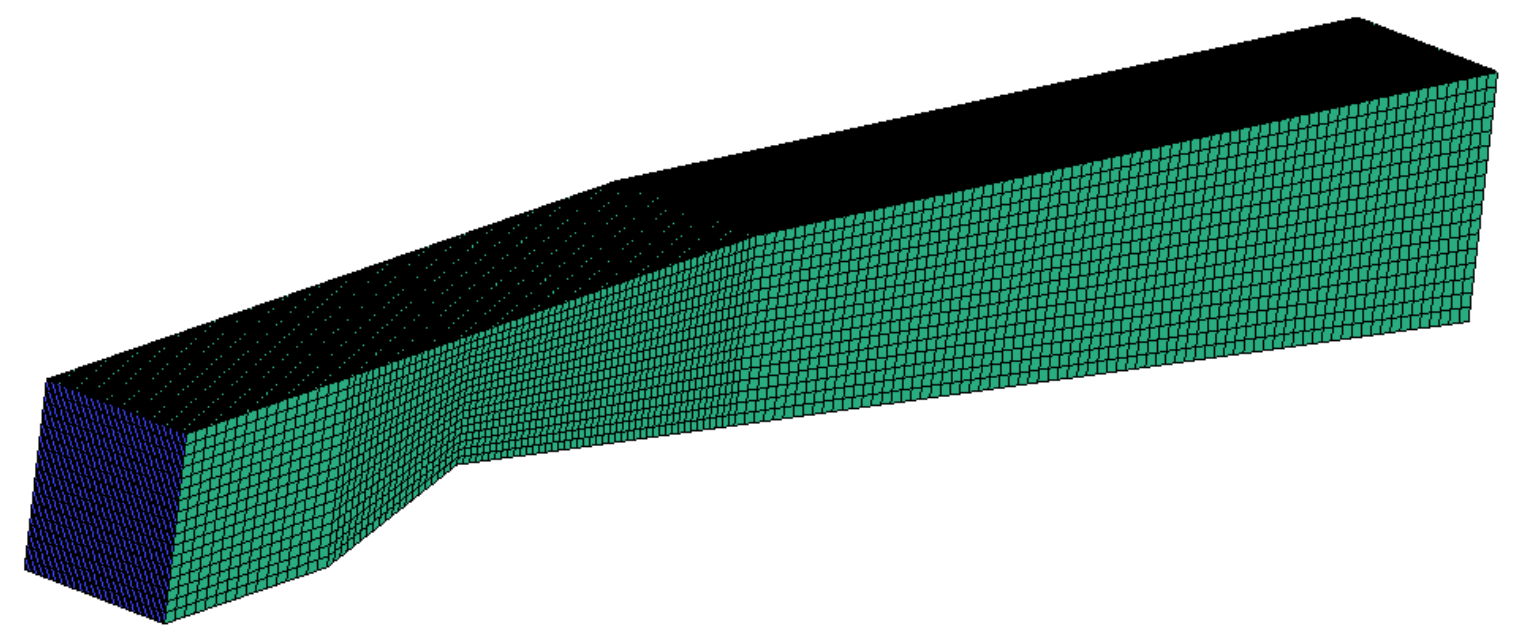

Figure 3-3 Meshing of Rectangular Venturi

\subsubsection{Circular and Rectangular Orifices}

A three-dimensional grid was built for the geometry, which corresponds to the design by Abuaf et al., (1981). The meshing of circular and rectangular orifices are shown in Figure 
3-4 and Figure 3-5. There are 9,600 quads, 41,248 hexas, 46,291 total nodes, and 42,464 quads, 285,760 hexas, 307,395 total nodes, respectively.

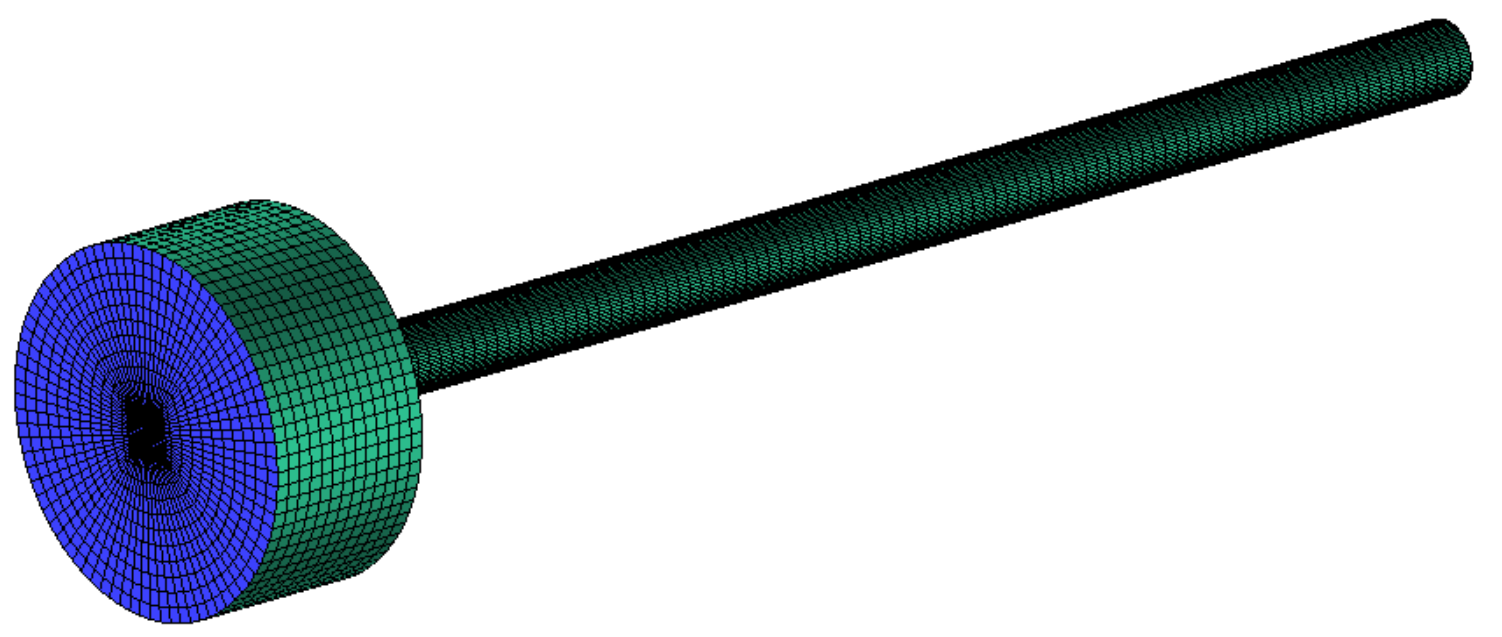

Figure 3-4 Meshing of Circular Orifice

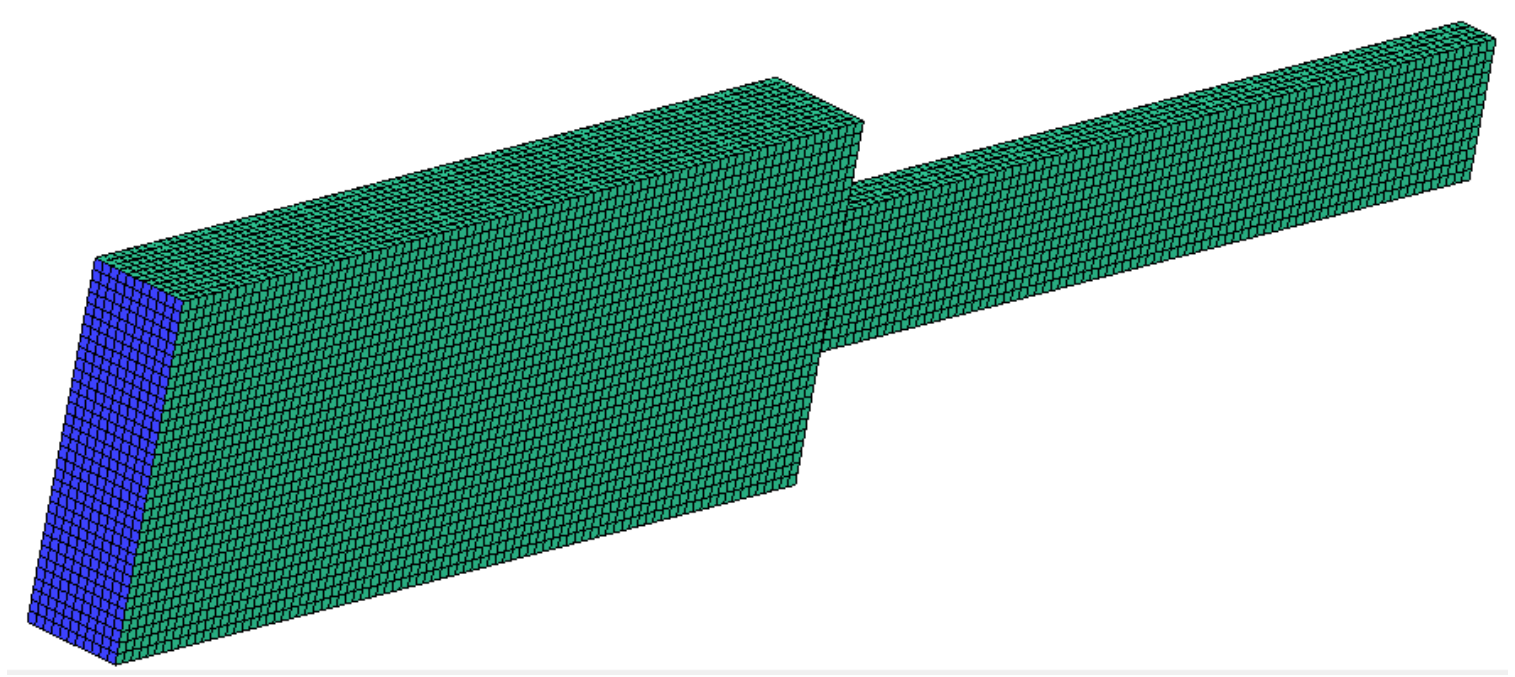

Figure 3-5 Meshing of Rectangular Orifice 


\subsubsection{Circular Nozzle}

The meshing of the circular nozzle is shown in Figure 3-6. There are 12,488 quads, 118,776 hexas, and 125,251 total nodes.

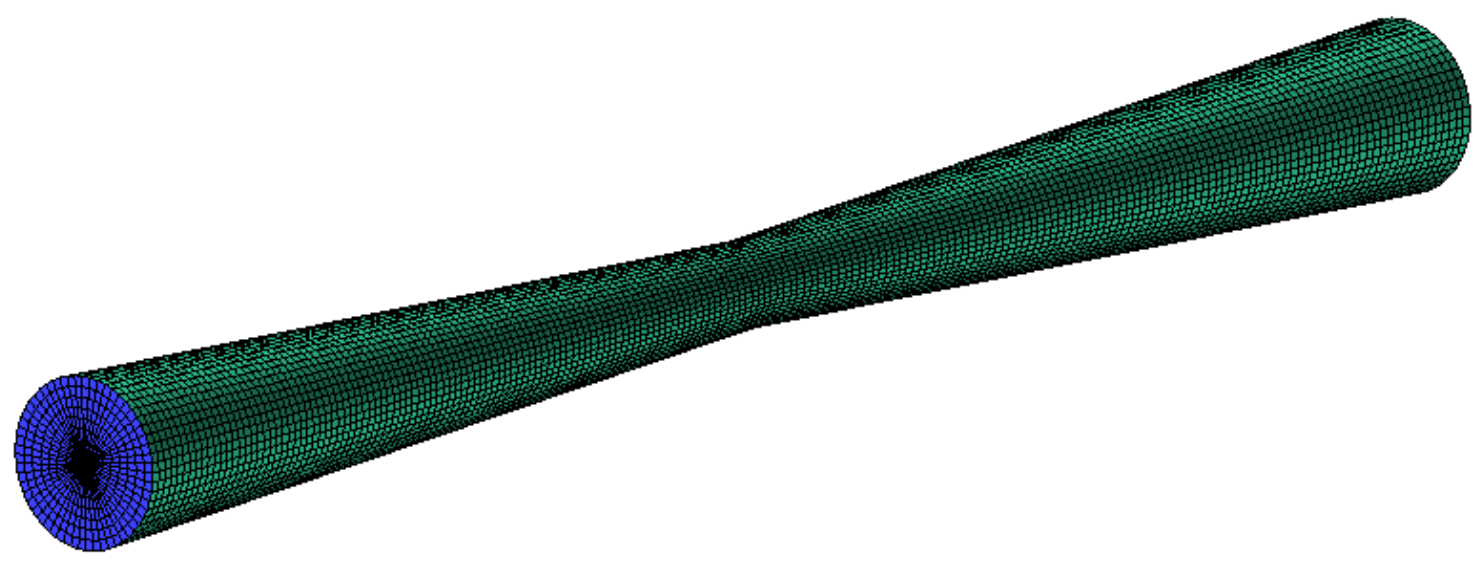

Figure 3-6 Meshing of Circular Orifice

\subsubsection{Model \& Boundary Conditions}

Mixture properties for the two phases were used for the entire computing domain, since Eulerian model is widely used for cavitation flows. Schnerr and Sauer cavitation model and Realizable $k-\varepsilon$ are used for water-liquid phase to water-vapor phase mass transfer inaction. The saturated pressure is $2505.15 \mathrm{~Pa}$ at room temperature $\left(70^{\circ} \mathrm{F}\right)$.

The boundary conditions are well-defined by the physical system limits. Solid boundaries are no slip velocity conditions. Previous studies have shown that a surfactant concentration up to $10^{-4} \mathrm{~mol} / \mathrm{L}$ and disperse phase content up to $10 \mathrm{wt} \%$ do not influence cavitation pattern transition (Schlender et al., 2015). Therefore, surfactant was not considering in this study. The primary phase was water-liquid, with a density of $997.925 \mathrm{~kg} / \mathrm{m}^{3}$ and a viscosity of $0.000975 \mathrm{~Pa} \cdot \mathrm{s}$. The second phase was water-vapor, with a density of $0.0185 \mathrm{~kg} / \mathrm{m}^{3}$ and a viscosity of $9.76 \times 10^{-6} \mathrm{~Pa} \cdot \mathrm{s}$. Phases were treated as interpenetrating continua.

Inlet velocities were taken from the experimental results of the venturi tube study by $\mathrm{Hu}$ et al., (1998). The velocity magnitude was set from 1.675 to $3.975 \mathrm{~m} / \mathrm{s}$ (the slurry jet out 
of the neck of the Venturi tube at a speed of 6.7 to $15.9 \mathrm{~m} / \mathrm{s}$ ). Turbulent intensity and the hydraulic diameter were calculated.

For the rectangular venturi tube, the dimensions used are the same as those used by Stutz and Reboud (2000). The total length was $520 \mathrm{~mm}$, the inlet height and width were $50 \mathrm{~mm}$ and $44 \mathrm{~mm}$, the throat diameter was $34.3 \mathrm{~mm}$, and the convergent angle and divergent angle were $18^{\circ}$ and $8^{\circ}$, respectively.

The dimensions for the circular and rectangular orifices were the same as those used by Nurick (1976). For the circular orifice, the inlet diameter and throat diameter ratio (D/d) was set to 5, the throat length and throat diameter ratio (L/d) was set to 20, and the inlet throat diameter (d) was $1.52 \mathrm{~mm}$. For the rectangular orifice, the throat length was 15.2 $\mathrm{mm}$, inlet and throat were $2.18 \mathrm{~mm} \times 7.32 \mathrm{~mm}$, and $0.36 \mathrm{~mm} \times 2.54 \mathrm{~mm}$, respectively.

The dimensions and conditions for the circular nozzle were the same as used by Abuaf et al., (1981). The total length was $600 \mathrm{~mm}$, the inlet diameter and the throat diameter were $51.2 \mathrm{~mm}$ and $25.6 \mathrm{~mm}$. The temperature for this test was $420 \mathrm{~K}$, so the saturated pressure was $437,242.21 \mathrm{~Pa}$. The water-liquid density of water-liquid was $919.927 \mathrm{~kg} / \mathrm{m}^{3}$, viscosity was $0.000187 \mathrm{~Pa} \cdot s$ and water-vapor with density was $2.352 \mathrm{~kg} / \mathrm{m}^{3}$, viscosity was $1.39 \times 10^{-5} \mathrm{~Pa} \cdot \mathrm{s}$.

\subsection{Mesh Sensitivity}

CFD simulation is sensitive to the mesh size. Mesh size and number have a great influence on the accuracy of simulation, and calculation time. To ensure the results do not vary by the different grid size, the mesh sensitivity was analyzed according to Figure 3-7, where the net integral pressure at inlet and out let is plotted against the total cells. The results were obtained from different injector cell numbers to analyze the mesh number independency. The net integral pressure stays at a certain value after 177,876 cells, which means the optimum number of cells is around 180,000. 


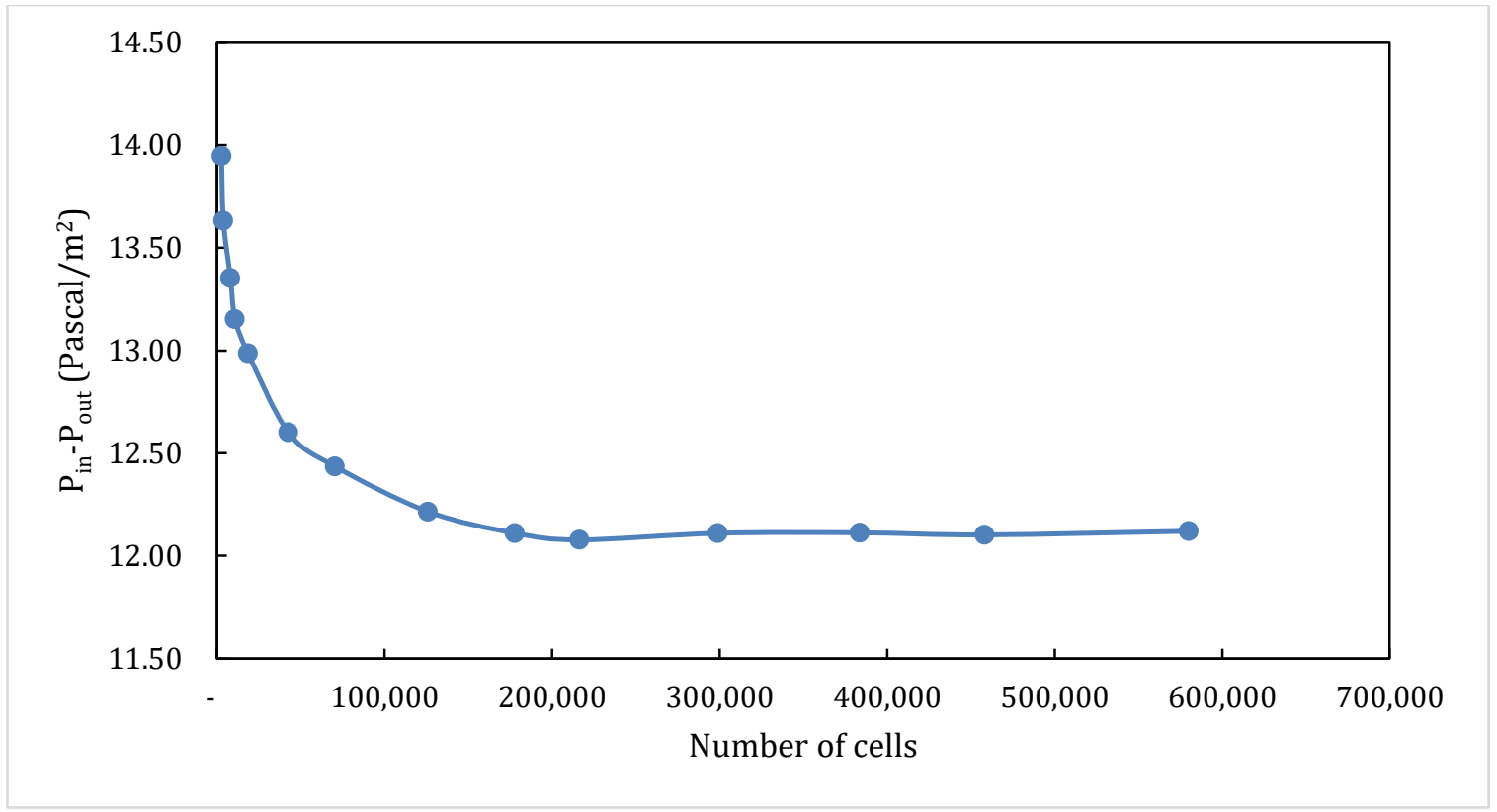

Figure 3-7 Net Integral Pressure versus the cell number

In order to compare different inlet diameters and length of tubes, the same mesh size was needed. Longer distances contain more nodes.

\subsection{Validation}

\subsubsection{Venturi Tube}

Hu et al., (1998) conducted experiments using a manifold connected to a differential pressure transducer to measure the macroscopic flow direction at seven locations of the venturi tube, as shown in Figure 3-8. 


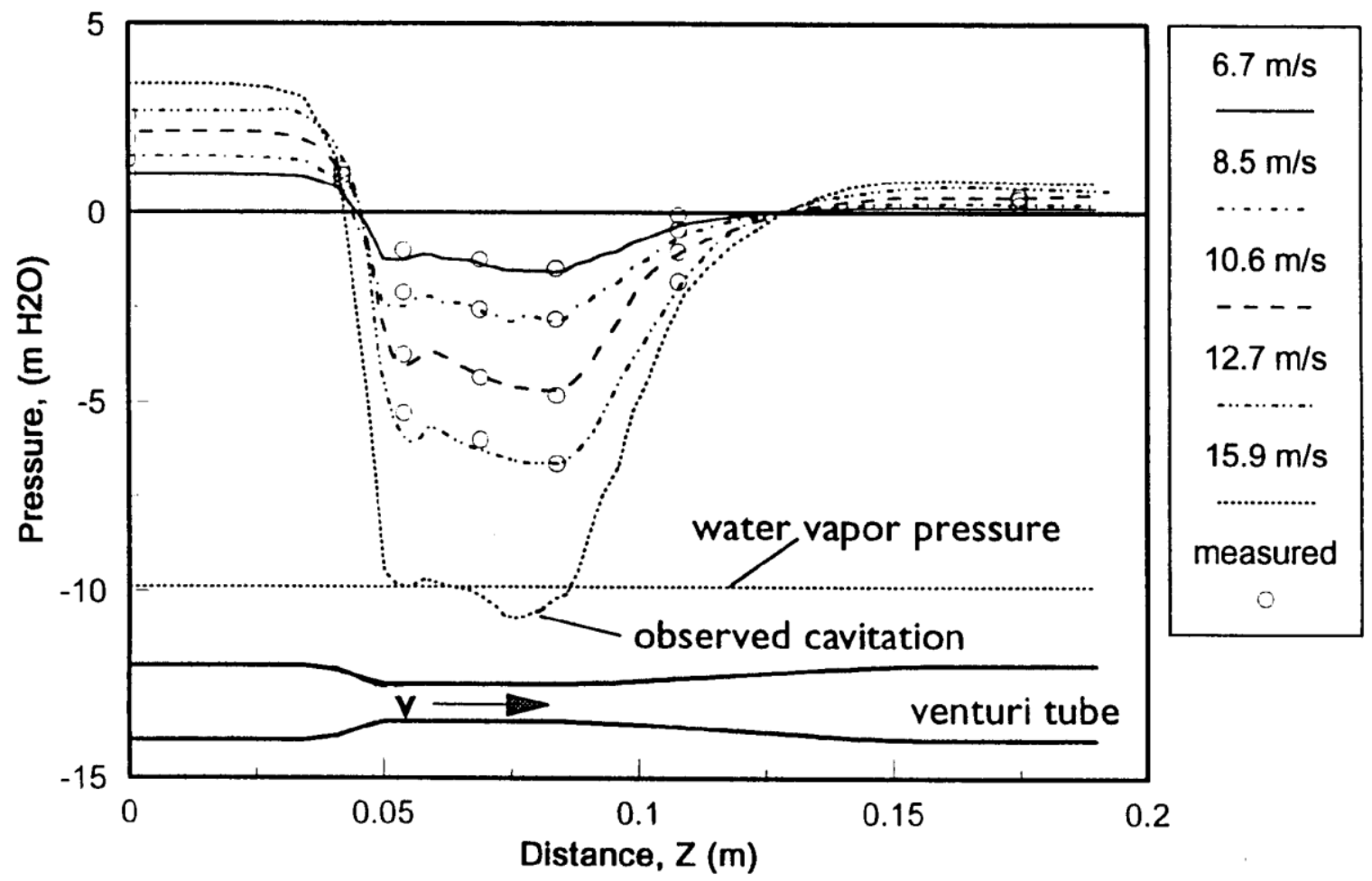

Figure 3-8 Pressure distributions along the venturi tube: experimentally measured pressures at corresponding water flow rates $(\mathrm{H}$. Hu, et al., 1998)

The diameter ratio of this Venturi tube was $0.5(1 \mathrm{~cm} / 2 \mathrm{~cm})$. The inlet velocities and initial turbulent intensity were calculated and listed in the table below.

Table 3-1 Values of variables for turbulence calculation

\begin{tabular}{|c|c|c|c|}
\hline $\begin{array}{c}\text { Throat } \\
\text { Velocity } \\
(\mathbf{m} / \mathbf{s})\end{array}$ & $\begin{array}{c}\text { Inlet } \\
\text { Velocity } \\
(\mathbf{m} / \mathbf{s})\end{array}$ & $\begin{array}{c}\text { Turbulent } \\
\text { Intensity } \\
\mathbf{I}(\mathbf{\%})\end{array}$ & $\begin{array}{c}\text { Hydraulic } \\
\text { Diameter } \\
(\mathbf{m})\end{array}$ \\
\hline 6.7 & 1.675 & 0.0434 & 0.02 \\
\hline 8.5 & 2.125 & 0.0421 & 0.02 \\
\hline 10.6 & 2.65 & 0.0410 & 0.02 \\
\hline 12.7 & 3.175 & 0.0400 & 0.02 \\
\hline 15.9 & 3.975 & 0.0389 & 0.02 \\
\hline
\end{tabular}




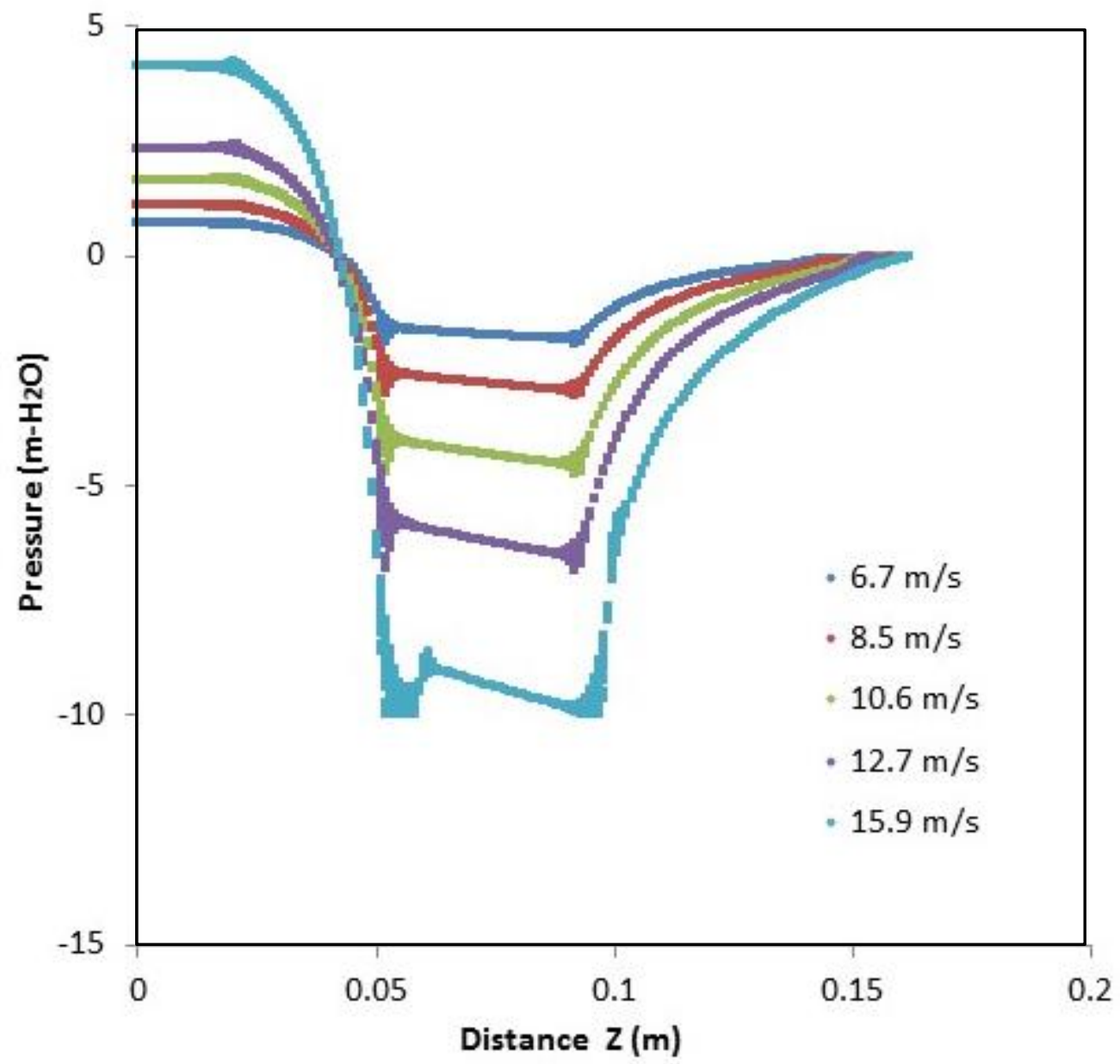

Figure 3-9 Pressure distributions along the venturi tube: ANSYS fluent model at different flow rates $\left(\mathbf{7 0}^{\circ} \mathrm{F}\right)$

The results of the ANSYS FLUENT model for pressure distributions (cross sectional averaged) along the Venturi tube are shown in Figure 3-9. With the same geometry of the Venturi tube as Hu's and the same flow rates $(6.7,8.5,10.6,12.7$ and $15.9 \mathrm{~m} / \mathrm{s})$, the model predictions closely match the experimental data. The pressures downstream are lower than the upstream values. As the flow rate increases, the static pressure drops. 


\subsubsection{Nozzle}

The results of the nozzle cavitation compared with the experimental tests carried out by Abuaf et al., (1981) are shown in Figure 3-10 and Figure 3-11.

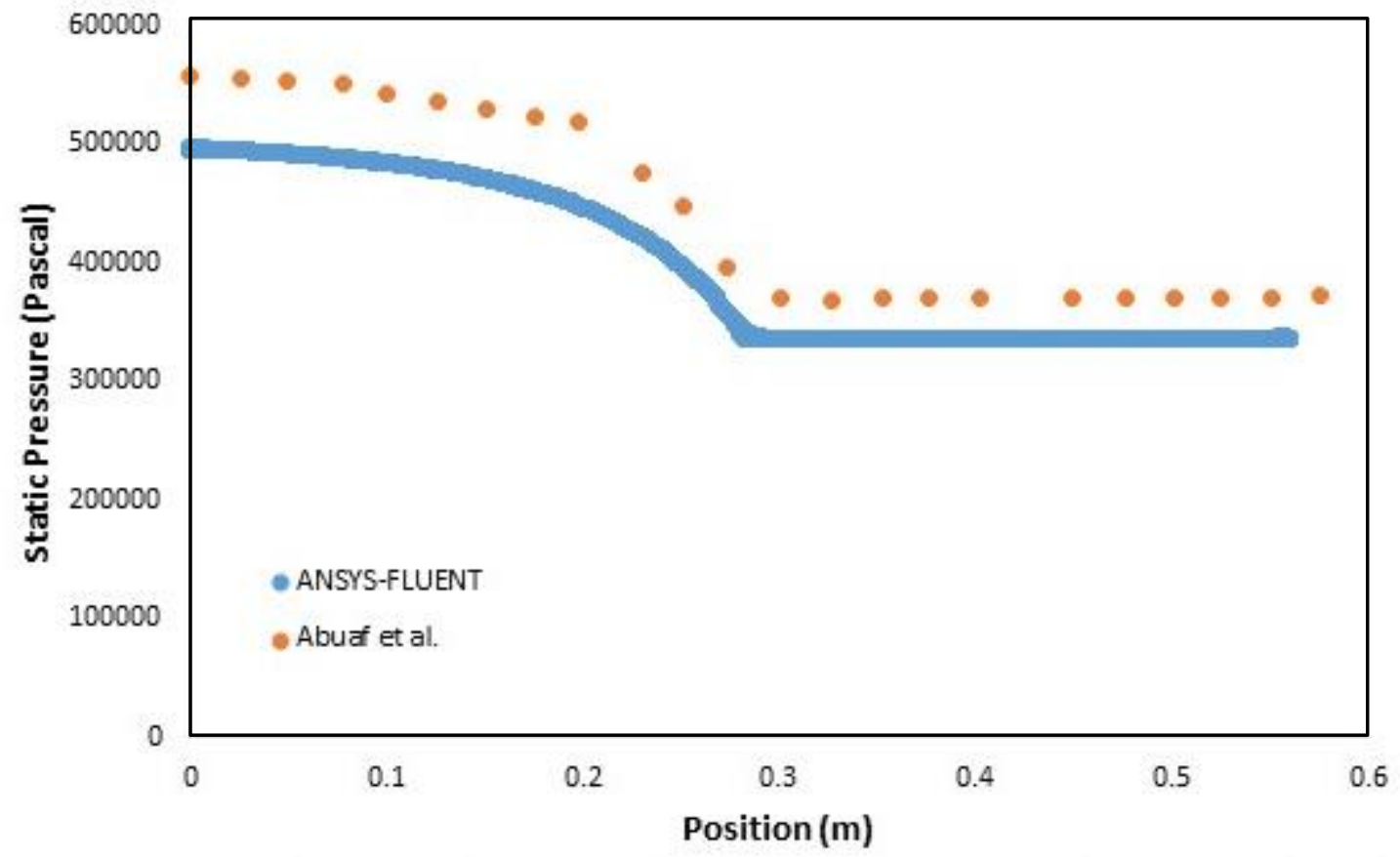

Figure 3-10 Static pressure distributions along the nozzle: ANSYS fluent vs. Abuaf et al., (1981)

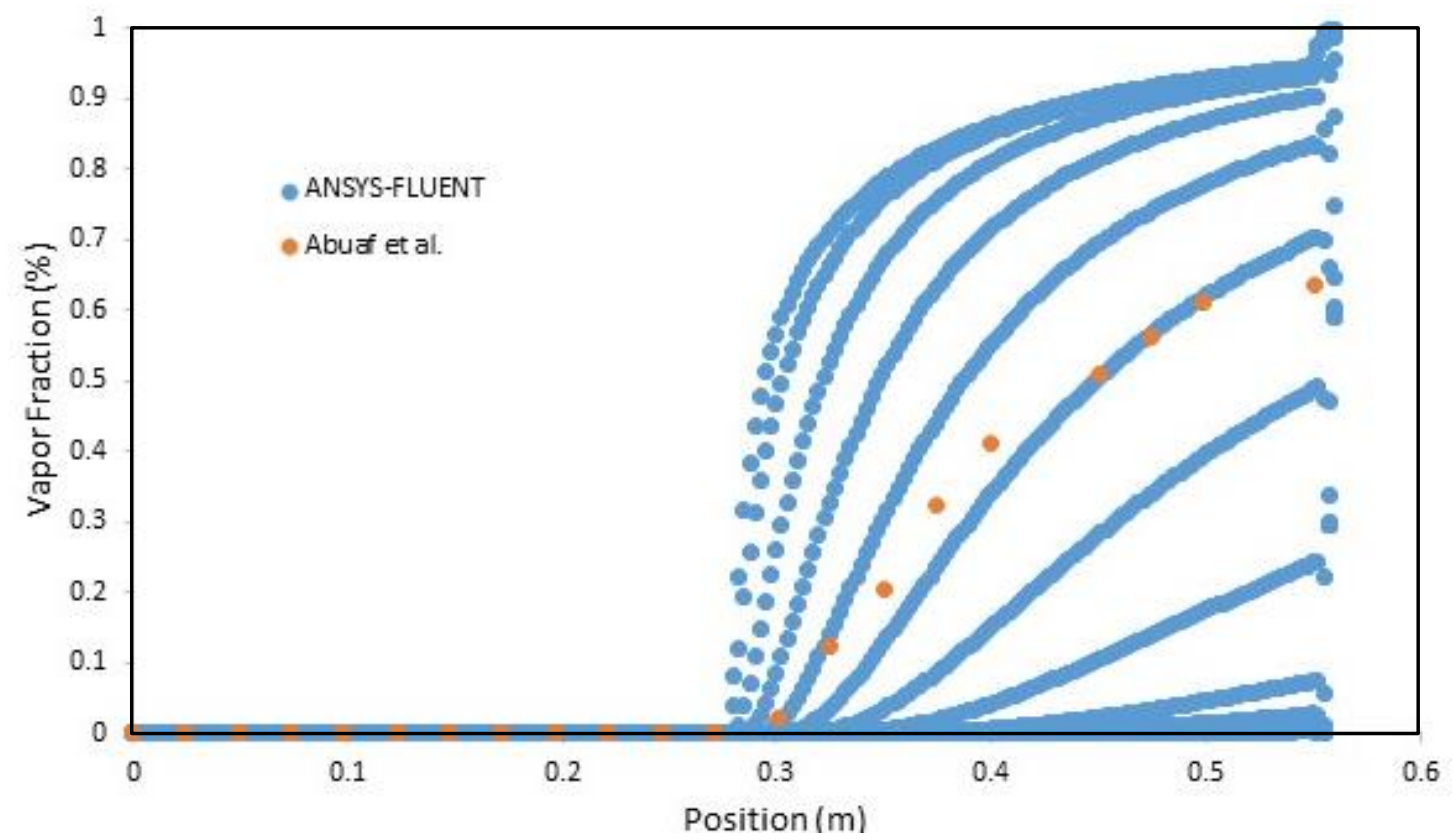

Figure 3-11 Vapor fraction along the nozzle: ANSYS fluent vs. Abuaf et al., (1981) 
Figure 3-10 shows the cross sectional averaged static pressure distributions and Figure 311 shows the vapor fraction along the nozzle, based relative to position. As illustrated by the trend lines, the model is a good predictor of the experimental data.

\subsubsection{Orifice}

The results of the orifice cavitation compared with the experimental tests are shown in Figure 3-12, which depicts the averaged static pressure distribution along the orifice during the experiment. The pressure drop is the difference between inlet pressure and outlet pressure.

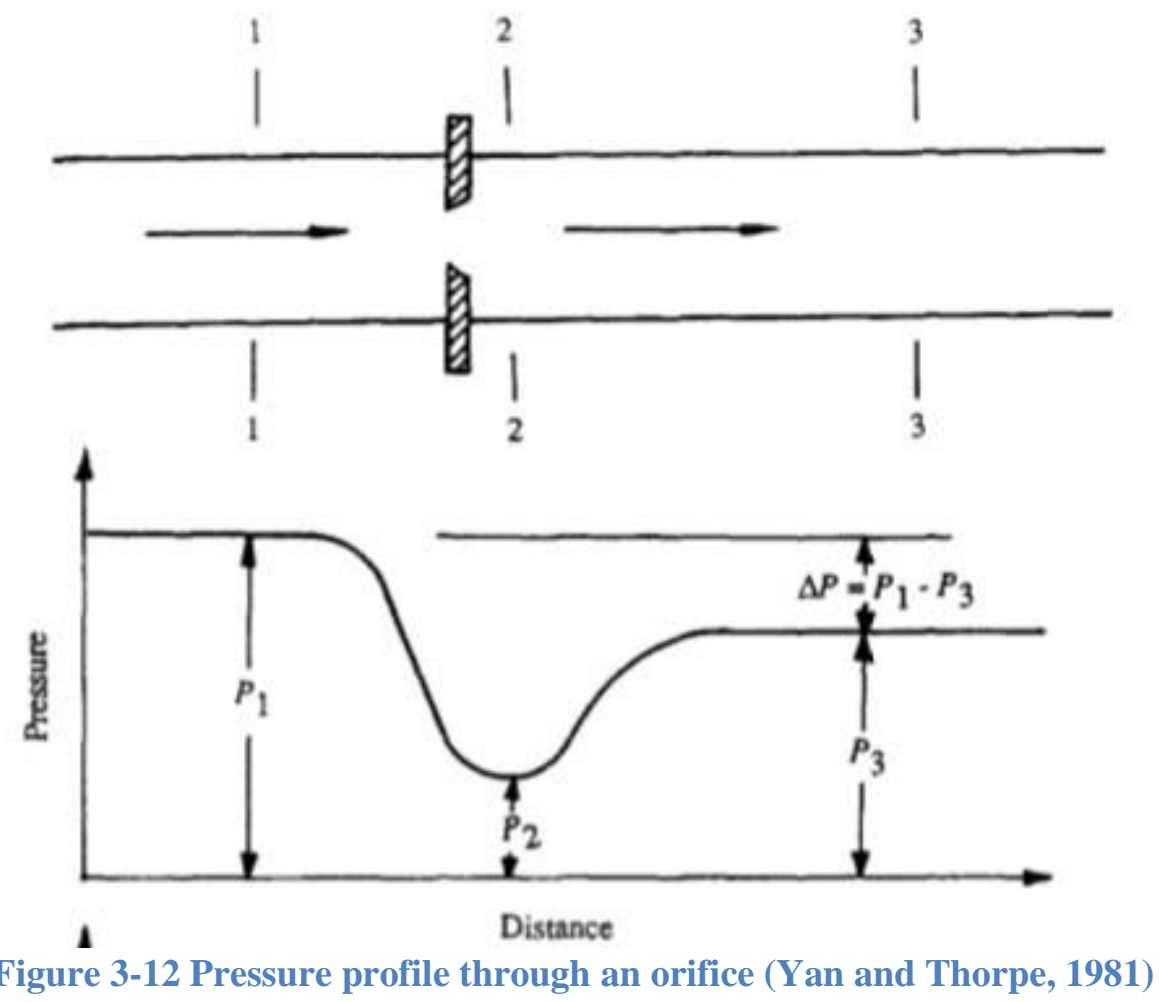

Figure 3-13 shows the ANSYS Fluent result. Pressure is consistent at the inlet and outlet, and is lowest at the vena-contracta, which matches the experimental results well. 


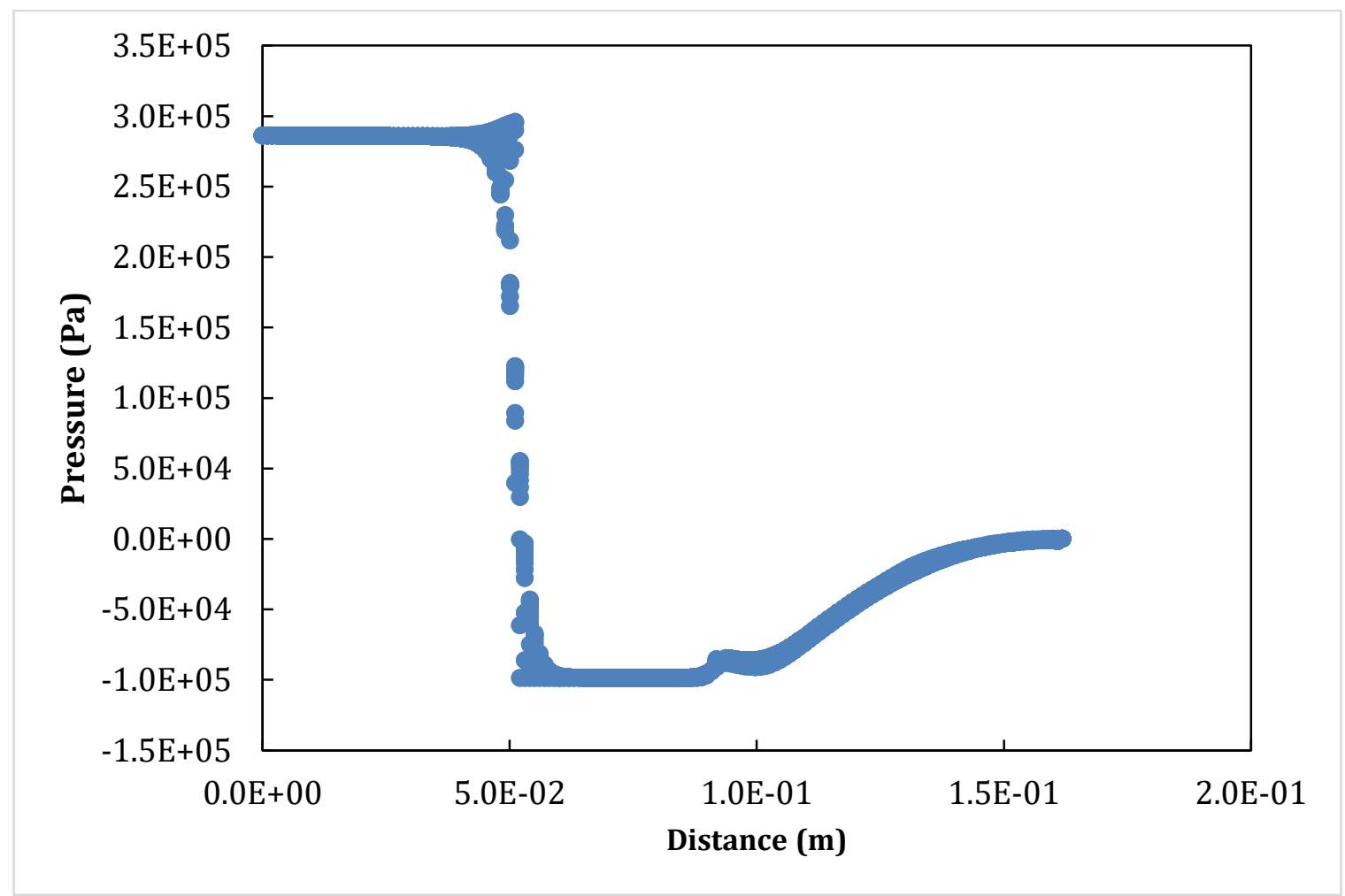

Figure 3-13 Pressure profile - ANSYS Fluent

\subsection{Contours of Pressure, Velocity and Volume Fraction of Vapor}

The contour results of FLUENT for different geology, at different flow rates are shown below:

\subsubsection{Venturi}

\subsubsection{Pressure}

Figure 3-14 shows the contour of pressure for a Venturi tube with different velocities at the throat. For a constant flow rate, the pressure decreases through the converging section due to the change in cross-section area, until it reaches the vapor pressure, where 
cavitation starts to occur. Thus, the pressure at the throat is the lowest, even potentially negative. The pressure gets higher at the divergent section.

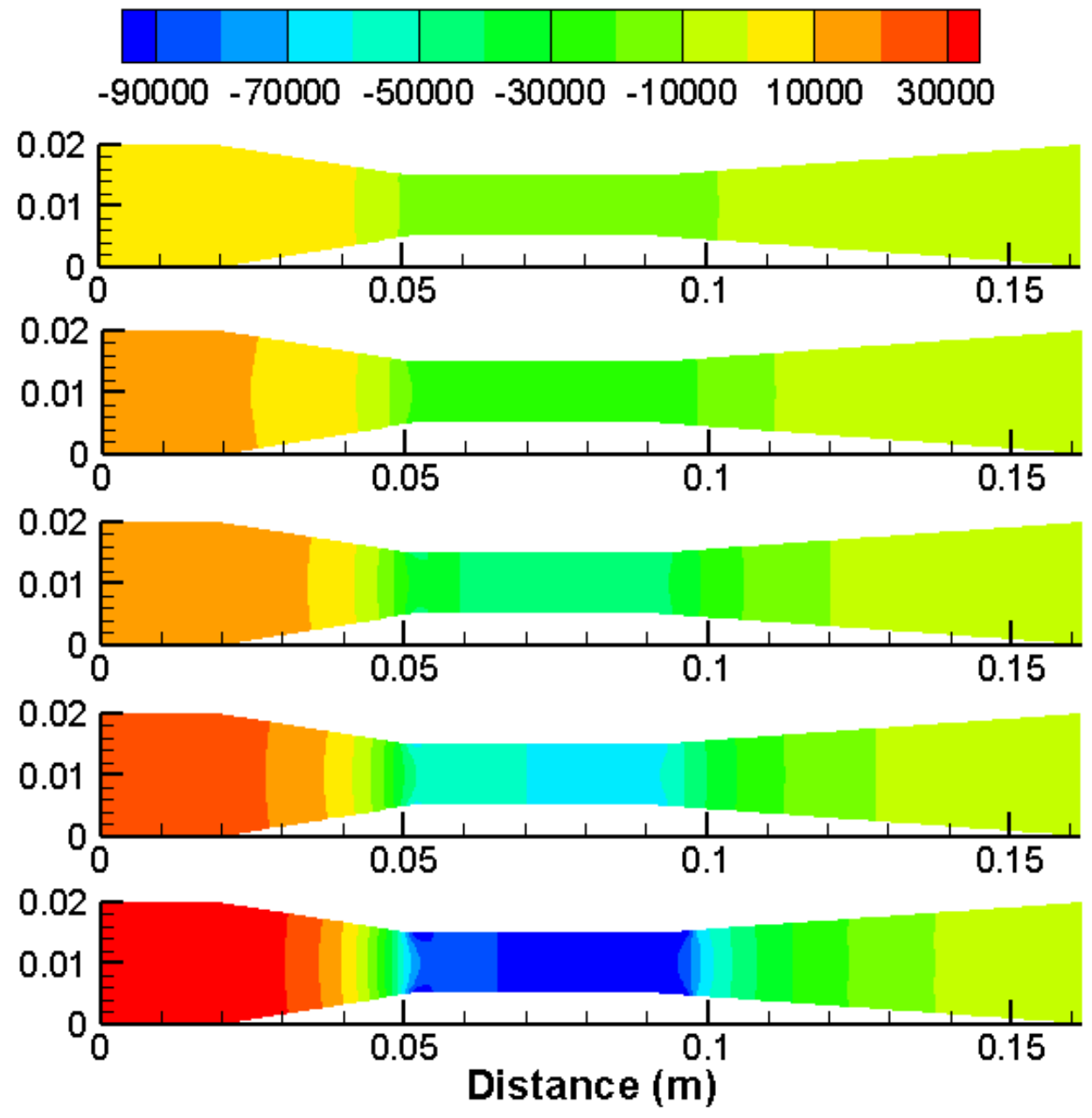

Figure 3-14 Contours of static pressure at flow rates $6.7 \mathrm{~m} / \mathrm{s}, 8.5 \mathrm{~m} / \mathrm{s}, 10.6 \mathrm{~m} / \mathrm{s}, 12.7 \mathrm{~m} / \mathrm{s}$ and $15.9 \mathrm{~m} / \mathrm{s}$ 


\subsubsection{Velocity}

The velocity contour of the middle plane ( $\mathrm{z}$ coordinate equals 0 ) of the Venturi tube is shown in Figure 3-15.

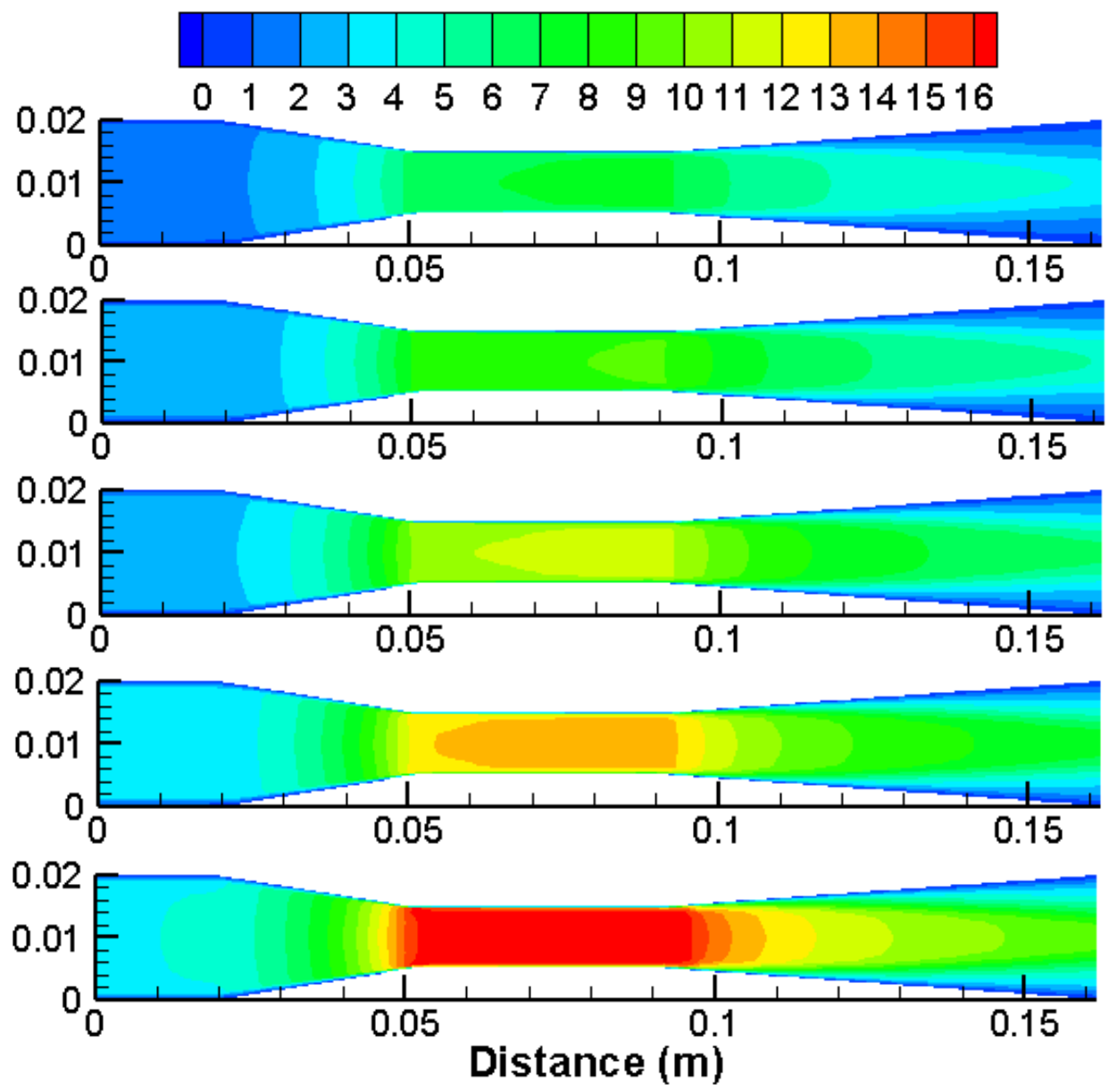

Figure 3-15 Contours of velocity at flow rates $6.7 \mathrm{~m} / \mathrm{s}, 8.5 \mathrm{~m} / \mathrm{s}, 10.6 \mathrm{~m} / \mathrm{s}, 12.7 \mathrm{~m} / \mathrm{s}$ and 15.9 $\mathrm{m} / \mathrm{s}$

\subsubsection{Vapor fraction}

The vapor fraction contour of the middle plane ( $\mathrm{z}$ coordinate equals 0 ) of the Venturi tube is shown in Figure 3-16. Vapor generated from cavitation phenomenon came from the walls of the throat, where the pressures are the lowest, and extended along the whole wall of the divergent part towards the outlet. 


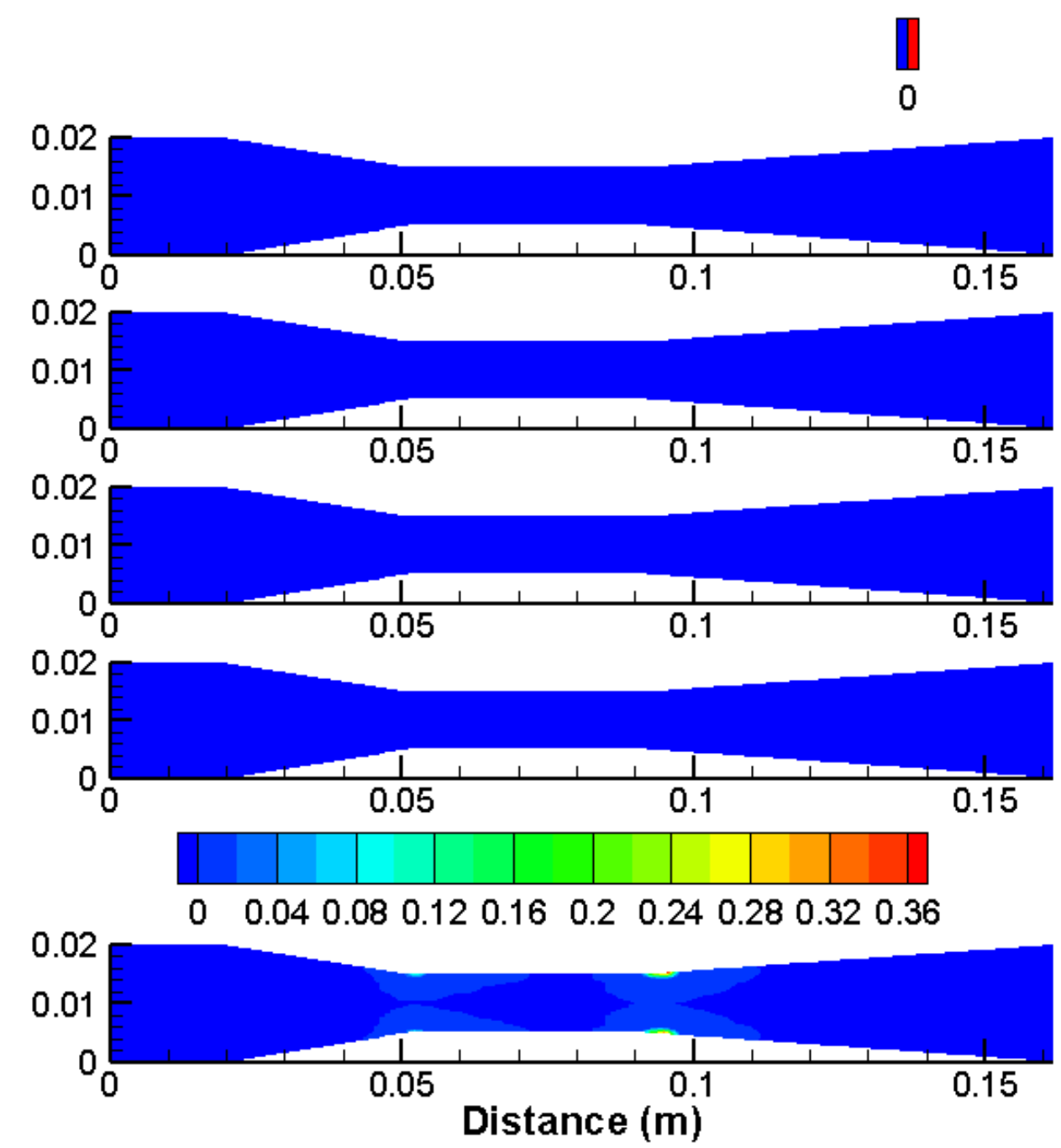

Figure 3-16 Contours of volume fraction (vapor) at flow rates $6.7 \mathrm{~m} / \mathrm{s}, 8.5 \mathrm{~m} / \mathrm{s}, 10.6 \mathrm{~m} / \mathrm{s}, 12.7$ $\mathrm{m} / \mathrm{s}$ and $15.9 \mathrm{~m} / \mathrm{s}$

Figure 3-14, 3-15, and 3-16 show the contours of pressure, velocity, and vapor volume fractions at different velocities. From Figure 3-16, we can see that there is no cavitation until the flow rate at the throat is $15.9 \mathrm{~m} / \mathrm{s}$. This is consistent with the results of $\mathrm{Hu}$ et al. (1998). 


\subsubsection{Rectangular Venturi}

For the rectangular venturi tube, Figure 3-17 shows the contours of static pressure, velocity, and vapor fraction at $12.5 \mathrm{~m} / \mathrm{s}$. The pressure gets lower at the throat at the convergent section, whenever there is a constant flow rate. Thus, the pressure at the throat is the lowest. The pressure gets higher at the divergent section. Cavitation happens at the walls of the throat, where the pressures are the lowest.
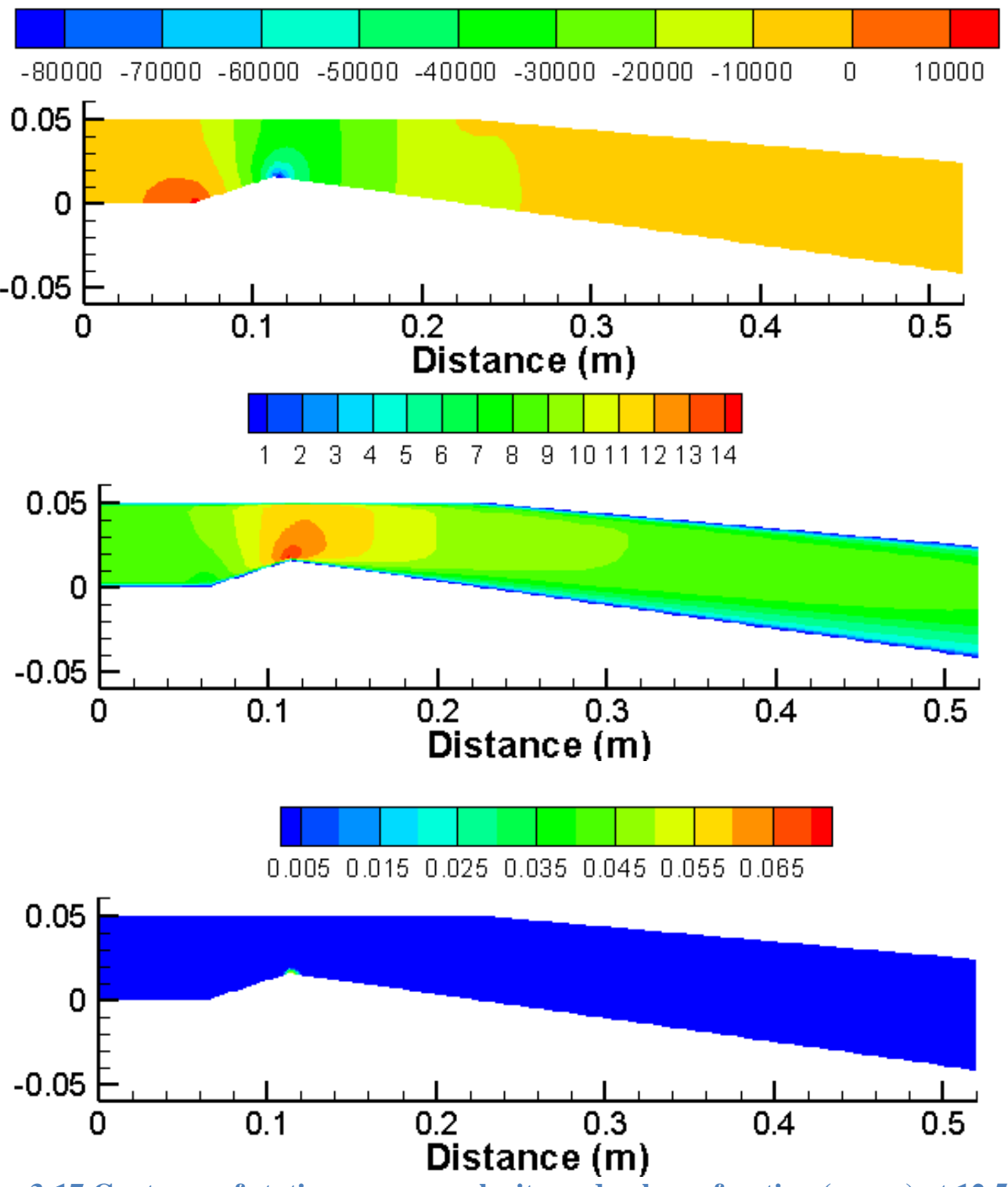

Figure 3-17 Contours of static pressure, velocity and volume fraction (vapor) at $12.5 \mathrm{~m} / \mathrm{s}$ 


\subsubsection{Circular and Rectangular Orifices}

\subsubsection{Pressure}

The contours of static pressure for the circular and rectangular orifices are shown in Figure 3-18. The pressure is lower in the smaller diameter sections, in comparison with the inlets.

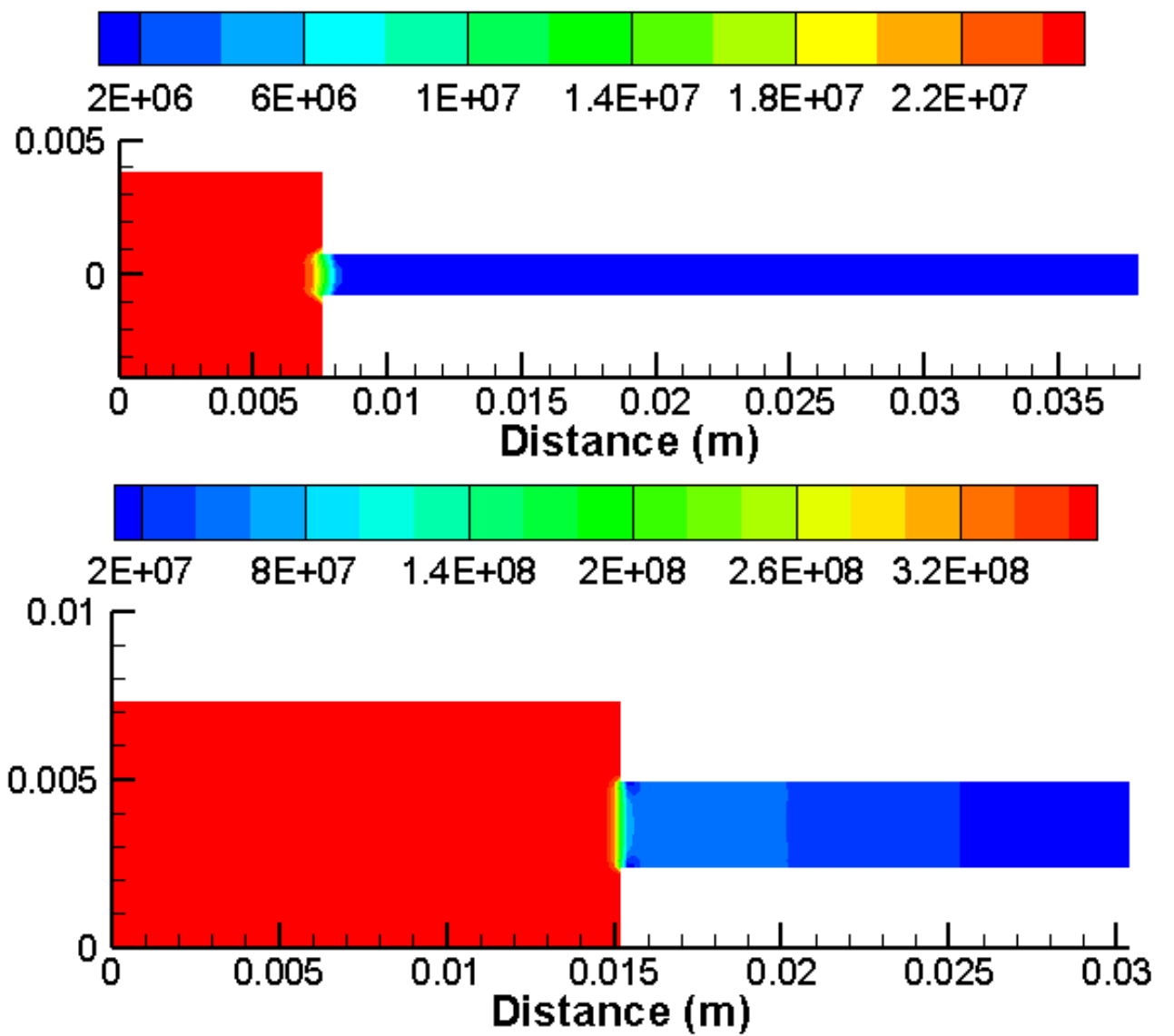

Figure 3-18 Contours of static pressure for circular and rectangular orifices at throat flow rates $150 \mathrm{~m} / \mathrm{s}$ and $600 \mathrm{~m} / \mathrm{s}$ 


\subsubsection{Velocity}

The velocity contours of the middle plane ( $\mathrm{z}$ coordinate equals 0 ) of the circular and rectangular orifices are shown in Figure 3-19.

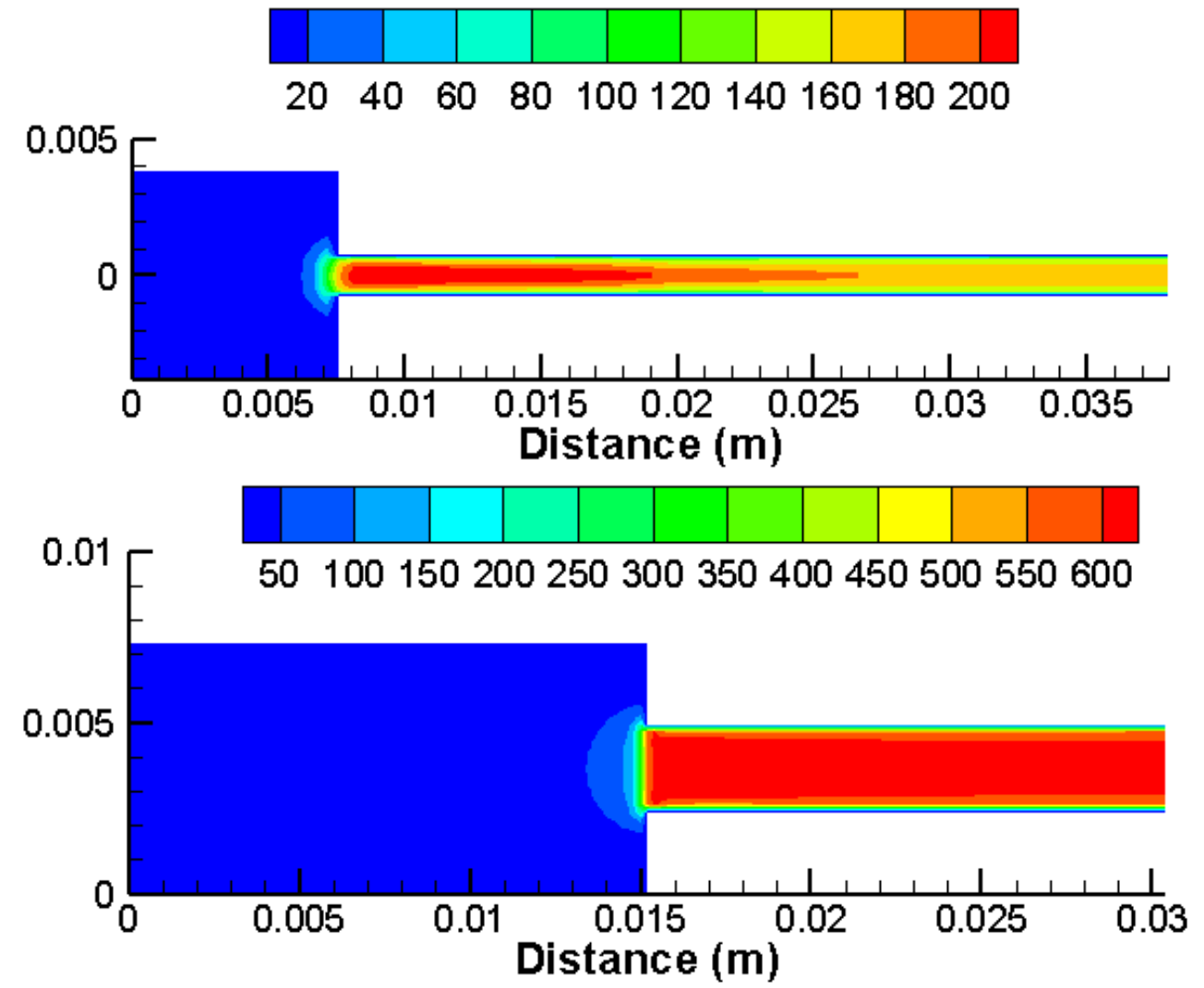

Figure 3-19 Contours of velocity for circular and rectangular orifices at throat flow rates $150 \mathrm{~m} / \mathrm{s}$ and $600 \mathrm{~m} / \mathrm{s}$

\subsubsection{Vapor fraction}

The vapor fraction contours of the middle plane (z coordinate equals 0 ) of the circular and rectangular orifices are shown in Fig. 3-20. Cavitation happens at the walls of the throat, where the pressures are the lowest. 

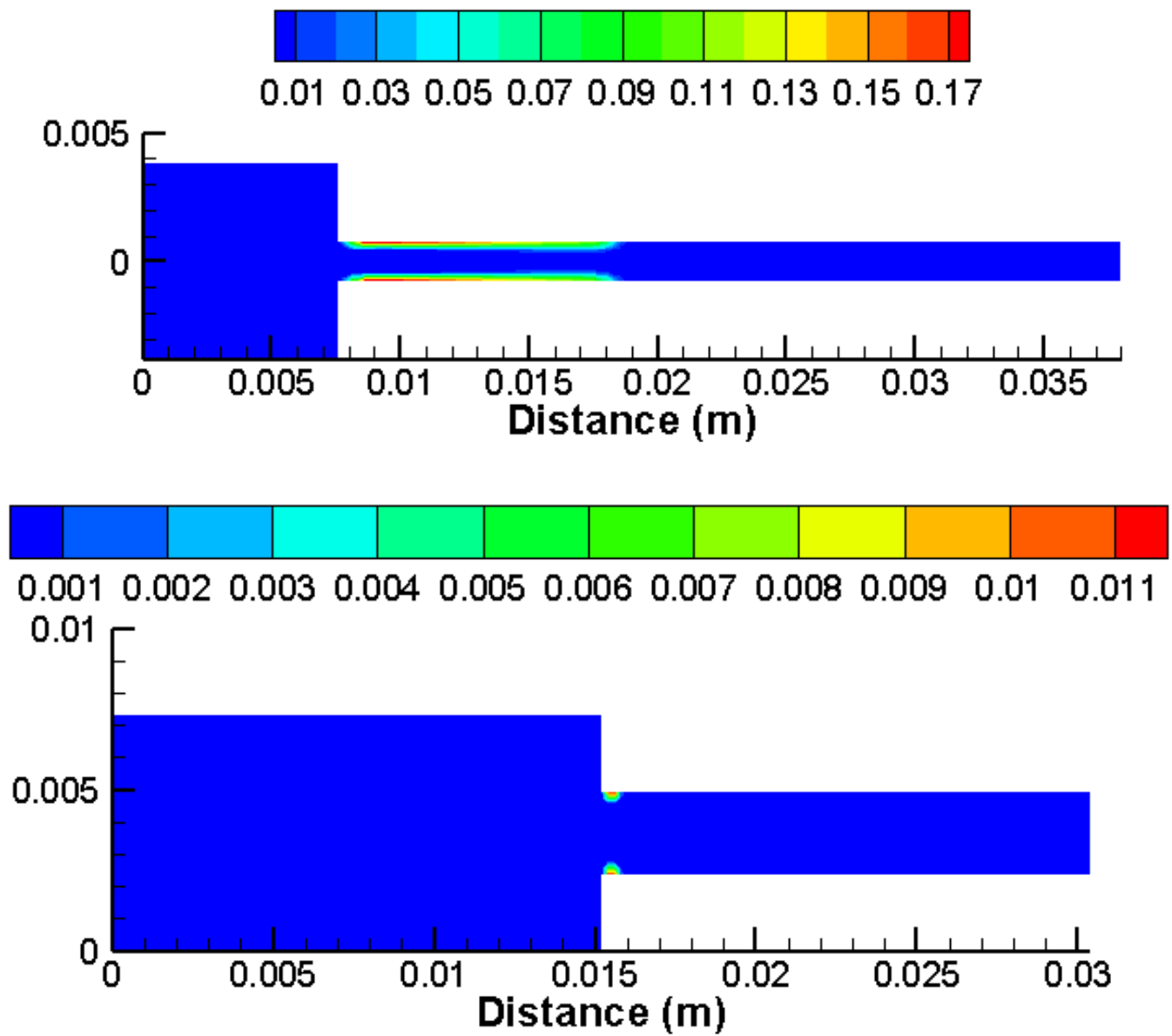

Figure 3-20 Contours of velocity for circular and rectangular orifices at throat flow rates $150 \mathrm{~m} / \mathrm{s}$ and $600 \mathrm{~m} / \mathrm{s}$

\subsubsection{Nozzle}

\subsubsection{Pressure}

Figure 3-21 shows the contours of static pressure for a nozzle with different temperatures. The pressures are lower at the smaller diameter locations. Thus, the pressure at the throat is the lowest, where the cavitation happens. This area increases as the temperature increases. The pressure increases at the divergent section. 

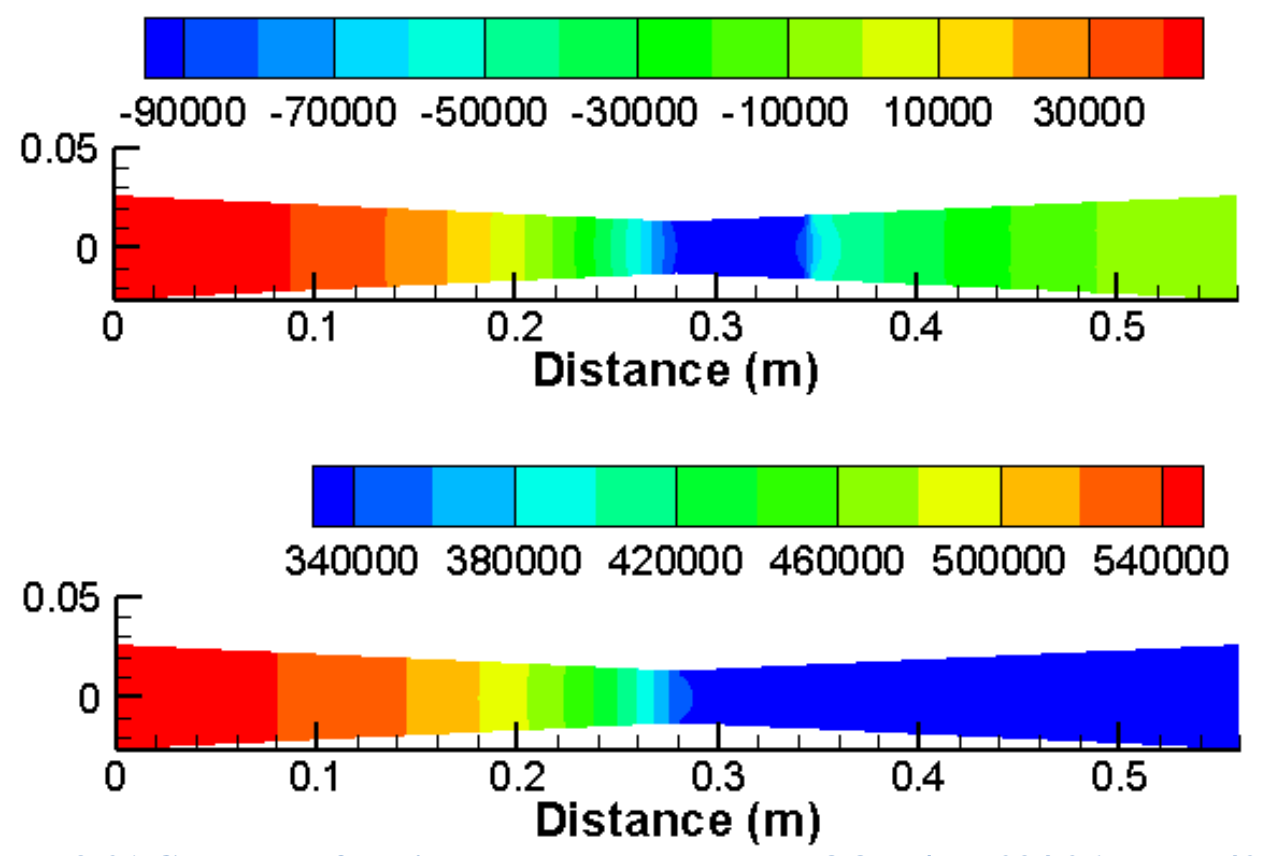

Figure 3-21 Contours of static pressure at mass rates $8.8 \mathrm{~kg} / \mathrm{s}$ at $294.26 \mathrm{~K}$ and $420 \mathrm{~K}$

\subsubsection{Velocity}

The velocity contours of the middle plane ( $\mathrm{z}$ coordinate equals 0 ) of the nozzle are shown in Figure 3-22.

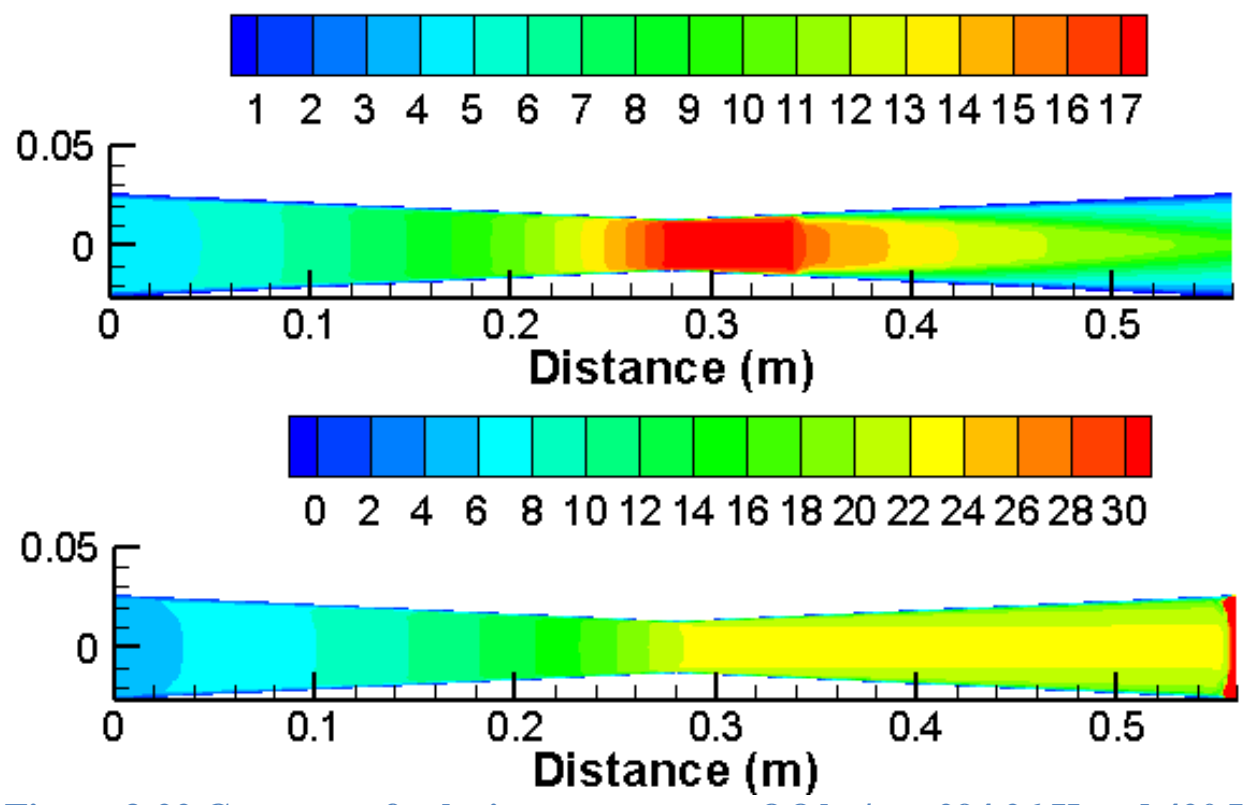

Figure 3-22 Contours of velocity at mass rates $8.8 \mathrm{~kg} / \mathrm{s}$ at $294.26 \mathrm{~K}$ and $420 \mathrm{~K}$ 


\subsubsection{Vapor fraction}

The vapor fraction contours of the middle plane ( $\mathrm{z}$ coordinate equals 0 ) of the nozzle are shown in Figure 3-23. Cavitation happens at the walls of the throat, where the pressures are the lowest. The cavitation area increases when the temperature increases.

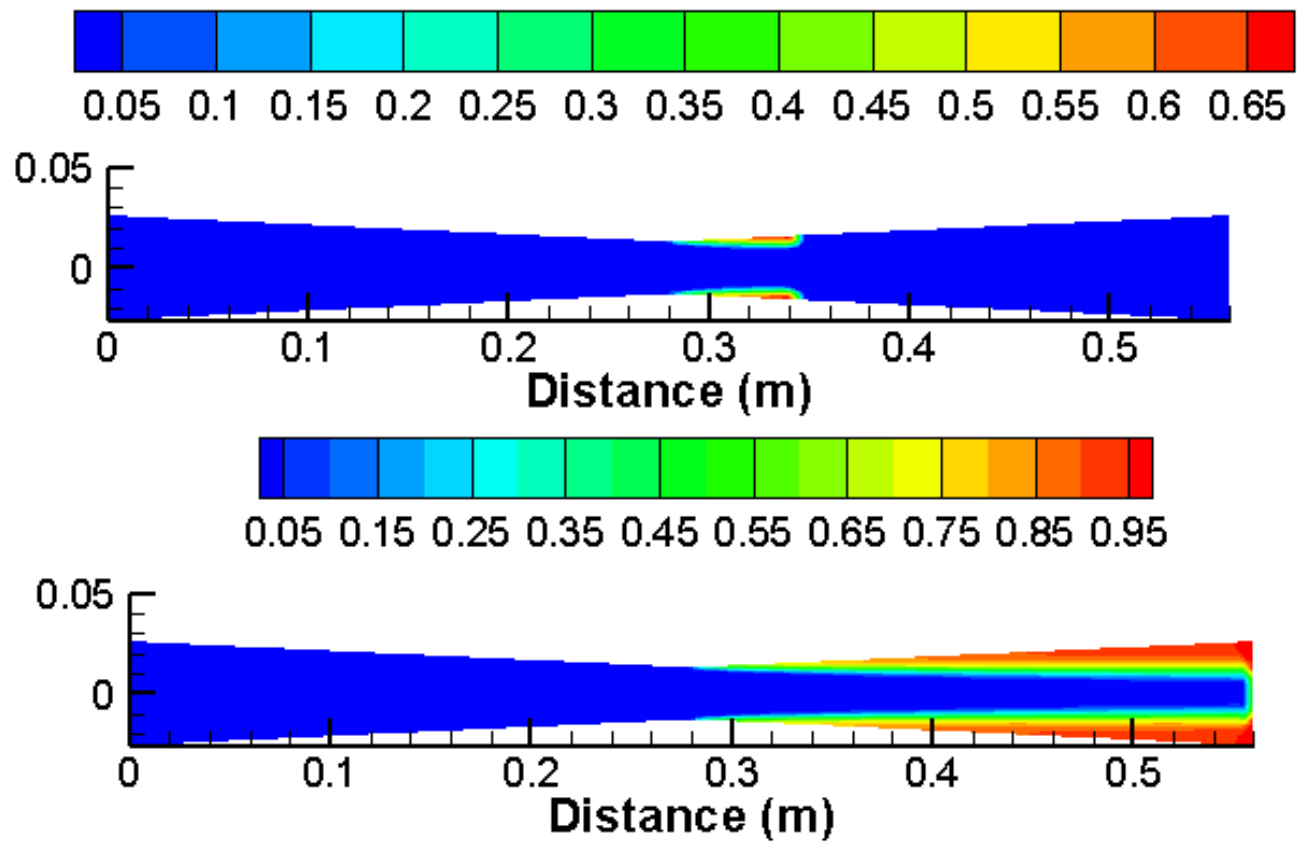

Figure 3-23 Contours of volume fraction (vapor) at mass rates $8.8 \mathrm{~kg} / \mathrm{s}$ at $294.26 \mathrm{~K}$ and $420 \mathrm{~K}$

For venturi tubes with the geometry used by $\mathrm{Hu}$ et al., (1998), the critical flow velocity for cavitation was found to be approximately $15 \mathrm{~m} / \mathrm{s}$ at the throat and $3.75 \mathrm{~m} / \mathrm{s}$ at the inlet. Using the rectangular venturi tube geometry used by Stutz and Reboud (2000), the critical flow velocity was found to be approximately $12.5 \mathrm{~m} / \mathrm{s}$ at the throat and $8.58 \mathrm{~m} / \mathrm{s}$ at the inlet. For the circular and rectangular orifice geometry used by Nurick (1976), the critical velocities were found to be approximately $150 \mathrm{~m} / \mathrm{s}$ at the throat and $6 \mathrm{~m} / \mathrm{s}$ at the inlet of the circular orifice, and over $550 \mathrm{~m} / \mathrm{s}$ at the throat and $31.52 \mathrm{~m} / \mathrm{s}$ at the inlet of the rectangular orifice. For the circular nozzle using the dimensions and conditions from Abuaf et al., (1981), the critical throat velocity was found to be lower than $12.88 \mathrm{~m} / \mathrm{s}$ and $3.22 \mathrm{~m} / \mathrm{s}$ at the inlet, when the temperature is $420 \mathrm{~K}$. However, for room temperature $(294.2611 \mathrm{~K})$, the critical velocity needs to be higher than $15.75 \mathrm{~m} / \mathrm{s}$ at the throat and $3.94 \mathrm{~m} / \mathrm{s}$ at the inlet. 


\subsection{Different Hydrodynamic Cavitating Devices}

Venturi and orifice are reported to be widely used for generating cavitation (Moholkar and Pandit, 1997). They both have advantages: orifice is easy to fabricate, and multiple holes can accommodate in a given cross sectional area. Venturi has smooth converging and diverging sections which gradually increase the kinetic energy of the stream, so it is not easily blocked at high velocities. To analyze the cavitating efficiency of different devices, circular, square, and slot-shaped venturi and orifice tubes with exact same dimensions (inlet area, diameter ratio, entrance length, throat length) are created and studied. These are illustrated in Figure 3-24.

(a)

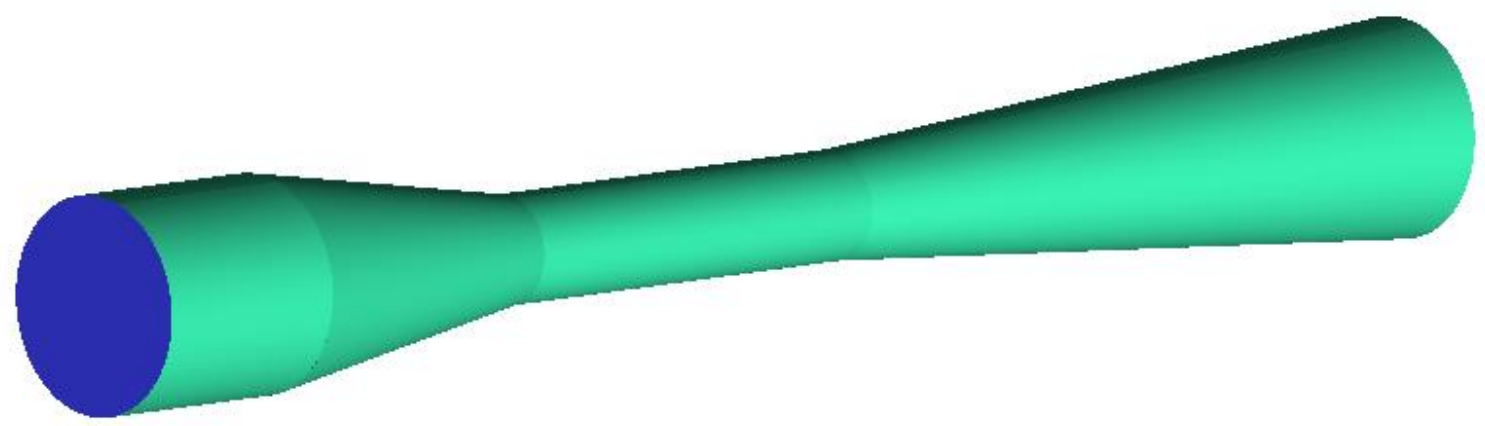

(b)

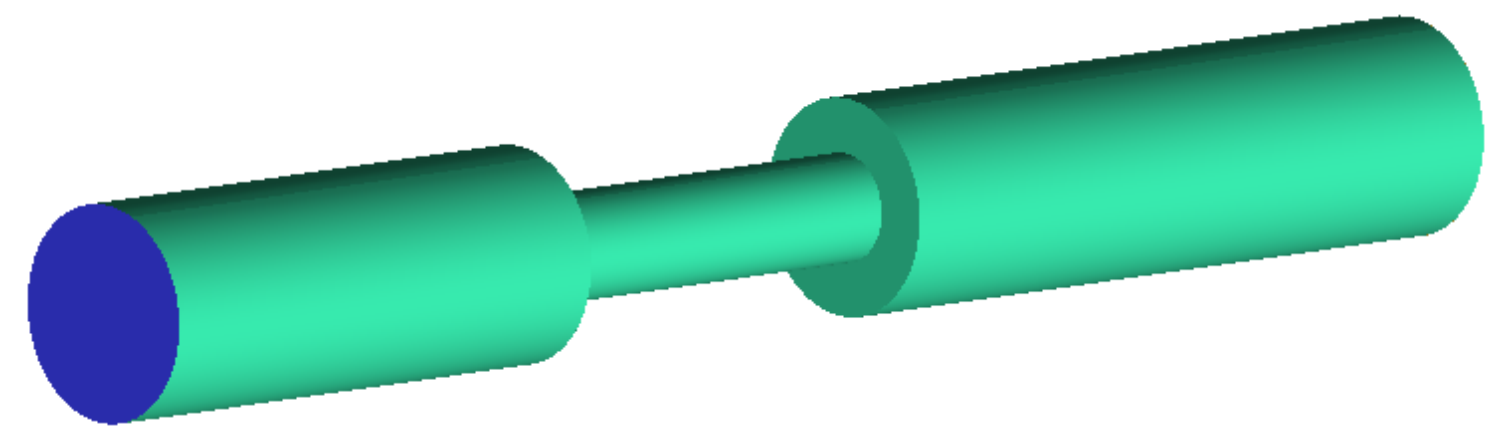


(c)

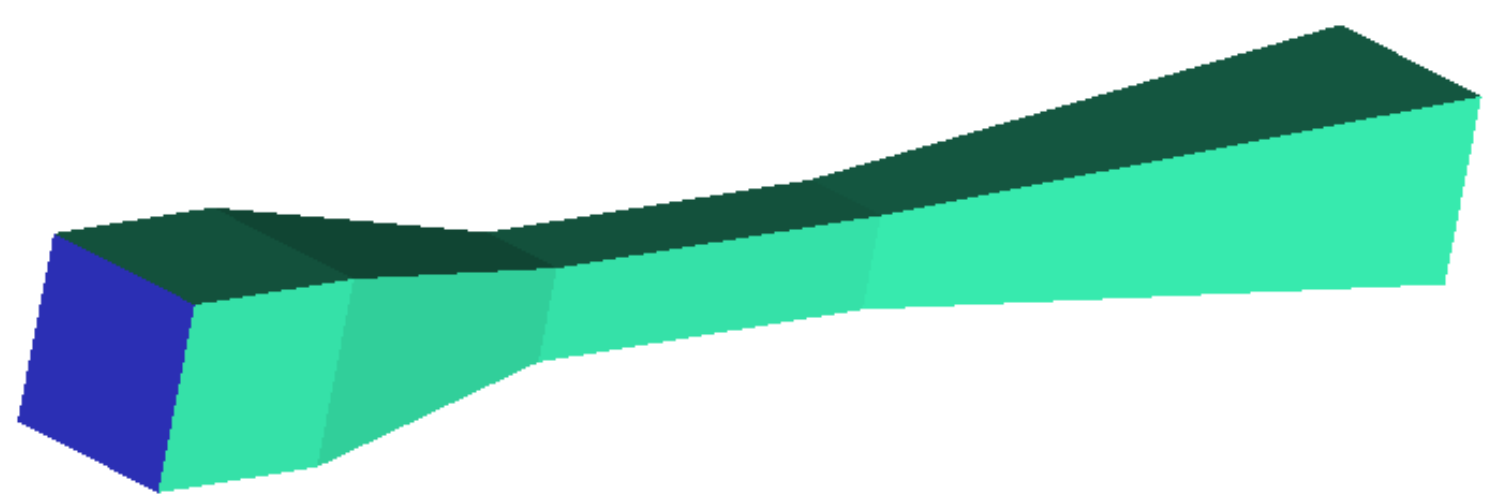

(d)

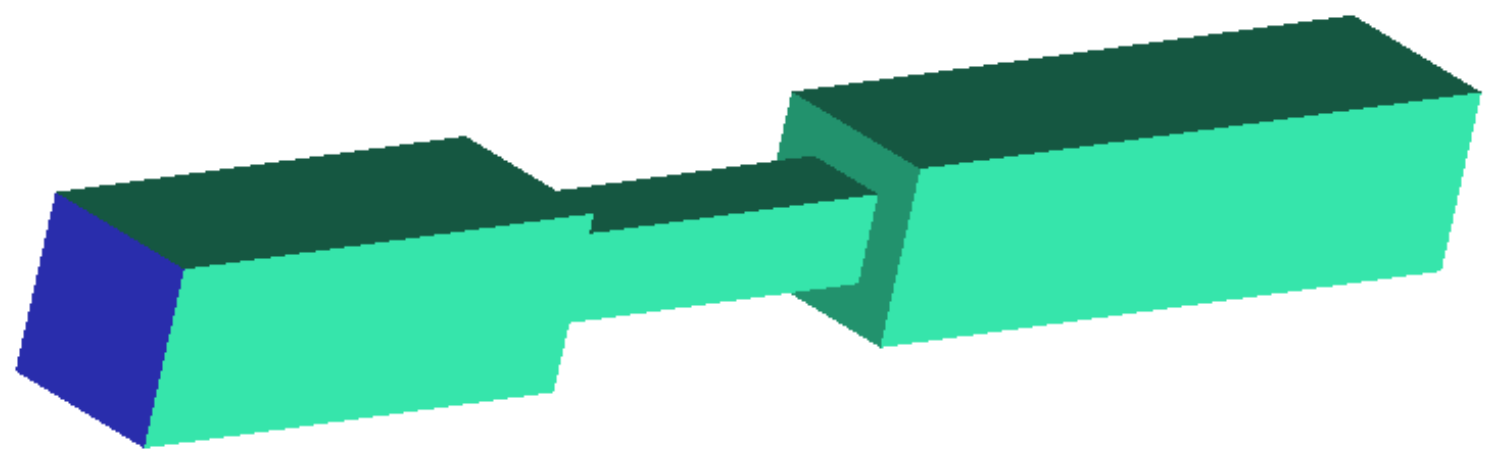

(e)

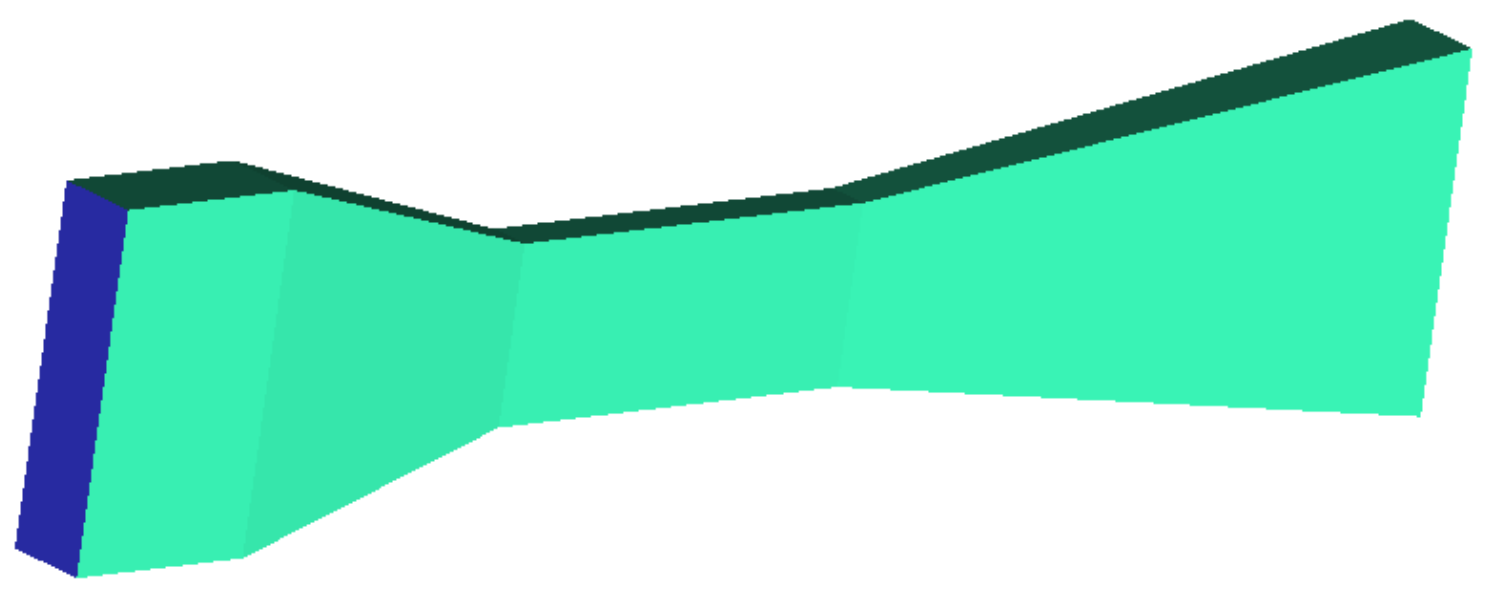


(f)

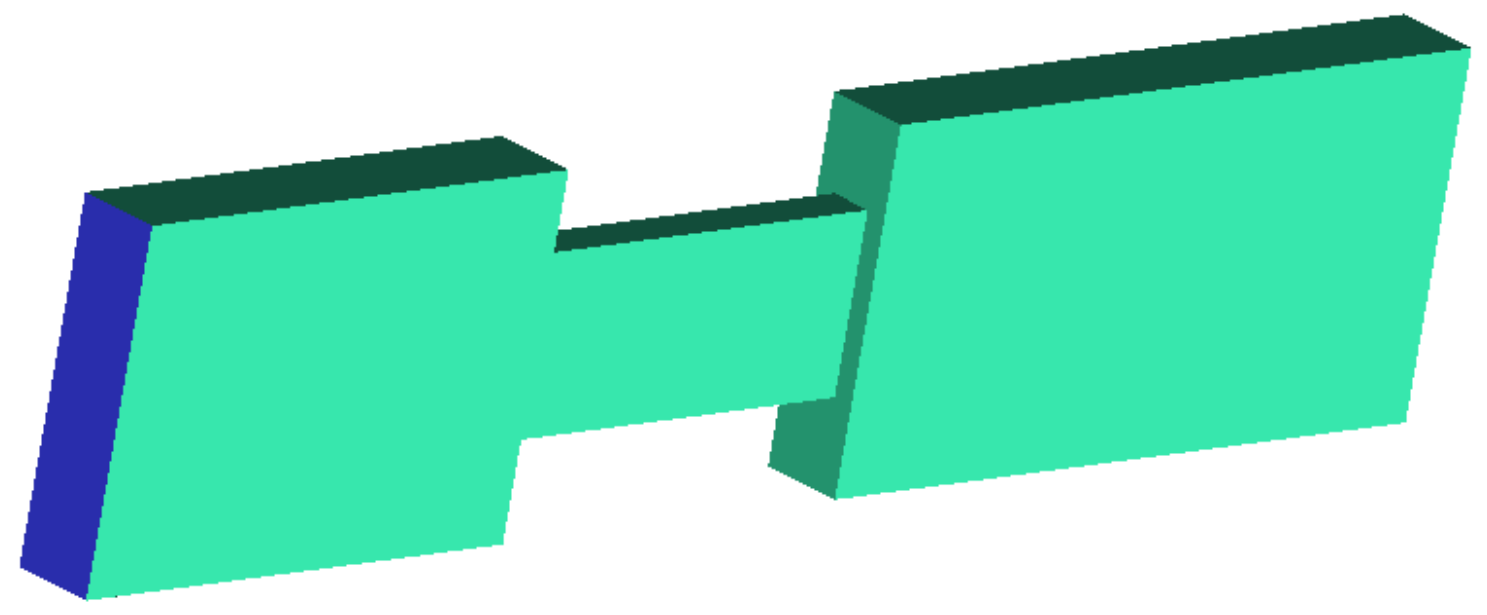

Figure 3-24 (a) circular venturi, (b) circular orifice, (c) square venturi, (d) square orifice, (e) slot venturi and (f) slot orifice

The critical cavitation velocities of different geometries and vapor volumes, at same inlet velocity, are shown in Table 3-2.

Table 3-2 Critical Cavitation Velocity and Vapor Volume of Different Geometries

\begin{tabular}{|c|c|c|c|c|}
\hline \multirow{2}{*}{ Geometry } & \multicolumn{2}{c|}{$\begin{array}{c}\text { Critical Cavitation Velocity } \\
(\mathbf{m} / \mathbf{s})\end{array}$} & \multirow{2}{*}{$\begin{array}{c}\text { Vapor Volume }\left(\mathbf{m}^{\mathbf{3}}\right) \\
\text { at } \mathbf{V}_{\text {inlet }}=\mathbf{5} \mathbf{~ m} / \mathbf{s}\end{array}$} \\
\cline { 3 - 4 } \multicolumn{2}{|c|}{} & Throat & Inlet & \\
\hline \multirow{2}{*}{ Circular } & Venturi & 15.3 & 3.83 & $1.0 \times 10^{-6}$ \\
\cline { 2 - 5 } & Orifice & 16.6 & 4.15 & $3.24 \times 10^{-7}$ \\
\hline \multirow{2}{*}{ Square } & Venturi & 14.6 & 3.65 & $7.78 \times 10^{-7}$ \\
\cline { 2 - 5 } & Orifice & 14.4 & 3.60 & $2.51 \times 10^{-7}$ \\
\hline \multirow{2}{*}{ Slot } & Venturi & 14.4 & 3.60 & $5.96 \times 10^{-7}$ \\
\cline { 2 - 4 } & Orifice & 15.2 & 3.80 & $4.62 \times 10^{-8}$ \\
\hline
\end{tabular}

In comparison to square and slot-shaped inlets, circular-shaped tubes do not have the lowest critical velocity. This is because cavitation occurs at the four corners of rectangleshaped tubes. It is not very stable, and the structures are easier to get erosion. However, circular-shaped tubes can create the most amount of vapor volume fraction, compared with square and slot shapes, at the same inlet velocity. For the inlet velocity at $5 \mathrm{~m} / \mathrm{s}$, circular venturi generated $1.0 \times 10^{-6} \mathrm{~m}^{3}$, which was more than square venturi made $\left(7.78 \times 10^{-7} \mathrm{~m}^{3}\right)$ and slot venture $\left(5.96 \times 10^{-7} \mathrm{~m}^{3}\right)$. The results are similar for orifices. 
Circular-shaped orifice has the highest vapor volume fraction. This matches the results of Balasundaram and Harrison (2011), in which circular is preferred over the other shapes. This is because it gives a higher number of jet streams for a given flow area.

\subsection{Effect of Velocity on Homogeneous Nucleation}

Zhou et. al. (1996) found that there is an increase in fine particle flotation when the velocity of the feed stream is increased through the cavitation tube. Finch et al. (2008) also found that velocity has little effect on the bubble size.

Vapor generated by homogeneous nucleation with increased velocity has been studied. The dimension of the Venturi tube for the velocity analysis uses the geometry of Peng and Xiong's (2015) experimental tube. The results show that the pressure drops $\left(\mathrm{P}_{\text {inlet }}-\right.$ $\left.\mathrm{P}_{\text {outlet }}\right)$ and total vapor volume increases with increasing velocity.

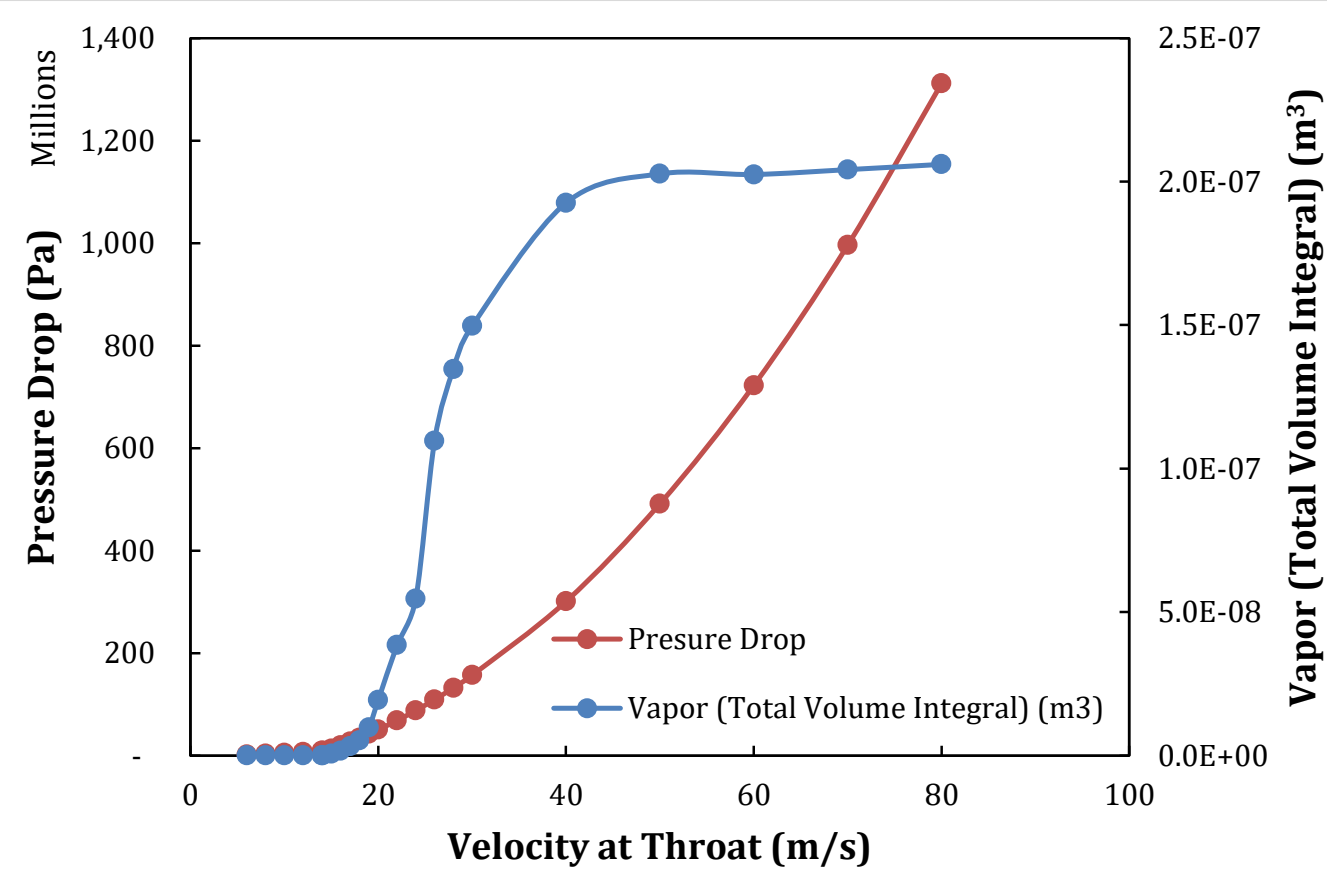

Figure 3-25 Vapor fraction vs. Velocity 
The minimum static pressure decreases as the feed velocity increases. However, after minimum cavitation is achieved, it levels off. For this geometry, the minimum static pressure is from $-17,909.82$ to $-98,919.85 \mathrm{~Pa}$, and it holds at $-98,919.85 \mathrm{~Pa}$ after cavitation. The maximum static pressure increases as the velocity increases. Thus, the total pressure drop increases, the vapor generated by cavitation increases. The amount of vapor generated by cavitation remains constant, after the neck velocity exceeds $40 \mathrm{~m} / \mathrm{s}$.

\subsection{Design of Experiments \& Data Analysis}

The inlet diameter, diameter ratio, convergent angle, divergent angle, throat length, and entrance length are important parameters for geometric optimization. The inlet diameter decides the flow rate. The diameter ratio determines the velocity and pressure change. The convergent and divergent angles control the rate of pressure recovery.

Not all of these parameters are independent, so they need to be considered together for the desired effects. The values of each numeric factor are listed in Table 3-3. The throat and entrance lengths are up to twice and three times the size of the throat diameter. The critical velocity for cavitation is the response. A response surface method, central composite design was conducted for evaluating the effect of these six parameters have on the efficiency of the Venturi tube. JMP 11 was used for experimental design and data analysis.

Table 3-3 Values of variables for response surface design of venturi tube design

\begin{tabular}{|l|c|c|}
\hline \multirow{2}{*}{\multicolumn{1}{|c|}{ Factors }} & \multicolumn{2}{c|}{ Values } \\
\cline { 2 - 3 } & Lower Limit & Upper Limit \\
\hline Inlet Diameter $(\mathrm{mm})$ & 10 & 250 \\
\hline Diameter Ratio* & 0.1 & 0.9 \\
\hline Convergent Angle $\left(^{\circ}\right)$ & 15 & 30 \\
\hline Divergent Angle $\left({ }^{\circ}\right)$ & 5 & 20 \\
\hline Throat Length $(\mathrm{d})(\mathrm{mm})$ & 0.5 & 3 \\
\hline Entrance Length $(\mathrm{d})(\mathrm{mm})$ & 0 & 2 \\
\hline *Diameter ratio $\beta=d / D$ & \multicolumn{2}{|c}{}
\end{tabular}


The results may be used to better understand the importance of each factor, better understand the importance of their interactions, and compare with the mechanism of cavitation of a Venturi tube, to optimize the design. The designed experiments and results are as shown in Appendix A.

\subsection{Population Balance Module}

The Rayleigh-Plesset equation is one of the most common models to simulate bubble growth and diameter changing rates. Cavitation models are good for determining the critical velocities of different geometries. However, with a given constant bubble number density/bubble size, they are not suitable for bubble size distribution calculations.

Population Balance Model (PBM) in FLUENT is an add-on module. It can be used for simulating nucleation, growth, dispersion, dissolution, aggregation, and breakage processes involving a secondary phase with a size distribution. The cavitation model is disabled once PBM model is selected. So for cavitation bubble size changing rate, User Defined Function (UDF) is needed. A mathematics model needs to be built before writing UDF code. 


\section{CHAPTER 4 Simulation of Cavitation Venturi Design}

The geometric parameters include the inlet diameter, diameter ratio, convergent angle, divergent angle, throat length, and entrance length of venturi tubes. They are numerically investigated by three-dimensional simulation. The influences on the flow and the characteristics of cavitation affected by those parameters were analyzed in terms of the distribution of the physical fields, such as, statistic pressure, velocity vector, turbulent kinetic energy, mass transfer coefficient, and vapor volume fraction.

48 venturi tubes with designed geometry, shown as table 3-3, were created using ANSYS ICEM, and the critical cavitation velocity for each tube was calculated using ANSYS FLUENT.

\subsection{Importance of Factors on Critical Cavitation Velocity}

The summary of fit of six essential parameters is shown as Table 4-1.

Table 4-1 Summary of Fit

\begin{tabular}{|l|r|}
\hline RSquare & 0.98694 \\
\hline RSquare Adj & 0.96931 \\
\hline Root Mean Square Error & 0.44087 \\
\hline Mean of Response & 16.18125 \\
\hline Observations (or Sum Wigts) & 48 \\
\hline
\end{tabular}

Table 4-1 shows that the summary of fit for the 48 observations $\left(R^{2}\right)$ is 0.987 , meaning the model fits data well. The comparison of the observed responses and predicted responses are shown in Figure 4-1. It also indicated that the model can predict the critical velocity precisely. 


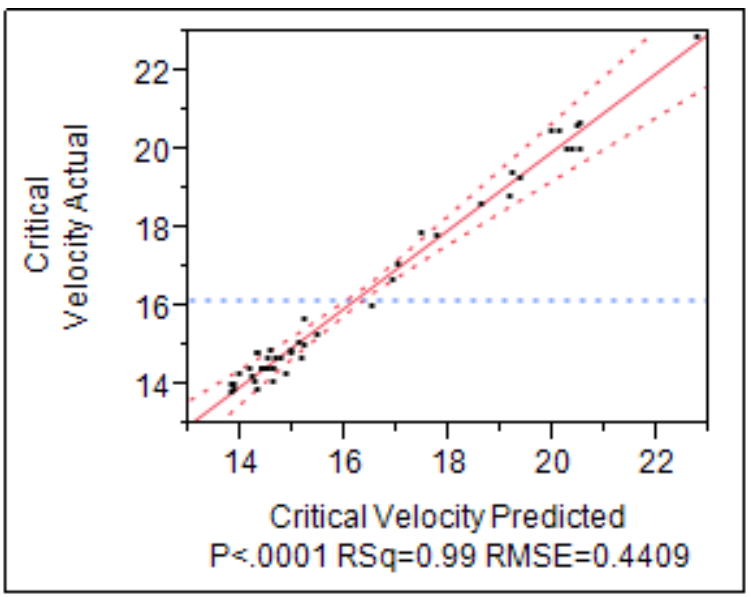

Figure 4-1 Actual by Predicted Plot

Table 4-2 is the ANOVA table of this experiment.

Table 4-2 Analysis of Variance

\begin{tabular}{|l|c|c|r|c|}
\hline Source & $\begin{array}{c}\text { Degree of } \\
\text { Freedom }\end{array}$ & $\begin{array}{c}\text { Sum of } \\
\text { Squares }\end{array}$ & Mean Square & F Ratio \\
\hline Model & 27 & 293.76575 & 10.8802 & 55.9771 \\
\hline Error & 20 & 3.88738 & 0.1944 & Prob $>$ F \\
\hline C. Total & 47 & 297.65313 & & $<.0001 *$ \\
\hline
\end{tabular}

The analysis of variance is illustrated in Table 4-2. The p-value is compared with the desired significance level of our test, and it is $<0.0001$, so the result is significant. The lack of fit table is showed in Table 4-3.

Table 4-3 Lack of Fit

\begin{tabular}{|c|c|c|c|c|}
\hline Source & $\begin{array}{l}\text { Degree of } \\
\text { Freedom }\end{array}$ & $\begin{array}{c}\text { Sum of } \\
\text { Squares }\end{array}$ & $\begin{array}{c}\text { Mean } \\
\text { Square }\end{array}$ & F Ratio \\
\hline Lack of Fit & 17 & 3.8873792 & 0.228669 & \multirow{3}{*}{ Prob $>$ F } \\
\hline Pure Error & 3 & 0.0000000 & \multirow[t]{4}{*}{0.000000} & \\
\hline Total Error & 20 & 3.8873792 & & \\
\hline & & & & Mas R Sq. \\
\hline & & & & 1.0000 \\
\hline
\end{tabular}


This model doesn't lack fit, because of Prob > F. Therefore, it is significant. Table 4-4 shows the significance of main and interaction coefficients.

Table 4-4 Sorted Parameter Estimates

\begin{tabular}{|c|c|c|c|c|c|c|c|c|c|}
\hline Term & Estimate & Std Error & t Ratio & & & & & & Prob $>|t|$ \\
\hline Diameter Ratio(0.1.0.9) & 2.3088235 & 0.075609 & 30.54 & & & & & & $<.0001^{*}$ \\
\hline Diameter Ratio*DiameterRatio & \begin{tabular}{|l|}
2.5029461 \\
\end{tabular} & 0.28573 & 8.76 & & & & & $\vdots$ & $\leq .0001^{*}$ \\
\hline Diameter Ratio*ConvergentAngle & -0.559375 & 0.077936 & -7.18 & & & & & 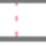 & $001^{*}$ \\
\hline Convergent Angle(15.30) & -0.5 & 0.075609 & -7.04 & & & & & 7 & $001^{*}$ \\
\hline InletDiameter(10.250) & -0.45 & 0.075609 & -6.07 & & & & 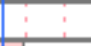 & 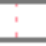 & $001^{*}$ \\
\hline ThroatLength(0.5.3) & 0.42 & 5609 & 5.64 & 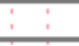 & & & 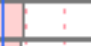 & i & $001^{*}$ \\
\hline Entrance Length(0.2) & \begin{tabular}{|l|}
0.3911765 \\
\end{tabular} & 0.075609 & 5.17 & & & & 7 & $?$ & $<.0001^{*}$ \\
\hline Diameter Rat & 0.3 & 936 & 4.93 & & & & & $\vdots$ & $001^{*}$ \\
\hline eter & -0.2 & 936 & -3.65 & & & & , & '? & $016^{*}$ \\
\hline InletDiamete & -0.2 & 936 & -2.77 & & & & & i & $119^{*}$ \\
\hline Convergent & 0.1 & 36 & 2.13 & & & & 7 & 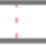 & $62^{*}$ \\
\hline Divergent $\mathrm{A}$ & -0.1 & 609 & -1.94 & & & & $\vdots$ & $\vdots$ & 660 \\
\hline heter R & & 36 & 1.40 & - & & & 7 & 7 & 58 \\
\hline *Entran & 0.0 & 0.0 & 1.24 & & & & 7 & I & 282 \\
\hline & & & 0.92 & & & & 7 & 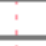 & \\
\hline Inle & 0.25 & 573 & 0.89 & & & & i & $\vdots$ & 865 \\
\hline Entrance & -0.1 & & -0.69 & & & & 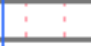 & $\div$ & 983 \\
\hline qule & & 0.0 & 0.44 & & & & & 7 & 39 \\
\hline & -0.0 & & -0.36 & & & & 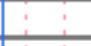 & 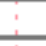 & 20 \\
\hline Thi & & 0.0 & 0.36 & & & & 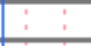 & $\vdots$ & 220 \\
\hline & -0.0 & & -0.34 & & & & - & $\therefore$ & 76 \\
\hline $\mathrm{Co}$ & & 0.0 & 0.28 & & & & 7 & $\vdots$ & 318 \\
\hline roatLer & -0.0 & 936 & -0.28 & & & & & $\rightarrow$ & 818 \\
\hline & 0.05 & & 0.19 & & & & & 4 & 549 \\
\hline ngth & 0.0 & 0.0 & 0.12 & & & & & 7 & 055 \\
\hline Inlet I & -0.0 & 0.077936 & -0.12 & & & & - & $\vdots$ & 055 \\
\hline Convergent Anqle ${ }^{\star}$ Convergent Ang & 0.0029461 & 0.28573 & 0.01 & 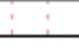 & & & 5 & $\rightarrow$ & 0.9919 \\
\hline
\end{tabular}

Note: * means significant factors

Parameter estimates are sorted by the P-value. The significant main effects include the diameter ratio, convergent angle, inlet diameter, throat length, entrance length, and the interactions of the diameter ratio and diameter ratio, diameter ratio and convergent angle, diameter ratio and entrance length and diameter ratio and divergent angle. All of these effects were found significant with a $99.99 \%$ confidence level, as indicated by $\mathrm{P}<$ 0.0001. P values of inlet diameter and diameter ratio interaction and convergent angle and divergent angle interaction have a P-value less than 0.05. Therefore, they are significant with a 95\% confidence level. All the parameters and interactions above have strong effects on the critical velocity for cavitation. 
The prediction profiler for all the parameters is shown in Figure 4-2. We can see that the diameter ratio is the most significant factor to the model. That means diameter ratio has the biggest effect on the critical velocity for cavitation and venturi design.

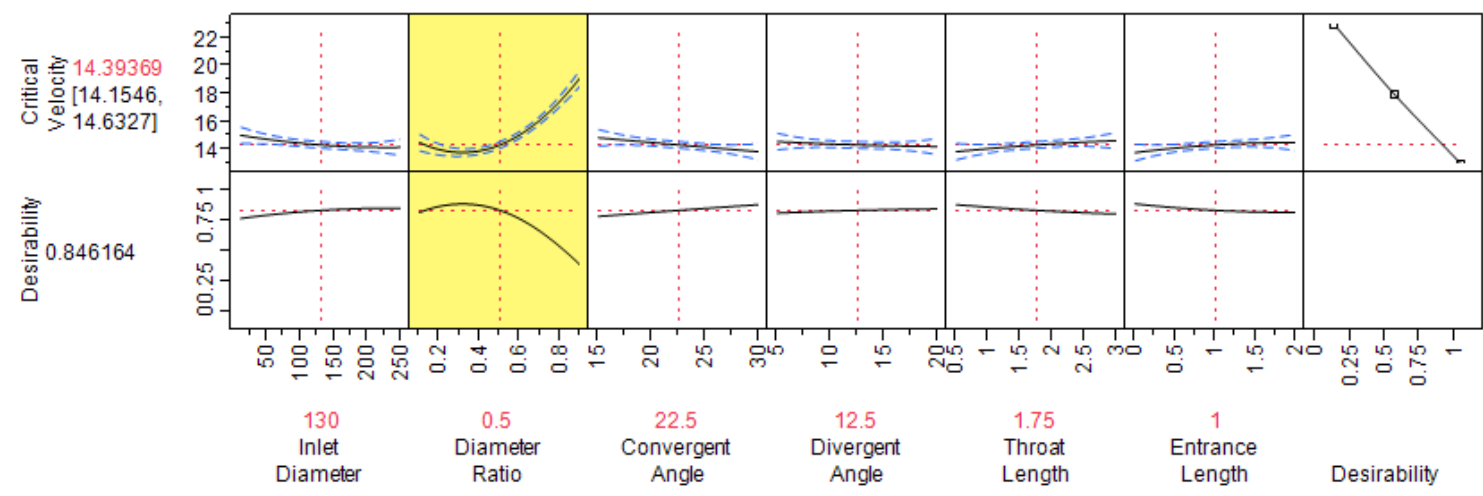

Figure 4-2 Prediction Profiler for Parameters

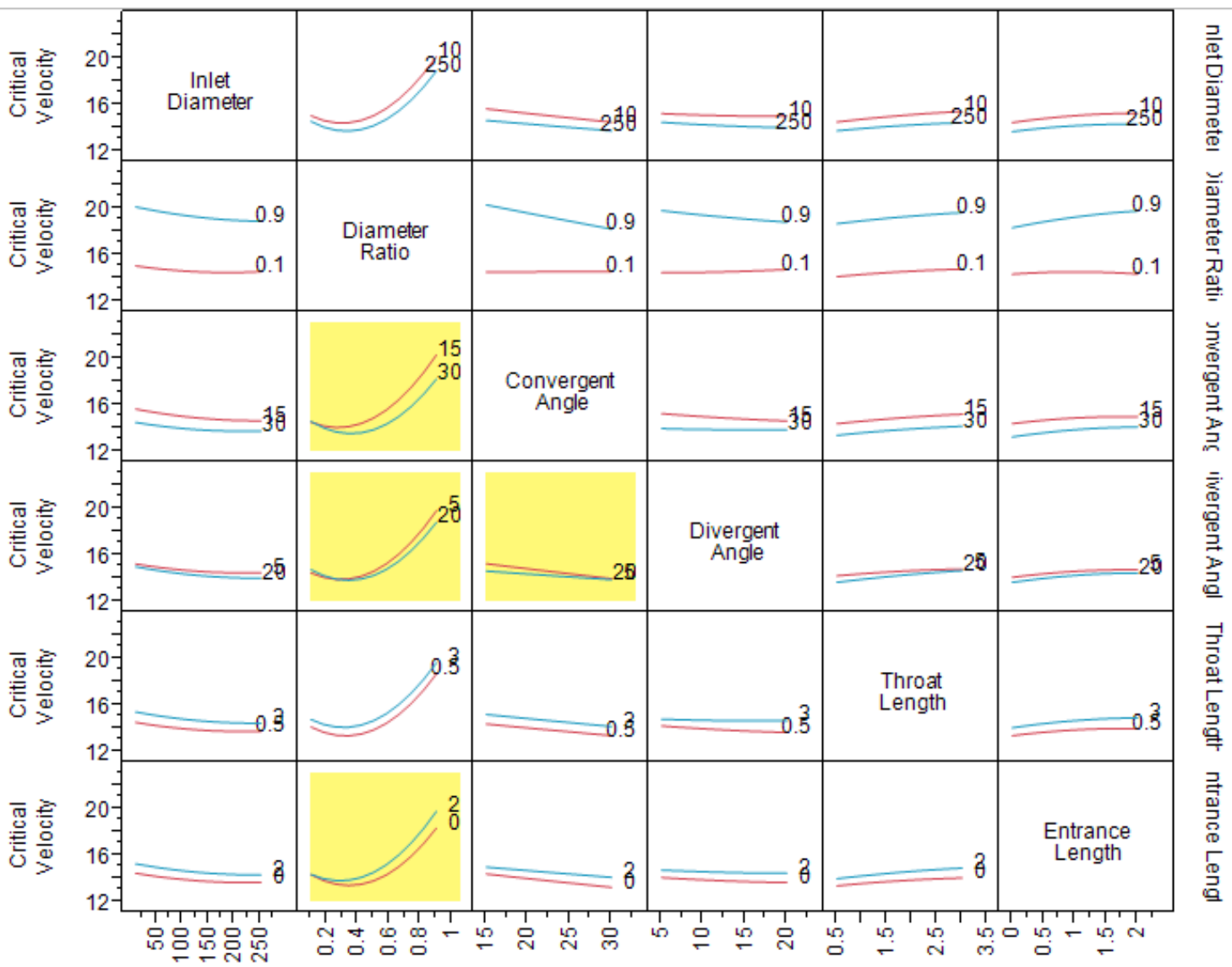

Figure 4-3 Interaction Profiles 
Figure 4-3 shows that the interactions of six key parameters are significant. These include diameter ratio and convergent angle interaction, diameter ratio and divergent angle interaction, diameter ratio and entrance length interaction, and convergent angle and divergent angle interaction. Their significance indicates that they affect the cavitation more than the other interactions.

After removing insignificant parameters, a new model was created with the nine main effects and interactions that were found to be significant from the previous model. The actual by predicted plot is shown in Figure 4-4. The new $\mathrm{R}^{2}$ value found was 0.969, which indicates that the new model is also a reliable model.

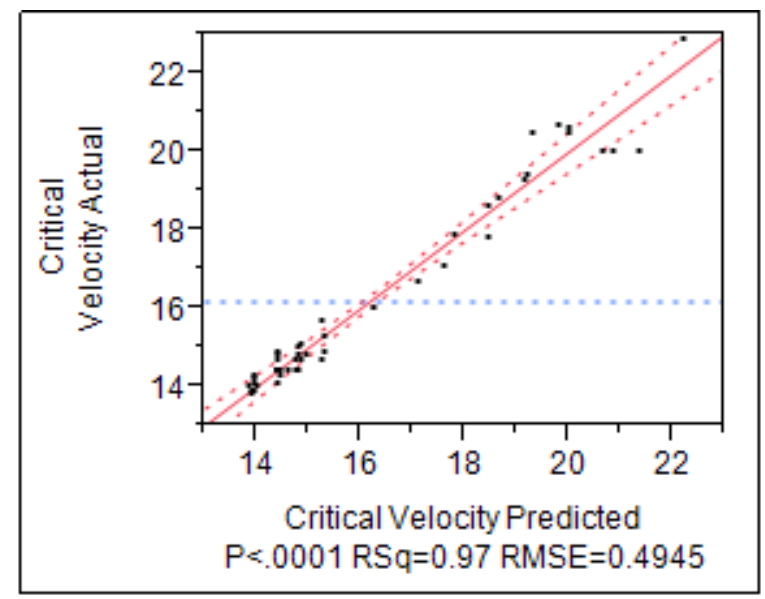

Figure 4-4 Actual by Predicted Plot

The lack of fit is shown in Table 4-5. P-values of the parameters and interactions are all less than 0.05 . There is no lack of fit. Thus, this model can describe the effects of dimensions of the venturi design on the critical velocity adequately.

Table 4-5 Lack of Fit

\begin{tabular}{|c|c|c|c|c|}
\hline Source & $\begin{array}{c}\text { Degree of } \\
\text { Freedom }\end{array}$ & $\begin{array}{c}\text { Sum of } \\
\text { Squares }\end{array}$ & $\begin{array}{c}\text { Mean } \\
\text { Square }\end{array}$ & F Ratio \\
\hline Lack of Fit & 33 & 9.0435 & 0.2741 & 5.5177 \\
\hline Pure Error & 5 & 0.2483 & 0.0497 & Prob > F \\
\hline Total Error & 38 & 9.2919 & & $0.0323 *$ \\
\hline \multicolumn{4}{|r}{} & Mas R Sq. \\
\cline { 2 - 3 } & \multicolumn{2}{|l}{} & 0.9992 \\
\hline
\end{tabular}


The leverage plots of critical velocity and each effect are shown in

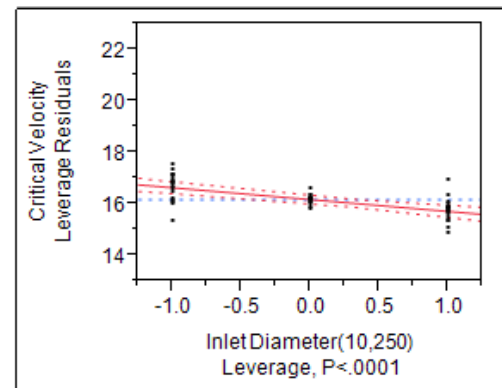

(1)

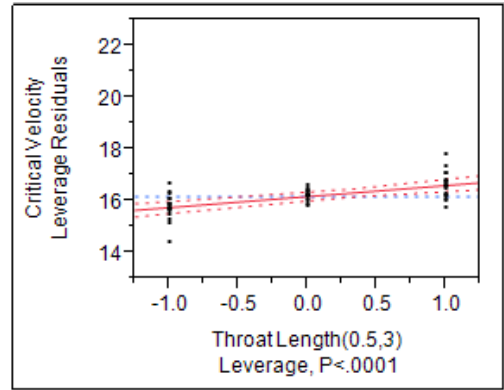

(4)

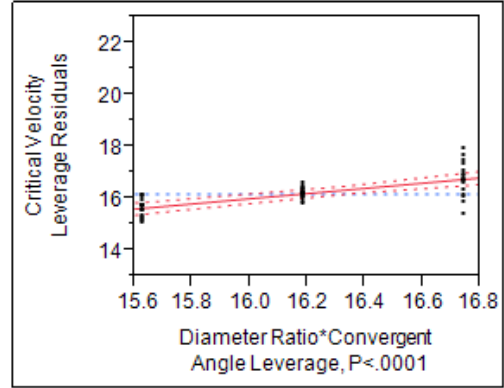

(7)

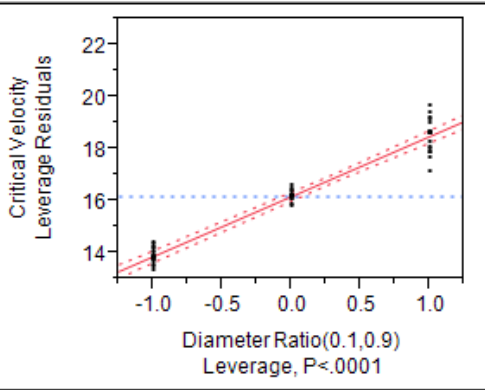

(2)

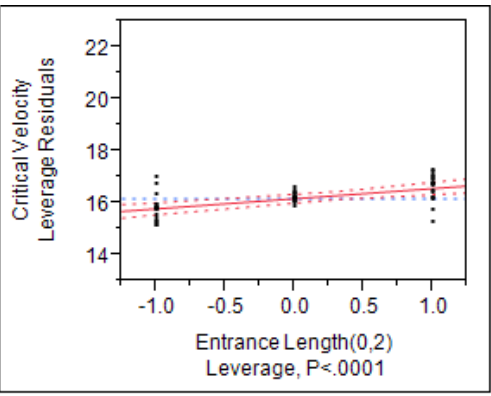

(5)

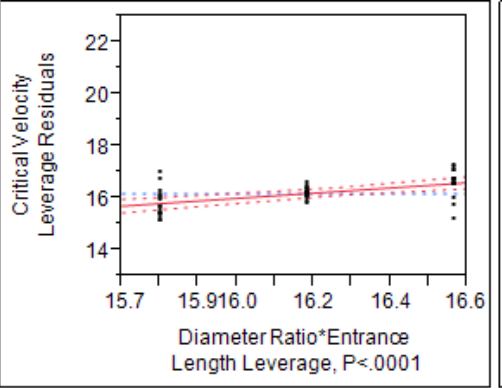

(8)

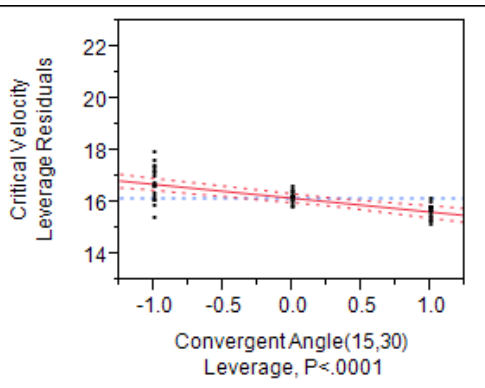

(3)

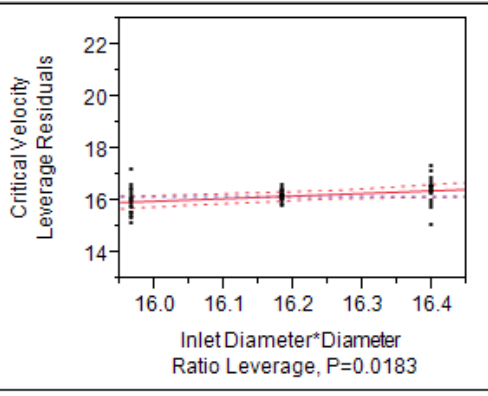

(6)

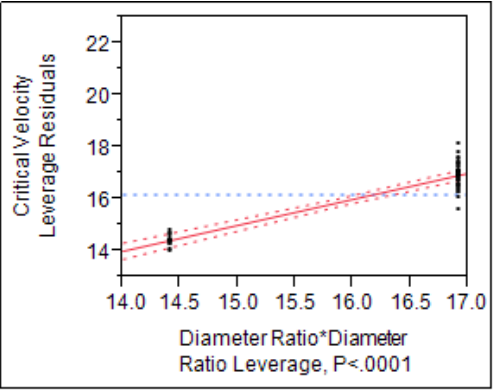

(9)

Figure 4-5 Leverage Plots of (1) Critical Velocity vs. Inlet Diameter; (2) Critical Velocity vs. Diameter Ratio; (3) Critical Velocity vs. Convergent Angle; (4) Critical Velocity vs.

Throat Length; (5) Critical Velocity vs. Entrance Length; (6) Critical Velocity vs. Inlet Diameter*Diameter Ratio; (7) Critical Velocity vs. Diameter Ratio*Convergent Angle; (8) Critical Velocity vs. Diameter Ratio*Entrance Length; (9) Critical Velocity vs. Diameter Ratio*Diameter Ratio;

All the nine factors above are significant. The greater the slope is on the plot, the more sensitive the factor is. The prediction can be expressed as: 
Critical Velocity (m)

$$
\begin{aligned}
& =14.4-0.4588235294118 \times \frac{\text { Inlet Diameter }-130}{120} \\
& +2.30882352941176 \times \frac{\text { Diameter Ratio }-0.5}{0.4} \\
& -0.5323529411765 \times \frac{\text { Convergent Angle }-22.5}{7.5} \\
& +0.42647058823529 \times \frac{\text { Throat Length }-1.75}{1.25} \\
& +0.39117647058824 \times(\text { Entrance Length }-1) \\
& -0.215625 \times \frac{\text { Inlet Diameter }-130}{120} \\
& \times \frac{\text { Diameter Ratio }-0.5}{0.4}-0.559375 \\
& \times \frac{\text { Diameter Ratio }-0.5}{0.4} \times \frac{\text { Convergent Angle }-22.5}{7.5} \\
& +0.384375 \times \frac{\text { Diameter Ratio }-0.5}{0.4} \\
& \times(\text { Entrance Length }-1)+2.51470588235294 \\
& \times \frac{\text { Diameter Ratio }-0.5}{0.4} \times \frac{\text { Diameter Ratio }-0.5}{0.4}
\end{aligned}
$$

From the JMP results, the minimum critical velocity was found to be $12.39 \mathrm{~m} / \mathrm{s}$ when the inlet diameter is $215.92 \mathrm{~mm}$, the diameter ratio is 0.42 , the convergent angle is 30 , the divergent angle is 14.14, and the throat length and entrance length are 0.5 and 0 , respectively.

\subsection{Surface Response}

Previous analysis of this system showed that the diameter ratio and inlet diameter interaction, diameter ratio and convergent angle interaction, diameter ratio and divergent angle interaction, and diameter ratio and entrance length interaction, and convergent angle and divergent angle interaction are important for venturi tube design. The surface 
response contour can simulate a wider range based on the experimental data, and the results are shown below.

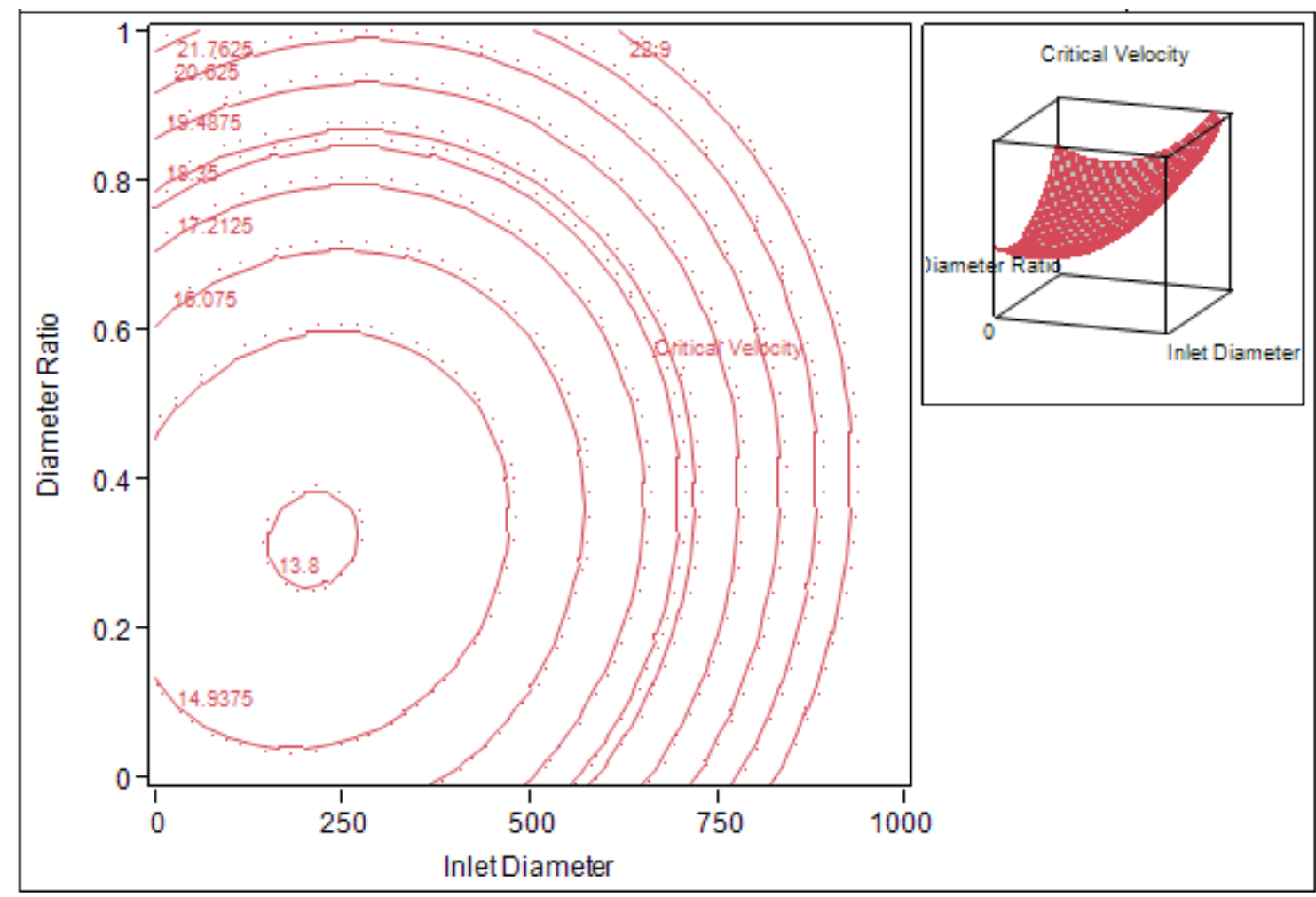

Figure 4-6 Interaction of Diameter Ratio and Inlet Diameter

Figure 4-6 illustrates the interaction between the diameter ratio and inlet diameter, where the diameter ratio is from 0 to 1 , and the inlet diameter is from 0 to $1000 \mathrm{~mm}$. The minimum critical velocity is found when the diameter ratio is approximately 0.35 and the inlet diameter is approximately $220 \mathrm{~mm}$. Increasing or decreasing the diameter ratio or inlet diameter can increase the critical cavitation velocity. 


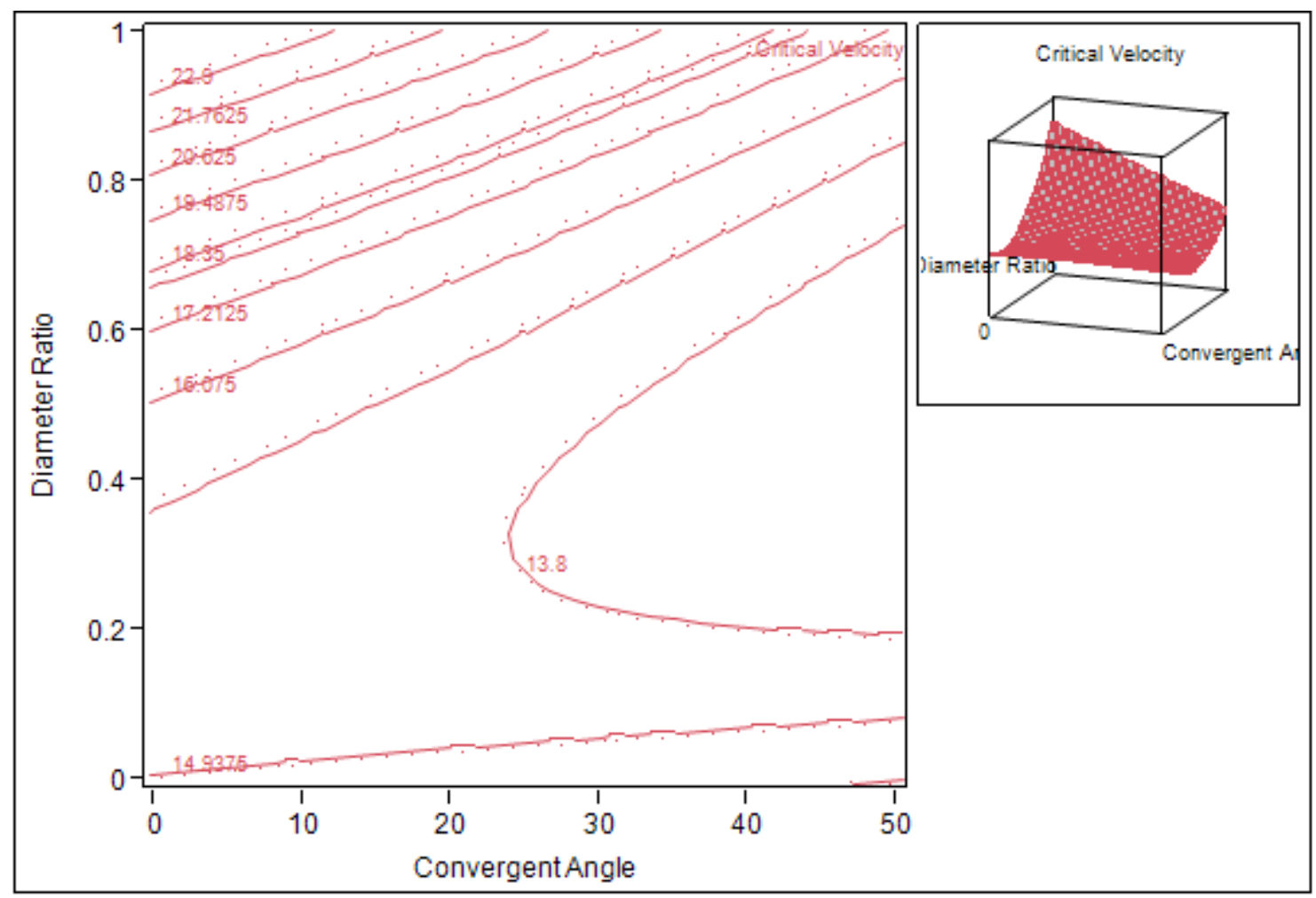

Figure 4-7 Interaction of Diameter Ratio and Convergent Angle

The diameter ratio and convergent angle interaction is shown in Figure. 4-7. It depicts that the required velocity for cavitation decreases as the convergent angle increases and the diameter ratio decreases, when diameter ratio is less than 0.25 . However, diameter ratio has opposite affection when it is higher than 0.25 . 


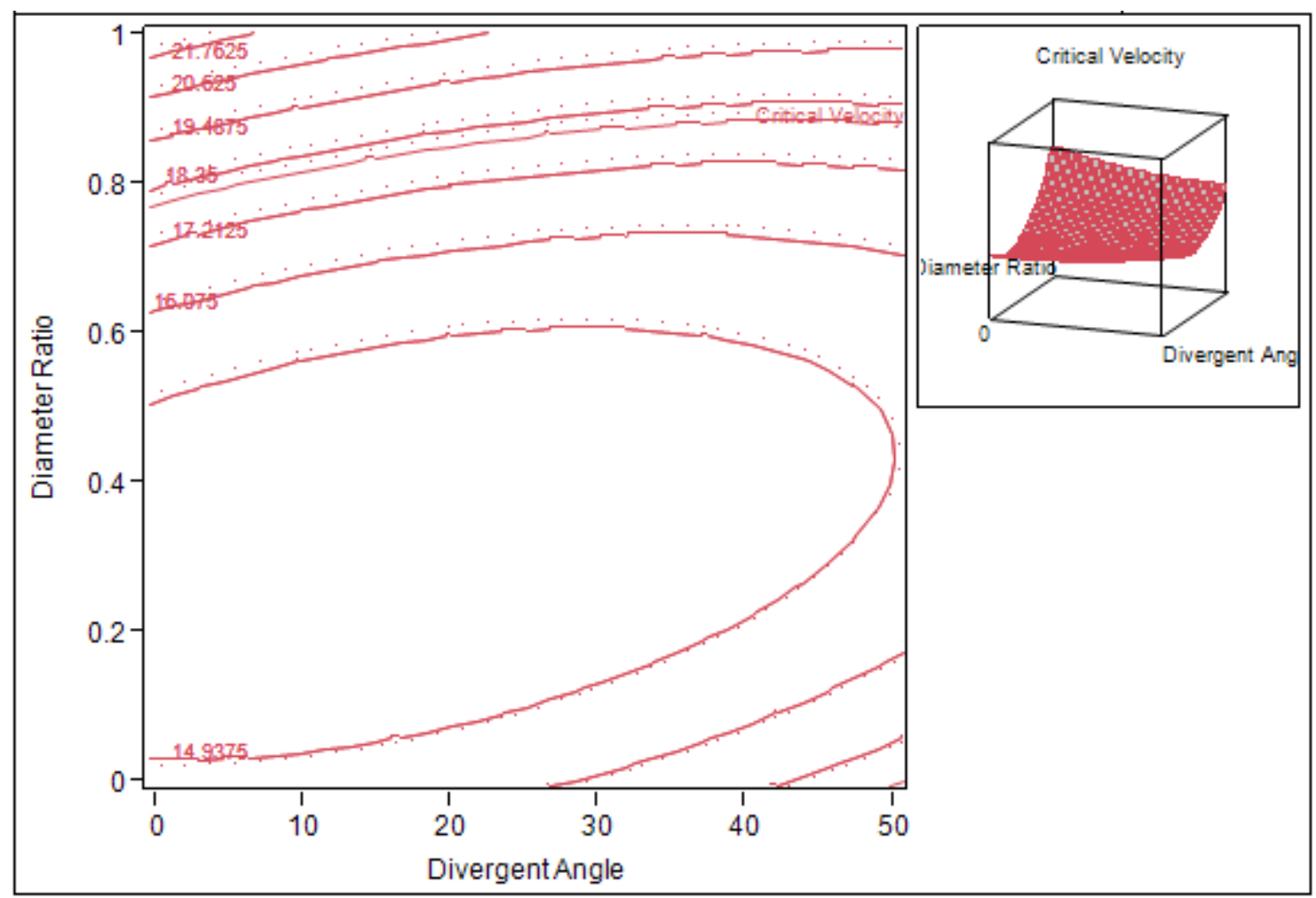

Figure 4-8 Interaction of Diameter Ratio and Divergent Angle

Figure 4-8 shows the interaction of the diameter ratio with the divergent angle. The minimum critical velocity is found when the diameter ratio is approximately 0.35 and when the divergent angle is approximately $17^{\circ}$. Either increasing or decreasing the diameter ratio or divergent angle could increase critical velocity. 


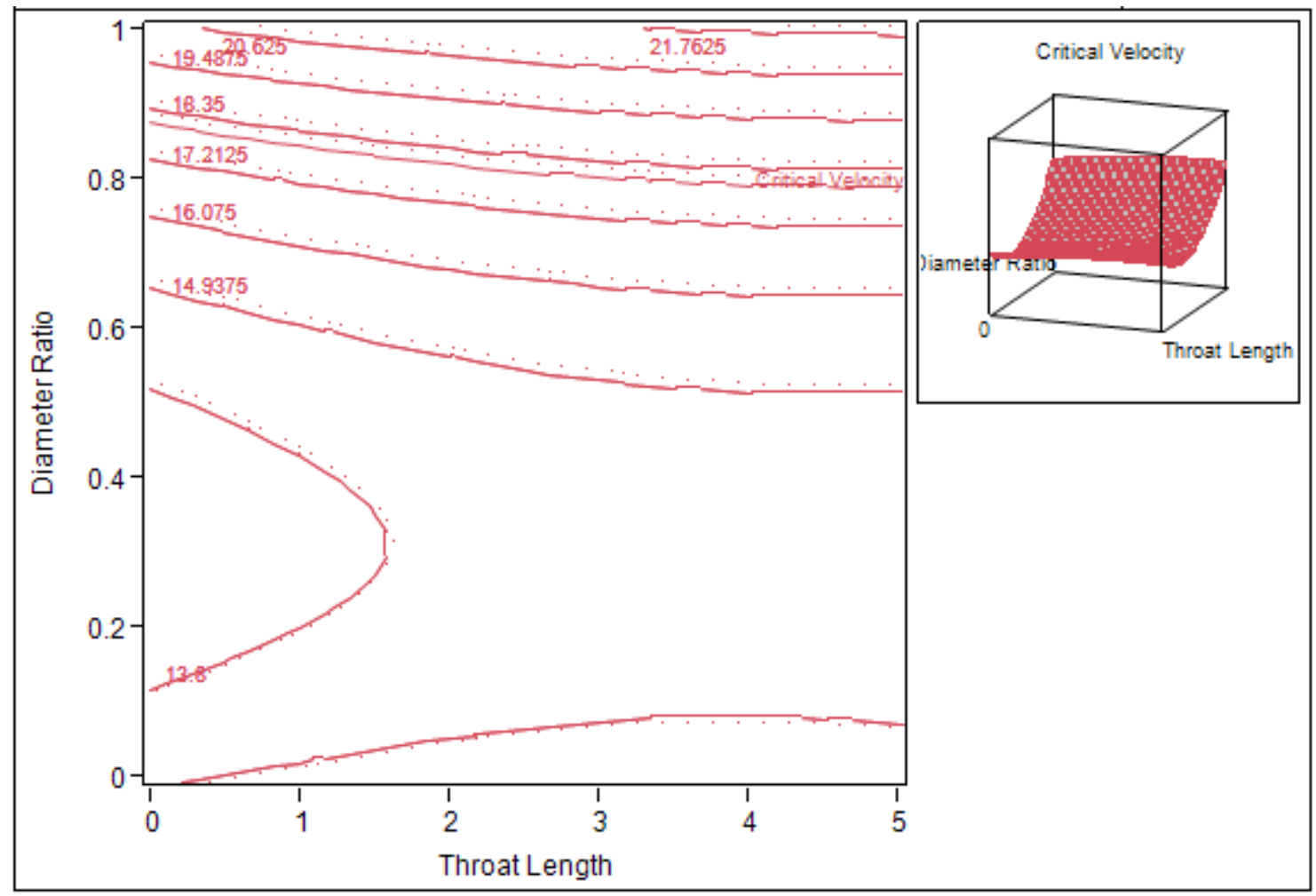

Figure 4-9 Interaction of Diameter Ratio and Throat length

Figure 4-9 shows the contour result of diameter ratio and throat length interaction. Increasing the throat length while the diameter ratio is from 0.15 to 0.35 could reduce the required minimum velocity for cavitation. However, the opposite is true, when the diameter ratio is higher than 0.35 . 


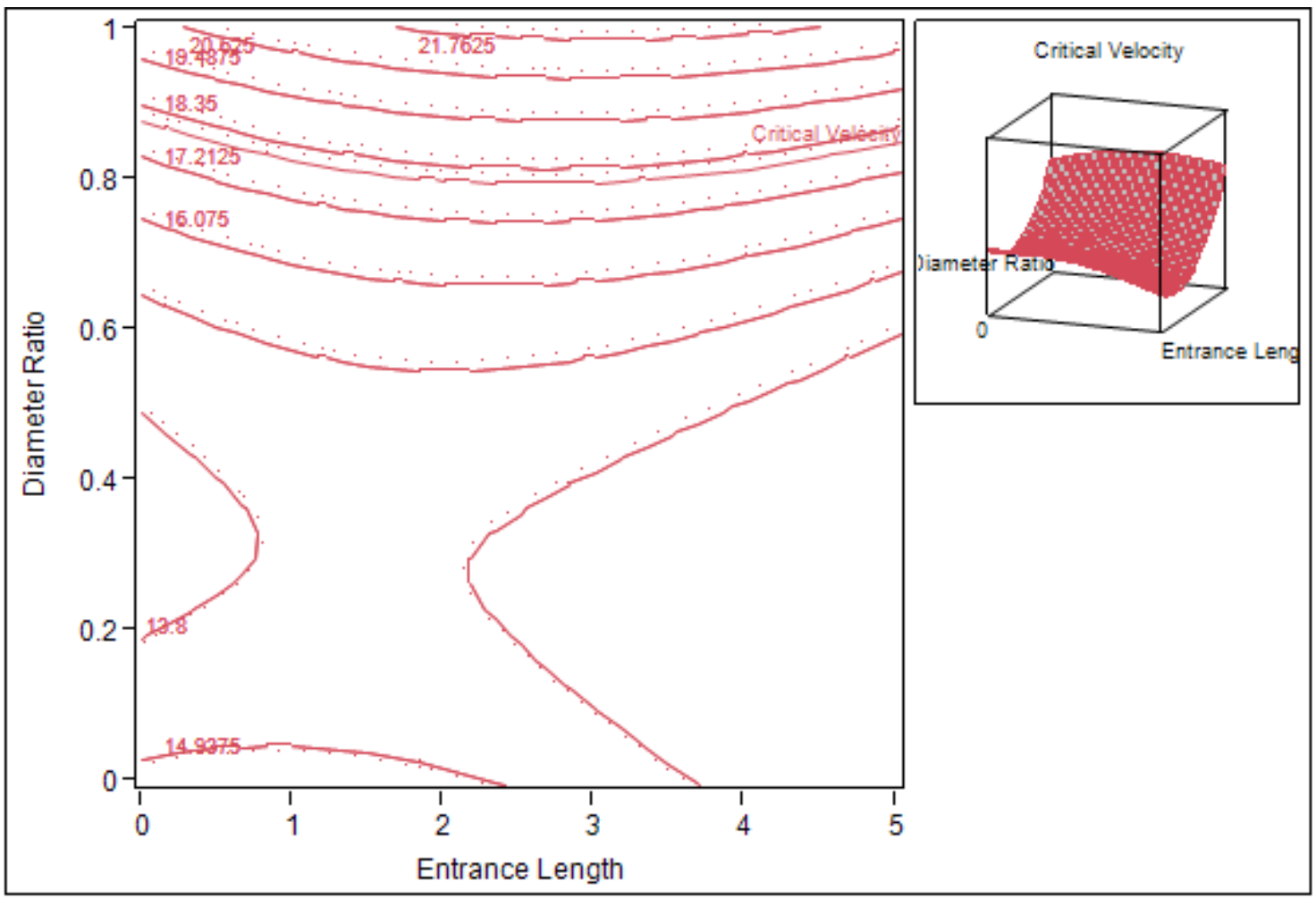

Figure 4-10 Interaction of Diameter Ratio and Entrance Length

The diameter ratio and entrance length interaction is shown in Figure 4-10. It shows that the critical velocity increases as the entrance length increases, from 0 to $2 \mathrm{~d}$, while the diameter ratio is 0.2 to 0.55 . The opposite is true, when the diameter ratio is higher than 0.6 , and/or the entrance length is longer than $2.5 \mathrm{~d}$. 


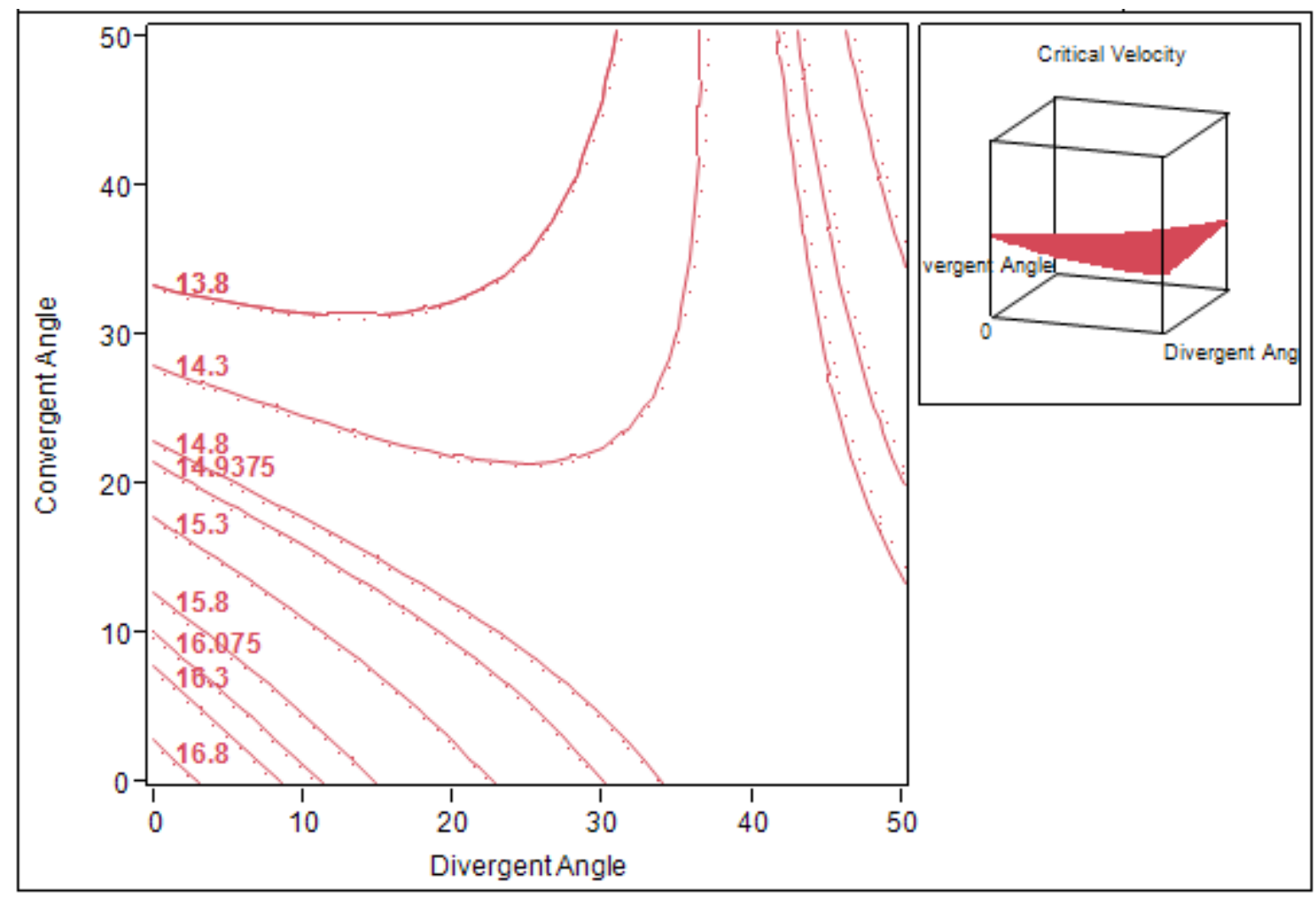

Figure 4-11 Interaction of Convergent Angle and Divergent Angle

Figure 4-11 shows the convergent angle and divergent angle interaction. Generally, the critical velocity decreases as the convergent angle increases and the divergent angle decreases. However, when the divergent angle is bigger than $25^{\circ}$ and the convergent angle is bigger than $25^{\circ}$, variations occur. 


\subsection{Validation with Experimental Data}

Xiong and Peng (2015) investigated the optimization of the cavitation venturi tube design, with experimental tests. The venturi tubes were made of plexiglass, and bubble sizes were measured by a Malvern Mastersizer 2000 laser particle size analyzer. Their results show the maximum volume and minimum mean size of the pico and nano bubbles would be achieved when the ratio of the diameter of inlet of the venturi tube and the diameter of throat $(D i n / D t)$ is $3-4$, the inlet angle is $26-27^{\circ}$, the outlet angle is $11-13^{\circ}$, and the ratio of the length of the throat and the diameter of the throat is 2.3-3.

The results of ANSYS Fluent compared with Xiong's experimental data are shown below:

Table 4-6 Validation with Experimental Data

\begin{tabular}{|l|c|c|}
\hline Factors & Xiong and Peng (2015) & This Study \\
\hline Inlet Diameter $(\mathrm{mm})$ & & 215.92 \\
\hline Diameter Ratio & $0.25-0.33$ (Medium) & 0.42 \\
\hline Convergent Angle $\left(^{\circ}\right)$ & $26-27$ (High) & 30 \\
\hline Divergent Angle $\left(^{\circ}\right)$ & $11-13$ (Medium) & 14.1 \\
\hline Throat Length $(\mathrm{d})(\mathrm{mm})$ & $2.3-3$ (High) & 0.5 \\
\hline Entrance Length $(\mathrm{d})(\mathrm{mm})$ & & 0 \\
\hline
\end{tabular}

The table indicates that the ANSYS fluent simulation results are good and are in agreeance with the results of the experimental tests of the diameter ratio, convergent angle and divergent angle design, which are medium, high, and high in Xiong's study.

The results also match the results of K. and Virendra (2016), which found that the optimized divergence angle for venturi type hydrodynamic cavitation reactors is from 11$15^{\circ}$. 


\section{CHAPTER 5 Simulation of Bubble Size}

Bubble size distribution is another important factor for cavitation devices to simulate and design. The CFD cavitation model calculates mass transfer in the multi-phase flow. However, the size of the bubbles generated by secondary phase cavitation is constant. The bubble number density is $1 \times 10^{13}$ for the Schnerr-Sauer cavitation model. The bubble diameter is $1 \times 10^{-6} \mathrm{~m}$ for the Zwart-Geber-Belamri cavitation model. Fluid flow could potentially cause bubble aggregation and breakage, and the size of bubbles change with surrounding pressure. Therefore, cavitation models are not suitable for bubble size simulation.

The Population Balance Model (PBM) calculates the rates of nucleation, growth, dispersion, aggregation, and breakage. The secondary phase bubble diameter is an equation instead of a constant number. It can achieve the purpose of analyzing the bubble size distribution. In this study, the sizes of cavitation bubbles generated by the venturi tube were calculated with a discrete population balance model. However, the PBM model cannot be used with the cavitation model. Therefore, the cavitation function was added with User Defined Functions (UDF). Cavitation bubbles can only generated when the pressure is lower than vapor pressure. The bubble number density model was written as UDF code, and compiled with a discrete population balance model in order to calculate the bubble nucleation rate based on the mixture static pressure. The Luo-model was used for aggregation and breakage kenels, and Ramakrishna formulation was selected. 


\subsubsection{Equation}

The transport equation for the number density function is as follows:

$$
\begin{aligned}
\frac{\partial}{\partial t}[n(V, t)]+ & \nabla \cdot[\vec{u} n(V, t)]+\nabla_{v} \cdot\left[G_{v} n(V, t)\right] \\
& =\frac{1}{2} \int_{0}^{V} a\left(V-V^{\prime}, V^{\prime}\right) n(V \\
& \left.-V^{\prime}, t\right) n\left(V^{\prime}, t\right) d V^{\prime} \\
& -\int_{0}^{\infty} a\left(V, V^{\prime}\right) n(V, t) n\left(V^{\prime}, t\right) d V^{\prime} \\
& +\int_{Q_{v}} p g\left(V^{\prime}\right) \beta\left(V \mid V^{\prime}\right) n\left(V^{\prime}, t\right) d V^{\prime} \\
& -g(V) n(V, t)
\end{aligned}
$$

The boundary and initial conditions are $\mathrm{n}(\mathrm{V}, \mathrm{t})=n_{v} ; n(\mathrm{~V}=0, \mathrm{t}) G_{v}=\dot{n}_{0}$;

Where term $\nabla_{v} \cdot\left[G_{v} n(V, t)\right]$ is the growth rate. It shows the changing rate of the volume

of a single bubble $V$ over time $t . \frac{1}{2} \int_{0}^{V} a\left(V-V^{\prime}, V^{\prime}\right) n\left(V-V^{\prime}, t\right) n\left(V^{\prime}, t\right) d V^{\prime}$ is the birth rate due to aggregation. $a\left(V, V^{\prime}\right)$ is the aggregation kernel, which means the collision frequency between bubbles of volumes $V$ and $V^{\prime}$. The whole term is divided by two, to avoid counting the collisions twice. $\int_{0}^{\infty} a\left(V, V^{\prime}\right) n(V, t) n\left(V^{\prime}, t\right) d V^{\prime}$ is the death rate of bubbles of volume $V$, due to aggregation. The birth rate of bubbles due to breakage is $\int_{Q_{v}} p g\left(V^{\prime}\right) \beta\left(V \mid V^{\prime}\right) n\left(V^{\prime}, t\right) d V^{\prime}$, where $g\left(V^{\prime}\right)$ is breakage frequency per unit time, $\beta\left(V \mid V^{\prime}\right)$ is the probability density function, and $p$ is newly produced bubble numbers. Finally, $g(V) n(V, t)$ is the death rate of bubbles of volume due to breakage. 


\subsubsection{Bubble Number Density}

The key part to calculating the bubble size is to get the bubble number density. Henri et al., (2000) proposed a model of bubble number density calculation using the theory of Laplace and a common non-convex energy for liquid and vapor bulks. The model used was to determine the bubble density. He extended the equilibrium equation of a liquid in presence of vapor bubbles based on the Laplace theory applied to a closed system. The model was simplified, and did not consider the mechanical and thermal characteristics of the fluid flow, such as the number of particles and microscopic gas bubbles.

The bubble number per unit of volume is:

$$
N=\frac{\left(P_{s a t}-P\right)^{4}}{32 \pi \gamma^{3} C_{l}^{2} \rho_{l s}}\left(1+\frac{V_{0}}{V}\right)
$$

Where $P_{\text {sat }}$ is the saturated vapor pressure, $\gamma$ is the constant surface tension at the temperature of the flow, $C_{l}$ is the sound velocity in the liquid, $\rho_{l s}$ is the density of saturation of liquid, and $V_{0}$ is the volume of the fluid part without cavitation.

To simplify this equation, the saturated pressure, $P_{\text {sat }}$ is $2505.15 \mathrm{~Pa}$ at room temperature $\left(70^{\circ} \mathrm{F}\right)$, the surface tension $\gamma$ for water is $0.0727 \mathrm{~N} / \mathrm{m}$, the speed of sound in water $C_{l}$ is $1482 \mathrm{~m} / \mathrm{s}$, and the density of water-liquid is $997.925 \mathrm{~kg} / \mathrm{m}^{3}$. Thus, equation 3.5 becomes,

$$
N=\frac{(2505.15-P)^{4}}{84,663,729.11}\left(1+\frac{V_{0}}{V}\right)
$$

The surface tension $\gamma$ is affected by pressure; the equation of surface tension with temperature is given as: 


$$
\gamma=235.8\left(1-\frac{T}{T_{C}}\right)^{1.256}\left[1-0.625\left(1-\frac{T}{T_{C}}\right)\right]
$$

Where $T$ and critical temperature $T_{C}$ are both in Kelvin; $T_{C}=647.098 \mathrm{~K}$.

Additionally, when temperature is between $1^{\circ}$ to $100^{\circ} \mathrm{C}$, the relationship between temperature and pressure:

$$
T=\frac{1730.63}{8.07131-\log _{10} P}-233.426
$$

Where the temperature is in Celsius, and pressure is in mmHg. Equation 3.13 can then be written as:

$$
T=\frac{1730.63}{8.07131-\log _{10}(P \times 0.0075)}+39.724
$$

The surface tension can be written as:

$\gamma$

$$
\begin{aligned}
& =235.8\left(1-\frac{\left(\frac{1730.63}{8.07131-\log _{10}(P \times 0.0075)}+39.724\right)}{647.098}\right)^{1.256}[1 \\
& \left.-0.625\left(1-\frac{\left(\frac{1730.63}{8.07131-\log _{10}(P \times 0.0075)}+39.724\right)}{647.098}\right)\right]
\end{aligned}
$$

The bubble number density can be calculated by substituting equation 5.7 with 5.2.

However, there are some assumptions in the simulation work. For the experimental work, surfactants were used in the solution. This could affect the energy required for bubble generation. In this study, liquid water at room temperature was used to focus on the 
cavitation function with bubble sizes. Additionally, the venturi was placed in series with the packed tube to generate bubbles before entering the venturi tube. The air bubbles from packed tube and particle surface were not considered in the cavitation-generated bubble size analysis. Furthermore, flotation is a three-phase interaction. It is important to understand the solid phase effects on hydrodynamic cavitation and bubble size distribution. Therefore, the functions of particle size and the relationship between particle size and bubble size was investigated in this study. However, only one particle was simulated in the geometries, in order to reduce the meshing numbers and calculation time.

\subsection{Bubble Size}

Fan et al., (2010) measured the size distribution of nano bubbles generated by venturi tube with varying surfactant concentrations: The peaks were from 0.3 to $0.8 \mu \mathrm{m}$. The size of bubbles generated by only venturi was analyzed by Peng and Xiong (2015). The results show that the distribution is bimodal, as shown in Figure 2-4. The two distinct peaks were 0.08 and $0.7 \mu \mathrm{m}$.

To calculate cavitation-generated bubble sizes, the dimension of ICEM mesh was generated using the lab designed venturi tube from Peng and Xiong (2015)'s study. The total length is $0.0808 \mathrm{~m}$ with a 0.267 diameter ratio (d/D). Since it is an asymmetric rotation model, a quarter of the geometry was used to reduce the mesh number and calculation time. Gravity can be ignored, since it is a pressure-based solver with a high velocity. Capillary phenomenon in physical chemistry shows that the smaller the bubble

size, the more additional pressure is required. From the equation $\Delta P=\frac{2 \sigma}{R}$ we can see, given a constant surface tension, in order to generate smaller bubbles, a higher pressure difference is needed to push the surrounding fluid. Therefore, the population balance model calculates larger bubble sizes first. Smaller bubbles can be generated with more energy in the system. 


\subsection{Solid Particle Effects}

To analyze the effects of solids in cavitation, and the interactions with particle size distribution, particle geometry is necessary in the model. The geometry of Peng and Xiong's experimental venturi was used in this study. The weighted average particle sizes of $186 \mu \mathrm{m}$ for coal and $270 \mu \mathrm{m}$ for phosphate were used in their experiments. A $200 \mu \mathrm{m}$ diameter ball was added to the venturi grid to simulate the solid particles in the system. To understand the effects of particle size on bubble size, the same venturi grid with a larger, $400 \mu \mathrm{m}$ diameter ball was created. Hexahedral meshing was used for most of the venturi, while quadrilateral meshing and fine size were used around the spherical shapes.

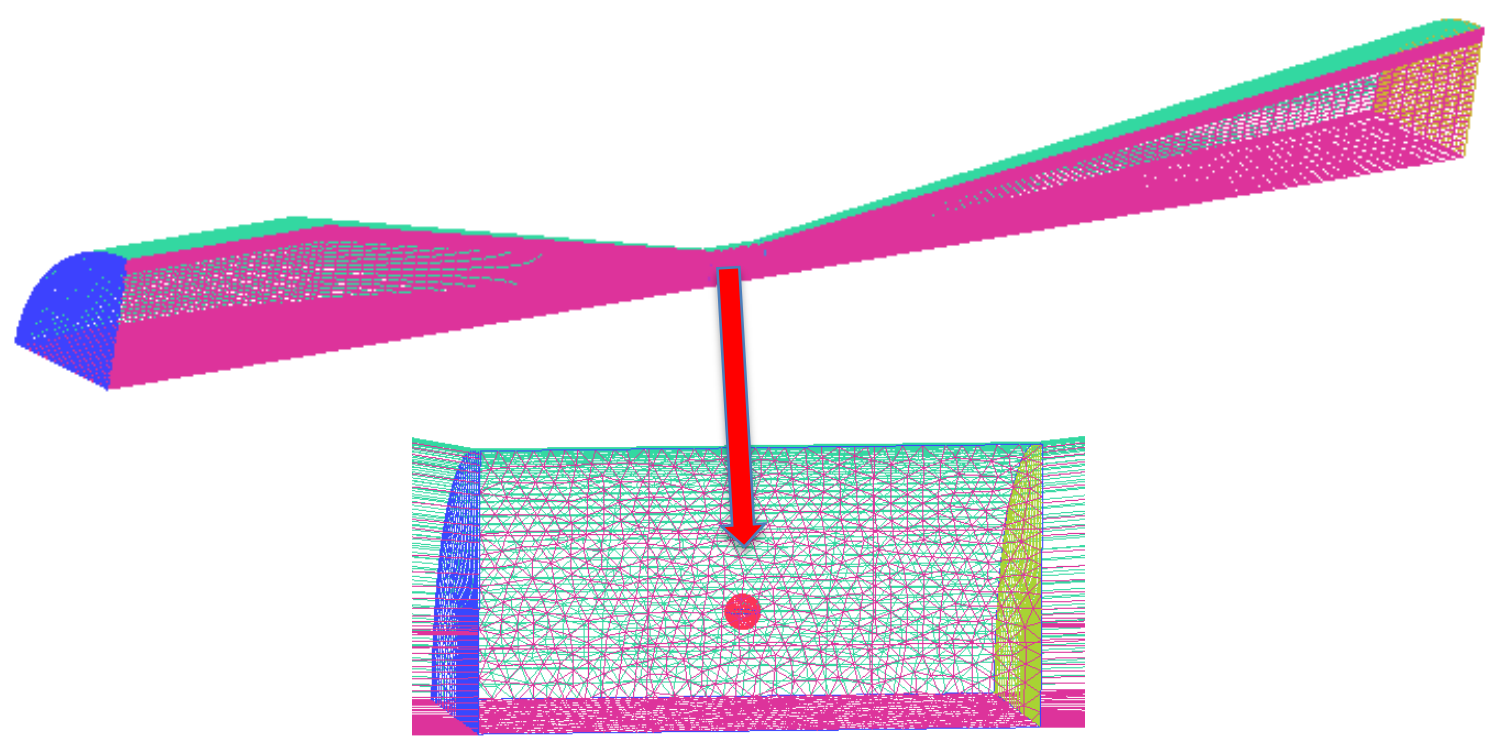

Figure 5-1 Grid of Venturi with Particle $(\mathrm{D}=200 \mu \mathrm{m})$ 


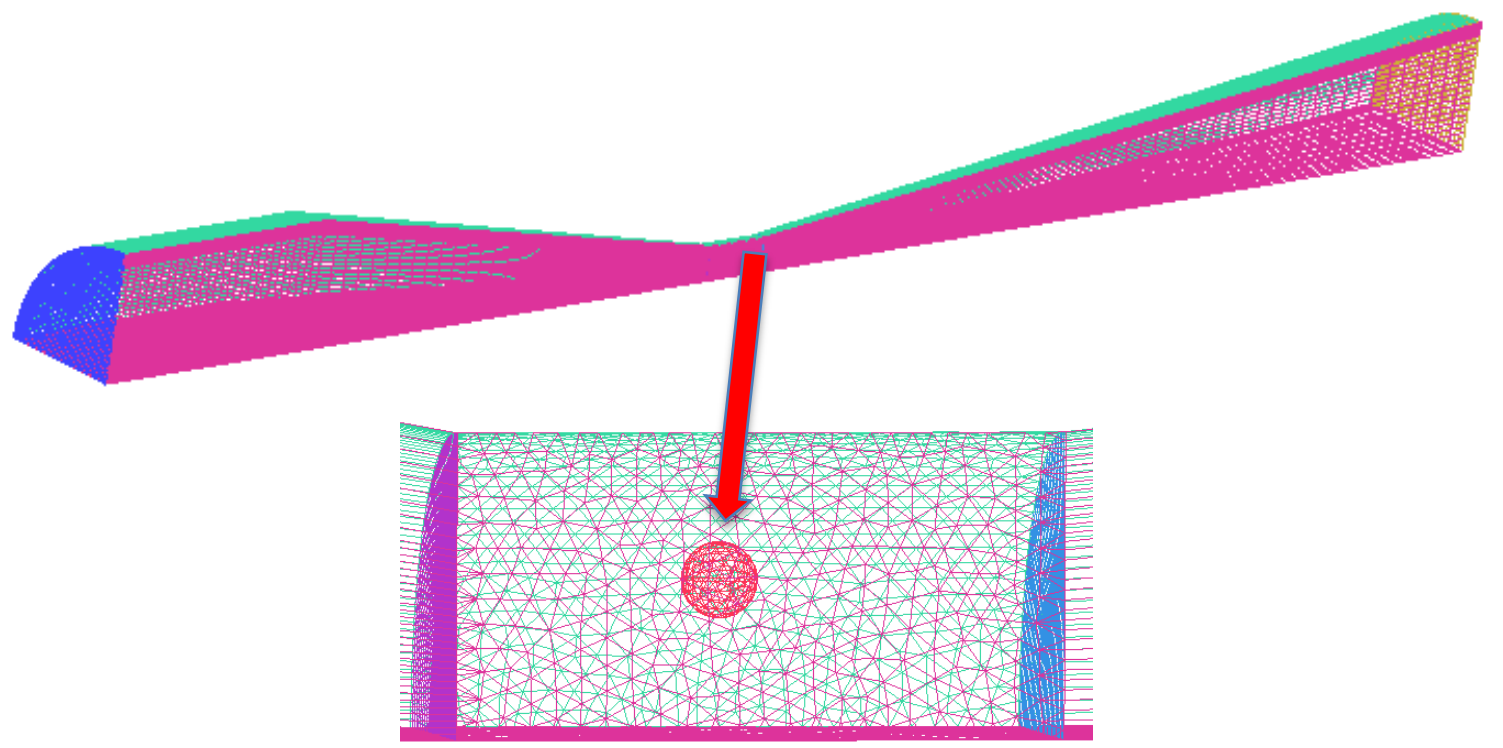

Figure 5-2 Grid of Venturi with Particle $(D=400 \mu \mathrm{m})$

The critical velocity for this venturi tube without particles was $14.1 \mathrm{~m} / \mathrm{s}(1.0027 \mathrm{~m} / \mathrm{s}$ at inlet). It dropped to $10.1 \mathrm{~m} / \mathrm{s}(0.7182 \mathrm{~m} / \mathrm{s}$ at inlet $)$ with the presence of a $200 \mu \mathrm{m}$ diameter particle, and $9.9 \mathrm{~m} / \mathrm{s}(0.7040 \mathrm{~m} / \mathrm{s}$ at inlet $)$ with a $400 \mu \mathrm{m}$ diameter particle.

Bubble size can be calculated using the bubble number density model from Chapter 3 without considering collapse, aggregation, dispersion, or breakage. The pressure and vapor volume without cavitation is obtained from ANSYS. Using equation 3.8, the mathematical result of the bubble number density can be calculated. The bubble diameter then can be found using equation 5.1.

$$
D=2 \times \sqrt[3]{\frac{3 \alpha}{4 N \pi}}
$$

The histogram of bubble diameters of three geometries from calculation is shown in Figure 5.3. When the throat velocity is $20 \mathrm{~m} / \mathrm{s}$ (inlet velocity: $1.42 \mathrm{~m} / \mathrm{s}$ ), the smallest bubble is $6.35 \times 10^{-11} \mathrm{~m}$. More bubbles can be generated using venturi with particle geometries. 


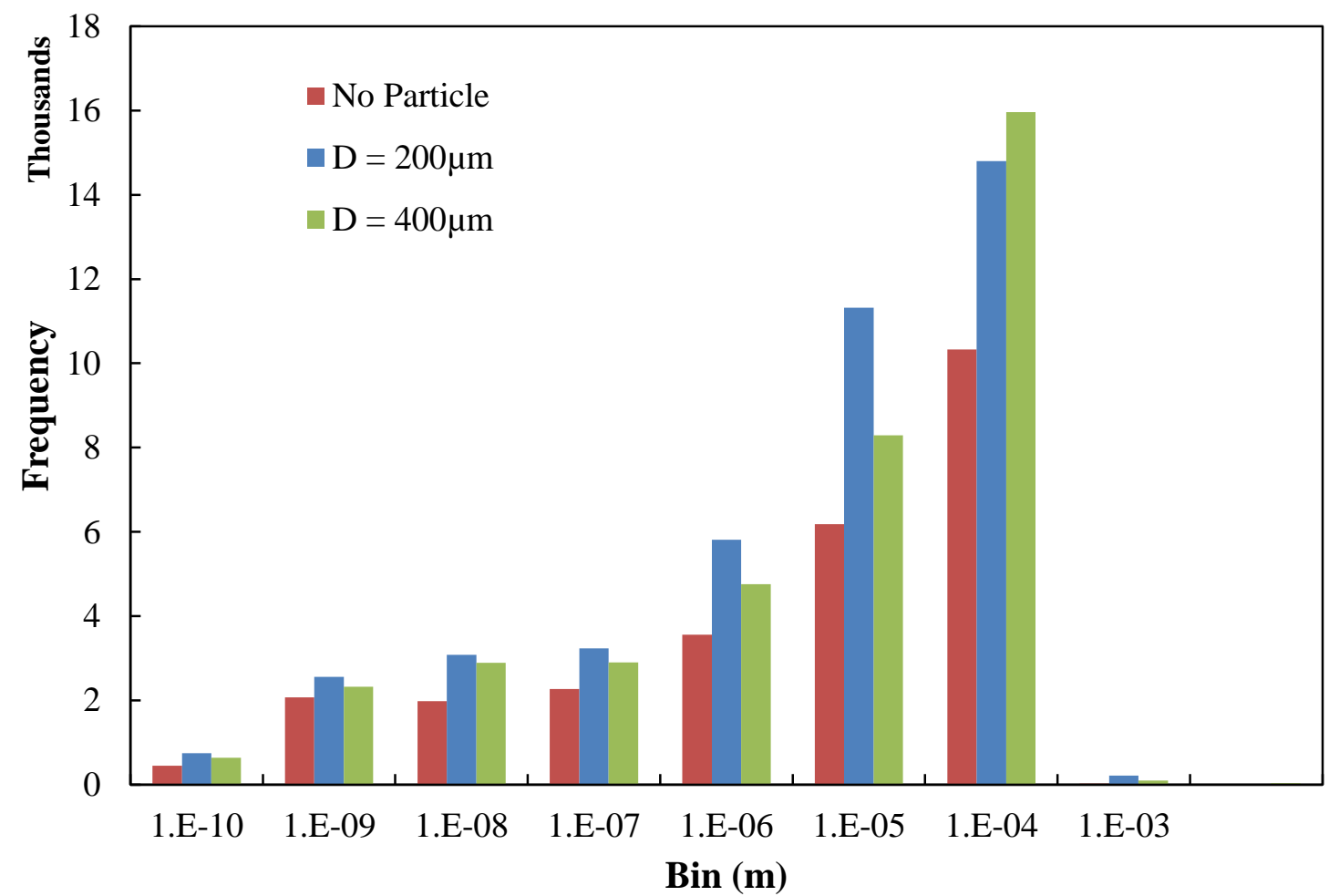

Figure 5-3 Histogram of Bubble Size with Three Geometries

This is only mathematical calculation using the bubble number density model. The pressure changes with each time step. The pressure affects the bubble generation and bubble size. Once a bubble is created, it affects the surrounding pressure. Additionally, the growth rate, dispersion, aggregation, and breakage cannot be neglected for bubble size calculation. PBM model with transient flow can yield more accurate results.

Using the experimental venturi geometry, the static pressure distribution was calculated with different throat velocities and different particle presence conditions. The static pressure distribution along the venturi tube without particles, with a $200 \mu \mathrm{m}$ diameter particle, and with a $400 \mu \mathrm{m}$ diameter particle is shown in Figure 5-4, Figure 5-5, Figure 5-6, respectively. As the throat velocity increases, the static pressure at the inlet increases, and the pressure at throat decreases. This is true for all three conditions. 


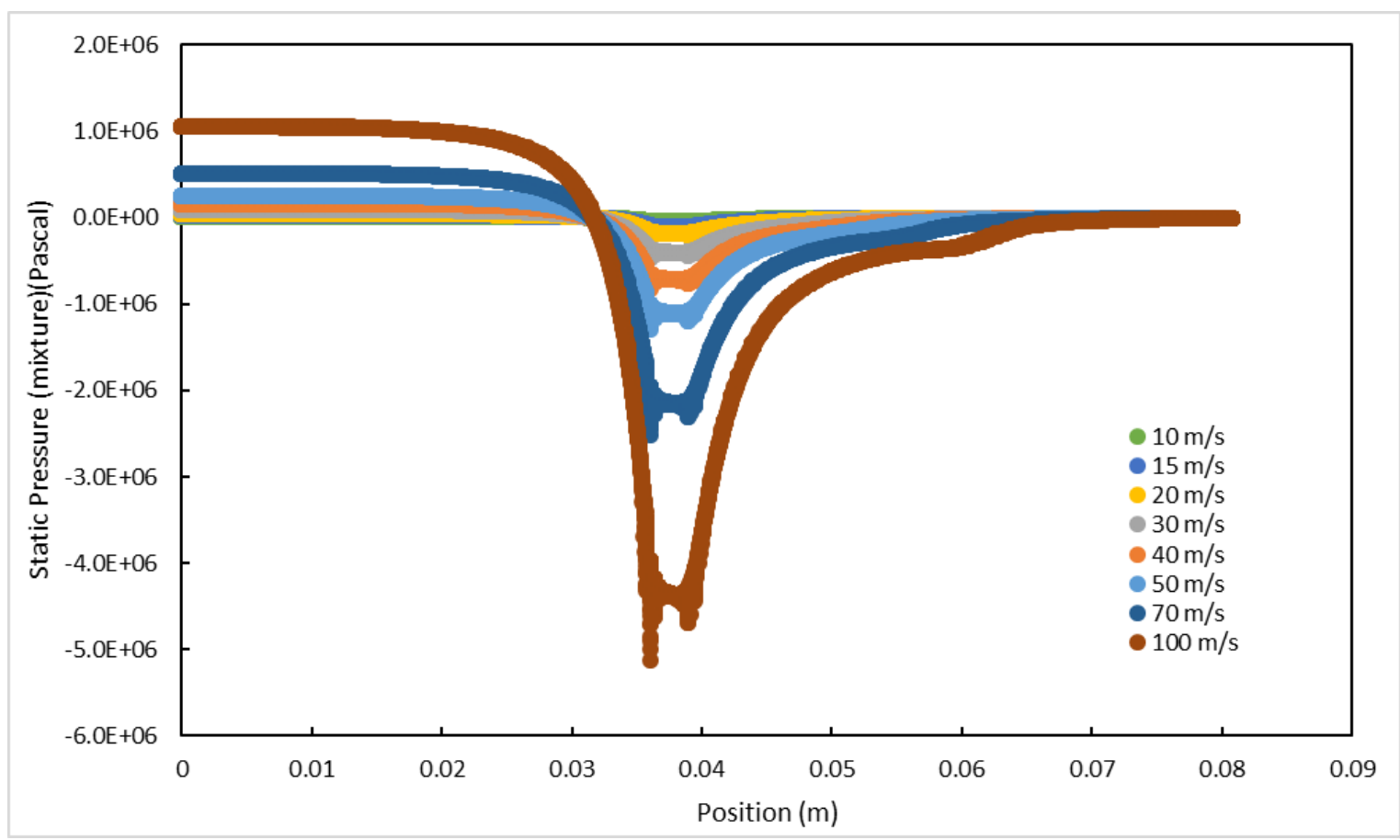

Figure 5-4 Pressure Distribution along the Venturi Tube - Without Particle

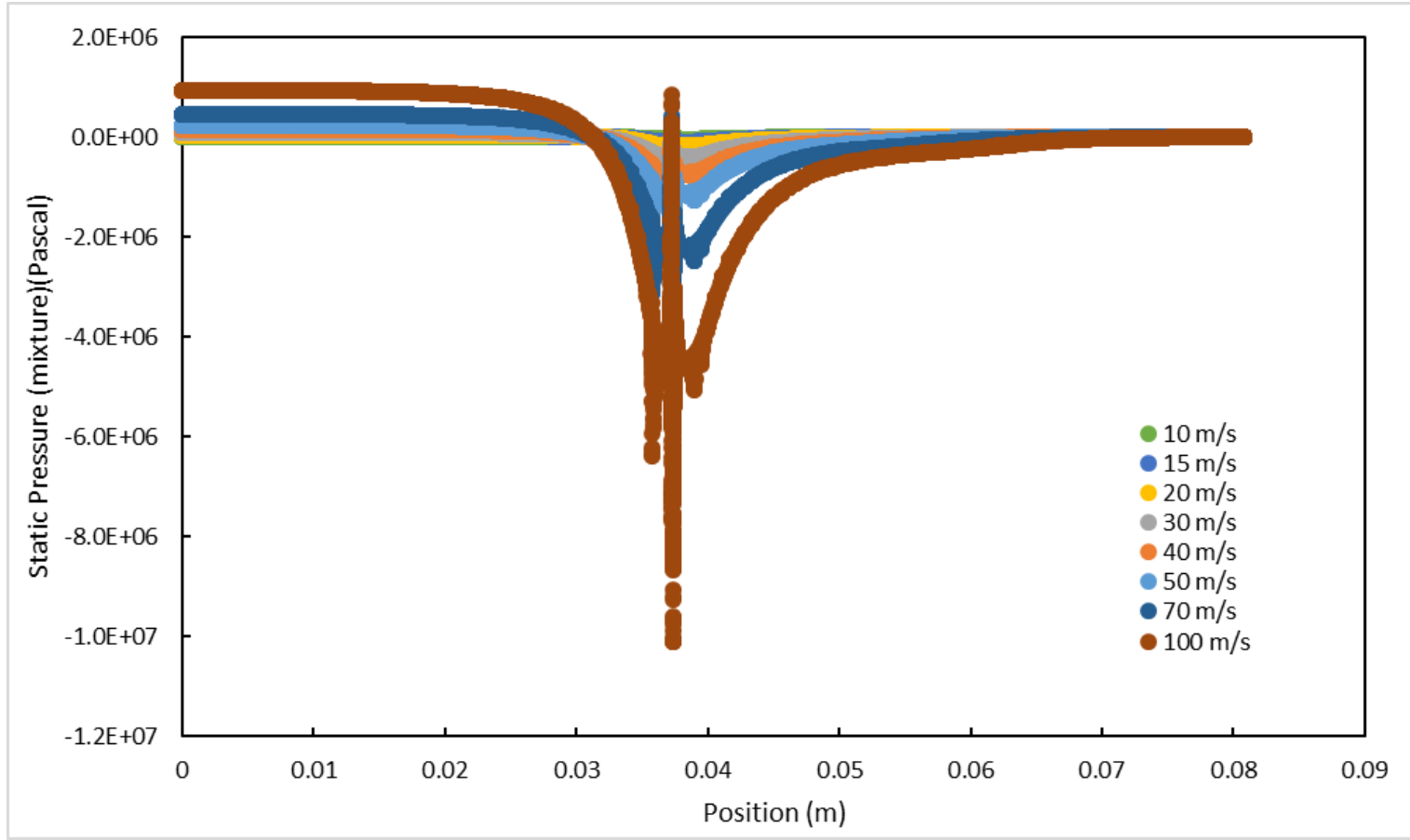

Figure 5-5 Pressure Distribution along the Venturi Tube - With Particle D = $200 \mu \mathrm{m}$ 


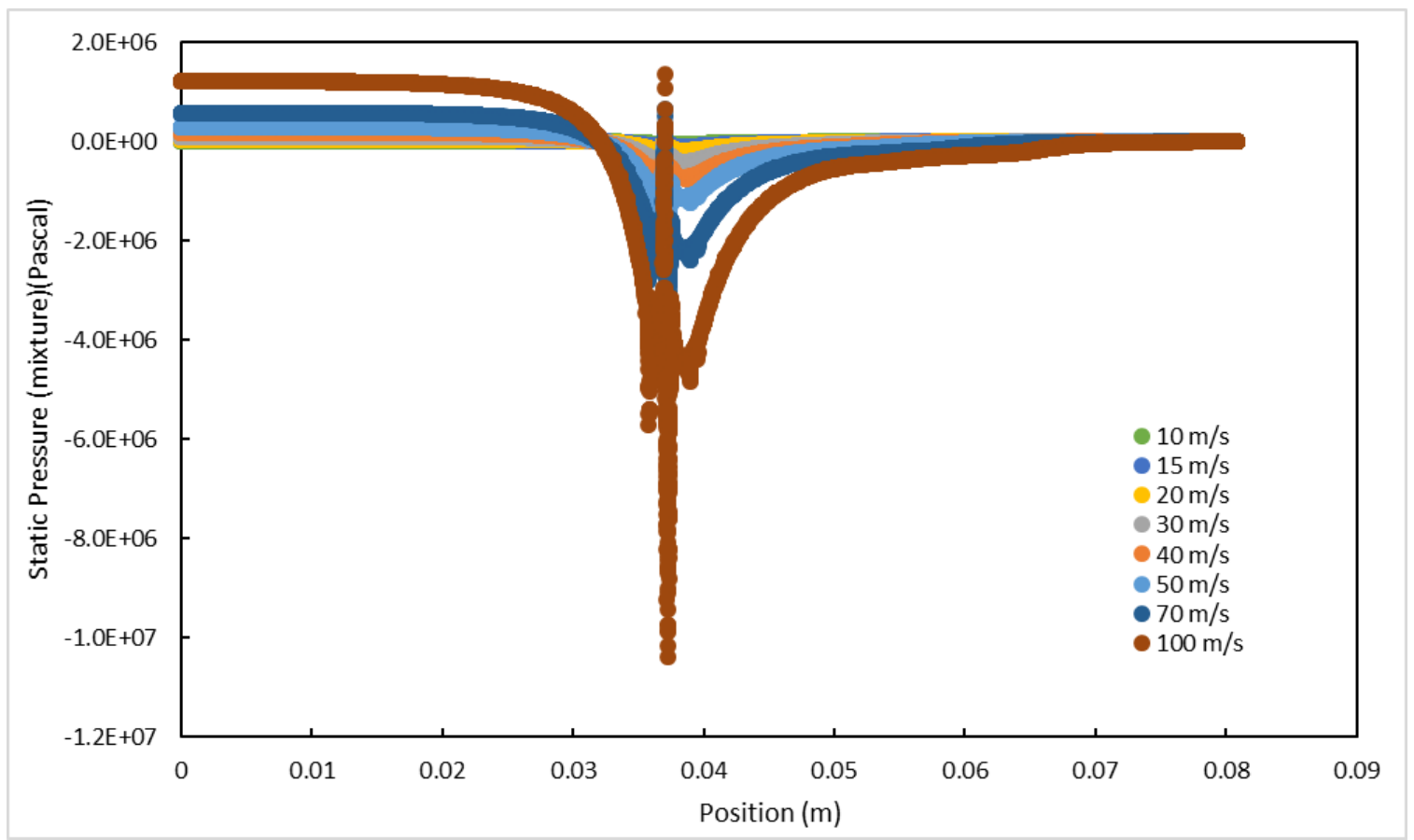

Figure 5-6 Pressure Distribution along the Venturi Tube - With Particle D $=400 \mu \mathrm{m}$

Pressure at the throat changed dramatically when solid particles were added. This is due to the vortexes created behind the solid particles. The maximum and minimum pressures of these three geometries with different throat velocities are shown in Figure 5-7. 


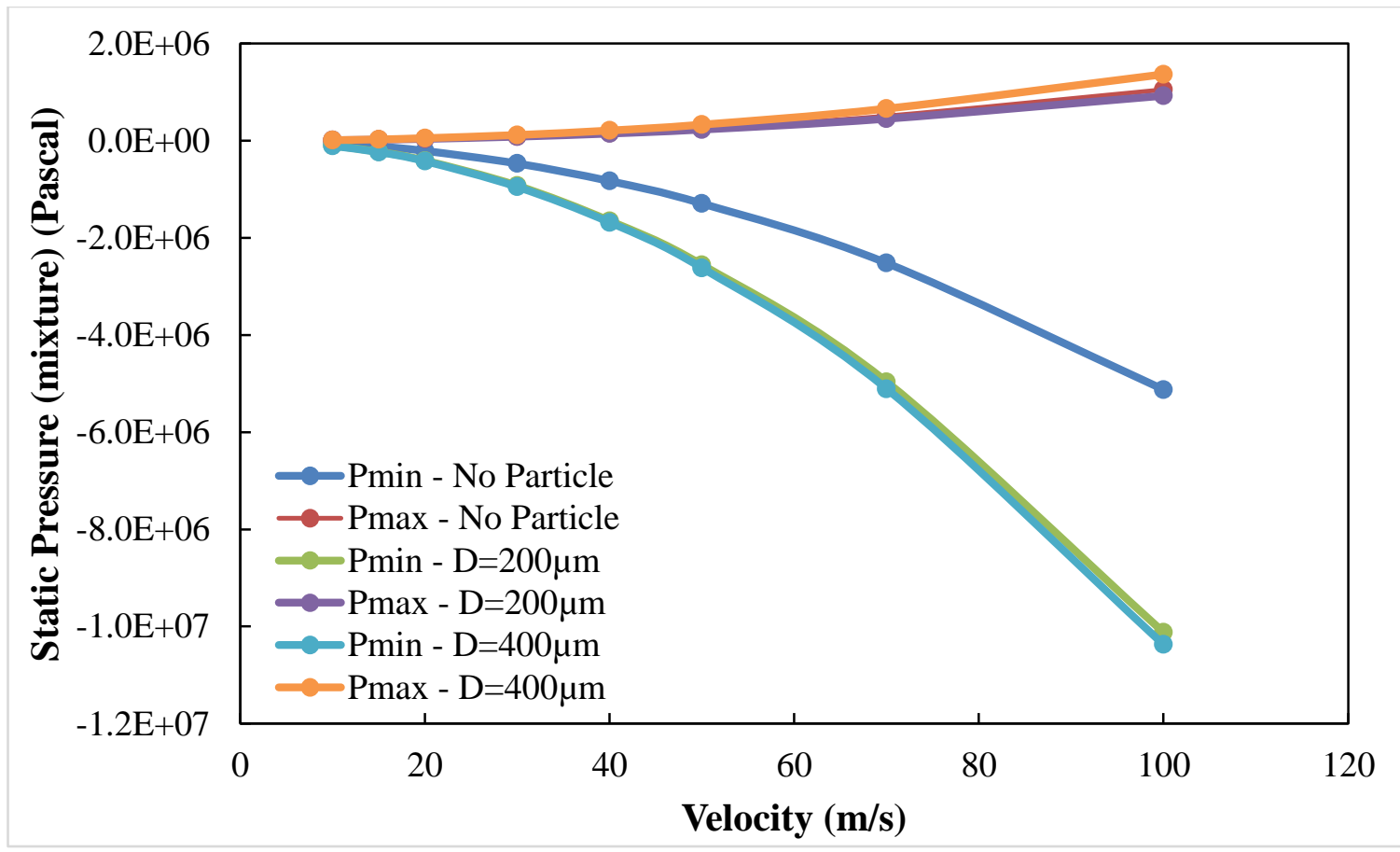

Figure 5-7 Maximum/Minimum Pressure of Venturi and Venturi with Particles at Different Velocities

The maximum pressures of the three geometries with throat velocities from $10 \mathrm{~m} / \mathrm{s}$ to 100 $\mathrm{m} / \mathrm{s}$ are very close. The minimum pressure of the venturi tubes with particles is much lower than the minimum pressure of the venturi tube without. The minimum pressure of the venturi systems with a particle diameter $\mathrm{D}=400 \mu \mathrm{m}$ and $\mathrm{D}=200 \mu \mathrm{m}$ have no significant difference at low velocity. The pressure of the venturi with a particle diameter $\mathrm{D}=400 \mu \mathrm{m}$ is slightly lower, when the velocity is over $50 \mathrm{~m} / \mathrm{s}$.

The contour images of vapor volume fractions for vemturi, venturi with a $200 \mu \mathrm{m}$ diameter particle, and venturi with a $400 \mu \mathrm{m}$ diameter particle with throat velocity $15 \mathrm{~m} / \mathrm{s}$ (inlet velocity is 1.0667) are shown in Figure 5-8. 
a) Venturi:

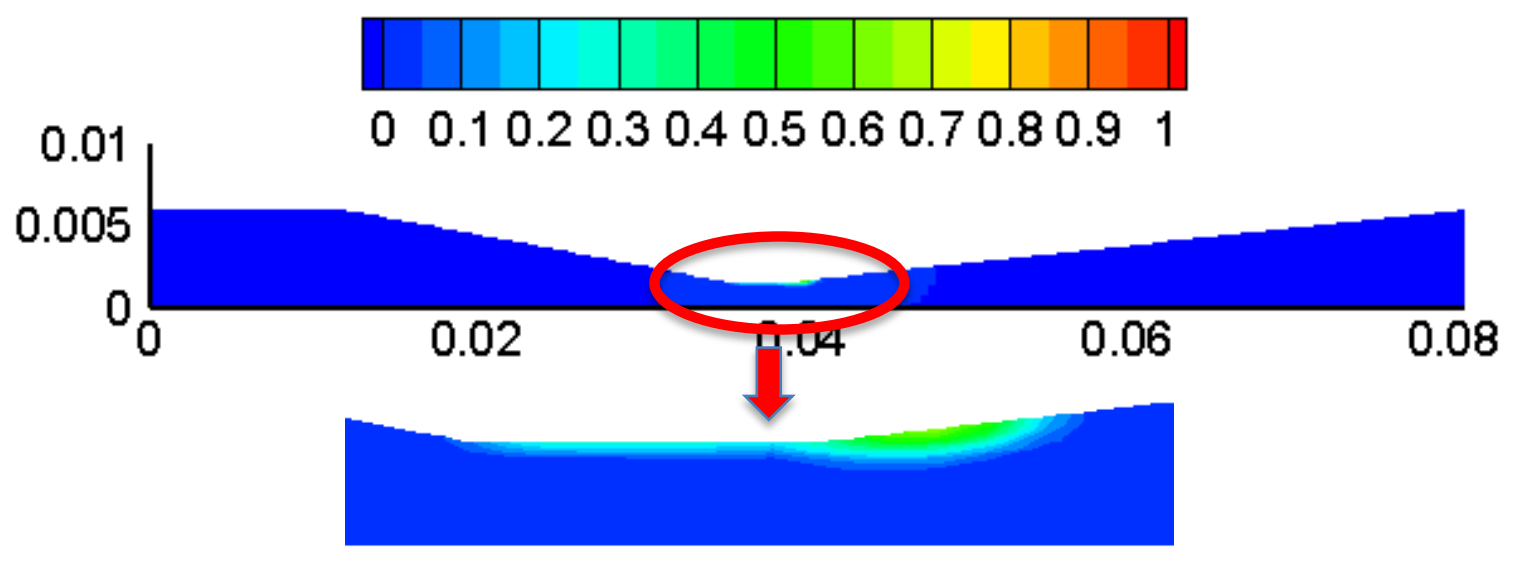

b) Venturi with $200 \mu \mathrm{m}$ diameter particles:

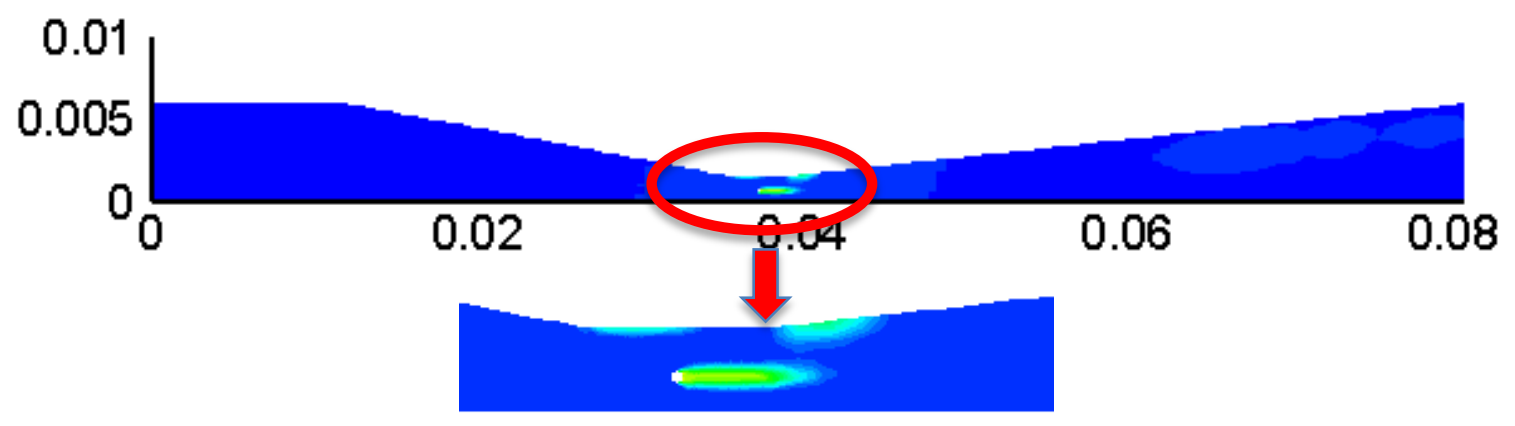

c) Venturi with $400 \mu \mathrm{m}$ diameter particles:

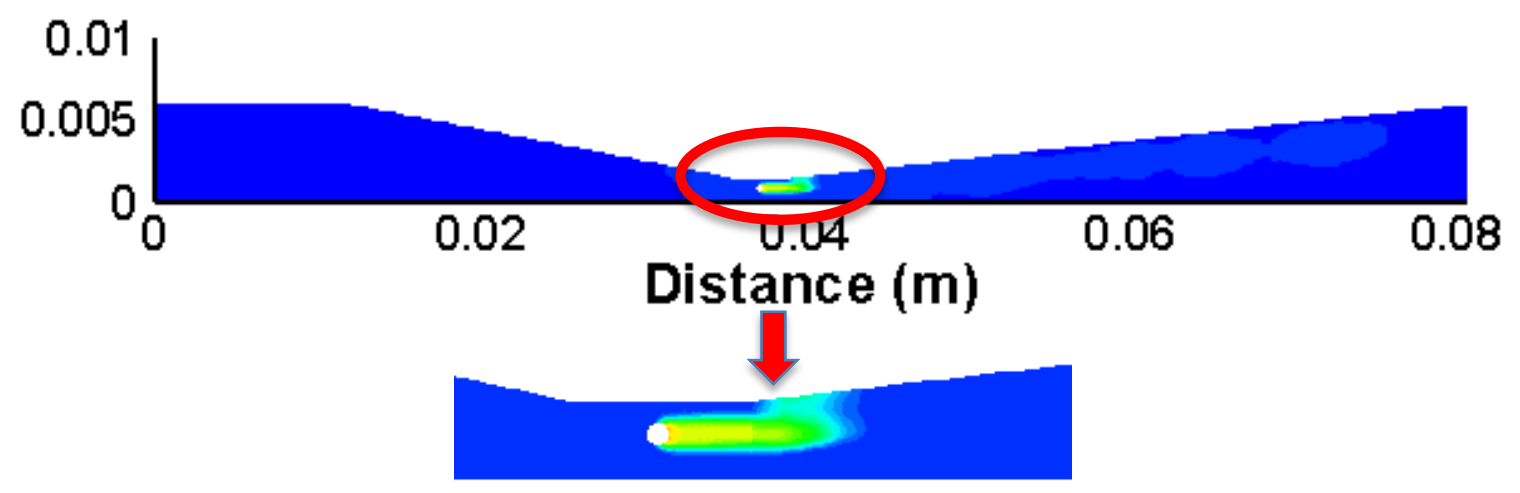

Figure 5-8 Contour Images of Vapor Volume Fractions (Throat Velocity is $15 \mathrm{~m} / \mathrm{s}$ )

The critical velocity for this venturi is $14.1 \mathrm{~m} / \mathrm{s}$. When the throat velocity is $15 \mathrm{~m} / \mathrm{s}$, cavitation only happened at the wall of the throat. With the same velocity, cavitation happened along the wall and around the particles, as shown in Figure 5-8. The particles affect the flow and most of those cavitation bubbles generated around the particles. When 
the velocity increases, the vapor volume fraction increases. Thus, the cavitation area in the contour image increases, as shown in Figure 5-9.

a) Venturi:

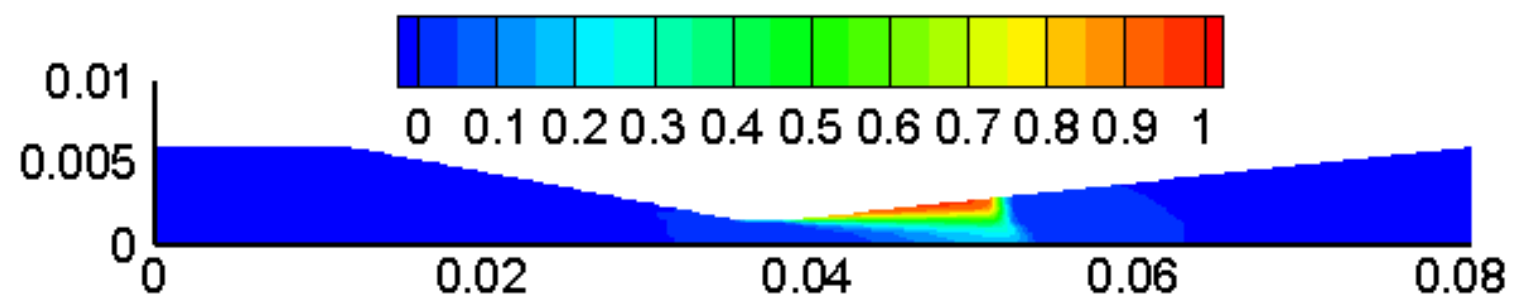

b) Venturi with $200 \mu \mathrm{m}$ diameter particles:

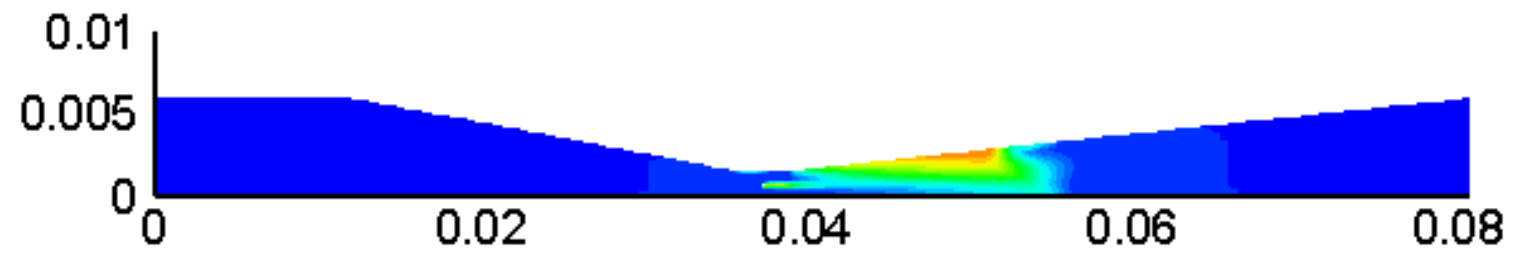

c) Venturi with $400 \mu m$ diameter particles:

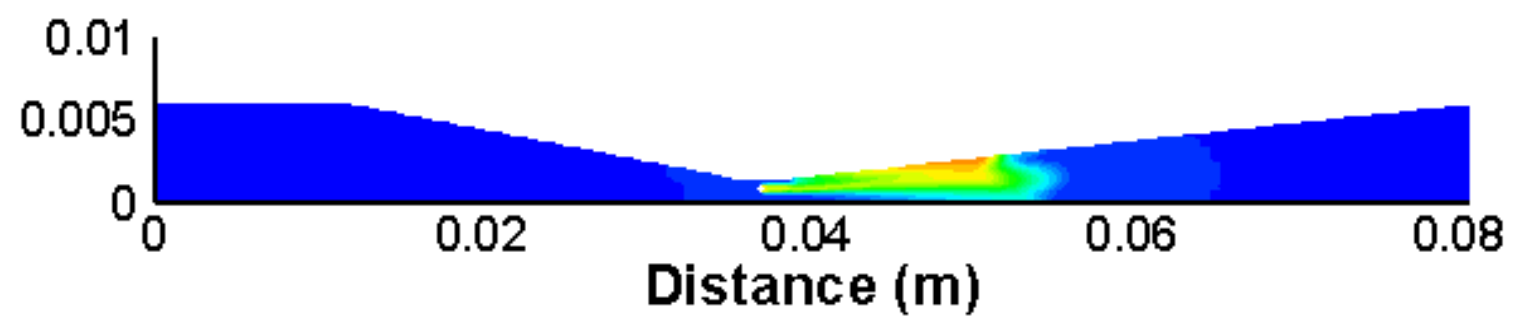

Figure 5-9 Contour Images of Vapor Volume Fractions (Throat Velocity is 20m/s)

The contour images of pressure and velocity when throat velocity is $20 \mathrm{~m} / \mathrm{s}$ are shown in Figure 5-10 and Figure 5-11. Close-up images of the particles are included. Pressure and velocity were both affected when particles were present. Additionally, particles reduce the tube diameter, which increases the velocity and decreases the pressure. 
a) Venturi:

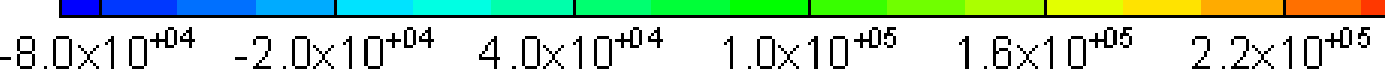

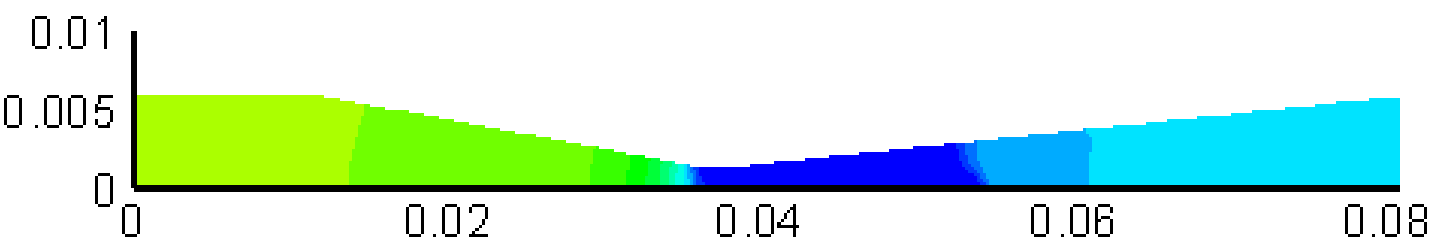

b) Venturi with $200 \mu \mathrm{m}$ diameter particles:
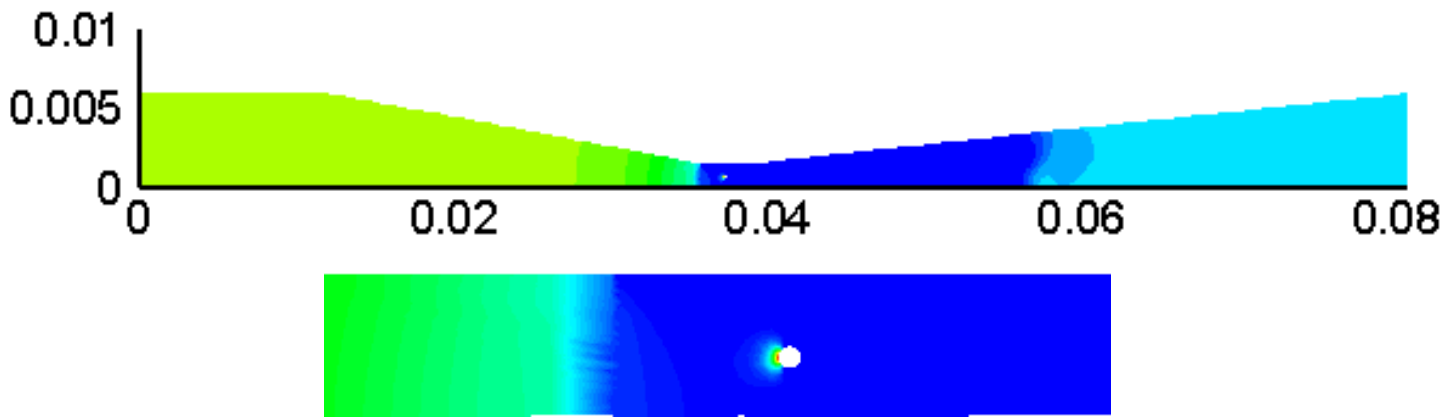

c) Venturi with $400 \mu \mathrm{m}$ diameter particles:
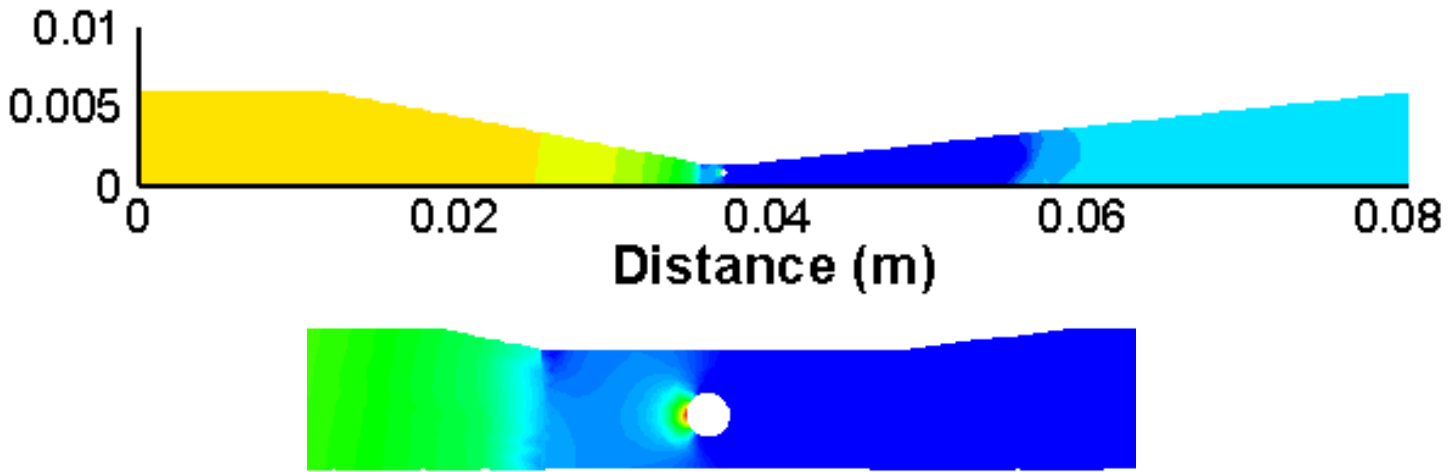

Figure 5-10 Contour Images of Pressure (Throat Velocity is $20 \mathrm{~m} / \mathrm{s}$ )

a) Venturi:

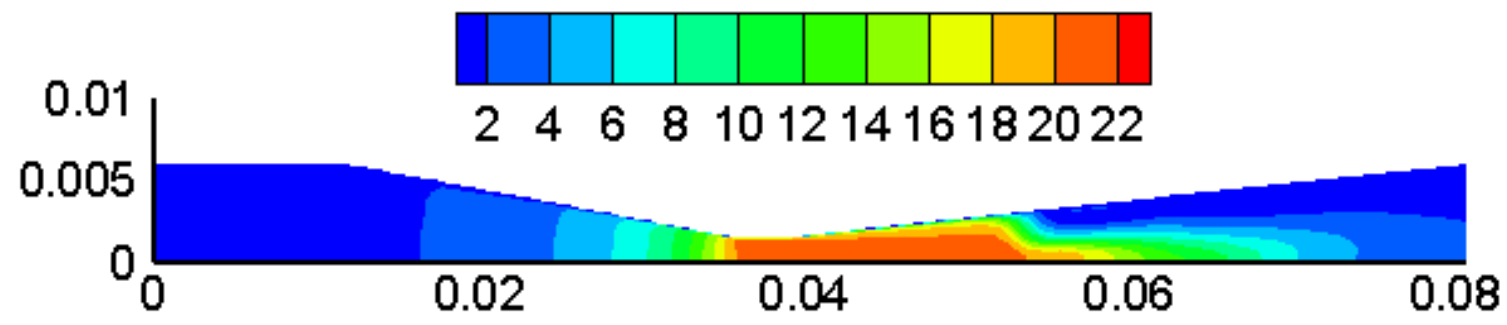




\section{b) Venturi with $200 \mu \mathrm{m}$ diameter particles:}

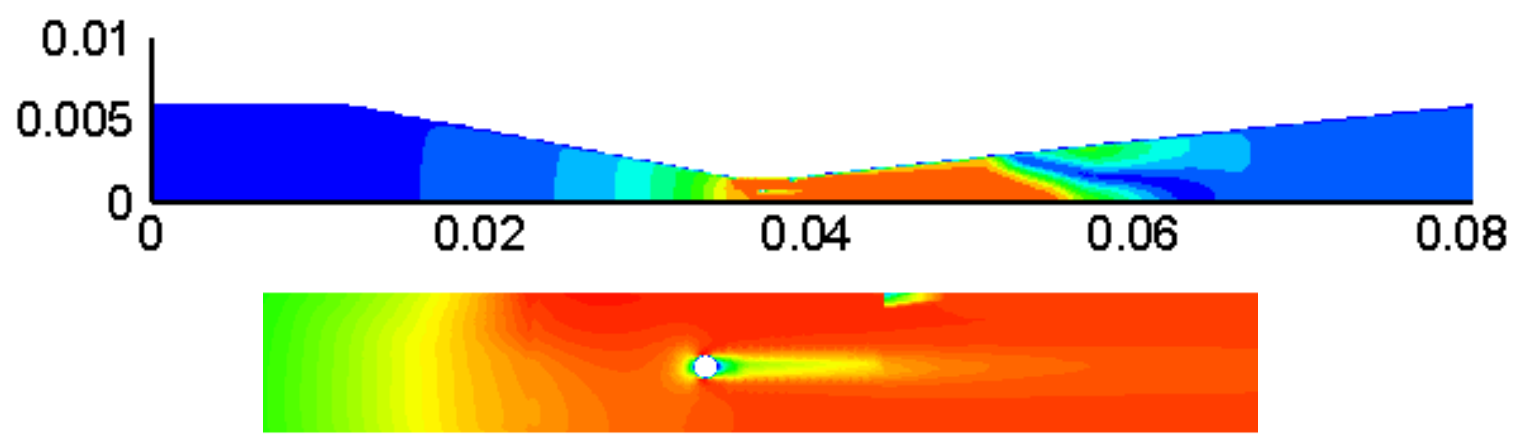

c) Venturi with $400 \mu m$ diameter particles
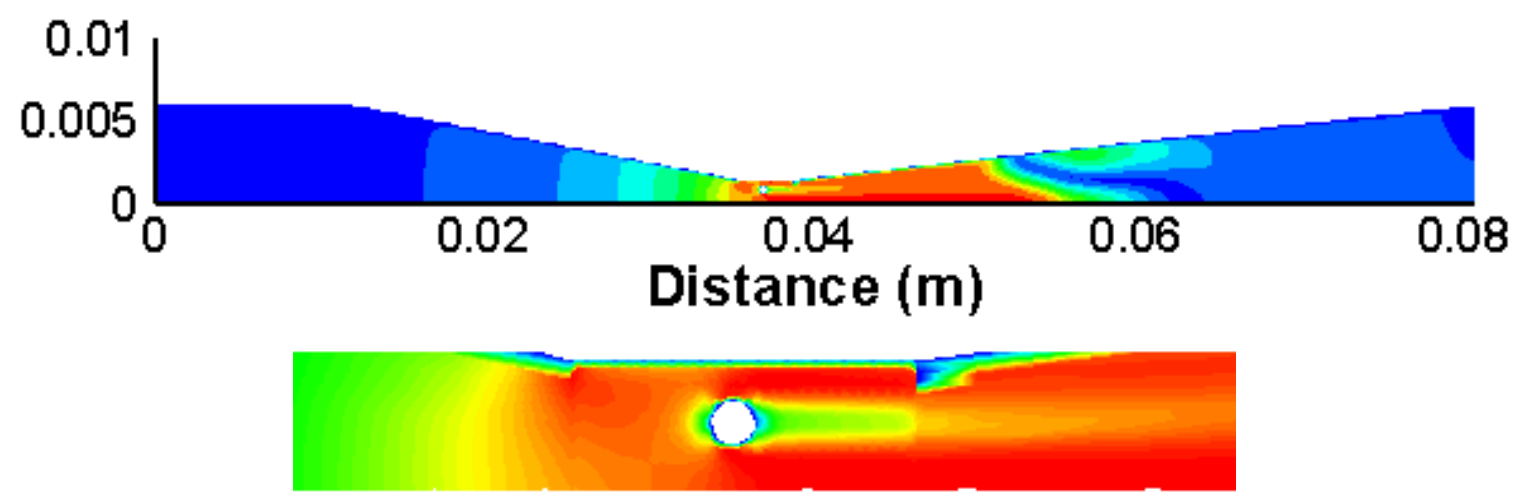

Figure 5-11 Contour Images of Velocity (Throat Velocity is $20 \mathrm{~m} / \mathrm{s}$ )

Cavitation happens at both the venturi throat and around the particle. The presence of particles in liquid can motivate and enhance cavitation. This is because the vortexes created behind solid particles affect the flow and pressure. Additionally, for a venturi tube with pure liquid, cavitation happens at the lower pressure area, where the pressure is lower than the vapor pressure. The system containing liquid with particles follows the same principle. Particles decrease the venturi diameter for the mixture to go through, which increases the velocity and reduces the pressure. Some dry particles have a lot of tiny pores, which contain microscopic amounts of air, and they don't release air bubbles in water (solution) at normal temperature and pressure. Bubbles are released during heating or cavitating, as a cavitation nuclei. 


\subsection{Effects of Bubble Size with Different Particle Size/Different Throat Velocities}

As discovered in Chapter 5.2, at a certain inlet velocity, the minimum pressure of the venturi with a particle diameter $\mathrm{D}=400 \mu \mathrm{m}$ and with a particle $\mathrm{D}=200 \mu \mathrm{m}$ are very close. To understand the bubble size affected by the particle size, a discrete population balance model was developed. This was used to analyze the bubble size distribution of three different geometries. 46 bins, from $10^{-12}$ to $1.0737 \times 10^{-3} \mathrm{~m}$, were used for the vapor phase volume fraction calculation.

As mentioned in Chapter 5.1, the PBM model calculates bigger sizes before calculating the smaller sizes, if there was even enough energy to create/break smaller bubbles. Once no more new bubbles were generated, and there was not much change at each bin, the calculation stabilizes. The size of the smallest bin is the smallest bubble size it could generate.

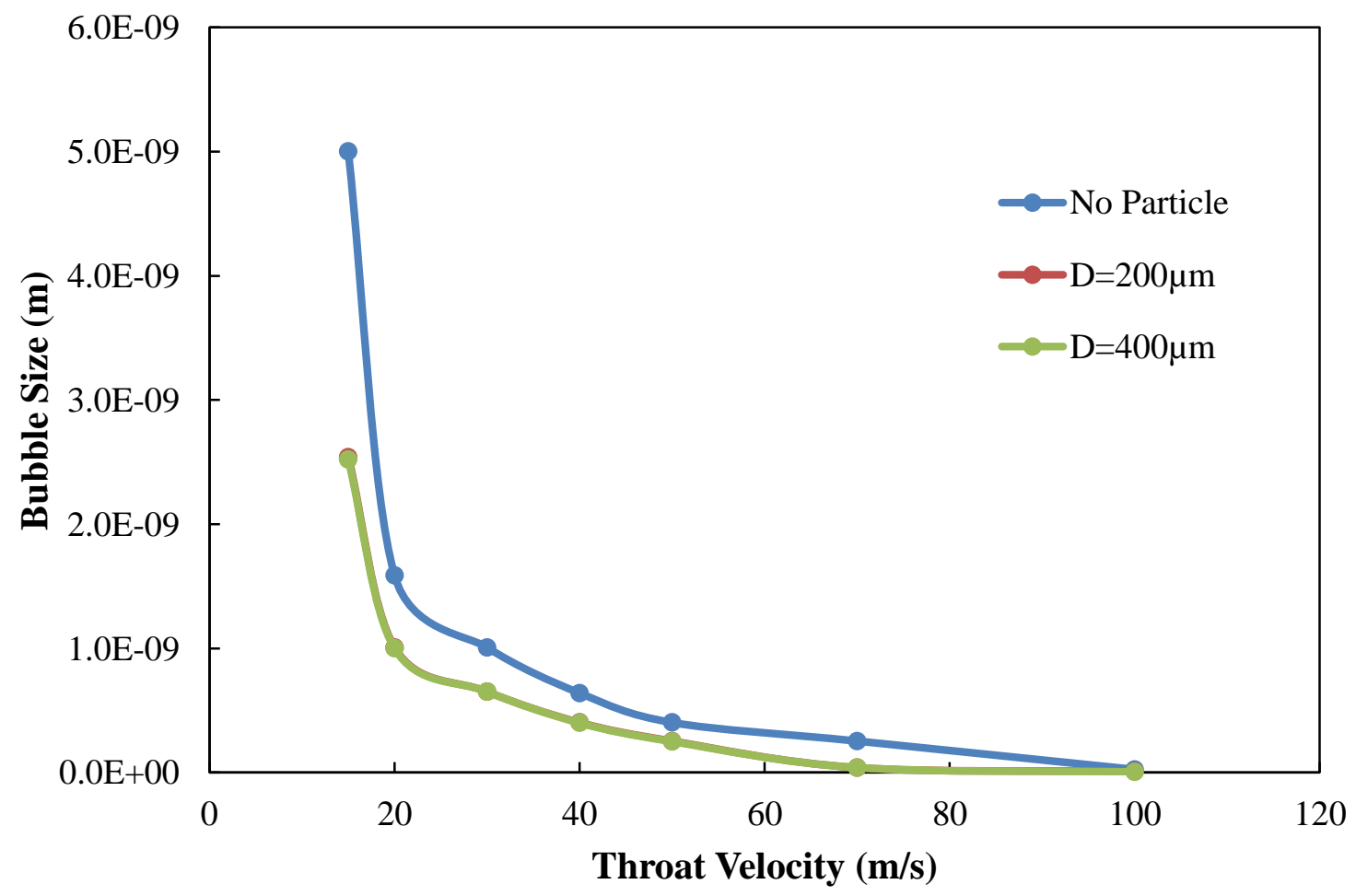

Figure 5-12 Bubbles Generated at Different Throat Velocities 
Figure 5-12 illustrates the smallest bubble sizes generated with different geometries: venturi tube, venturi tube with a $200 \mu \mathrm{m}$ particle, and venturi tube with a $400 \mu \mathrm{m}$ particle, at different throat velocities, ranging from 15 to $100 \mathrm{~m} / \mathrm{s}$. The lowest level of venturi tube only was from $5 \times 10^{-9}$ to $2.54 \times 10^{-11} \mathrm{~m}$. The venturi tube with a $200 \mu \mathrm{m}$ diameter particle generated small bubbles from $2.54 \times 10^{-9}$ to $1 \times 10^{-11} \mathrm{~m}$, and the venturi tube with a $400 \mu \mathrm{m}$ diameter particle generated small bubbles from $2.54 \times 10^{-9}$ to $6.35 \times 10^{-}$ $12 \mathrm{~m}$. In addition to the fact that venturi tubes with solid particles generated more cavitation bubbles, they also generated smaller bubbles than the venturi tube alone. This is consistent with experimental measurement results that pico bubbles can be created when particles are present.

The minimum pressure distributions along the venturi tubes with a $200 \mu \mathrm{m}$ diameter particle and a $400 \mu \mathrm{m}$ diameter particle are very similar, as similarly shown in Figure 5-7. The smallest sizes of bubbles generated from cavitation with different particle sizes at different throat velocities are very similar as well. The venturi tube with a $400 \mu \mathrm{m}$ diameter particle can generate slightly smaller bubbles, since it has slightly lower pressure.

As the throat velocity increases, the smallest bubbles generated by all three geometries decrease. This means smaller bubbles and wider bubble size range will be created with higher velocities using the same geometry. This is because only the low-pressure field where pressure is lower than vapor pressure could have cavitation bubbles, and the bubble size is related with local pressure. Higher velocity leads to a lower pressure. Therefore, more cavitation and smaller bubbles are generated. 


\section{CHAPTER 6 Simulation of Venturi Scale-up}

Column flotation with cavitation bubbles technology has been successfully developed in the lab, and thus it is important to apply it in industry. The flotation column used in the lab is $2.4 \mathrm{~m}$ in height and $0.0508 \mathrm{~m}$ diameter. The total volume of the column is 4.86 $\times 10^{-3} \mathrm{~m}^{3}$. Industrial flotation columns are normally 6 to $14 \mathrm{~m}$ in height, and range in diameter from 0.5 to $5 \mathrm{~m}$ (Dobby, 2002). The total volume of industrial flotation columns ranges from 1.18 to $274.89 \mathrm{~m}^{3}$, as shown in Table 6-1.

Table 6-1 Geometries of Different Flotation Columns

\begin{tabular}{|c|c|c|c|}
\hline Flotation Column & Height (m) & Diameter $(\mathbf{m})$ & Volume $\left(\mathbf{m}^{\mathbf{3}}\right)$ \\
\hline Lab & 2.1 & 0.0508 & $4.26 \times 10^{-3}$ \\
\hline Scale-up 1 & 6 & 0.5 & 1.18 \\
\hline Scale-up 2 & 14 & 5 & 274.89 \\
\hline
\end{tabular}

Flow rate is the flow of volume of fluid through a surface per unit time. This can be calculated as:

$$
Q=v A
$$

Where $v$ is inlet velocity, and A is surface area. Volumes of scaled-up columns are 277 to 64,583 times that of the lab column:

$$
Q_{\text {Scale-up }}=277 \text { to } 64,583 \text { times of } Q_{L a b}
$$

Using the same inlet velocity, $A=\pi\left(\frac{D}{2}\right)^{2}$, the diameter of scaled-up venturi is:

$$
D_{\text {Scale-up }}=16.64 \text { to } 254.13 \text { times of } D_{L a b}
$$

A $0.012 \mathrm{~m}$ diameter venturi was used in the lab, and it was found to be sufficient in generating cavitation bubbles for the lab-scale flotation column. However, it is important 
to note that venturi diameters for industry columns are about 16.64 to 254.13 times that of the lab venturi, and range from 0.20 to $3.05 \mathrm{~m}$.

\subsection{Venturi Scale-Up}

Results from Chapter 4 show that the critical cavitation velocity is at a minimum when the inlet diameter is $0.21592 \mathrm{~m}$, the diameter ratio is 0.42 , the convergent angle is 30 , the divergent angle is 14.14, and the throat length and entrance length are 0.5 and 0 , respectively. This geometry was used as a standard venturi tube in this study. For scaling up one column, the required venturi diameter is $0.20 \mathrm{~m}$. Thus, a standard tube $(\mathrm{D}=0.22$ $\mathrm{m})$ can be used. The desired venturi diameter of scaling up two columns is about 15 times the scale-up of 1 . Therefore, one 15 times of the diameter $(D=3.24 \mathrm{~m})$ and one lab scale $(\mathrm{D}=0.012 \mathrm{~m})$ venturi tube are compared with the standard diameter tube.

Three different 3D mesh sizes of venturi tubes were created using ANSYS ICEM. Besides inlet diameter, the throat lengths were designed with the same ratio (0.12: 0.22 : 3.24). The diameter ratio, convergent angle, and divergent angle were the same as with the standard venturi tube design.

Table 6-2 Vaper Generated Rates of Different Venturi Tubes with 20 m/s Throat Velcocity

\begin{tabular}{|c|c|c|c|c|}
\hline Venturi & Diameter $(\mathbf{m})$ & Volume $\left.\mathbf{( m}^{\mathbf{3}}\right)$ & $\begin{array}{c}\text { Vapor } \\
\text { Volume } \\
\left.\text { Integral } \mathbf{( m}^{\mathbf{3}}\right)\end{array}$ & $\begin{array}{c}\text { Vapor } \\
\text { Volume Ratio }\end{array}$ \\
\hline Lab & 0.012 & $2.51 \times 10^{-6}$ & $3.03 \times 10^{-7}$ & 0.12 \\
\hline Standard & 0.2159 & $1.47 \times 10^{-2}$ & $2.73 \times 10^{-3}$ & 0.19 \\
\hline Scale-up & 3.2388 & 49.54 & 6.60 & 0.13 \\
\hline
\end{tabular}

Table 6-2 shows inlet diameters, volumes and vapor volume fractions of three scales of venturi tube with $20 \mathrm{~m} / \mathrm{s}$ throat velocity. The vapor volume ratios (vapor volume/venturi tube volume) of three venturi tubes are $0.12,0.19$ and 0.13 , respectively. The vapor volume ratios of the three venturi tubes at different throat velocities are shown in Figure 6-1. 


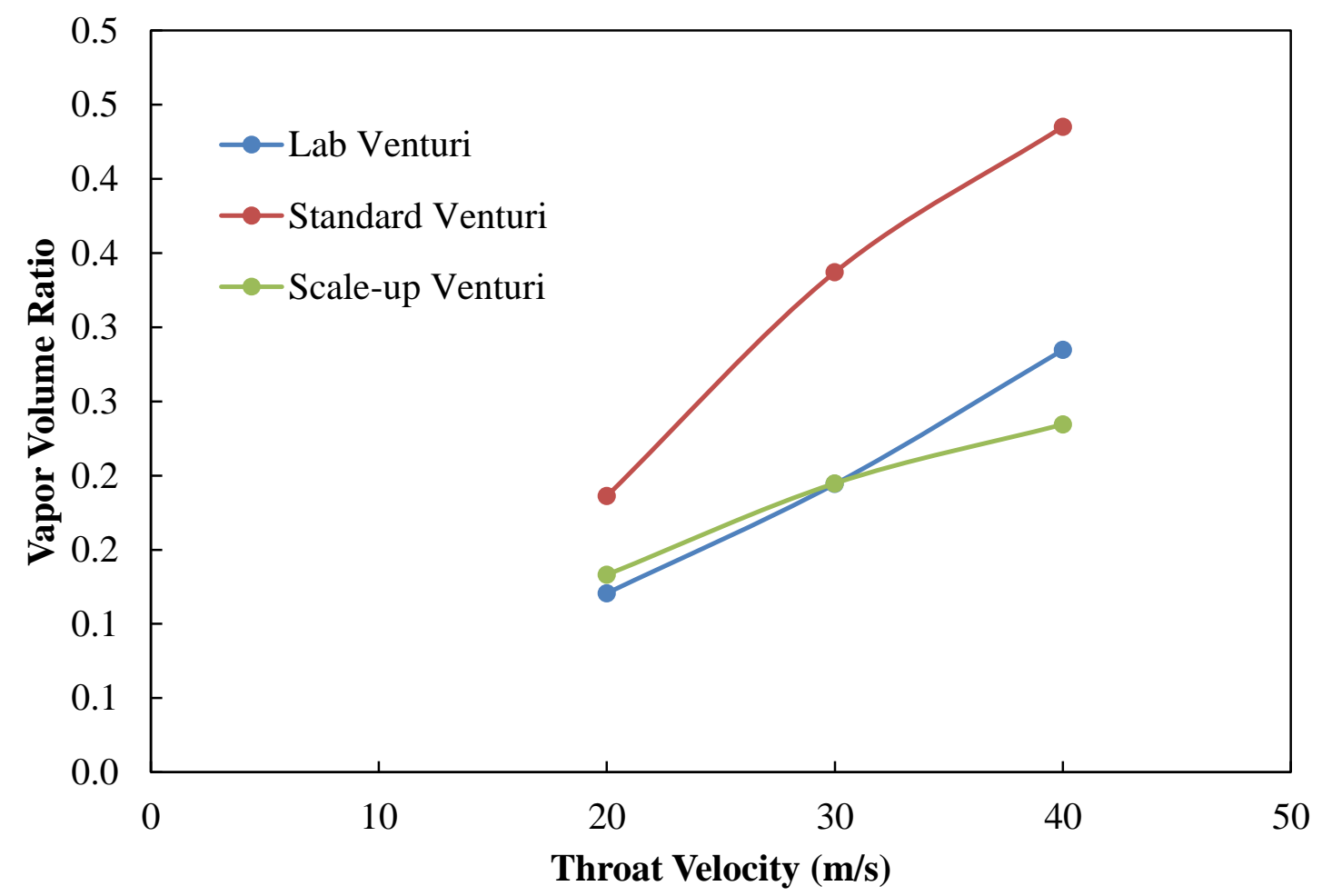

Figure 6-1 Vapor volume ratio of three venturi tubes at different velocities

The vapor volume ratios of the standard tube are higher than both the lab scale and scaleup venturi tubes, when the throat velocity is from 20 to $40 \mathrm{~m} / \mathrm{s}$. This indicates that the standard venturi tube can generate the most amount of vapor at a certain volume, which favors flotation. For a big flotation column, multiple standard venturi tubes functions better than one scaled-up tube. This supports the results from Chapter 4, Figure 4-6. The required energy increases as the diameter increases, after $215.96 \mathrm{~mm}$.

Additionally, smaller tubes are easier to fabricate and replace. Multiple tubes may also allow avoiding process shutdown during maintenance. Thus, multiple small venturi tubes are recommended for flotation. 


\subsection{Parallel and Series}

In the reference experiment, Peng and Xiong (2015) used one packed column and venturi tube, either in parallel or in series, for cavitation bubble generation. This is shown in Figure 6-2. They found that the series order of the packed column and venturi tube is better than the parallel order. They also found that micro-sized bubbles are generated most from the packed column, and pico and nano bubbles are generated by the venturi tube. One packed column and one venturi tube were generated, and the effects of cavitation using parallel and series designs were calculated and compared. The meshing used is the same as the lab designed venturi tube from Peng and Xiong (2015)'s study, where the diameter ratio (d/D) is 0.267 . The inlet diameter of the packed column used was the same value as the venturi tube $(12 \mathrm{~mm})$. The flowrate ratio of the packed column and the venturi tube used was 1:1. Based on flowrate calculation, $Q=v A$, with the same flowrate, velocity in both packed column and venturi tube of parallel design is $1 / 2$ of what it is in series.

To simulate the order of the packed column and venturi tube, geometries of one packed column and one venturi tube were generated. The first design placed the packed column first, then the venturi tube second. The second design placed the venturi tube first, then the packed column second. 


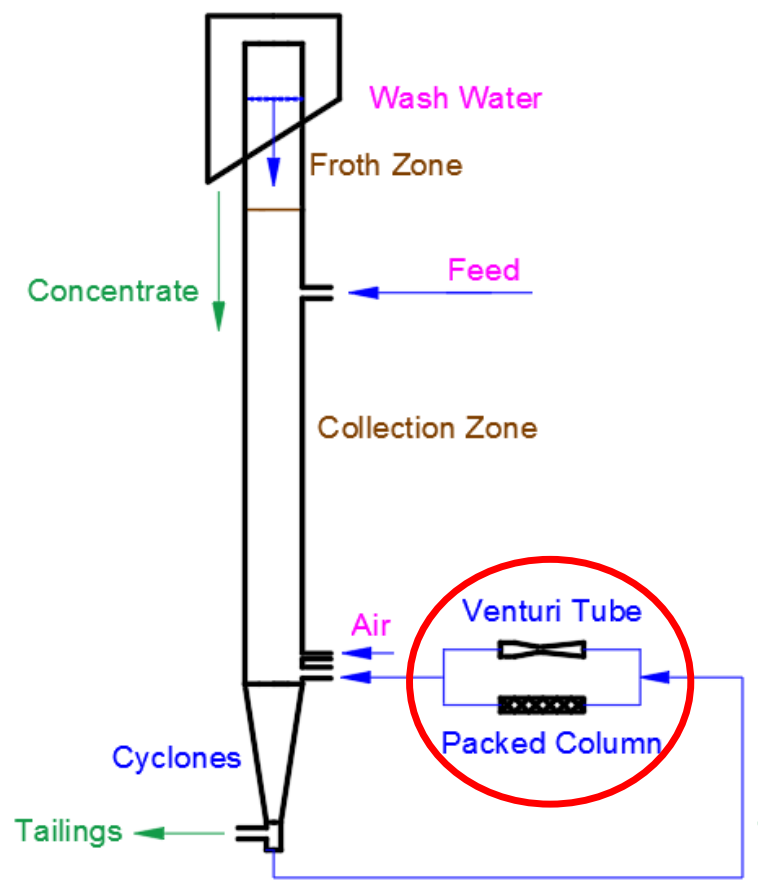

(a)

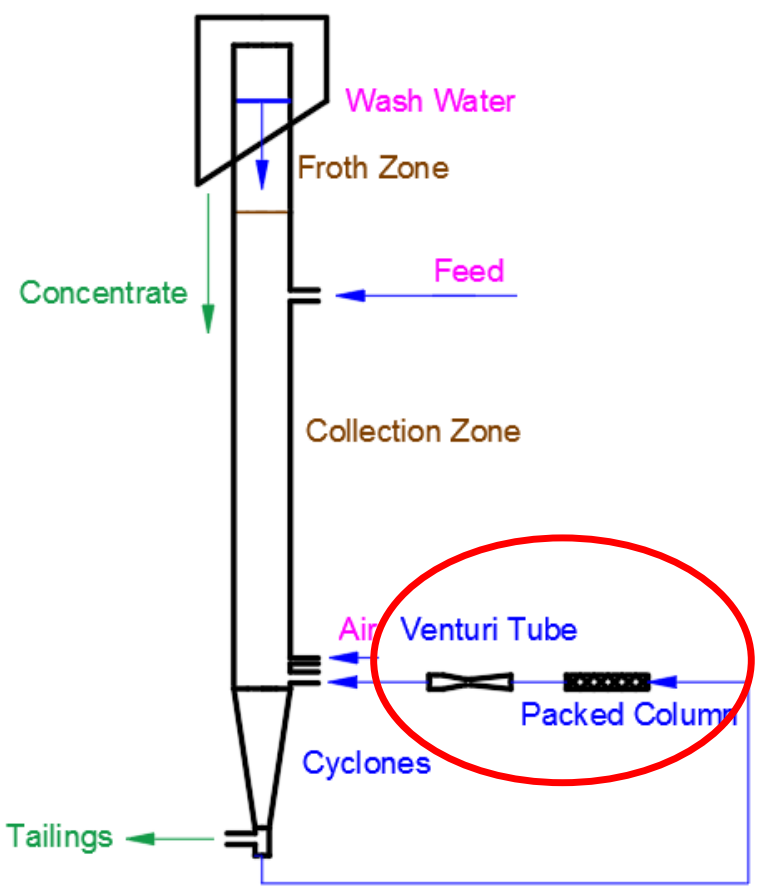

(b)

Figure 6-2 Schematics of (a) Packed Column and Venturi Tube in Parallel Order (b) Packed Column and Vencuti Tube in Series Order

Both cavitation and PBM models were applied to geometries of two designs. From Chapter 3, the critical velocity for this venturi tube without particles is $14.1 \mathrm{~m} / \mathrm{s}$. So the inlet velocity is

$$
v_{\text {inlet }}=v_{\text {throat }} \times \beta^{2}=14.1 \times 0.267^{2}=1.003(\mathrm{~m} / \mathrm{s})
$$

The inlet area of the venturi tube is

$$
A=\pi\left(\frac{D}{2}\right)^{2}=1.13 \times 10^{-4}\left(m^{2}\right)
$$

the critical flow rate for cavitation is

$$
\begin{gathered}
Q_{\text {inlet }}=v_{\text {inlet }} \cdot A_{\text {inlet }}=1.003 \times 1.13 \times 10^{-4} \\
=1.134 \times 10^{-4}\left(\mathrm{~m}^{3} / \mathrm{s}\right)
\end{gathered}
$$


When packed column and venturi tube are in parallel with a 1:1 flow rate ratio, the required flowrate for the parallel designed system is $2 \times 1.134 \times 10^{-4}=2.268 \times 10^{-4} \mathrm{~m}^{3} / \mathrm{s}$.

The contour images of pressure and vapor volume fractions, at the middle plane, of three designs with $2.41 \times 10^{-4} \mathrm{~m}^{3} / \mathrm{s}$ inlet flow rate are shown in Figure 6-3 and Figure 6-4.

\section{(a) Parallel Design:}
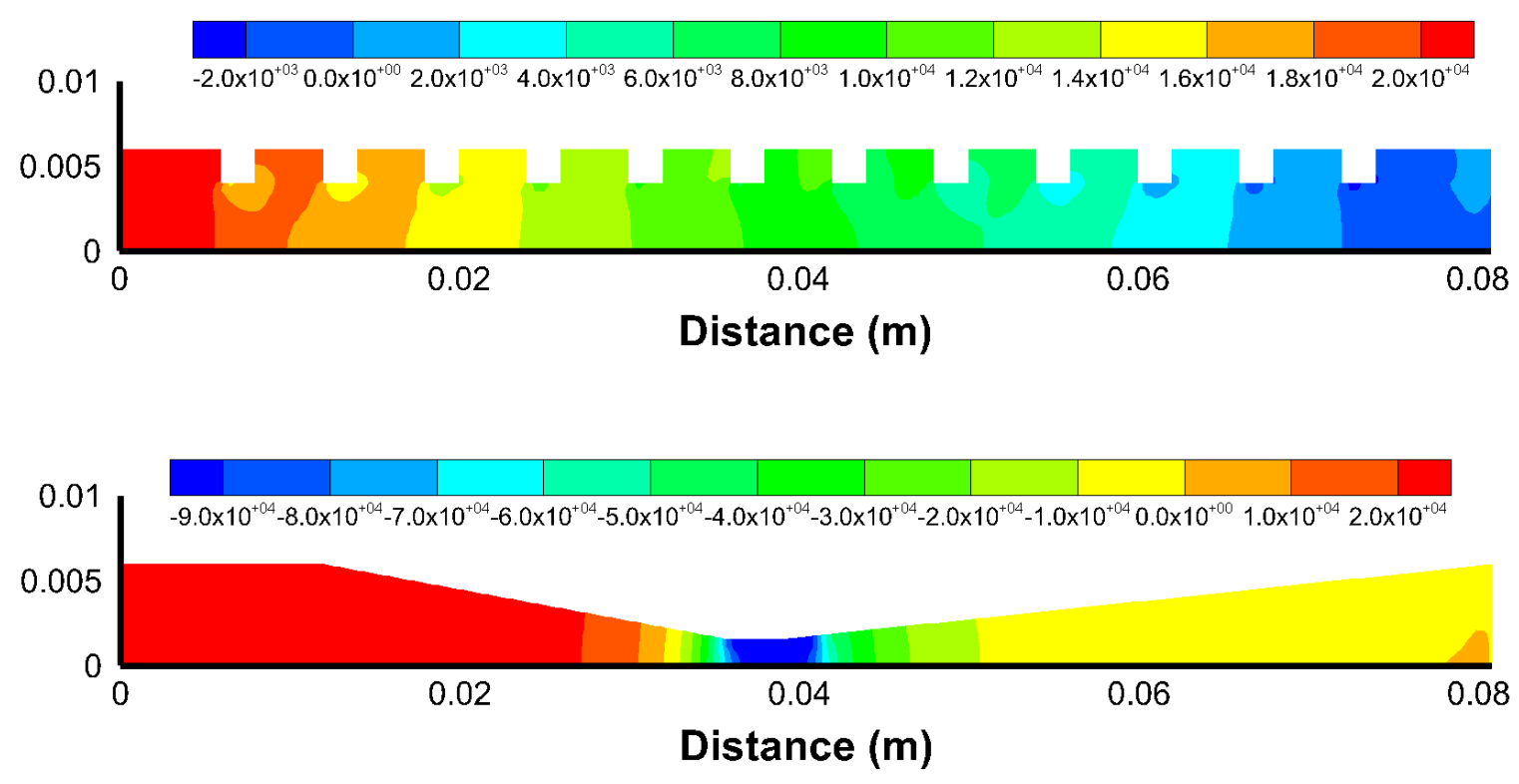
(b) Series Design \#1:

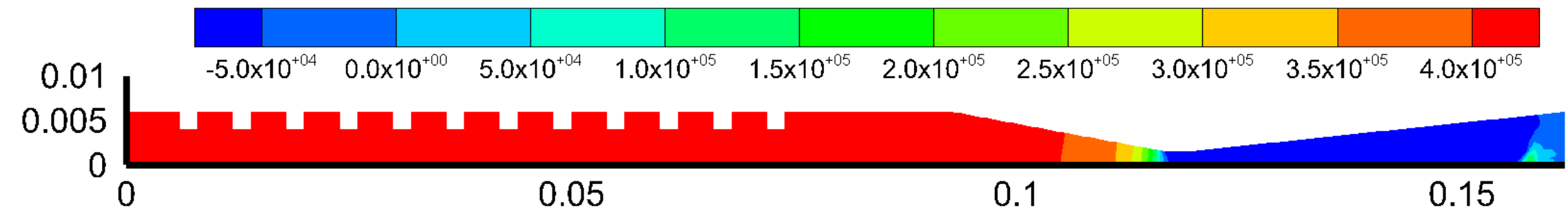

(c) Series Design \#2:

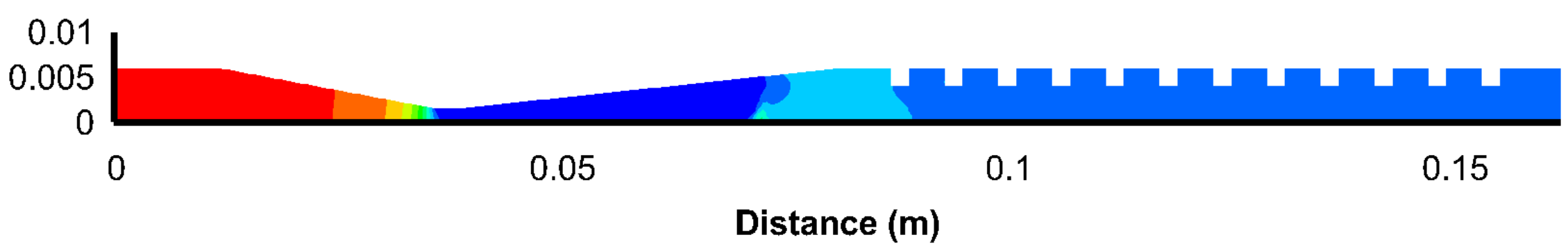

Figure 6-3 Contour Images of Pressure with $2.41 \times 10^{-4} \mathrm{~m}^{3} / \mathrm{s}$ inlet flow rate of (a) Parallel Design; (b) Series Design \#1; (c) Series Design \#2

(a) Parallel Design:

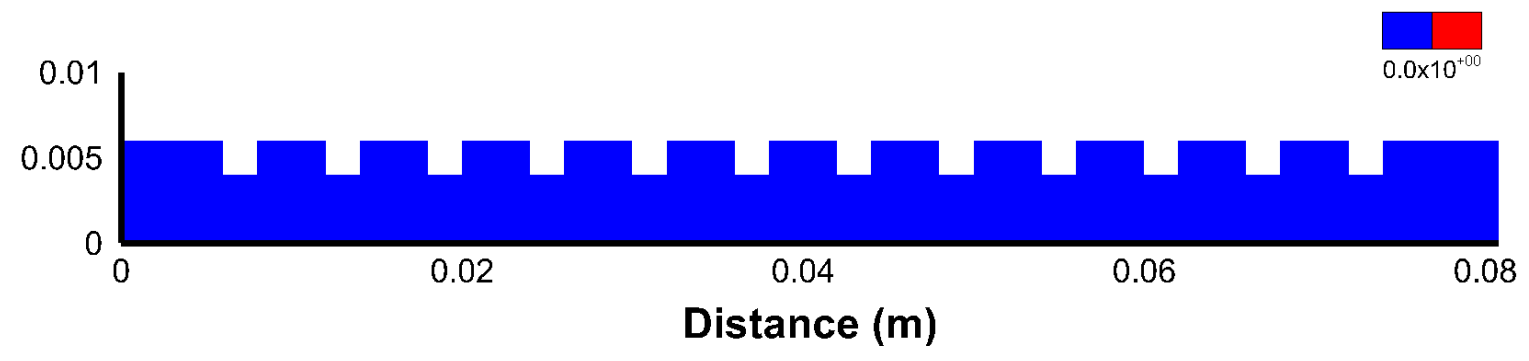




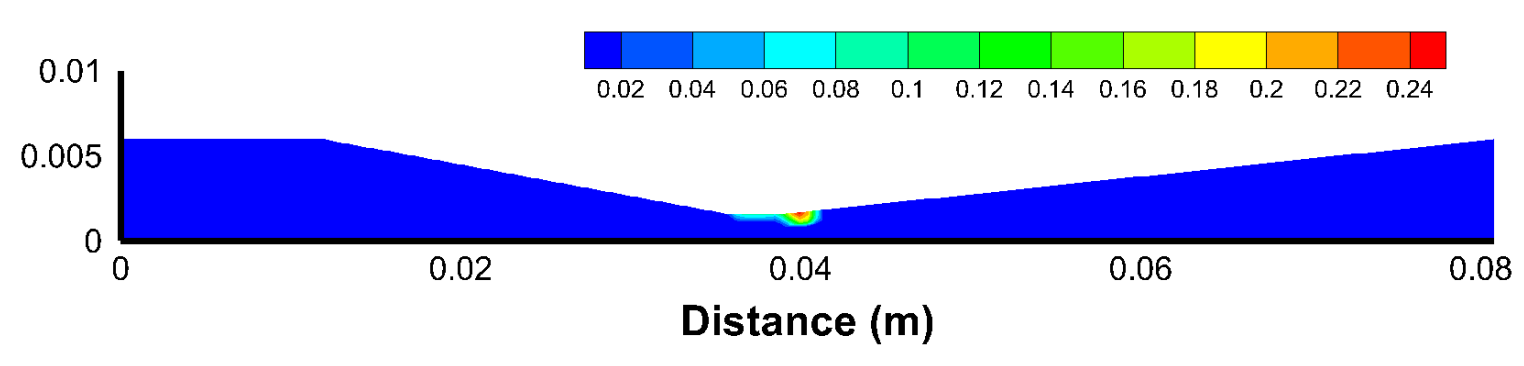

(b) Series Design \#1:

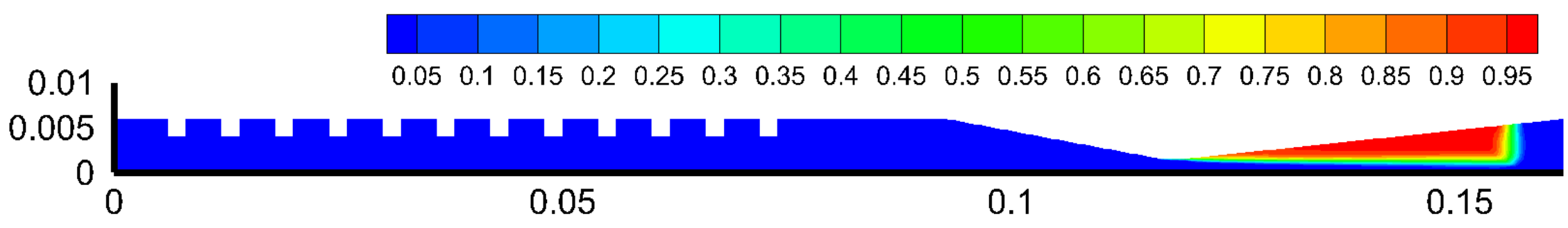

(c) Series Design \#2:

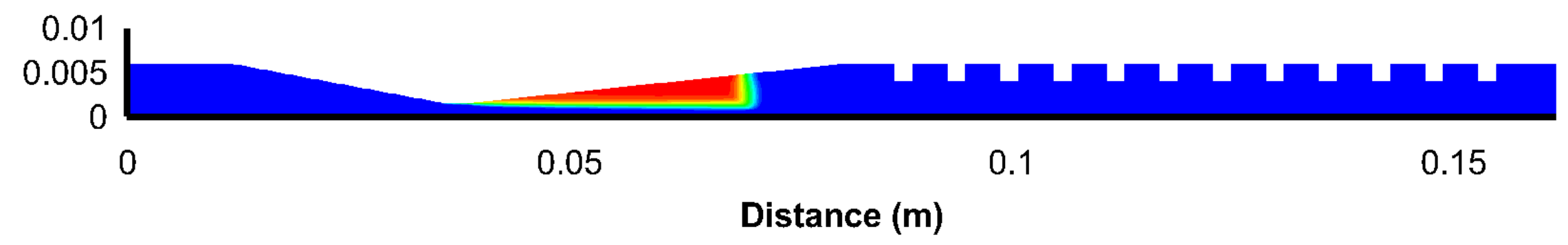

Figure 6-4 Contour Images of Vapor Volume Fractions with $2.41 \times 10^{-4} \mathrm{~m}^{3} / \mathrm{s}$ inlet flow rate of (a) Parallel Design; (b) Series Design \#1; (c) Series Design \#2 
For the first design, smaller bubbles were generated at the first part, then bubbles and fluid mixture pass through the second generator. For the second design, bigger bubbles were generated first, then pass through the venturi tube. The vapor volume integrals of three designs with different inlet flow rates from $1.21 \times 10^{-4}$ to $4 \times 10^{-4} \mathrm{~m}^{3} / \mathrm{s}$ are shown in Figure 6-5.

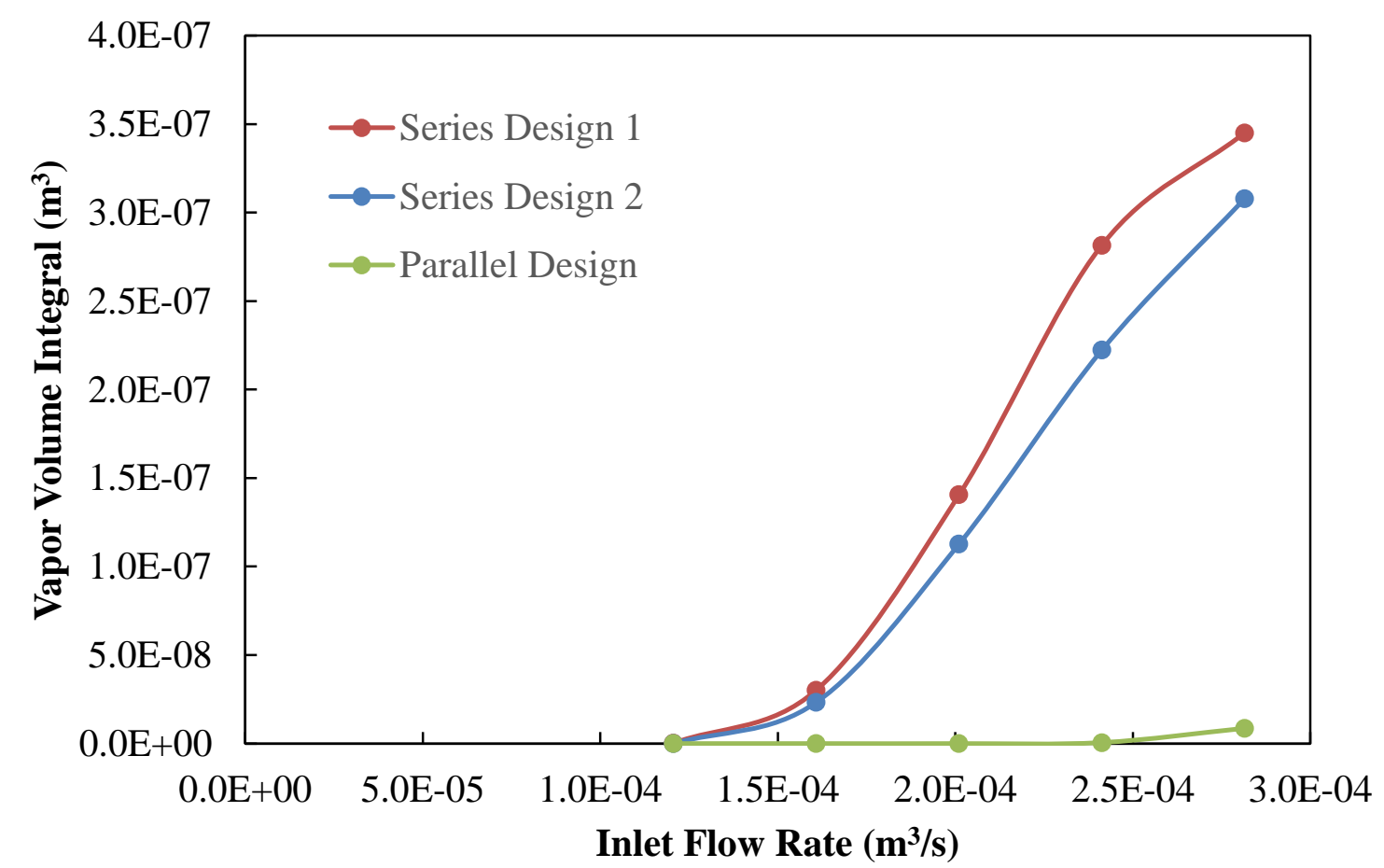

Figure 6-5 Vapor volume integral of three design with different inlet flow rates

As found with previous results, cavitation vapor is not created by the parallel design until the flowrate is higher than $2.268 \times 10^{-4} \mathrm{~m}^{3} / \mathrm{s}$. With the same flowrate, two series designs generate more vapor than the parallel design. For two series designs, the first design created more vapor than the second one. 


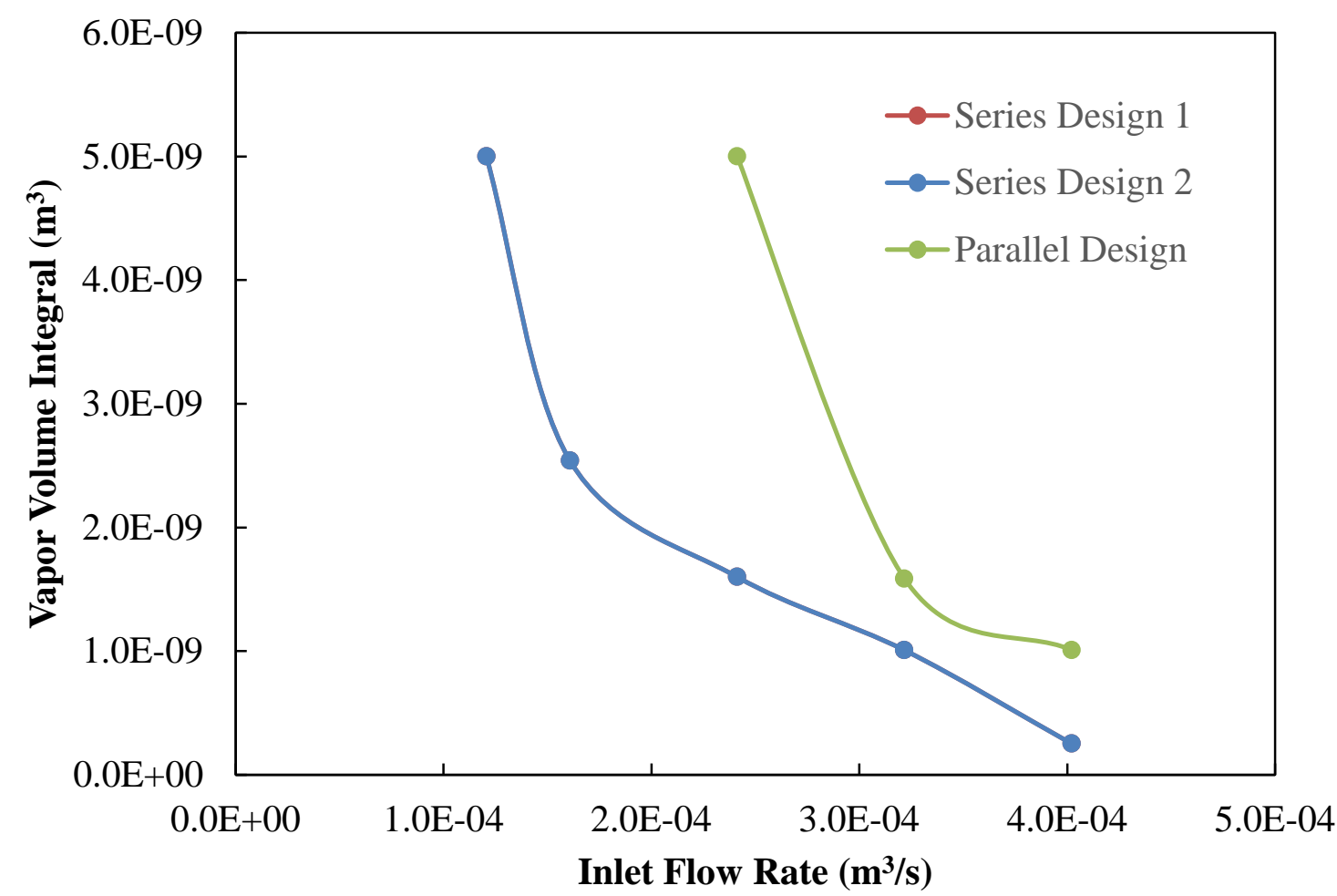

Figure 6-6 Vapor bubble size of three design with different inlet flow rates

The minimum bubble sizes created by three designs were calculated using PBM, the results are shown in Figure 6-6. Vapor bubble sizes created by two series designs at different flowrates were very close. The parallel design generated cavitation bubbles when the inlet flowrate reached the critical value. With the same flowrate, the bubble sizes generated using series designs were smaller than the parallel design.

The design with the packed column and venturi tube in series generated more vapor volume and smaller cavitation bubble sizes, compared to the parallel design; which is more favorable to flotation process. There was no significant difference of cavitation bubble size between the two series designs; however, the first design generated more vapor than the second. Therefore, the system with the packed column and venturi tube in series, with the packed column first and venturi tube second, is recommended. 


\section{CHAPTER 7 Conclusions}

- The efficiency of cavitation bubble generating devices and their geometry design is analyzed using CFD in this study. Different geometries, venturi tubes, nozzles, and orifice from literature were used. Mathematical models were validated through comparison with experimental results. Critical cavitation velocities and volume fractions of venturi and orifice with different devices, circular, square, and slot shaped venturi and orifice tubes with exact same dimensions (inlet area, diameter ratio, entrance length, throat length) were created and studied. It was found that circular venturi tubes were better than the other shapes.

- Six parameters: the inlet diameter, diameter ratio, convergent angle, divergent angle, throat length and entrance length were studied for geometric optimization. The response of the model is called the critical velocity for cavitation; which means the minimum required velocity for cavitation generated by each geometry. A response surface method central composite design was conducted for evaluating the effect of these six parameters affecting the efficiency of the Venturi tube. JMP 11 was used for experimental design and data analysis. 48 venturi tubes with designed geometry were created using ANSYS ICEM. The vapor volume fractions of each geometry was calculated using ANSYS FLUENT. Critical velocities of cavitation of different designs were compared. Simulation shows that the diameter ratio is the most significant factor. It had the biggest impact on the critical velocity for cavitation and venturi design. Several interactions of key parameters were found to be significant $(\mathrm{P}<0.0001)$. These include the diameter ratio and inlet diameter interaction, diameter ratio and convergent angle interaction, diameter ratio and divergent angle interaction, diameter ratio and entrance length interaction, and convergent angle and divergent angle interaction. The results also show that the minimum critical cavitation velocity is $12.39 \mathrm{~m} / \mathrm{s}$, when the inlet diameter is $215.92 \mathrm{~mm}$, the diameter ratio is 0.42 , the convergent angle is $30^{\circ}$, the divergent angle is $14.14^{\circ}$, and the throat length and entrance 
length are 0.5 and 0 time of throat diameter, respectively. These results are supported by previous experimental work.

- CFD cavitation models are not suitable for bubble size simulation because they calculate mass transfer in the multi-phase flow, and the bubble size of secondary phase generated by cavitation is constant. Population Balance Module (PBM) was developed to analyze the bubble size distribution for the secondary phase. This module includes the rates of nucleation, growth, dispersion, aggregation, and breakage. The secondary phase bubble diameter is an equation instead of a constant number. A mathematical model was created and written as User Defined Functions (UDF) code and complied with ANSYS-FLUENT, in order to calculate nucleation rate for PBM model. In order to understand the interactions of bubble size distribution with particle size distribution, a $200 \mu \mathrm{m}$ and a $400 \mu \mathrm{m}$ diameter ball were added to the venturi grid. These were used to simulate the flow field affected by particles within. Using room temperature liquid water as medium, with the same inlet velocity, the cavitation generated more vapor volume.

- The smallest bubble sizes generated with different geometries at different throat velocities from 15 to $100 \mathrm{~m} / \mathrm{s}$ were investigated. The lowest level of venturi tube only was from $5 \times 10^{-9}$ to $2.54 \times 10^{-11} \mathrm{~m}$. The venturi tube with a $200 \mu \mathrm{m}$ diameter particle generated small bubbles from $2.54 \times 10^{-9}$ to $1 \times 10^{-11} \mathrm{~m}$, and the venturi tube with a $400 \mu \mathrm{m}$ diameter particle generated small bubbles from $2.52 \times 10^{-9}$ to $6.35 \times 10^{-12} \mathrm{~m}$. In addition to the fact that venturi tubes with solid particles generated more cavitation bubbles, they also generated smaller bubbles than the venturi tube alone. This indicated that particles could enhance cavitation and reduce the bubble size. The minimum pressure distributions along the venturi tubes with a $200 \mu \mathrm{m}$ diameter particle and a $400 \mu \mathrm{m}$ diameter particle are very similar. The smallest sizes of bubbles generated from cavitation with different particle sizes at different throat velocities are very similar as well. The venturi tube with a $400 \mu \mathrm{m}$ diameter particle can generate slightly smaller bubbles, since it has slightly lower pressure. As the throat velocity increases, the smallest 
bubbles generated by all three geometries decrease. Higher velocity leads to a lower pressure. Therefore, more cavitation and smaller bubbles are generated. This is consistent with experimental measurement results.

- Column flotation with cavitation bubbles technology scale-up for industry was investigated. A venturi design from a previous CFD study with a minimum critical velocity was used as the standard tube. Lab scale venturi tube $(\mathrm{d}=0.012$ $\mathrm{m})$, standard tube $(\mathrm{d}=0.2159 \mathrm{~m})$ and scale-up venturi tube $(\mathrm{D}=0.2159 \times 15=$ $3.2388(\mathrm{~m})$ ) were compared. The vapor volume ratio of the standard tube is higher than both the lab venturi and scale-up venturi tubes. This suggests that multiple standard venturi tubes function better than one large tube. JMP simulation found the same result. The required energy increases as the diameter increases, after the CFD optimum diameter of $215.96 \mathrm{~mm}$. Additionally, smaller tubes are easier to fabricate and replace. Multiple tubes may also prevent process shutdown during maintenance. Thus, multiple small venturi tubes are suggested.

- Parallel design and different orders of the packed column and venturi tube in series were tested. For series designs, the first design placed the packed column first, then the venturi tube second. The second design placed the venturi tube first, then the packed column second. The results show that the amount of cavitation bubbles generated by series designs is higher, and the bubbles are smaller compared with using the parallel design. Therefore, packed column and venturi tube in series are better design for flotation process. For two series orders, the vapor bubble size was similar. However, the first design, which has packed column first and venturi tube second, can create larger amounts of vapor. Since vapor volume is important for flotation, the first series design is recommended. 


\section{Recommendations for Future Work}

- Some assumptions may be more accurately simulated. For example, a perfectly spherical, smooth was used to simulate particles. Realistically, particles have imperfect symmetry and are not smooth.

- Only one solid particle was added in the venturi tube in this study. The location of the particle can affect the pressure and cavitation bubble size. The particle is not moving with mixture fluid, as observed experimentally. Dynamic mesh and/or other methods should to be considered.

- The properties of the mixture with surfactants could be received from experiments. Those results can be used for future simulation.

- The roughness of venturi tube and particle surfaces may need to be tested and considered.

- Since particle sizes can affect cavitation bubble sizes, what is a good particle size range for this system needed to be studied.

- Packed columns affect the inlet fluid conditions of the venturi tube. Packed column and a combination of packed column and venturi tube designs needed to be investigated.

- To better understand and control the flotation process, cavitation bubbles in the whole flotation column can be investigated. For example, how cavitation bubbles attach to conversional sized bubbles/particles. The ideal environments for different types of ore flotation need to be investigated. 


\section{References}

Abuaf, N., Wu, B.J.C., Zimmer, G.A., Saha, P., (1981). A study of non-equilibrium flashing of water in a converging-diverging nozzle, NUREG/CR 1864. Office of Nuclear Regulatory Research, BNL-NUREG-51317 - Vol. 1. NY (USA).

Ahmed S. Sayed Ahmed, (2013). Cavitation nano-bubble enhanced flotation process for more efficient coal recovery, Lexington, Kentucky.

ANSYS, Inc., ANSYS Fluent Theory Guide, Release 15.0, November 2013.

ANSYS, Inc., ANSYS Fluent Population Balance Module Manual, 2013.

ANSYS, Inc., ANSYS Fluent UDF Manual, 2013

Ashrafizadeh, S. M., \& Ghassemi, H. (2015). Experimental and numerical investigation on the performance of small-sized cavitating venturis. Flow Measurement and Instrumentation, 42, 6-15.

Balasundaram, B., \& Harrison, S. (2011). Optimising orifice geometry for selective release of periplasmic products during cell disruption by hydrodynamic cavitation. Biochemical Engineering Journal, 54(3), 207-209. doi:10.1016/j.bej.2011.03.002

Bashir, T. A., Soni, A. G., Mahulkar, A. V., \& Pandit, A. B. (2011). The CFD driven optimisation of a modified venturi for cavitational activity. Can. J. Chem. Eng. The Canadian Journal of Chemical Engineering, 89(6), 1366-1375. doi:10.1002/cjce. 20500

Bertoldi, D., Dallalba, C. C., \& Barbosa, J. R. (2015). Experimental investigation of twophase flashing flows of a binary mixture of infinite relative volatility in a Venturi tube. Experimental Thermal and Fluid Science, 64, 152-163.

Brennen, Christopher E. Cavitation and Bubble Dynamics. New York: Oxford UP, 1995. Print.

Brinkhorst, S., Lavante, E. V., \& Wendt, G. (2015). Numerical investigation of cavitating Herschel Venturi-Tubes applied to liquid flow metering. Flow Measurement and Instrumentation, 43, 23-33. doi:10.1016/j.flowmeasinst.2015.03.004

Charrière, B., Decaix, J., \& Goncalvès, E. (2015). A comparative study of cavitation models in a Venturi flow. European Journal of Mechanics - B/Fluids, 49, 287297. 
Chen, G., Wang, G., Hu, C., Huang, B., Gao, Y., \& Zhang, M. (2015). Combined experimental and computational investigation of cavitation evolution and excited pressure fluctuation in a convergent-divergent channel, International Journal of Multiphase Flow, 72, 133-140.

Chen, Y., Lu, C., \& Wu, L. (2006). Modelling and computation of unsteady turbulent cavitation flows. Journal of Hydrodynamics, Ser. B, 18(5), 559-566.

D'Agostino, Luca, and María Guillén Salvetti. Fluid Dynamics of Cavitation and Cavitating Turbopumps. Wien: Springer, 2007.

Decaix, J., \& Goncalvès, E. (2013). Investigation of three-dimensional effects on a cavitating Venturi flow. International Journal of Heat and Fluid Flow, 44, 576595.

Dobby G. (2002). Column Flotation, SGS Minerals Services, Technical Paper 2002-23

Emmanouil, Vasiliki A., Thodoris D. Karapantsios, and Kostas A. Matis, (2011). Twoand Three-phase Simulations of an Ill-functioning Dissolved-air Flotation Tank, International Journal of Environment and Waste Management IJEWM 8.3/4: 215.

Fan, M., Tao, D., Honaker, R., and Luo, Z., (2010). Nano-bubble Generation and Its Application in Froth Flotation (part I): Nano-bubble Generation and Its Effects on Properties of Microbubble and Millimeter Scale Bubble Solutions, Mining Science and Technology (China) 20.1: 1-19.

Fan, M., Tao, D., Honaker, R., and Luo, Z., (2010). Nano-bubble generation and its applications in froth flotation (part II): fundamental study and theoretical analysis, Mining Science and Technology (China), 20.2: 159-177.

Fan, M., Tao, D., Honaker, R., and Luo, Z., (2010). Nano-bubble Generation and Its Application in Froth Flotation (part III): specially designed laboratory scale column flotation of posphate, Mining Science and Technology (China), 20.3: 317338.

Fan, M., Tao, D., Honaker, R., and Luo, Z., (2010). Nano-bubble generation and its applications in froth flotation (part IV): mechanical cells and specially designed column flotation of coal, Mining Science and Technology (China), 20.5: 641-671.

Fan, M., Zhao, Y. and Tao, D., (2012). Fundamental studies of nano-bubble generation and applications in flotation, Separation Technologies for Minerals, Coal and 
Earth Resources, 2012 Society for Mining, Metallurgy, and Exploration (SME), 459-469.

Finch, J. \& Dobby, G., (1990). Column flotation, Pergamon Press: Elmsford, New York.

Finch, J., \& Dobby, G. (1991). Column flotation: A selected review. Part I. International Journal of Mineral Processing, 33, 343-354.

Ghorbani, H., Ghorbani, V., (2014). Numerical study and simulation of nano--bubble formation with CFD, Oriental journal of chemistry, 30.3: 1323-1328.

Goncalves, E., Decaix, J., \& Patella, R. F. (2010). Unsteady simulation of cavitating flows in Venturi. Journal of Hydrodynamics, Ser. B, 22(5), 753-758. doi:10.1016/s1001-6058(10)60026-1

Hampton, M.A. and Nguyen, A.V., (2010). Nano-bubbles and the nano-bubble bridging capillary force, Advances in Colloid and Interface Science, 154(1-2): 30-55.

Hart, G., Morgan, S., Bramall, N., (2002). Generation of pico- bubbles in flotation feed A means to reduce collector use, Processings of the Ninth Australian Coal Preparation Conference, Yeppoon, Page 136-148.

He, Z., Chen, Y., Leng, X., Wang, Q., \& Guo, G. (2016). Experimental visualization and LES investigations on cloud cavitation shedding in a rectangular nozzle orifice. International Communications in Heat and Mass Transfer, 76, 108-116.

He, Z., Guo, G., Tao, X., Zhong, W., Leng, X., \& Wang, Q. (2016). Study of the effect of nozzle hole shape on internal flow and spray characteristics. International Communications in Heat and Mass Transfer, 71, 1-8.

Henri Gouin, Laurent Espanet. Bubble number in a caviting flow. Comptes rendus de l'Acad_emie des sciences. S_erie IIb, M_ecanique, Elsevier, 2000, 328 (2), pp.151-157. <10.1016/S1287-4620(00)00105-8>. <hal-00308594>

Honaker, R.Q., and Ozsever, A.V., (2002). Evaluation of the selective detachment process in froth flotation, Presented in: National Energy Technology Laboratory, September 4, 2002.

Hu, H., Zhou, Z., Xu, Z., Finch, J. A., Numerical and experimental study of a hydrodynamic cavitation tube, Metallurgical and Materials Transactions B: Process Metallurgy and Materials Processing Science, vol. 29, no. 4, pp. 911-917, 1998. 
Johnson, D.J., Al Malek, S.A., Al-Rashdi, B.A.M., Hilal, N., (2012). Atomic force microscopy of nano-filtration membranes: effect of imaging mode and environment. J. Membr. Sco. 389, 486-498.

Jowett, A., (1980). Formation and disruption of particle-bubble aggregates in flotation. Fine particles Processing, 1: P Somasundaran (Ed.) AIME, New York, N.Y., 720-754.

K., \& Saharan, V. K. (2016). Computational study of different venturi and orifice type hydrodynamic cavitating devices. Journal of Hydrodynamics, Ser. B, 28(2), 293305. doi:10.1016/s1001-6058(16)60631-5

Kabeel, A., \& Abdelgaied, M. (2016). Study on the effect of alumina nano-fluid on sharp-edge orifice flow characteristics in both cavitations and non-cavitations turbulent flow regimes, Alexandria Engineering Journal, 55(2), 1099-1106.

Kerdouss, F., Bannari, A. and Proulx, P., (2006). CFD modeling of gas dispersion and bubble size in a double turbine stirred tank, Chemical Engineering Science, 61(10): 3313-3322.

Kho, C.-J., Sohn, H.-J., (1989). Column flotation of talc. International Journal of Mineral Processing, 27, 157-167.

King, R. P., (2001). Modeling and Simulation of Mineral Processing Systems, Boston: Butterworth-Heinemann.

Koh, P.t.l, M. Manickam, and M.p Schwarz, (2000). CDF Simulation of Bubble-particle Collisions in Mineral Flotation Cells, Minerals Engineering 13.14-15: 1455-1463.

Koh, P., Schwarz, M., Zhhu, Y., Bourke, P., Peaker, R., and Franzidis, J., (2003 a). Development of CFD Models of Mineral Flotation Cells, Third International Conference on CFD in the Minerals and Process Industries, CSIRO, Melbourne, Austrilia, December 10-12, 2003.

Koh, P.t.l., and M.p. Schwarz, (2003 b). CFD Modeling of Bubble-particle Collision Rates and Efficiencies in a Flotation Cell, Minerals Engineering, 16.11: 10551059.

Koh, P.t.l., and M.p. Schwarz, (2006). CFD Modeling of Bubble-particle Attachments in Flotation Cells, Minerals Engineering, 19.6-8: 619-626. 
Koh, P.t.l., and M.p. Schwarz, (2008). Modelling Attachment Rates of Multi-sized Bubbles with Particles in a Flotation Cell, Minerals Engineering, 21.12-14: 989993.

Koh, P.t.l., and Schwarz, M.P., (2009). CFD Models of Microcel and Jameson Flotation Cells, Seventh International Conference on CFD in the Minerals and Process Industries, CSIRO, Melbourne, Australia, 9-11 Dec, 2009.

Lee, K.Y., Pate, W.T., Oblad, A.E., Herbst, J.A., (1991). Methodology for selecting a control strategy for a column flotation unit. In: Agar, G., Huls, B., Hyma, D. (Eds.), Column'91 - Proceedings of an International Conference on Column Flotation, vol. 2. Canadian Institute of Mining, Metallurgy and Petroleum, Sudbury, Ontario, pp. 422-436.

Li, B., Tao, D., Ou, Z., \& Liu, J. (2003). Cyclo-microbubble column flotation of fine coal. Separation science and technology, 1125-1140.

Li, H., (2014). Role of hydrodynamic cavitation in fine particle flotation, Master's thesis, University of Alberta.

Li, R., Tang, K., Han, W., Li, Q., and Shen, J., (2009). Numerical Simulation of Gasliquid-solid Three-phase Inner Flow in Mechanically Stirring Air-charging Flotation Machine, 1: 37-40, 1673-5196 (2009) 01-0037-04.

Liu, T., and Schwarz, M., (2006). CFD-based modeling of bubble-particle collision efficiency with mobile bubble surface in a turbulent environment, International Journal of mineral Processing, 45-55.

Liu, T., and Schewarz, M., (2009). CFD-based multiscale model of bubble-particle collision efficiency in a turbulent flotation cell, Chemical Engineering Science, 64:5287-5301.

Luttrell, G. H., and R. H. Yoon, (1988). Determination of the Probability of Bubbleparticle Adhesion Using Induction Time Measurements. Production and Process of Fine Particles, Proceedings of the International Symposium on the Production and Processing of Fine Particles. Montreal, pg159-167.

Moholkar, V. S., \& Pandit, A. B. (1997). Bubble behavior in hydrodynamic cavitation: Effect of turbulence. AIChE Journal AIChE J., 43(6), 1641-1648. doi:10.1002/aic.690430628 
Montgomery, D., \& Montgomery, D. (2012). Regression and design of experiments: IE 433 Department of Industrial and Manufacturing Engineering, the Pennsylvania State University. Hoboken, NJ: Wiley Custom Learning Solutions.

Nurick, W.H., (1976). Orifice cavitation and its effect on spray mixing. J. Fluids Eng. 98, 681-687.

Ohrn, T. R., Senser, D. W., \& Lefebvre, A. H. (1991). Geometrical Effects On Discharge Coefficients for Plain-Orifice Atomizers. Atomization and Sprays Atomiz Spr, 1(2), 137-153. doi:10.1615/atomizspr.v1.i2.10

Peng, F., and Xiong Y., (2015). "Pico-nano Bubble Column Flotation Using Static Mixer-venturi Tube for Pittsburgh No. 8 Coal Seam. International Journal of Mining Science and Technology 25.3: 347-54.

Qian, M. and J. Ma. (2009). Heterogeneous nucleation on convex spherical substrate surfaces: A rigorous thermodynamic formulation of Fletcher's classical model and the new perspectives derived, Journal of Chemical Physics 130(21): 214709.

Rodio, M., \& Congedo, P. (2014). Robust analysis of cavitating flows in the Venturi tube. European Journal of Mechanics - B/Fluids, 44, 88-99.

Rodrigues, R., \& Rubio, J. (2003). New basis for measuring the size distribution of bubbles. Minerals Engineering, 757-765.

Ryan, W.L. and Hemmingsen, E.A., (1993). Bubble formation in water at smooth hydrophobic surfaces, Journal of Colloidal Interface Sciences, 157, 312-317.

Saharan, V. K., Rizwani, M. A., Malani, A. A., \& Pandit, A. B., (2013). Effect of geometry of hydrodynamically cavitating device on degradation of orange-G. Ultrasonics Sonochemistry, 20(1), 345-353. doi:10.1016/j.ultsonch.2012.08.011

Sahbaz, O., Ercetin, U., Oteyaka, B., (2012). Determination of Turbulence and Upper Size Limit in Jameson Flotation Cell by the Use of Computational Fluid Dynamic Modeling, Physicochemical Problems of Mineral Processing, 48(2): 533-544, ISSN 1643-1049.

Salvador, F. J., Hoyas, S., Novella, R., \& Martinez-Lopez, J. (2011). Numerical simulation and extended validation of two-phase compressible flow in diesel injector nozzles. Proceedings of the Institution of Mechanical Engineers, Part D: Journal of Automobile Engineering, 225(4), 545-563. 
Salvador, F., Martínez-López, J., Romero, J., \& Roselló, M. (2013). Computational study of the cavitation phenomenon and its interaction with the turbulence developed in diesel injector nozzles by Large Eddy Simulation (LES), Mathematical and Computer Modelling, 57(7-8), 1656-1662. doi:10.1016/j.mcm.2011.10.050

Salvador, F., Jaramillo, D., Romero, J., \& Roselló, M. (2016). Using a homogeneous equilibrium model for the study of the inner nozzle flow and cavitation pattern in convergent-divergent nozzles of diesel injectors. Journal of Computational and Applied Mathematics. doi:10.1016/j.cam.2016.04.010

Sam, A., Gomez, C.O. and Finch, J.A., (1996). Axial velocity profiles of single bubbles in water/frother solutions, International Journal of Mineral Processing, 47(3-4): 177- 196.

Saracoglu, M.,(2013). Froth flotation performance enhancement by feed cavitation and magnetic plastic particle, PhD Dissertation, Lexington, Kentucky.

Sarrot, Vincent, Pascal Guiraud, and Dominique Legendre, (2005). Determination of the Collision Frequency between Bubbles and Particles in Flotation, Chemical Engineering Science, 60.22: 6107-117.

Schlender, M., Spengler, A., \& Schuchmann, H. P., (2015). High-pressure emulsion formation in cylindrical coaxial orifices: Influence of cavitation induced pattern on oil drop size. International Journal of Multiphase Flow, 74, 84-95.

Schubert, H., (2005). Nano-bubbles, hydrophobic effect, heterocoagulation and hydrodynamics in flotation, International Journal of Mineral Processing, 78, 1121.

Schnerr, G. H., and Sauer, J. (2001) "A Two-Phase Flow Model for Predicting Cavitation Dynamics." In Fourth International Conference on Multiphase Flow, New Orleans, USA

Schwarz, M. P., (1991). Flow Simulation in Mineral Engineering, Minerals Engineering, Vol. 4, Nos 7-11, pp. 727-732.

Shah, M. S., Joshi, J. B., Kalsi, A. S., Prasad, C., \& Shukla, D. S. (2012). Analysis of flow through an orifice meter: CFD simulation. Chemical Engineering Science, 71, 300-309. doi:10.1016/j.ces.2011.11.022 
Shen, Z., Chen, J., (2012). Flow Field Simulation and Application of Flotation Cells, Technology Press, Beijing, China, ISBN 978-7-03-035793-9.

Shen, Z., Chen, J., (2012). Simulation and application of flotation machine flow field, Beijing, ISBN 978-7-03-035793-9.

Shih, T., Liou, W. W., Shabbir, A., Yang, Z., \& Zhu, J. (1995). A new k-€ eddy viscosity model for high reynolds number turbulent flows. Computers \& Fluids, 24(3), 227238.

Singh, V., \& Tharakan, T. J. (2015). Numerical simulations for multi-hole orifice flow meter. Flow Measurement and Instrumentation, 45, 375-383.

Singhal, A. K., Athavale, M. M., Li, H., \& Jiang, Y. (2002). Mathematical Basis and Validation of the Full Cavitation Model. Journal of Fluids Engineering, 124(3), 617

Sobhy, A., \& Tao, D. (2013). Nano-bubble column flotation of fine coal particles and associated fundamentals. International Journal of Mineral Processing, 109-116.

Stutz, B., Reboud, J.L., (2000). Measurements within unsteady cavitation. Exp. Fluids 29, $545-552$.

Sun, Z., Li G., Chen G., Yu Y., and Gao G., (2015). Numerical Investigation on Effects of Nozzle's Geometric Parameters on the Flow and the Cavitation Characteristics within Injector's Nozzle for a High-pressure Common-rail DI Diesel Engine. Energy Conversion and Management 89: 843-61.

Taghavifar, H., Mohammad T. S., and Majid A., (2015), Numerical Study of the Effects of Injector Needle Movement and the Nozzle Inclination Angle on the Internal Fluid Flow and Spray Structure of a Group-hole Nozzle Layout, Applied Mathematical Modelling 39.23-24: 7718-733.

Tao, Y., Liu, J., Yu, S., \& Tao, D. (2006). Pico-bubble Enhanced Fine Coal Flotation. Separation Science and Technology, 3597-3607.

Thang, N., \& Davis, M. (1979). The structure of bubbly flow through venturis. International Journal of Multiphase Flow, 5(1), 17-37. doi:10.1016/03019322(79)90003-X 
Thang, N., \& Davis, M. (1981). Pressure distribution in bubbly flow through venturis. International Journal of Multiphase Flow, 7(2), 191-210. doi:10.1016/03019322(81)90005-7

Ushikubo, F.Y., Furukawa, T., Nakagawa, R., Enari, M., Makino, Y., Kawagoe, Y., Shiina, T. and Oshita, S., (2010). Evidence of the existence and the stability of nano-bubbles in water, Colloids and Surfaces A: Physicochemical Engineering Aspects, 361: 31-37.

Wang, F., (2004). Computational Fluid Dynamics Analysis: Principles and Applications of CFD, Qinghua University Press, Beijing, China.

Wang, X., Li, K., \& Su, W. (2012). Experimental and numerical investigations on internal flow characteristics of diesel nozzle under real fuel injection conditions. Experimental Thermal and Fluid Science, 42, 204-211. doi:10.1016/j.expthermflusci.2012.04.022

Wu, T.Y., (1969). Cavity flow analysis: a review of the state of knowledge. In: Robertson, J.M., and Wislicenus, G.F., (Eds.), Cavitation State of Knowledge, The American Society of Mechanical Engineers, New York, USA.

Xia, J., Antti, R., Sami, G., (2009). Effect of Turbulence Models on Prediction of Fluid Flow in an Outotec Flotation Cell, Minerals Engineering, 22: 880-885.

Xiong, Y, and Peng. F. (2015). Optimization of Cavitation Venturi Tube Design for Pico and Nano Bubbles Generation. International Journal of Mining Science and Technology: 523-29.

Xu, M., Zhou, Z.A., Xu, Z., (2001). Pre-aeration of feed, Flotation - Encyclopedia of Separation Science, vol. II., Academic Press, London, pp. 1556 - 1562.

Yan, Y., \& Thorpe, R. (1990). Flow regime transitions due to cavitation in the flow through an orifice. International Journal of Multiphase Flow, 16(6), 1023-1045.

Yang, R., and Wang. H., (2012). Study of Fluid Dynamics Simulation and Experiment of Wide Particle Grade Slime Flotator, Coal Science and Technology, Vol. 40, No. 11. Pp. 120-124.

Yang, R., and Wang, H., (2013). A Numerical Simulation Study on the Flow Field of Wide-size-fraction Coal Flotation Machine, Journal of China Coal Society, Vol. 38, No. 4, 0253-9993(2013) 04-0657-05. 
Yang, S., Dammer, S.M., Bremond, N., Zandvliet, H.J.W., Kooij, E.S. and Lohse, D., (2007). Characterization of nano-bubbles on hydrophobic surfaces in water, Langmuir, 23: 7072-7077.

Yoon, R.H., (2000). The role of hydrodynamic and surface forces in bubble-particle interaction, International Journal Mineral Processing, 58, 128-143.

Young, F. (1989). Cavitation. London: McGraw-Hill.

Young, F. R., (1999). Cavitation. Watford College-Hertfordshire, McGraw-Hill, London, UK.

Yu, Y., Zhang, J., Jiang, L., (2008). Introductory and Advanced Tutorial of FLUENT, Bejing Institute of Technology Press, Beijing, China.

Yuan, Q., Chen, W., Liu, W., (2010). Analysis of the Numerical Simulation of Cyclone Flotation Cell, Coal Preparation Technology, 1001-3571, 03-0001-03.

Zhang X., Quinn, A., Ducker, W., (2008). Nano-bubbles at the interface between water and hydrophobic solid, Langmuir, 24.9: 4756-4764.

Zhang, D., (2007). Eulerian modeling of reactive gas-liquid flow in a bubble column. PhD Thesis. Universiteit Twente, Enschede, the Netherlands.

Zhong, W., He, Z., Wang, Q., Shao, Z., \& Tao, X. (2014). Experimental study of flow regime characteristics in diesel multi-hole nozzles with different structures and enlarged scales. International Communications in Heat and Mass Transfer, 59, 110.

Zhou, Z., Xu, Z., \& Finch, J. (1994). On the role of cavitation in particle collection during flotation - a critical review. Minerals Engineering, 1073-1084.

Zhou Z., (1996). Gas nucleation and cavitation in flotation, Department of Mining and Metallurgical Engineering, McGill University, Montreal, Canada.

Zhou, Z. A., Xu, Z. H., and Finch, J. A. (1997). Role of hydrodynamic cavitation in fine particle flotation, International Journal of Mineral Processing, vol. 51, no. 1-4, pp. 139-149.

Zhou, Z., Xu, Z., Finch, J., Masliyah, J., \& Chow, R. (2009). On the role of cavitation in particle collection in flotation - A critical review. II. Minerals Engineering, 419433. 
Zhu, J., Zhao, D., Xu, L., \& Zhang, X. (2016). Interactions of vortices, thermal effects and cavitation in liquid hydrogen cavitating flows. International Journal of Hydrogen Energy, 41(1), 614-631. doi:10.1016/j.jhydene.2015.10.042

Zwart, P. J., Gerber, A. G., and Belamri, T. (2004) "A Two-Phase Flow Model for Predicting Cavitation Dynamics." In Fifth International Conference on Multiphase Flow, Yokohama, Japan. 


\section{Appendix A}

Design of Experiments Data

Table A-1 Response surface design for venturi tube design tests

\begin{tabular}{|c|c|c|c|c|c|c|c|}
\hline Pattern & $\begin{array}{c}\text { Inlet } \\
\text { Diameter }\end{array}$ & $\begin{array}{l}\text { Diameter } \\
\text { Ratio }\end{array}$ & $\begin{array}{c}\text { Convergent } \\
\text { Angle }\end{array}$ & $\begin{array}{c}\text { Divergent } \\
\text { Angle }\end{array}$ & $\begin{array}{l}\text { Throat } \\
\text { length } \\
\text { (d) }\end{array}$ & $\begin{array}{c}\text { Entrance } \\
\text { (d) }\end{array}$ & $\begin{array}{l}\text { Critical } \\
\text { Velocity }\end{array}$ \\
\hline+++-++ & 250 & 0.9 & 30 & 5 & 3 & 2 & 18.8 \\
\hline-+++++ & 10 & 0.9 & 30 & 20 & 3 & 2 & 20.5 \\
\hline+--+-+ & 250 & 0.1 & 15 & 20 & 0.5 & 2 & 13.8 \\
\hline++-+++ & 250 & 0.9 & 15 & 20 & 3 & 2 & 20.0 \\
\hline++---+ & 250 & 0.9 & 15 & 5 & 0.5 & 2 & 20.6 \\
\hline+++++- & 250 & 0.9 & 30 & 20 & 3 & 0 & 16.7 \\
\hline 000A00 & 130 & 0.5 & 22.5 & 20 & 1.75 & 1 & 14.8 \\
\hline+----- & 250 & 0.1 & 15 & 5 & 0.5 & 0 & 13.9 \\
\hline--+--- & 10 & 0.1 & 30 & 5 & 0.5 & 0 & 14.4 \\
\hline 0a0000 & 130 & 0.1 & 22.5 & 12.5 & 1.75 & 1 & 14.4 \\
\hline---+-- & 10 & 0.1 & 15 & 20 & 0.5 & 0 & 14.9 \\
\hline 000000 & 130 & 0.5 & 22.5 & 12.5 & 1.75 & 1 & 14.4 \\
\hline+-+-+- & 250 & 0.1 & 30 & 5 & 3 & 0 & 14.8 \\
\hline---+++ & 10 & 0.1 & 15 & 20 & 3 & 2 & 15.7 \\
\hline+-++++ & 250 & 0.1 & 30 & 20 & 3 & 2 & 15 \\
\hline 0A0000 & 130 & 0.9 & 22.5 & 12.5 & 1.75 & 1 & 19.4 \\
\hline 00a000 & 130 & 0.5 & 15 & 12.5 & 1.75 & 1 & 14.8 \\
\hline 000000 & 130 & 0.5 & 22.5 & 12.5 & 1.75 & 1 & 14.4 \\
\hline----+- & 10 & 0.1 & 15 & 5 & 3 & 0 & 14.7 \\
\hline-+++-- & 10 & 0.9 & 30 & 20 & 0.5 & 0 & 17.1 \\
\hline 00A000 & 130 & 0.5 & 30 & 12.5 & 1.75 & 1 & 14 \\
\hline 00000a & 130 & 0.5 & 22.5 & 12.5 & 1.75 & 0 & 14 \\
\hline+-++- & 250 & 0.1 & 15 & 20 & 3 & 0 & 14.7 \\
\hline-+--++ & 10 & 0.9 & 15 & 5 & 3 & 2 & 22.9 \\
\hline+---++ & 250 & 0.1 & 15 & 5 & 3 & 2 & 14.4 \\
\hline 000000 & 130 & 0.5 & 22.5 & 12.5 & 1.75 & 1 & 14.4 \\
\hline-+-+-+ & 10 & 0.9 & 15 & 20 & 0.5 & 2 & 20.0 \\
\hline--++-+ & 10 & 0.1 & 30 & 20 & 0.5 & 2 & 14.3 \\
\hline+-+--+ & 250 & 0.1 & 30 & 5 & 0.5 & 2 & 14.3 \\
\hline 000000 & 130 & 0.5 & 22.5 & 12.5 & 1.75 & 1 & 14.4 \\
\hline++++-+ & 250 & 0.9 & 30 & 20 & 0.5 & 2 & 17.9 \\
\hline-+---- & 10 & 0.9 & 15 & 5 & 0.5 & 0 & 20.7 \\
\hline
\end{tabular}




\begin{tabular}{|c|c|c|c|c|c|c|c|}
\hline++-+- & 250 & 0.9 & 15 & 20 & 0.5 & 0 & 17.8 \\
\hline-++-++ & 10 & 0.9 & 30 & 5 & 0.5 & 2 & 19.3 \\
\hline--+-++ & 10 & 0.1 & 30 & 5 & 3 & 2 & 14.9 \\
\hline+-++- & 250 & 0.1 & 30 & 20 & 0.5 & 0 & 14.1 \\
\hline 0000A0 & 130 & 0.5 & 22.5 & 12.5 & 3 & 1 & 14.7 \\
\hline $00000 \mathrm{~A}$ & 130 & 0.5 & 22.5 & 12.5 & 1.75 & 2 & 14.4 \\
\hline $\mathrm{a} 00000$ & 10 & 0.5 & 22.5 & 12.5 & 1.75 & 1 & 15.1 \\
\hline++--+- & 250 & 0.9 & 15 & 5 & 3 & 0 & 20.5 \\
\hline--+++- & 10 & 0.1 & 30 & 20 & 3 & 0 & 15.3 \\
\hline-+-++- & 10 & 0.9 & 15 & 20 & 3 & 0 & 20.0 \\
\hline-++-+- & 10 & 0.9 & 30 & 5 & 3 & 0 & 18.6 \\
\hline $0000 \mathrm{a} 0$ & 130 & 0.5 & 22.5 & 12.5 & 0.5 & 1 & 13.9 \\
\hline $000 \mathrm{a} 00$ & 130 & 0.5 & 22.5 & 5 & 1.75 & 1 & 14.1 \\
\hline----+ & 10 & 0.1 & 15 & 5 & 0.5 & 2 & 14.7 \\
\hline A00000 & 250 & 0.5 & 22.5 & 12.5 & 1.75 & 1 & 14.2 \\
\hline+++-- & 250 & 0.9 & 30 & 5 & 0.5 & 0 & 16.00 \\
\hline
\end{tabular}




\section{Appendix B}

\section{UDF code}

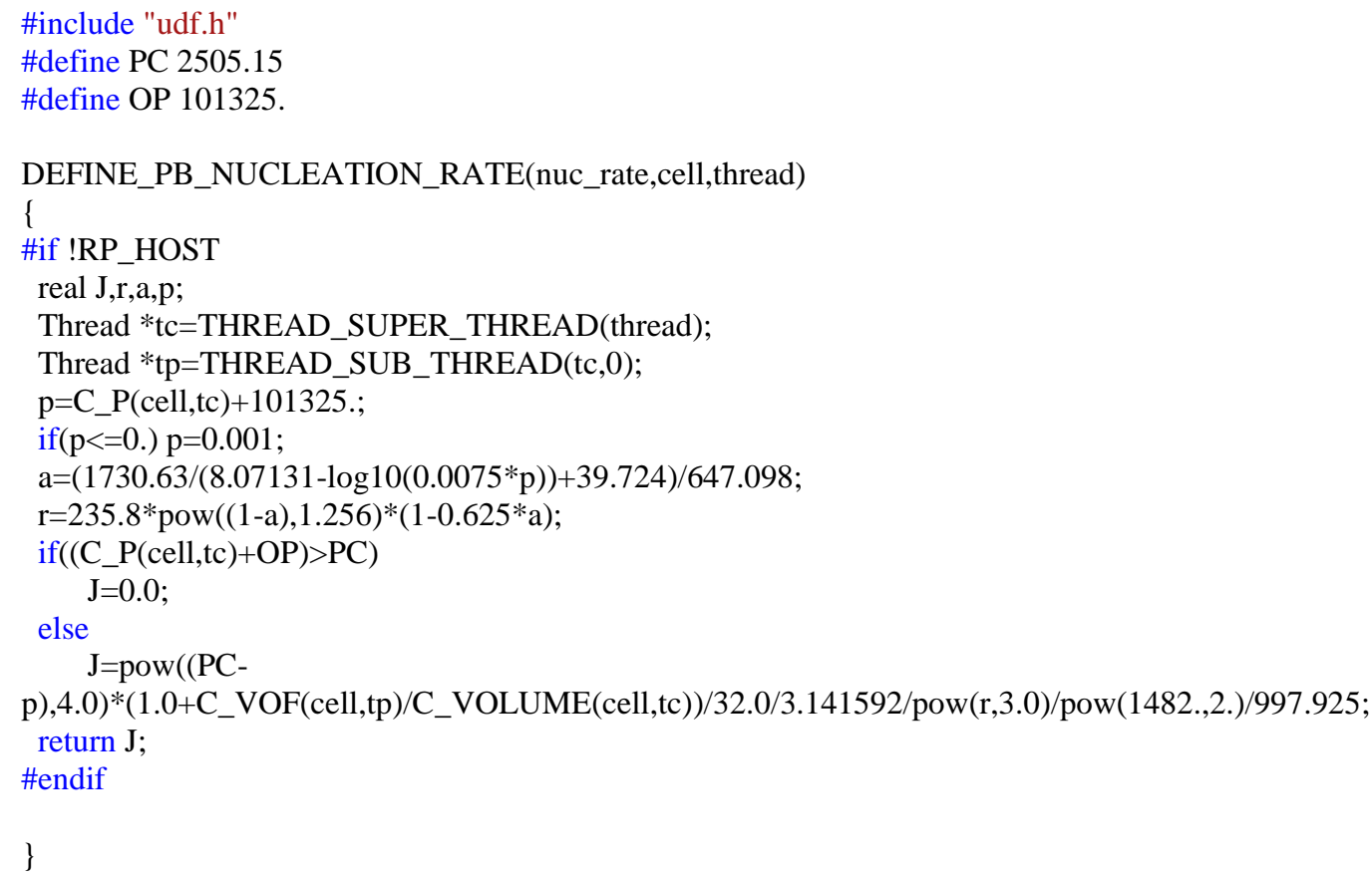




\section{VITA}

Wan Wang is originally from Dalian city, Liaoning province, P.R. China. She joined the Mining Engineering Department at WVU in August 2012. Prior to joining WVU, Wan earned her B.S. in Mineral Processing Engineering from Liaoning Technical University, and M.S. in Mining and Earth Systems Engineering from Colorado School of Mines, respectively.

Wan Wang 